\title{
The hindering effect of EU VAT on the access to health care
}

Citation for published version (APA):

Gabriel, M. M. (2018). The hindering effect of EU VAT on the access to health care. [Doctoral Thesis, Maastricht University]. Datawyse. https://doi.org/10.26481/dis.20180706mg

Document status and date:

Published: 01/01/2018

DOI:

10.26481/dis.20180706mg

Document Version:

Publisher's PDF, also known as Version of record

\section{Please check the document version of this publication:}

- A submitted manuscript is the version of the article upon submission and before peer-review. There can be important differences between the submitted version and the official published version of record.

People interested in the research are advised to contact the author for the final version of the publication, or visit the DOI to the publisher's website.

- The final author version and the galley proof are versions of the publication after peer review.

- The final published version features the final layout of the paper including the volume, issue and page numbers.

Link to publication

\footnotetext{
General rights rights.

- You may freely distribute the URL identifying the publication in the public portal. please follow below link for the End User Agreement:

www.umlib.nl/taverne-license

Take down policy

If you believe that this document breaches copyright please contact us at:

repository@maastrichtuniversity.nl

providing details and we will investigate your claim.
}

Copyright and moral rights for the publications made accessible in the public portal are retained by the authors and/or other copyright owners and it is a condition of accessing publications that users recognise and abide by the legal requirements associated with these

- Users may download and print one copy of any publication from the public portal for the purpose of private study or research.

- You may not further distribute the material or use it for any profit-making activity or commercial gain

If the publication is distributed under the terms of Article $25 \mathrm{fa}$ of the Dutch Copyright Act, indicated by the "Taverne" license above, 
The Hindering Effect of EU VAT on the Access to Health Care

Mandy M. Gabriël 
The Hindering Effect of EU VAT on the Access to Health Care

Mandy M. Gabriël 
This dissertation was finalized on 28 December 2017. Later developments have been discussed only incidentally.

This dissertation was realized with the financial support of Maastricht University and the Indirect Tax Fund (Fonds Indirect Tax).

Layout and printing by: Datawyse - Universitaire Pers Maastricht

(C) 2018 by M.M. Gabriël

All rights reserved. No part of this publication may be reproduced, stored in a retrieval system, or transmitted, in any form or by any means, electronic, mechanical, photocopying, recording, or otherwise, without the prior consent in writing from the author 


\title{
The Hindering Effect of EU VAT on the Access to Health Care
}

\author{
DISSERTATION \\ to obtain the degree of Doctor at the Maastricht University, \\ on the authority of the Rector Magnificus, \\ Prof. dr. Rianne M. Letschert \\ in accordance with the decision of the Board of Deans, \\ to be defended in public \\ on Friday 6 July 2018, at 10:00 hours
}

by

Mandy Maria Gabriël 


\section{Supervisors:}

Prof. dr. A.J. van Doesum

Prof. dr. A.H.R.M. Denie

\section{Assessment Committee:}

Prof. dr. A. Bollen (chair)

Prof. dr. M.E. van Hilten, University of Amsterdam

Dr. M.M. ten Hoopen

Dr. K. Vyncke, KU Leuven

Prof. dr. M.J.G.A.M. Weerepas 
For Tijn 


\section{Acknowledgements}

I remember driving in my car one day, hearing the following lyrics on the radio: "wake me up when it's all over, when I'm wiser and I'm older". This thought often crossed my mind, especially during the last stage of my PhD research. And yet here I am. I just completed the most challenging project of my life, up until now. Wiser and older.

There are a lot of people who supported me during this process. I am grateful for their support and want to thank some of them with special mentioning.

In the first place I am grateful to my co-supervisor Arthur Denie for his inspirational lectures on VAT during my time as a tax law student and his support and enthusiasm during my first years as a PhD researcher. It was Arthur who convinced me to consider writing a PhD thesis. I am very grateful for that. Furthermore, my gratitude goes out to my supervisor Ad van Doesum. Ad's remarks and advice on my research approach improved the structure and quality of my thesis a lot. It was his support and faith that gave me enough confidence and joy to stay motivated until the very end. Furthermore, I am grateful for our friendship and the motivational talks we had so far.

I am also grateful to my other colleagues of the Law Faculty's department of Tax Law, for their interest in my research and their support and helpfulness in general. I thank Anouk Bollen, for her support as well as for introducing me to Maastricht carnival. I am thankful to Marjon Weerepas, for her support and concern. To Marcel Schaper I am thankful for welcoming me to faculty in the very beginning and introducing me to faculty life. I want to thank Raymond Luja and Rainer Prokisch, for their support in general and faith in me. Luc Hautvast, for his support and career advice. Joyce Berghmans, for all her kind help. Frank Nellen - my roomie - for his friendship, his humor, willingness to help and many useful comments on my PhD thesis. I also want to thank Fernando de Man for his friendship, advice, and eating lots of lunch sandwiches with me. I am also grateful to Licette Poll, Len Cuppens and Fabienne Dingena for all their help. Furthermore, I am grateful to my former Law Faculty colleagues Tiiu Albin and Paul Dekkers, for their friendship and support. I also want to thank Jacq. Linssen, for being an inspiring VAT teacher and the other members of our VAT department for their support and advice with regard to my thesis: Michelle Mutsaers, Erik van Norden, Kim Wiersma and Mathijs Klemm.

I am very grateful to the members of the assessment committee for their willingness and efforts to assess my thesis and providing me with useful comments: prof. dr. Anouk Bollen, prof. dr. Mariken van Hilten, dr. Rankie ten Hoopen, dr. Kenneth Vyncke and prof. dr. Marjon Weerepas. I feel honored with such an assessment committee. Furthermore, I am grateful to the other members of the corona, including prof. dr. Herman van Kesteren. I want to thank Herman for his support and advice on my PhD thesis and my career in general. 
A special gratitude goes out to the sponsors of the Fonds Indirect Tax, for financially supporting my PhD position. I am thankful to Carol Ní Ghiollarnáth for editing my manuscript.

Furthermore, I want to thank my colleagues at the Dutch Tax Authorities for their support and their interest shown in my PhD thesis. I am grateful to Josine Walschot for her understanding and support in dealing with two jobs at a time. I am also grateful to the (former) colleagues of the VAT department, amongst whom Menno Talsma, Claudia Boelkens, Fred Stoelinga and Mathieu Huntjens for their help, support and the interest they have shown in my research. I also want to thank Peter Bekkers for many interesting discussions on EU VAT and his support with regard to my career. With special mentioning I want to thank the following colleagues for their sincere interest and support: Edith Dobbelstein, Carin Evertz, Roger Hinskens, Adnan Suhopoljac and Sandra Witjes.

On a personal note I want to thank my proud parents Stella and Wiel Gabriël for their love and support. Thank you for teaching me that everything is possible, as long as you really want it and are willing to work for it. I want to thank some of my friends and family members with special mentioning: Joyce, Babette, Manja, Tiiu, Marcia, Kim and Sarah, for their unconditional support and friendship. I am grateful to Myrthe Hinskens and Fernando de Man for their support and having them as friends. I am honoured to have them as my paranymphs.

I am incredibly grateful to my son Tijn. He brought so much joy to my life. I am grateful for his unconditional love. Finally, I want to thank my partner Jurjen Knarren. I could not have done this without his love and encouragements. I admire his ability to remain calm and positive at all times. I am very thankful for the many ways in which he has supported me without expecting anything in return.

Mandy Gabriël, June 3, 2018 


\section{Table of contents}

$\begin{array}{ll}\text { Acknowledgements } & 7\end{array}$

$\begin{array}{ll}\text { Abbreviations } & 15\end{array}$

$\begin{array}{ll}\text { Part I Introduction } & 17\end{array}$

1. Introduction 19

1.1. Synopsis 19

1.2. Research relevance and motivation 24

1.3. Research questions $\quad 27$

1.4. Research structure 28

1.5. Research scope and limitations 29

Part II The Relationship Between the Principle of Access to Health Care and EU VAT 31

2. Relevant definitions and common denominators in EU health care systems 33

2.1. Introduction 33

2.2. Definitions of health (care) activities, suppliers and systems 34

2.2.1. Definitions of Health (Care) Activities 34

2.2.1.1. Exploration of Definitions for Health Care Activities 34

2.2.1.2. Definition of Health Care Activities for the Purpose of this Research 39

2.2.2. Definitions of Health (Care) Suppliers 40

2.2.2.1. WHO definition of health workers 40

2.2.2.2. OECD definition of health workforce and health care providers 44

2.2.2.3. Definition of health care suppliers for the purpose of this research 47

2.2.3. Definitions of Health Systems 48

2.3. The model health care system 49

2.3.1. Requirements of the model health care system from a VAT perspective 49

2.3.1.1. The model health care system for the purpose of this research 52

2.3.2. Schematic overview of the model health care system 54

2.4. The health care system in the Netherlands 56

2.4.1. General information on the Dutch health care system 57

2.4.2. Definitions and types of health care in the Netherlands 58

2.4.3. Conclusions in relation to the model health care system 60

2.5. Interim conclusion 60

3. Legal framework as regards the application of VAT on health care transactions 63

3.1. Introduction 63

3.2. Characteristics 64

3.2.1. General consumption tax 64 
3.2.2. All stages tax 65

3.2.3. Proportionality to the price 66

3.2.4. The right to deduct input VAT 66

3.3. Neutrality principle $\quad 69$

3.4. Ability to pay principle 70

3.5. The subject of taxation: taxable persons 71

3.5.1. Role of a health care supplier in relation to the taxability of health care transactions under positive EU VAT law 72

3.5.2. Consequences of the taxable person status for health care suppliers 73

3.5.3. The definition of taxable person in positive EU Law 73

3.5.3.1. Any health care supplier acting independently 74

3.5.3.2. Economic activities $\quad 76$

3.5.3.3. Regardless of place, purpose and results 78

3.6. The object of taxation: taxable transactions 80

3.6.1. Importance of the (right) qualification as taxable transactions in the relation to the taxability of health care transactions under positive EU Law 81

3.6.2. Application of the doctrine of composite supplies in relation to health care transactions 81

3.6.3. For consideration 83

3.6.4. Consequences of the qualification as taxable transactions for health care transactions 84

3.7. Reduced rates 84

3.8. Exemptions $\quad 85$

3.8.1. General 85

3.8.2. Types of exemptions 86

3.8.3. Effects of the application of exemptions 90

3.9. Conclusion 90

4. The principle of access to health care 93

4.1. Introduction 93

4.2. The human right to health in an international context 94

4.2.1. Recognition of the right to health in international human rights law 95

4.2.2. Definition of the right to health in the ICESCR 96

4.2.3. Binding character of the right to health in the ICESCR 100

4.3. Recognition of the human right to health in an EU context 102

4.3.1. The 2006 statement of EU Health Ministers 103

4.3.2. Directive 2011/24/EU 103

4.3.3. The Charter of Fundamental Rights of the European Union 104

4.4. Conclusion $\quad 105$ 
5.2. The conflicting objectives of the right to health and the application of EU VAT 108

5.2.1. Objectives of the right to health in relation to health care consumption 108

5.2.2. Objectives of the EU VAT system in relation to health care consumption 110

5.3. Different hierarchies of the right to access to health care and the application of VAT

5.3.1. Different hierarches in relation to sources of EU law 111

5.3.2. Role of the EU Charter in CJEU cases on EU VAT law 113

5.4. Conclusions 118

5.4.1. Conclusions on the conflicting objectives 118

5.4.2. Conclusions on the hierarchy and the role of the CJEU 119

Part III How the Application of Positive EU VAT Law Impedes Access to Health Care $\quad 121$

6. Elements of positive EU law that may mitigate the VAT burden on health care transactions

6.1. Exclusions in relation to health care transactions 124

6.1.1. The exclusion in Article 13 of the EU VAT Directive 125

6.1.1.1. General $\quad 125$

6.1.1.2. Public bodies acting as public authorities 127

6.1.1.3. Exceptions to the exclusion 128

6.1.2. Differential treatment of public and private sector bodies 130

6.1.3. Differential treatment of (bodies involved in) health care activities 131

6.1.4. Effects of non-economic activities of health care suppliers 133

6.1.4.1. Health care suppliers as 'non-taxable persons' 133

6.1.4.2. No or reduced input VAT deduction $\quad 134$

6.1.4.3. Acting in multiple capacities $\quad 135$

6.1.5. Interim conclusion 136

6.2. The application of VAT exemptions in relation to health care transactions $\quad 137$

6.2.1. Making health care more accessible to individuals by reducing costs 139

6.2.2. Requirements as regards the health care supplier under the exemption provision for intramural care 142

6.2.2.1. Legal form neutrality 143

6.2.2.2. 'Duly recognised establishments of a similar nature' 144

6.2.3. Requirements as regards the health care supplier for the exemption provision $\begin{array}{ll}\text { for extramural care } & 146\end{array}$

6.2.3.1. The exercise of medical and paramedical professions 148

6.2.3.2. Relationship with criteria for health care suppliers under Article 132(1)(b) of the EU VAT Directive 150

6.2.4. Requirements of the health care activities provided 151

6.2.4.1. Covered medical and hospital care $\quad 151$ 
6.2.4.2. 'Medical care' under Articles 132(1)(b) and (c) of the EU VAT Directive

6.2.4.3. Interpreting the term 'medical care' 152

6.2.4.4. Therapeutic aim 153

6.2.5. Closely related activities 156

6.2.5.1. The temporal requirement 158

6.2.6. The functioning and effects of exemptions under EU VAT 159

6.3. Conclusions 161

7. How VAT exemptions impede access to health care in specific situations 163

7.1. Introduction 163

7.2. The hindering effect of VAT exemptions in the health care sector in basic situations 165

7.2.1. Introduction $\quad 165$

7.2.2. Basic situations under Article 132(1)(b) of the EU VAT Directive 167

7.2.2.1. Assessment of the application of the exemption provision for intramural care in $\begin{array}{ll}\text { the basic situation } & 167\end{array}$

7.2.2.2. Consequences of the application of the exemption provision for intramural care in the basic situation $\quad 171$

7.2.3. Basic situations under Article 132(1)(c) of the EU VAT Directive 172

7.2.3.1. Assessment of the application of the exemption provision for extramural care in the basic situation $\quad 172$

7.2.3.2. Consequences of the application of the exemption provision for extramural care in the basic situation

7.3. The hindering effect of VAT exemptions in the health care sector in parallel situations

7.3.1. Introduction 183

7.3.2. Parallel one-on-one situations 185

7.3.2.1. Assessment of the application of the exemption provisions for medical care in $\begin{array}{ll}\text { parallel one-on-one situations } & 185\end{array}$

7.3.2.2. Assessment of the application of the exemption provision for intramural care in $\begin{array}{ll}\text { parallel one-on-one situations } & 190\end{array}$

7.3.2.3. Assessment of the application of the exemption provision for extramural care in parallel one-on-one situations 193

7.3.3. Parallel two-on-one situations 197

7.3.3.1. Assessment of the application of the exemption provision for intramural care in $\begin{array}{ll}\text { parallel two-on-one situations } & 197\end{array}$

7.3.3.2. Assessment of the application of the exemption provision for extramural care in parallel two-on-one situations 200

7.3.4. Consequences of the application of the exemption provisions in parallel situations 
7.4. The hindering effect of VAT exemptions in the health care sector in successive situations

7.4.1. Introduction

7.4.2. The application of VAT Exemptions in the health care sector in successive situations

7.4.2.1. Composite supplies in successive situations

7.4.2.2. Assessment of the application of the VAT exemption for intramural care in successive situations

7.4.2.3. Assessment of the application of the VAT exemption for extramural care in successive situations

7.4.3. Example of the application of the exemption provision for health care in the successive situation: hiring out of medical staff

7.4.3.1. Hiring out of medical staff as a closely related service

7.4.3.2. The horizon criteria

7.4.3.3. The hindering effect of the application of the application of VAT in relation to the supply of staff

7.5. Conclusion

7.5.1. Conclusions on the application of the exemption provision for intramural care in the basic situation

7.5.2. Conclusions on the application of the exemption provision for extramural care in the basic situation

7.5.3. Conclusions on the application of the exemption provision for intramural care in parallel one-on-one situations

7.5.4. Conclusions on the application of the exemption provision for extramural care in parallel one-on-one situations

7.5.5. Conclusions on the application of the exemption provision for intramural care in parallel two-on-one situations

7.5.6. Conclusions on the application of the exemption provision for extramural care in parallel two-on-one situations

7.5.7. Conclusions on the application of the exemption provision for intramural care in successive situations

7.5.8. Conclusions on the application of the exemption provision for extramural care in successive situations

7.5.9. Schematic overview of the assessment criteria per situatuion

8. Alternative ways to mitigate the VAT burden on health care transactions while respecting the principle of access to health care

8.1. Framework for alternative measures $\quad 237$

8.1.1. Purpose of alternative measures 238

8.1.2. Access to health care as a standard 238 
8.1.3.1. General consumption tax 239

8.1.3.2. All stages tax $\quad 239$

8.1.3.1. System neutrality 239

8.1.3.2. Legal neutrality and the principle of equality 240

8.1.3.3. Ability to pay 240

8.2. Alternatives measures 241

8.2.1. Abolition of exemption provisions for health care 241

8.2.2. Reduced rates for health care transactions 242

8.2.3. Full taxation up until the penultimate supply 243

8.2.4. Adjustment of current exemption provisions for health care transactions 244

8.3. Conclusion 246

$\begin{array}{ll}\text { Part V Summary and Conclusions } & 249\end{array}$

9. Summary and conclusions 251

9.1. Introduction 251

9.2. Summary and conclusions 251

9.2.1. Conclusions as regards the principle of access to health as a standard 251

9.2.2. Conclusions as regards EU health care systems in relation to this research 252

9.2.3. Conclusions on the EU VAT perspective on health care transactions 252

9.2.4. Conclusions as regards the application of EU VAT in specific types of situations $\quad 254$

$\begin{array}{ll}\text { Bibliography } & 257\end{array}$

Literature $\quad 257$

EU Documents $\quad 261$

CJEU Case Law 263

A-G Opinions, CJEU 268

Other resources Error! Bookmark not defined.

$\begin{array}{ll}\text { Valorization addendum } & 273\end{array}$

1. Societal and economic relevance 273

2. To whom are the research results of interest and why? 273

3. Into which concrete activities, products, services and processes or commercial activities will the research results be translated and shaped? 274

4. To what degree can the research results be called innovative in respect to the existing range of products, services, processes, activities and commercial activities? $\quad 275$

5. How will this/these plan(s) for valorization be shaped? 276

$\begin{array}{ll}\text { Curriculum vitae } & 277\end{array}$ 


\section{Abbreviations}

$\begin{array}{ll}\text { CESCR } & \text { UN Committee on Economic, Social and Cultural Rights } \\ \text { CJEU } & \text { Court of Justice of the European Union } \\ \text { CRPD } & \text { Convention on the Rights of Persons with Disabilities } \\ \text { EC } & \text { European Commission } \\ \text { ECHR } & \text { European Convention on Human Rights, the Convention for the Protection } \\ & \text { of Human Rights and Fundamental Freedoms } \\ \text { ECOSOC } & \text { United Nations Economic and Social Council } \\ \text { EU } & \text { European Union } \\ \text { EU Charter } & \text { The Charter of Fundamental Rights of the European Union } \\ \text { HC } & \text { Health Care } \\ \text { ICCPR } & \text { International Covenant on Civil and Political Rights } \\ \text { ICESCR } & \text { International Covenant on Economic, Social and Cultural Rights } \\ \text { ICHA-HP } & \text { Classification of Health Care Providers } \\ \text { ISCO } & \text { International Standard Classification of Occupations } \\ \text { ISIC } & \text { International Standard Industrial Classification of All Economic Activities } \\ \text { OECD } & \text { Organisation for Economic Co-operation and Development } \\ \text { OJ } & \text { Official Journal (of the European Union) } \\ \text { OJ C } & \text { Official Journal (of the European Union), Information and Notices } \\ \text { OJ L } & \text { Official Journal (of the European Union), Legislation } \\ \text { SHA } & \text { System of Health Accounts } \\ \text { TCAM } & \text { Traditional Complementary and Alternative Medicine } \\ \text { TFEU } & \text { Treaty on the Functioning of the European Union } \\ \text { UDHR } & \text { Universal Declaration of Human Rights of 1948 } \\ \text { UN } & \text { United Nations } \\ \text { UStG } & \text { Umsatzsteuergesetz/ German Value Added Tax Act } \\ \text { VAT } & \text { Value Added Tax } \\ \text { WHO } & \text { World Health Organisation } \\ & \end{array}$


Part I Introduction 


\section{Introduction}

\subsection{Synopsis}

The human right to health entails that every person is entitled to the enjoyment of the highest attainable standard of physical and mental health. ${ }^{1}$ The right to health is included in a number of international human rights treaties and it is recognized and supported worldwide in many countries. One of the elements distinguished within the scope of this human right is the element of accessibility to health care:

"Health facilities, goods and services have to be accessible to everyone without discrimination."

This also includes financial accessibility and implies that it has to be ensured that health facilities, goods and services are affordable for all and that payment therefore is based on the principle of equity (the ability to pay principle). The right to health is, inter alia, included in the International Covenant on Economic, Social and Cultural Rights ${ }^{3}$ (hereafter: ICESCR). The ICESCR is a human rights treaty to which all EU Member States are party. As a result, this intentional human right creates obligations for EU Member States for a progressive realization of the human right and creates obligations of immediate effect in relation to the right to health. Furthermore, a right of access to preventive health care and to benefit from medical treatment within health care is included in the Charter of Fundamental Rights of the European Union. ${ }^{4}$ With the entry into force of the Lisbon Treaty ${ }^{5}$ on 1 December 2009, the EU Charter gained the same legal value as the EU Treaties and hence became part of primary EU law. The human right to health and access to health care can therefore not be denied in an EU context. It is obviously a right of a higher order (a standard) that has to be taken into account by the EU legislator and the Member States when drafting legislation and policies.

The EU VAT is a general tax. ${ }^{6}$ Moreover, it is a tax on consumption. ${ }^{7}$ Health care transactions are, like other supplies of services or goods, transactions that are ultimately consumed by

\footnotetext{
${ }^{1}$ UN Committee on Economic, Social and Cultural Rights (CESCR), General Comment No. 14: The Right to the Highest Attainable Standard of Health (Art. 12 of the Covenant), 11 August 2000; See also Chapter 2.

${ }^{2}$ Idem, para. 12.

${ }^{3}$ UN General Assembly, International Covenant on Economic, Social and Cultural Rights, 16 December 1966, United Nations, Treaty Series, vol. 993, p. 3, entered into force on 3 January 1978, retrievable via: http://www.ohchr.org.

${ }_{5}^{4}$ Article 35 of the Charter of Fundamental Rights of the European Union, OJ C 303, 14 December 2007.

${ }^{5}$ Treaty of Lisbon amending the Treaty on European Union and the Treaty establishing the European Community, signed at Lisbon, 13 December 2017, OJ C 306, 17 December 2007.

${ }^{6}$ See section 3.2.1. The general EU VAT system differs from specific consumption taxes - e.g. excise taxes and customs duties - as it intends to cover all economic activities resulting in supplies of goods and services within the EU.

${ }^{7}$ According to its legal character it aims to tax final consumption from final consumers.
} 
final consumers. ${ }^{8}$ This implies that, without any further measures, the consumption of health care should in principle be subject to VAT. The general application of VAT is illustrated by the broad definition of both the subject and the object of taxation. ${ }^{9}$ A subject of taxation - the taxable person - can be any person, regardless of the legal form. In principle, the taxable person definition covers all economic activities, regardless of where they take place, the purpose of the activities and the legal form of the person carrying out those activities. The definition of the object of taxation - the taxable transaction ${ }^{10}-$ is also rather broad. As a result, many persons and bodies are potentially confronted with Value Added Tax on a wide range of transactions in the commercial as well as the non-profit and the public sector. The broad scope of VAT is in keeping with the character of the tax as a general tax on consumption. ${ }^{11}$ The foregoing implies that the extensive scope of VAT to a certain extent covers health care transactions. Considering the aim of Value Added Tax and the system of levying, this is only logical. That, however, does not necessarily mean that it is desirable or justifiable with regard to the application of the human right to health.

The imposition of this consumption tax can be expected to lead to an increased cost price of health care for the end consumer. By nature, a general tax on consumption has other aims than the human right to health and hence the principle of access to health care. More than that, one could say that they clearly have conflicting aims in relation to health care consumption. The EU VAT intends to tax consumption in as general a manner as possible, whereas the human right to health seeks to ensure that (financial) accessibility of health care is guaranteed in the best way possible. Figure 1.1 below illustrates the conflicting aims of the two 'forces'. It is shown that the general character of EU VAT - represented by the inner circle in figure 1.1 - tries to include a large part of the health care consumption in its scope. The right to health - represented by the outer circle - is required to ensure the accessibility of health care. This implies that it aims to relieve health care consumption from burdens like a value added tax that can have the effect of increasing the cost price of that health care.

\footnotetext{
${ }^{8}$ In economics the term consumption is often used as a starting point for measuring health care expenditure. The OECD for instance takes the approach that health care goods or services are either used as inputs to the production of other health care goods and services, or to satisfy the needs of the population, for example: OECD, World Health Organization and Eurostat, 2011, A System of Health Accounts: 2011 Edition, OECD Publishing, p. 35-36.

${ }^{9}$ Respectively Article 2 and Article 9 of the EU VAT Directive.

${ }^{10}$ Article 2 of the EU VAT Directive.

11 Proposal for a Sixth Council Directive on the harmonisation of legislation of Member States concerning turnover taxes, Common system of value added tax: uniform basis of assessment, COM(73) 950, 20 June 1973, p. 8.
} 


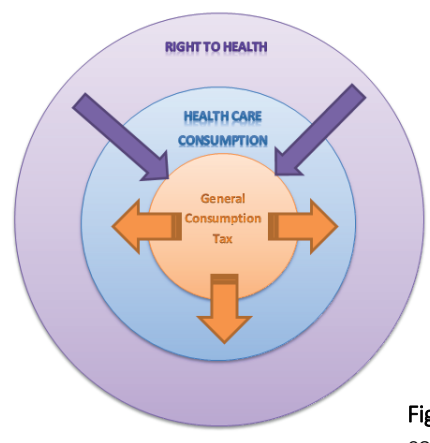

Figure 1.1 The conflicting aims of the human right to health and VAT as a general consumption tax.

In Ordre des barreaux francophones et germanophone, ${ }^{12}$ the CJEU seems to acknowledge the fact that the levying of VAT is in principle capable of increasing the price of a transaction, it even acknowledges that the imposition of VAT by itself can potentially create an obstacle to access to a fundamental right (i.e. the right to an effective remedy). It, however, concluded in that case that the imposition of VAT on the supply of services by lawyers did not, by itself, create an 'insurmountable obstacle' to access to justice, despite the eventual increased costs. ${ }^{13}$ In my view, the CJEU has created confusion at this point with this decision. Although the CJEU was not yet asked to establish a possible infringement of the human right to health as a result of the imposition of VAT on health care, it has on multiple occasions explicitly confirmed the proposition that the imposition of EU VAT on health care transactions hinders the access to health care. ${ }^{14}$ According to the CJEU, it has to be ensured that the benefits flowing form hospital and medical care:

"are not hindered by the increased costs of providing it that would follow if it, or closely related activities were subject to VAT". ${ }^{15}$

The CJEU even stated that the objective of the VAT exemptions for health care ${ }^{16}$ is to reduce health care costs, making it more accessible to individuals. ${ }^{17}$ The foregoing implies in my view that the CJEU is of the opinion that the right to health or, more specifically, the access to

\footnotetext{
${ }^{12}$ CJEU 28 July 2016, Case C-543/14 Ordre des barreaux francophones et germanophone, ECLI:EU:C:2016:605.

${ }^{13}$ CJEU 28 July 2016, Case C-543/14 Ordre des barreaux francophones et germanophone, ECLI:EU:C:2016:605, para. 36

${ }^{14}$ CJEU 1 December 2005, Joined Cases C-395/04 and C-394/04 Ygeia, ECLI:EU:C:2005:734, para. 23; CJEU 11 January 2001, Case C-76/99 Commission vs. France, ECLI:EU:C:2001:12, para. 23; CJEU 20 June 2002, Case C287/00 Commission vs. Germany, ECLI:EU:C:2002:388, para. 47 (as regards education services, however in the same line); CJEU 6 November 2003, Case C-45/01 Dornier, ECLI:EU:C:2003:595, para. 40.

${ }^{15}$ CJEU 11 January 2001, Case C-76/99 Commission vs. France, ECLI:EU:C:2001:12, para. 23.

${ }^{16}$ Article $132(1)(b)$ and (c) of the EU VAT Directive.

${ }^{17}$ CJEU 20 November 2003, Case C-212/01 Margarete Unterpertinger, ECLI:EU:C:2003:625, para. 41; CJEU 8 June 2006, Case C-106/05 L.u.P., ECLI:EU:C:2006:380, para. 25; CJEU 6 November 2003, Case C-45/01 Dornier, ECLI:EU:C:2003:595, para. 48; CJEU 10 September 2002, Case C-141/00 Kügler, ECLI:EU:C:2002:473, para. 29; CJEU 1 December 2005, Joined Cases C-395/04 and C-394/04 Ygeia, ECLI:EU:C:2005:734, para. 23; A-G Opinion 10 September 2009, Case C-262/08 CopyGene, ECLI:EU:C:2009:541, para. 33.
} 
health care is a standard that has to be taken into account in relation to the imposition of EU VAT. Furthermore, it seems that the Court, to some extent, values the ability to pay principle. It is, however, not clear whether the ability to pay principle ever played a role during the drafting of the VAT exemptions for medical care (see section 3.4). Despite the fact that the CJEU seems to value the effects of the imposition of VAT on the services of lawyers differently, I assume it did not intend to make an exception to its steady line of reasoning in relation to the imposition of VAT on health care (see also chapter 5 ).

The EU VAT Directive already contains provisions that aim to relieve the tax burden on goods and services for social and economic reasons. ${ }^{18}$ These provisions also affect health care transactions. The application of these provisions depends on the quality of the (health care) supplier and the nature of the supply itself. The consequence of the application of these provisions also differs. The consequence of the application of exclusions for public sector bodies is that health care transactions are excluded from the scope of EU VAT (non-taxable transactions). The same consequence occurs in case health care transactions are supplied with an absence of consideration. Another possibility is that one of the exemption provisions of the EU VAT Directive applies. If an exemption applies, the transaction remains covered under the EU VAT Directive (taxable transactions), the transaction is however not taxed. A direct consequence of the application of a VAT exemption on health care transactions is that there is no right to deduct input VAT that was charged to the supplier in relation to the exempt health care transactions. Finally, the other possibility under the EU VAT Directive to relieve the tax burden on health care transactions is the application of reduced rates. According to the CJEU, the application of reduced rates has as its purpose:

"to render less onerous, and thus more accessible to final consumers - who ultimately bear the VAT - certain goods regarded as being particularly necessary". ${ }^{19}$

In this context, a reduced rate for health care transactions mainly applies in relation to the supply of pharmaceutical products and medical equipment (supplies of goods). The result of the application of reduced rates is that supplies are taxed (taxable supplies) at a rate that is below the standard VAT rate, but not below $5 \% .{ }^{20}$

The question that arises is whether the measures that the EU legislator took to mitigate the VAT burden on health care transactions do justice to the right to health and, more in particular, the principle of access to health care. The measures do relieve the VAT burden to a certain extent. It is however questionable whether they do so in a sufficient manner to

\footnotetext{
${ }^{18}$ E.g. the exclusion for activities of certain public bodies (Article 13 of the EU VAT Directive), exemptions for certain activities in the public interest (Articles 132-134 of the EU VAT Directive), exemptions for other activities (Articles 135-136 of the EU VAT Directive), and reduced rates for certain supplies of goods and services (Articles 98 jo. Annex III of the EU VAT Directive).

${ }^{19}$ CJEU 17 January 2013, Case C-360/11 Commission vs. Kingdom of Spain, ECLI:EU:C:2013:17, para. 48; CJEU 9 March 2017, Case C-573/15 Oxycure Belgium, ECLI:EU:C:2017:189, para. 22.

${ }^{20}$ Article 9 of the EU VAT Directive.
} 
guarantee the access to health care for everyone. Does EU VAT, despite the aforementioned measures, still hinder access to health care in a way which cannot be justified by other principles? For example, the application of an exemption provision within a supply chain can cause a cascading of VAT, which is inconsistent with the neutral character of the EU VAT. Next to this cascading effect, the application of an exemption provision can influence the choices of health care suppliers. This is especially true if health care suppliers are not entitled to a right to deduct input VAT, they may be tempted to make economically inefficient choices while avoiding investments in relation to which VAT would be charged to them (bias to selfsupply). This causes friction. Provisions like VAT exemptions aim to promote access to health care, while the inefficient choices that they lead to are responsible for making health care more expensive and, hence, less accessible for individuals. Distortions are not only caused by exemptions, they may also be caused by the fact that certain transactions or supplies are excluded from the scope of VAT. The application of a reduced rate, in comparison with the application of exemption provisions, has the advantage that the supplier is entitled to deduct input VAT. On the other hand, the transaction that is subject to the reduced rate is not relieved from VAT and the cost price of health care is still affected, as the transaction is still taxed, albeit at a lower VAT rate.

The starting point of this thesis is that it takes the existence of the EU VAT system, which finds its basis in primary EU law, as a given. ${ }^{21}$ Moreover, it is very unlikely that the harmonized EU VAT system will be abolished, considering the large share of tax revenue that it raises and the ongoing shift from direct to indirect taxes. In my view, however, it is certain that the imposition of EU VAT hinders the access to health care. I already indicated that the hindering effect is present, despite the provisions that the EU VAT Directive contains in order to mitigate the VAT burden on health care transactions. One of the research aims of this thesis is to identify how the application of positive EU VAT law - notwithstanding the mitigating measures contained within it, still - impedes the principle of access to health care and in which specific situations ('where') this occurs. Furthermore, I will explore which side effects this impediment causes, i.e. effects beyond the direct effect of the imposition of VAT on the cost price of health care (e.g. changes in the behaviour of health care providers or consumers). The side effects will be identified from a theoretical perspective, albeit that the extent of the side effects is hard to determine, and not only due to a lack of data. Once the specific situations in which the imposition of VAT impedes the principle of access to health care are known, it will be studied whether there are alternative and more effective ways to safeguard the access to health care from a VAT perspective under positive EU law, i.e. without the side effects that currently arise as a result of the present measures in the EU VAT Directive. These alternative ways can be measures that are already included in the EU VAT Directive, but they are currently not applicable as regards health care transactions (for

\footnotetext{
${ }^{21}$ Article 112 of the TFEU (Consolidated version of the Treaty on the Functioning of the European Union, OJ C 202, 7 June 2016).
} 
example exemptions with a right to deduct input VAT) or measures outside EU VAT law (for example the application of a VAT compensation scheme).

\subsection{Research relevance and motivation}

Health care systems in EU Member States are a national matter. Consequently, their design and funding structure differ per Member State. The European health care systems, however, interact increasingly with each other, inter alia, as a result of increased patient mobility and the mobility of health care professionals. Cross-border patient mobility has increased exponentially in the EU over the past two decades, although the absolute volumes of patients seeking treatment across European borders is relatively small. ${ }^{22}$ Cross-border mobility is caused by a number of reasons, including availability, affordability, familiarity, and perceived quality of health care. ${ }^{23}$ Another important factor, in my view, is the presence of a legal framework on the coverage of health care costs within the EU. Regulation 883/2004 ${ }^{24}$ ensures that EU citizens can receive reimbursable health care in another Member State if the costs of that health care would also be covered in their Member State of residence. In principle, patients are unwilling to travel significant distances for care. It appears, however, that, in some border regions, the most accessible care is available in another Member State. ${ }^{25}$ The cross-border mobility in these regions is often facilitated by several factors, such as the concentration of health care in larger facilities. ${ }^{26}$

EU Health care systems also face common challenges like increased health care spending and an ageing population. ${ }^{27}$ In the past two decades, health care spending has grown even faster than the GDP growth in OECD countries. ${ }^{28}$ It is therefore also in the countries common interest to improve the fiscal sustainability of health care. Fiscal sustainability is the ability to maintain public finances at a credible and serviceable level over the long term. ${ }^{29}$ Despite the deviating structure and funding of the national health care systems, they are built upon

\footnotetext{
22 Footman, K., Knai, C., Baeten, R. et al., 2014, Cross border health care in Europe, Policy Summary 14, WHO, 2014; Legido-Quigley, H., Passarani, I., Knai, C. et al., 2011, Cross-border healthcare in Europe: clarifying patients' rights. BMJ, 342(7793):364-7.

${ }^{23}$ Glinos, I.A., Baeten, R., Helble, M. et al., 2010, A typology of cross-border patient mobility. Health \& Place, 16(6):1145-55.

24 Regulation (EC) No 883/2004 of the European Parliament and of the Council of 29 April 2004 on the coordination of social security schemes, OJ L 166, 30 April 2004, p. 1.

${ }^{25}$ Glinos, I.A., Baeten, R., Helble, M. et al. 2010, A typology of cross-border patient mobility. Health \& Place, 16(6):1145-55.

${ }^{26}$ Legido-Quigley, H., Glinos, I.A., Baeten, R. et al., 2012, Analysing arrangements for cross-border mobility of patients in the European Union: A proposal for a framework. Health Policy, 108:27-36; Bertinato, L., Busse, R., Fahy, N. et al., 2005, Cross-Border Health Care in Europe, Brussels.

${ }^{27}$ Communication from the Commission on effective, accessible and resilient health systems, COM(2014) 215 final, 4 April 2014.

28 OECD, 2015, Fiscal Sustainability of Health Systems Policy Brief, September 2015, retrievable via: http://www.oecd.org/health/health-systems/Fiscal-Sustainability-Health-Systems-Policy-Brief.pdf.

29 OECD, 2015, Fiscal Sustainability of Health Systems: Bridging Health and Finance Perspectives, OECD Publishing, Paris, p. 25; OECD, 2013, Health at a Glance 2013: OECD Indicators, OECD Publishing, Paris, retrievable via: http://dx.doi.org/10.1787/health_glance-2013-en.
} 
common values that are recognized at the EU level. One of these values is the access to health care. ${ }^{30}$ The accessibility of health care is increasingly taken into account with research on improvements to health care systems and the fiscal sustainability of those systems. ${ }^{31}$

CJEU decisions on the application of EU VAT in relation to health care transactions confirm, on the one hand, that the imposition of VAT reduces accessibility to health care. On the other hand, the CJEU states that the application of VAT exemptions prevents a reduction in the access to health care. Moreover, in those decisions, the CJEU considered access to health care as a standard in relation to the imposition of EU VAT. It held in a number of cases that VAT should not be levied if it would result in increased costs of health care and, hence, reduce access to health care. ${ }^{32}$ In my view, the CJEU weighs the application of EU VAT against the value or standard of access to health care. In the field of EU VAT, research has been conducted on the application of exemption provisions and exclusions in relation to public sector bodies and other sectors. ${ }^{33}$ Exemption provisions and provisions that exclude transactions from VAT ('out of scope transaction', i.e. supplies by public bodies under public $\left(a w^{34}\right)$ are provisions included in the current EU VAT system. The application of both types of provisions have as a result that a transaction is not subject to VAT. At the same time, a supplier carrying out such a transaction is not entitled to deduct the VAT that was charged to him on the costs or investments that he made in relation to that exempt or excluded transaction. ${ }^{35}$ It is common that the application of VAT exemptions and exclusions provide an exception to the general application of EU VAT. Moreover, a number of studies have already confirmed the distortive effect of exemptions and exclusion provisions included in positive EU VAT law. The distortive effects of exemptions and exclusions (e.g. the bias to self-supply and cascading of VAT) result in a substantial VAT burden for health care suppliers and inevitably increased costs for health care consumers.

So far, no extensive research has been conducted on the interaction between positive EU VAT law and access to health care. In my view, the growing importance and recognition of access to health care at the EU level, as a value for designing and improving health care

\footnotetext{
${ }^{30}$ Communication from the Commission of 4 April 2014, On effective, accessible and resilient health systems, $\operatorname{COM}(2014) 215$ final.

31 See for example OECD, 2015, Fiscal Sustainability of Health Systems: Bridging Health and Finance Perspectives, OECD Publishing, Paris.

32 Inter alia CJEU 5 October 2016, Case C-412/15 TMD, ECLI:EU:C:2016:738, para. 32; CJEU 26 February 2015, Joined cases C-144/13, C-154/13 and C-160/13 VDP Dental Laboratory and Others, EU:C:2015:116, para. 46.

${ }^{33}$ See for example Henkow, O., 2013, The VAT/GST Treatment of Public Bodies, Series on International Taxation vol. 41, Kluwer Law International; De la Feria, R., 2009, EU VAT Treatment of Public Sector Bodies: Slowly Moving in the Wrong Direction, Intertax, 37, p. 148; the following studies performed by Copenhagen Economics: VAT in the public sector and exemptions in the public interest, Final report TAXUD/2009/DE/316 of 1 March 2011 and VAT in the public sector and exemptions in the public interest, Final report for TAXUD/2011/DE/334 of 10 January 2013.

${ }^{34}$ Article 13 of the EU VAT Directive.

${ }^{35}$ This is a result of the application of Article 15 of the EU VAT Directive. There are also exemptions with a right to deduct, for example the exemption of Article 138 of the EU VAT Directive.
} 
systems on the one hand, and CJEU case law on the application of EU VAT on health care transactions on the other hand call for such research to be carried out. In its report on the Fiscal Sustainability of Health Care Systems, the OECD holds that the 'distortionary costs' of taxes have to be taken into account in economic policy discussions on the financing of public services. ${ }^{36}$ Along the same lines, De la Feria stated that, in the context of budget restraints, one cannot only focus on health care spending. ${ }^{37}$ An efficient application of EU VAT, in my view, also contributes to the fiscal sustainability of health care systems. This study, which is a qualitative study, not only contributes to a more efficient levying of EU VAT on health care, it also contributes to quantitative research on the fiscal sustainability of health care systems. Moreover, this study aims at providing insights in relation to the application of VAT in other sectors, i.e. the education sector, as this sector is confronted with similar EU VAT rules and by nature is also predominantly financed with public funds.

It seems to me that EU VAT legislators in the 1960s did not weigh the imposition of EU VAT on health care transactions against the standard of access to health care. There are, at least to my knowledge, no documents (travaux préparatoires) available that provide evidence that such an assessment was considered or carried out. Nevertheless, the CJEU seems to take access to health care into account as a standard for the interpretation and application of positive EU VAT law. Almost 50 years have passed since the harmonized EU VAT system entered into force. During these years, the health care sector has changed drastically, while the provisions in the EU VAT Directive that relate to health care have not. Compared to 50 years ago, for example, costs of health care have increased for both governments and consumers, while at the same time the ageing of the population continues. Another example of a change is that cross-border patient mobility has increased exponentially. ${ }^{38}$ Inevitably, one of the effects of these changes is that more investments have to be made, which are also subject to VAT. These changes require an exploration of the adequacy of the relevant provisions in the current EU VAT Directive and possible alternative options.

The imposition of EU VAT hinders access to health care. This is, on the one hand, a result of the way in which VAT is levied, which increases the cost price of goods and services. On the other hand, this is a result of inadequate measures contained in the EU VAT Directive, which have the aim to mitigate the VAT burden on certain transactions. In this study, I will explore alternative approaches to the VAT treatment of health care transactions under positive EU law, which may be more effective and do justice to the principle of access to health care. In situations in which the current EU VAT system does not prove to be adequate, recommendations to improve the VAT treatment of health care transactions will be put forward.

\footnotetext{
${ }^{36}$ OECD, 2015, Fiscal Sustainability of Health Systems: Bridging Health and Finance Perspectives, OECD Publishing, Paris, p. 184.

${ }^{37}$ De la Feria, R., 2006, The EU VAT System and the Internal Market, IBFD, p. 170.

${ }^{38}$ See also section 1.2 .
} 


\subsection{Research questions}

In the previous sections, I indicated that the application of positive EU VAT law impedes the principle of access to health care. Departing from that proposition, the first research question aims to establish how and where this impediment occurs.

\section{Research question 1:}

How does the application of positive EU VAT law on health care transactions impede the principle of access to health care? Moreover, in which specific situations does the application of positive EU VAT law impede the principle of access to health care and what are the side effects of this impediment?

This research question requires in the first place a general understanding of what access to health care entails. There is no common EU definition of health care. Health care systems are a national matter, and therefore the understanding of what health care is and which transactions are carried out within a health care system differ per Member State. It is therefore necessary to define the common denominators of EU health care systems. Within this study, the principle of access to health care is considered a standard that has to be respected while designing and applying positive EU VAT law. In the context of this first research question I will, therefore, explore this standard and establish its scope, relevance and application in relation to positive EU VAT law. The first research question furthermore requires an exploration of the scope and application of positive EU VAT law, including the underlying principles of the EU VAT system. This is necessary to be able to determine how the imposition of EU VAT impedes the principle of access to health care and which specific provisions in the EU VAT Directive have this effect.

With the second sub question, I aim to establish in more detail in which types of situations the imposition of VAT on health care transactions impedes access to health care. Moreover, I aim to establish which side effects this impediment brings along. Presumably, side effects are also capable of hindering access to health care. For example, legal uncertainty or substantial administrative obligations also lead to increased costs for health care suppliers, and - as a result - to more expensive health care for individuals. The measures that the EU VAT legislator took to mitigate the VAT burden on certain transactions are not sufficiently effective in safeguarding the principle of access to health care. Therefore, the second research aim is to establish if there are alternative ways to mitigate the VAT burden on health care transactions while respecting the principle of access to health care. The second research question is, therefore, as follows:

\section{Research question 2:}

Are there alternative ways to tax health care transactions under an EU VAT system that mitigate the hindering effect on the access to health care and which do not have the side effects of the present measures under positive EU Law? 


\subsection{Research structure}

This research consists of five parts:

\section{Part I: Introduction}

Chapter 1: Introduction

Part II: The Relationship Between the Principle of Access to Health Care and EU VAT

Chapter 2: Relevant definitions and common denominators in EU health care systems

Chapter 3: Legal framework as regards the application of VAT on health care transactions

Chapter 4: The principle of access to health care

Chapter 5: Balance between the application of VAT and the principle of access to health care

Part III: How the Application of Positive EU VAT Law Impedes Access to Health Care

Chapter 6: Elements of positive EU VAT law that may mitigate the VAT burden on health care transactions

Chapter 7: How VAT exemptions impede access to health care in specific situations

Part IV: How to Mitigate the Hindering Effect of EU VAT on Access to Health Care

Chapter 8: Alternative ways to mitigate the VAT burden on health care transactions while respecting the principle of access to health care

\section{Part V: Summary and Conclusions}

Chapter 9: Summary and Conclusions

Part I introduces the reader to the research topic and explains the relevance of the study and the research aims and approach.

Part // discusses the relationship between the principle of access to health care and the application of EU VAT. Chapter 2 explores common denominators of health care systems in the EU. These common denominators of the health care systems will serve as a 'model EU health care system' and be used to measure the effect of the imposition of VAT on the access to health care in the EU. To come to this model health care system, definitions for health care, health care suppliers and health care systems will be explored.

The aim and purpose of the EU VAT system, its scope of application and underlying principles will be discussed in chapter 3. At this point in the study, this chapter serves as part of the legal framework. The application of EU VAT will be balanced, at a later stage (chapter 5), 
against the application of the principle of access to health care. The principle of access to health care is one of the elements distinguished within the scope of the human right to health. It is this element of accessibility that the CJEU, in a number of cases on EU VAT law, seems to refer to. In relation to the application of EU VAT law, I consider the principle of access to health care as a standard that cannot be denied. In chapter 4 I explore the human right to health and the principle of access to health care and I will demonstrate the relevance of this principle in relation to EU VAT law.

Part III serves to answer the first research question - i.e. how and in which specific situations the application of positive EU VAT law impedes the access to health care - after setting up the framework and demonstrating the area of tension between the EU VAT and the principle of access to health care in the previous part.

Part IV discusses alternative ways to mitigate the VAT burden on health care transactions under the current VAT system, while respecting the principle of access to health care. Furthermore, measures under an alternative EU VAT system will also be explored. This part therefore serves to answer the second research question as it discusses possible alternatives.

Finally, in part $V$, the conclusions that have been drawn in the chapters will be summarized and analysed briefly. On the basis of this analysis, recommendations as regards improvements of the current EU VAT system will be made and possible alternatives will be suggested.

\subsection{Research scope and limitations}

In this section I will set out the scope of this research. Within this research, the presence of the EU VAT system is considered as a given. ${ }^{39}$ In the first place, this research, therefore, focusses on the application of positive EU VAT law. As a result, the provisions of the EU VAT Directive and the case law of the CJEU that relates to these provisions form the starting point of the VAT perspective that is part of this research. No extensive study has been conducted on the national VAT provisions that concern the taxation of health care transactions. To provide examples, references will be made to national legislation, decrees, court cases or practices. In line with the EU VAT Directive, the research topic is limited to the territorial scope of that Directive. ${ }^{40}$ As a result, in principle, only the supplies of goods and services that take place (from a VAT point of view) within the territory of an EU Member State are taken into account in this research.

Another limitation that directly follows from the research topic concerns the type of transactions addressed. This research focusses on the health care. As explained in section 1.2 , there is no common EU definition of health care and the design and funding structure of

\footnotetext{
${ }^{39}$ See also section 1.1 .

${ }^{40}$ The territorial scope of EU VAT is defined in Article 2 of the EU VAT Directive.
} 
health care systems also differ per Member State. Therefore, common denominators and definitions as regards health care (supplies) and health care suppliers will be explored in chapter 2. With this exploration, I do not intend to create new definitions in relation to health care. The definitions used in this research are only used in order to serve the research purpose, i.e. to come to an understanding of the transactions and operators that are involved in an average EU health care system.

Even though in this study I frequently refer to increased costs of health care, this study is by no means intended to be of a quantitative nature. This study focusses on the legal and practical results of the application of legislation and only takes into account budgetary effects to a very limited extent. This study does however contribute to quantitative research by suggesting alternatives for the EU VAT system that require further (quantitative) research. Furthermore, I would like to note at this point once more that it is an assumption in this research that the imposition of VAT on health care transactions leads to increased health care costs. This is an expected but not a necessary effect, depending on a few factors, e.g. the possibility of the right to deduct input VAT for suppliers in a supply chain and to what extent VAT incurred forms part of the cost components of future taxable transactions. Case law on the right of deduction seems to suggest that VAT imposed on acquired goods and supplies is part of the cost components of the taxable transactions for which the acquisitions were made. ${ }^{41}$ This supports my view that the imposition of VAT on health care transactions can be expected to lead to an increase in health care costs.

\footnotetext{
${ }^{41}$ See, for example, CJEU 22 February 2001, Case C-408/98 Abbey National, ECLI:EU:C:2001:110, para. 28; CJEU 8 June 2000, Case C-98/98 Midland Bank, ECLI:EU:C:2000:300, para. 30; CJEU 6 April 1995, Case C-4/94 BLP Group, ECLI:EU:C:1997:107, para. 19.
} 
Part II The Relationship Between the Principle of Access to Health Care and EU VAT 


\section{Relevant definitions and common denominators in EU health care systems}

\subsection{Introduction}

In order to establish how the application of VAT impedes access to health care, it is necessary to establish what kind of transactions are actually covered under the term 'health care'. Therefore, I will - as a starting point of this research - explore terminology in relation to health care. In that regard, this chapter serves to establish whether there is a (EU) definition, or at least a common understanding, of the EU health care system. It is, in particular, interesting to see whether there are common definitions of health care (supplies) and health care suppliers.

As VAT is based on a European Directive ('EU VAT Directive') ${ }^{42}$ and is harmonised, it hence applies in every EU Member State in a more or less uniform manner. Unlike VAT, health care systems are not harmonised in the EU. Health care systems are regulated at the national level, with their own quality standards, legislation and definitions. What the different health systems do have in common is, according to the World Health Organisation (WHO), that they require financing, a workforce, facilities, reliable information, and logistics. ${ }^{43}$ A detailed study of every EU health care system, its transactions and operators would go beyond the scope of this research and rather be confusing than clarifying. It is, however, possible to determine the common denominators of the various EU health care systems in terms of health care transactions and health care suppliers. The idea is that the common denominators together form a 'model EU health care system', meaning that it covers the main health care transactions and operators and also takes into account the various contractual (or legal) ways to provide health care to patients in the EU.

The model health care system serves as a means to determine the consequences of the application of VAT on health care transactions. To come to this EU model health care system, definitions for health care, health care suppliers and health care systems will be explored. Subsequently, the requirements of the model will be determined. Since the purpose of the model is to establish the VAT consequences of health care transactions, it is also important to take into account the relevant factors in determining the VAT consequences. After all, the model EU health care system is only capable of providing relevant information on the VAT burden on health care transactions if it at least contains the necessary elements to determine the taxability and the effect of VAT on the cost price of health care. For this reason, I focus on transactions and suppliers within a health care system as they are the main indicators for the

\footnotetext{
${ }^{42}$ Council Directive 2006/112/EC of 28 November 2006 on the common system of value added tax, OJ L 347,11 December 2006 (otherwise referred to as 'EU VAT Directive').

${ }^{43}$ Information retrievable via: http://www.who.int/topics/health_systems/en.
} 
imposition of VAT. ${ }^{44}$ Next to the analysis of the model health care system, the Dutch health care system will be analysed briefly in order to test the applicability of the designed model health care system, without elaborating on the specific national (legal) conditions that apply. At this point, I would like to emphasize that I do not intend to give recommendations on the design and structure of the Dutch health care system or any other EU health care system. I will limit myself to the effects of the imposition of VAT on (the access to) health care within the EU.

\subsection{Definitions of health (care) activities, suppliers and systems}

International and European organisations concerned with health care, either from a qualitative or a quantitative point of view, apply definitions for health care and health care related transactions in order to carry out research and perform an analysis in this field. In the following sections, definitions used by these organisations will be explored to establish whether there is a common understanding of what health care activities, health care suppliers and health care systems are. Subsequently, the relevant definitions for the model EU health care system will be defined.

\subsubsection{Definitions of Health (Care) Activities}

\subsubsection{Exploration of Definitions for Health Care Activities}

While looking for a definition of a model health care system, the question arises what health care actually is. As also follows from the previous chapter, health care is not a fixed concept. The WHO defines health services as:

"...services which can contribute to improved health or the diagnosis, treatment and rehabilitation of sick people and not necessarily limited to medical or health-care services". These services can include "health education, health promotion, and environmental services such as housing, sanitation, etc., which have a known health benefit..." ${ }^{4}$

This definition is broad, but it can be reduced to the objectives of health care activities are. According to the $\mathrm{WHO}$, the objective of health care is to contribute to improved health or to provide for the diagnosis, treatment and rehabilitation of sick people. ${ }^{46}$ The qualification of

\footnotetext{
${ }^{44}$ The VAT as such is an objective tax (see e.g. CJEU 6 April 1995, Case C-4/94 BLP Group, ECLI:EU:C:1997:107, para. 24), although applicability of VAT exemptions is in many cases dependent on the quality of the service provider.

${ }^{45}$ Roberts, J. L. and World Health Organization, 1998, Terminology: a glossary of technical terms on the economics and finance of health services, Doc. Nr. EUR/ICP/CARE 94 01/CN01, retrievable via: http://www.euro.who.int; see also http://www.who.int/topics/health_services/en.

${ }^{46}$ The CJEU likewise defined 'medical services' (for the purpose of the application of VAT) as "services effected for the purpose of protecting, of maintaining or of restoring human health", see CJEU 13 March 2014, Case C366/12 Klinikum Dortmund, ECLI:EU:C:2014:143, para. 29; CJEU 20 November 2003, Case C-212/01 Margarete Unterpertinger, ECLI:EU:C:2003:625, paras. 40 and 41; CJEU 20 November 2003, Case C-307/01 d'Ambrumenil and Dispute Resolution Services, ECLI:EU:C:2003:627, paras. 58 and 59; CJEU 8 June 2006, Case C-106/05 L.u.P., ECLI:EU:C:2006:380, para. 29.
} 
an activity as a health service is thus dependent on the purpose of that service. A Dictionary of Public Health ${ }^{47}$ explicitly mentions self-care and informal care provided by family members and friends as examples of care that also fall under the definition of health care. ${ }^{48}$

In my view it is interesting to also take a look at health care definitions from an economic point of view, more in particular in relation to costs of health care and health care expenditure. Concerns on the increase of health care expenditure have led to numerous discussions and research in that field. Health care systems have been analysed and compared at the international level in order to discover the cause of the increase in health care expenditure and to gain insights on how to control a further increase. The reason that research on health care expenditure is useful in this search for a model health care system is that measuring health care expenditure requires insights on what health care transactions are. Furthermore, as analysts seek to compare the amount of health care expenditure among countries, common and comparable definitions are required. Moreover, these definitions have to be applicable in relation to all health care systems included in the comparison.

Over the last 20 years, the average annual growth of health spending exceeded the GDP growth in all OECD countries. ${ }^{49}$ It is therefore in the common interest of countries to improve the fiscal sustainability of health care. One of the organizations that conducts research in the field of fiscal sustainability of health care systems is the Organisation for Economic Cooperation and Development (OECD). Fiscal sustainability is defined by the OECD as the ability to maintain public finances at a credible and serviceable position over the long term. ${ }^{50}$ Around three-quarters of health spending comes from public funding. From a fiscal sustainability point of view, the increased spending on health is a concern, as public funds account for approximately three-quarters of the total spending on health across the OECD. According to the OECD, controlling the health expenditure growth is particularly difficult for budget officials for two reasons. In the first place, health care is perceived as a very high priority. Secondly, a great number of stakeholders intervene between the beneficiaries of health care and the public resources financing it. OECD figures show that, after the global financial crisis, the increase in health spending has been slower than the GDP growth in a majority of the EU Member States. ${ }^{51}$ Despite this slow down, the OECD expects that government health care spending will rise in the medium long-term, which raises fiscal sustainability issues. These issues are particularly present in the health care sector, as the

\footnotetext{
47 Last, J.M. (Ed.), 2007, A Dictionary of Public Health, Oxford University Press, retrievable via: http://www.oxfordreference.com.

${ }^{48}$ For the application of VAT, the latter are not directly relevant as self-care and care between family members will in principle not fall within the scope of VAT.

49 OECD, 2015, Fiscal Sustainability of Health Systems Policy Brief, OECD Publishing, retrievable via: http://www.oecd.org/health/health-systems/Fiscal-Sustainability-Health-Systems-Policy-Brief.pdf.

50 OECD, 2015, Fiscal Sustainability of Health Systems: Bridging Health and Finance Perspectives, OECD Publishing, Paris, p. 25; OECD, 2013, Health at a Glance 2013: OECD Indicators, OECD Publishing, retrievable via: http://dx.doi.org/10.1787/health_glance-2013-en.

${ }^{51}$ Idem, p. 26.
} 
share of health spending has represented an increasing share of public expenditure and it is unlikely that health care can continue to be prioritized over other areas of government budgets as it has in the past. ${ }^{52}$

The fiscal sustainability issues concern the funding of health care expenditure and are, from that perspective, not directly linked to the aim of this research on the effects of the application of positive EU VAT law on the access to health care. In this research, access to health care is mainly discussed in relation to the costs of health care for individuals. The OECD indicates in the report that it supports ways to promote greater sustainability of health spending without compromising important achievements in relation to access to and the quality of health care. ${ }^{53}$ Moreover, it holds that 'distortionary costs' of taxes have to be taken into account in economic policy discussions on the financing of public services. ${ }^{54}$ In the same line, De la Feria stated that, in the context of budget restraints, one cannot only focus on health care spending. ${ }^{55}$

As indicated, analysts and policy makers are increasingly seeking comparable data in order to answer questions such as what are the main drivers of health expenditure growth are and what factors explain the observed differences between countries, due to increased health expenditure. ${ }^{56}$ One of the tools used to generate comparable data on health spending in various countries is the OECD System of Health Accounts ('SHA'). The SHA is an accounting framework that tracks all health spending in a given country over a defined period of time, regardless of the entity or institution that financed and managed that spending. ${ }^{57}$

In the 2011 SHA Manual, an effort was made to determine the common boundary of health care activities in order to make international comparisons possible. ${ }^{58}$ Before referring to this SHA classification of health care functions (figure 2.1), I will briefly explain the background of the accounting framework of the SHA. The core accounting framework of the SHA is organized by means of a tri-axial system (consumption, provision and financing) for recording health care expenditure. For the model health care system, the classifications are rather interesting, as they address three basic questions with the ultimate goal of describing each financial flow in the health care sector:

\footnotetext{
52 See also OECD, 2015, Fiscal Sustainability of Health Systems Policy Brief, OECD Publishing, retrievable via: http://www.oecd.org/health/health-systems/Fiscal-Sustainability-Health-Systems-Policy-Brief.pdf.

53 Idem, p. 4; OECD, 2015, Fiscal Sustainability of Health Systems: Bridging Health and Finance Perspectives, OECD Publishing, p. 3, retrievable via: http://www.oecd.org/health/health-systems/Fiscal-Sustainability-HealthSystems-Policy-Brief.pdf.

54 OECD, 2015, Fiscal Sustainability of Health Systems: Bridging Health and Finance Perspectives, OECD Publishing, p. 184.

${ }^{55}$ De la Feria, R., 2006, The EU VAT System and the Internal Market, IBFD, p. 170.

${ }^{56}$ See http://www.oecd.org/els/health-systems/health-expenditure.htm.

${ }^{57}$ See http://www.who.int/health-accounts/methodology/en.

${ }^{58}$ OECD, World Health Organization and Eurostat, 2011, A System of Health Accounts: 2011 Edition, OECD Publishing.
} 
- Which kinds of health care goods and services are consumed?

- Which health care providers deliver these goods and services?

- Which financing scheme pays for these goods and services? ${ }^{59}$

The first question addresses the health care transactions (provision of goods and services) that lead to consumption. The second question, which is discussed in section 2.2.2, addresses the providers of those goods and services. This will be further discussed in relation to definitions of health care suppliers. In particular, the answers to these first two questions are interesting for determining the impact of the imposition of VAT on health care transactions.

Within the SHA framework, consumption is measured by means of a functional approach, describing the direct consumption by the population according to the type of health purpose. According to the concept underlying this functional approach, the boundary of health care activities contains "...all activities with the primary purpose of improving, maintaining and preventing the deterioration of the health status of persons and mitigating the consequences of ill-health through the application of qualified health knowledge [medical, paramedical and nursing knowledge, including technology, and traditional, complementary and alternative medicine (TCAM)]" ${ }^{60}$ According to the 2011 SHA Manual, this primary purpose is pursued by the following groups of health care activities:

- Health promotion and prevention;

- Diagnosis, treatment, curing, and rehabilitation of illness;

- Caring for persons affected by chronic illness;

- Caring for persons with health-related impairment and disability;

- Palliative care;

- Providing community health programs;

- Governance and administration of the health system.

From the SHA report, it can be derived that these activities entail health care goods and services that are consumed by the population in a given country. According to the report, one of the main defining criteria in carrying out these activities is the prerequisite of a basic level of medical, paramedical and nursing knowledge (on basis of national standards of accreditation). It appears that the requirement of this basic level of knowledge of health care service suppliers is necessary for the activities to be qualified as health care activities.

\footnotetext{
${ }^{59}$ OECD, Eurostat and World Health Organization, 2017, A System of Health Accounts 2011: Revised edition, OECD Publishing, p. 53-54.

${ }^{60}$ Idem, p. 52.
} 
Another interesting aspect in my view is that the SHA manual explicitly states that administration is an embedded activity in the provision of health care goods and services (e.g. administrative activities carried out in a hospital or in a physician's practice) and, as such, it is included as an inherent part of the abovementioned activities. ${ }^{61}$ The fundamental approach applied by the OECD has led to the following classification of health care functions within the SHA framework. Figure 2.1 below, shows the categories of first-level health care functions, reflecting the aggregates used by most countries, which are distinguished in the 2011 SHA Manual: ${ }^{62}$

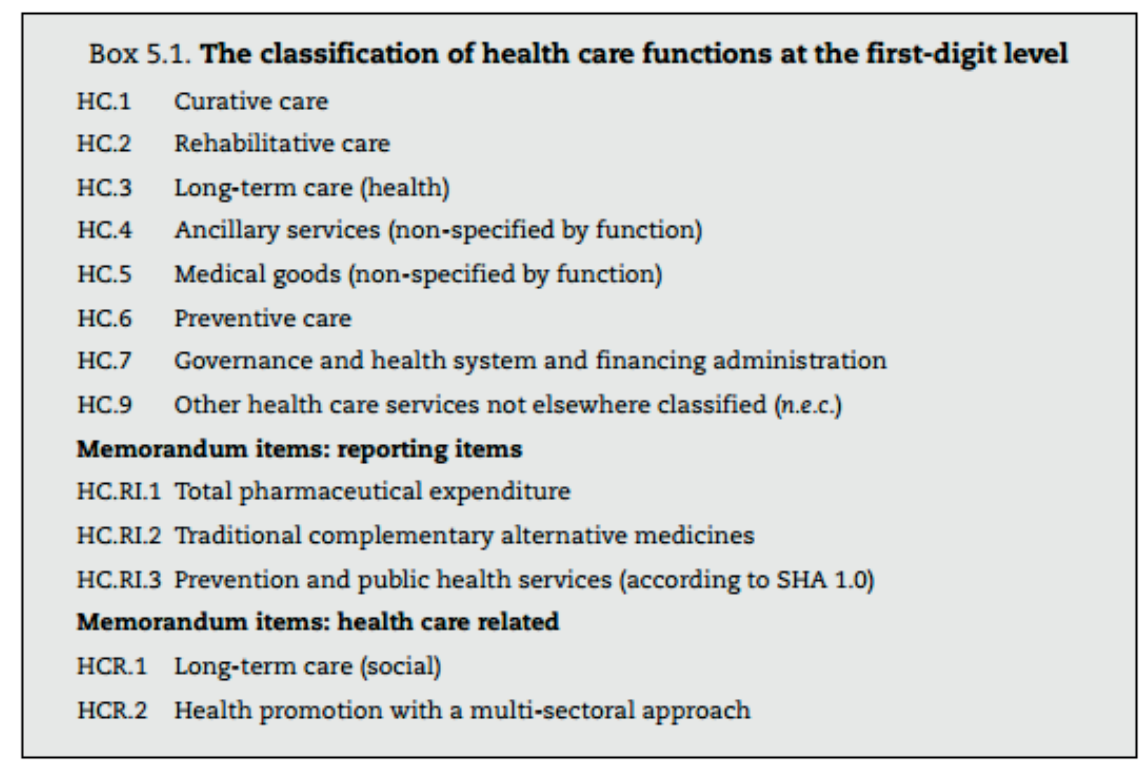

Figure 2.1: Classification of health care functions at the first-digit level (Source: SHA 2011, p. 75)

Although this is a classification at 'first-digit-level', and the SHA table containing the full list of health care functions is far more extensive, it does provide for a basic understanding of the main types of health care services that are consumed, especially while keeping in mind the concept of health care activities underlying the functional classification as mentioned before.

The functions that follow from the 2011 SHA Manual are in keeping with the WHO definition of health services that was mentioned in the beginning of this section. Both the WHO definition and the definition used within the SHA framework take the aim of purpose of the transactions as a starting point for their qualification as health care. For the purpose of this research, the health care functions that follow from the SHA Manual can therefore be considered a common denominator in health care systems worldwide.

\footnotetext{
${ }^{61}$ Idem, p. 53.

${ }^{62}$ Idem, p. 73-75.
} 


\subsubsection{Definition of Health Care Activities for the Purpose of this Research}

In the previous section, I explored definitions of health (care) activities. The definitions used by international organisations are rather broad and refer to the aim with which the activities are carried out. As was shown, the WHO definition for health services refers to "services which can contribute to improved health or the diagnosis, treatment and rehabilitation of sick people". Moreover, according to the WHO definition health services are not limited to medical or health care services.

In section 2.2.1.1, OECD's SHA - a tool to generate comparable data on health spending in countries - was addressed. From the 2011 SHA Manual (2011), it follows that, according to the definition of health care activities used as an underlying principle of the SHA, the boundary of health care activities contains "...all activities with the primary purpose of improving, maintaining and preventing the deterioration of the health status of persons...". Health care activities pursuing this purpose, in addition to the actual diagnosis, treatment, cure, and rehabilitation of illness, also include, for example, health promotion and prevention and administration of the health system.

Taking those definitions as a starting point, I conclude that health care activities at least cover all activities carried out with the aim of improving a person's health status with diagnosis, cure, treatment, or rehabilitation. Activities can qualify as health care regardless of the place where they are provided and regardless of the level at which it is organized and how it is funded. Moreover, I deduce, in particular from the OECD definition in relation to the SHA, that a certain level of knowledge is required from the health care supplier in order to qualify a health activity as a health care activity.

I understand that health care activities are only a part of the activities that the WHO qualifies as 'health services', as it was shown in section 2.2.1.1. that the latter definition also covers other non-medical services, such as health education. The classification of health care functions by the OECD in the 2011 SHA Manual also includes activities which are, as such, non-medical. This can be explained by the fact that the functional approach to classification takes the purpose of consumption as a starting point. It is also acknowledged in the manual that health care is generally consumed as an integrated service package and that a contact with the health system normally includes a "personalised mix of services". ${ }^{63}$ From the foregoing, I deduce, on the one hand, that there are health related activities that are as such not (core) health care services, as they do not entail the diagnosis, cure, treatment, or rehabilitation of a person with the aim of improving that person's health status. I also deduce that these activities can, on the other hand, be part of a composition of services that does qualify as health care.

\footnotetext{
${ }^{63}$ OECD, Eurostat and World Health Organization, 2017, A System of Health Accounts 2011: Revised edition, OECD Publishing, p. 73.
} 
In conclusion, for the purpose of coming to common denominators of a EU health care system, I consider the following as health care activities:

'activities consisting of diagnosing, curing, treating and rehabilitating the health status of a person with the aim to improve that person's health status'.

\subsubsection{Definitions of Health (Care) Suppliers}

In the previous section, definitions of health care transactions have been explored. This has led to defining a definition of 'health care activities' for the purpose of this research. It was also shown that the OECD, while setting the boundaries of health care as regards the SHA accounting framework, holds that a basic level of medical, paramedical and nursing knowledge is a prerequisite for carrying out health care activities. ${ }^{64}$ This criterion is associated with the suppliers of these activities, as it refers to the knowledge of the supplier. As a starting point, in the search for a workable definition and EU typical examples of health care suppliers, I refer to the definition included in the Oxford Dictionary of Public Health for health care provider:

"A bureaucratic term to describe a health service worker who encounters a patient or client and deals with one or more aspects of a person's health problem. This may be a physician, nurse, dentist, physiotherapist, social worker, or other professional person. The term could also apply to a radiographer, pharmacist, or others who provide diagnostic or therapeutic services but usually are agents carrying out orders rather than active interveners in the encounter." 65

It is noticeable that this definition is rather broad and the scope is illustrated by means of several examples. What it does show is that the definition is apparently not limited to health care suppliers that actively encounter patients. To get a better idea of what a health care supplier is, it is useful to look at the definitions used by organizations that are active (at least in the EU) in the field of research on health care, the WHO and the OECD, as was also done in the search for a definition of health care transactions. For the collection and analysis of data, they use, inter alia, a variety of standard qualifications of health care related occupations.

\subsubsection{WHO definition of health workers}

The theme of the 2006 WHO Health Report was 'Working together for health'. This report focusses extensively on health workers, denoted as 'the health workforce'. In this report, the WHO defines health workers as "all people engaged in actions whose primary intent is to enhance health". ${ }^{66}$ This definition is a derivative of the broader WHO definition of health systems: "comprising all activities with the primary goal of improving health - inclusive of

\footnotetext{
${ }^{64}$ Idem, p. 52-53 (see also section 2.2.1.1).

65 Last, J.M. (Ed.), 2007, A Dictionary of Public Health, Oxford University Press, retrievable via: http://www.oxfordreference.com.

${ }^{66}$ World Health Organization, 2006, The World Health Report 2006: working together for health, WHO, p. 1.
} 
family caregivers, patient-provider partners, part-time workers (especially women), health volunteers and community workers". ${ }^{67}$

Both definitions refer to the aim pursued by the activities carried out by the supplier. The activities must be aimed at enhancing or improving health. Since the definition is based on the aim pursued by the activities, this results in a broad range of health care workers being included. This is also acknowledged in the 2006 WHO Health Report. In addition to paid workers, many persons with a primary aim to enhance health but who do not receive any remuneration for their work nevertheless fall under the definition of health worker. The report mentions in this context, as an example, a mother nursing a sick child. Logically, little or no (financial) data are available about this group, the unpaid care providers or volunteer workers. Even if only paid care providers would qualify as health workers, this would still be a large group of people (employed and self-employed), of which it is not easy to establish according to objective standards - what the main objective of their actions is. This was also recognized in the report. Moreover, it is difficult to divide the employees of one organization into employees who are directly involved in the improvement of care and workers who are not. In the report, therefore, the practical assumption is made that all employees of an organization with the primary intent to enhance health are hence qualified as health workers. In addition, all workers whose personal actions are primarily intended to improve health but who work for other types of organizations - not having that primary aim - are also included. This means, for example, that a doctor who is an employee of a mining company also qualifies as a health care worker. ${ }^{68}$

Figure 2.2, which is taken over from the WHO report, shows the sectors in which health care workers are active, according to the WHO. All health care workers with occupations mentioned in the white circle represent the 'health work force'.

\footnotetext{
${ }^{67}$ Idem, p. xvi.

${ }^{68}$ Idem, p. 2.
} 


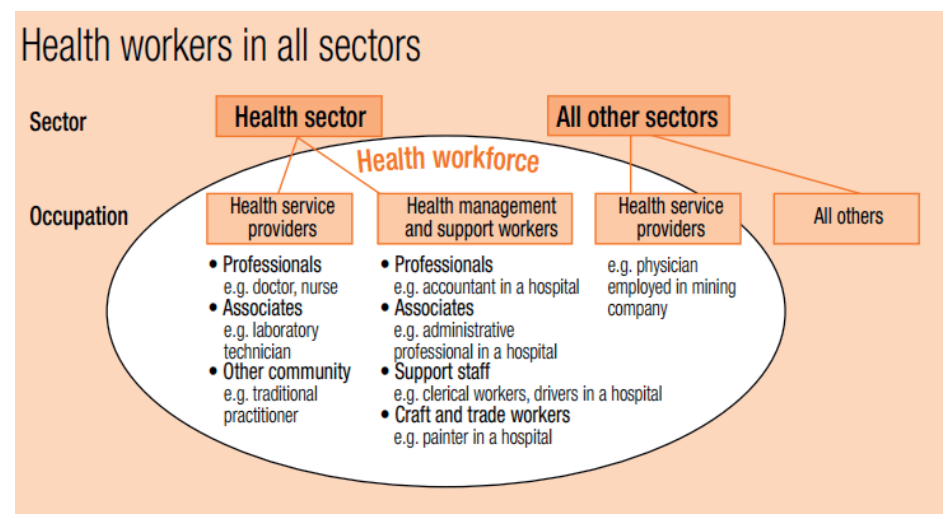

Figure 2.2: Health work in all sectors (Source: World Health Report 2006: working together for health, Geneva, Switzerland, WHO 2006, p. 3)

In 2006, the health care workforce in Europe consisted of 16.6 million people, out of the 59.2 million worldwide. Over two thirds of these workers are 'health service providers', while the rest are 'health management and support workers'. The latter group of workers support the health system, but they are not themselves directly involved in providing health care to patients. The WHO explicitly includes this group of workers in the health care workforce. It is stressed that "...health management and support workers provide an invisible backbone for health systems; if they are not present in sufficient is numbers and with appropriate skills, the system cannot function - for example, salaries are not paid and medicines are not delivered." 69 This idea corresponds to the OECD definition of health care activities underlying the SHA framework (see section 2.2.1.1). The OECD explicitly states in the SHA report that the activities include administrative activities. What is obvious is that the definition of the global health workforce is (again) a broad one, involving each person engaged in actions with the primary intent to enhance health. Even volunteer workers satisfy the definition, but they are not taken into account for the data analysis because of the lack of financial flows in relation to their activities.

Even though, on the basis of the foregoing, it is possible to gain an idea of the size of the workforce, but for determining the effects of VAT on health care transactions, the definition may not be sufficiently specific. The definitions used by the WHO and the Oxford Dictionary of Public health do not establish any requirements as to the (legal) form of the supplier, nor the quality of the health care provided. ${ }^{70}$ The only requirements concern the aim of the activities carried out by the supplier. A delineation of the group called health (care) suppliers is thus not possible without information on the (intended) aim of the activities carried out.

\footnotetext{
${ }^{69}$ Idem, p. 4.

${ }^{70}$ Although in relation to the health care activities shown in the 2011 SHA manual, the OECD presumes the prerequisite of a basic level of knowledge from the supplier (see section 2.2.1.1).
} 
To give an idea of the possible occupations in health care that are carried out in the EU, or better on a global level, the WHO definition of the global health workforce is certainly useful to a certain extent. An interesting aspect of the WHO definition of the health care workforce is furthermore the inclusion of the health management and support workers. In the 2006 Health Report health management and support workers are referred to as being the "invisible back bone for health systems". ${ }^{71}$ In section 2.2.1.1 it was already shown, in relation to health care transactions, that the OECD also seems to consider administration as an embedded activity in the provision of health care goods and services. Both organisations clearly acknowledge the need for supporting the staff and activities necessary in order to provide health care.

At this point, another remark has to be made as regards WHO's definition of the health care work force. For the classification of health workers, the WHO uses the International Standard Classification of Occupations (ISCO). ${ }^{72}$ At the time the WHO Health Report was released (2006), the ISCO classification did not yet contain a detailed breakdown of health workers. The ISCO classification, however, was revised in 2008. Following that revision, the WHO issued a 'map' with guidelines on how health workers are to be classified in accordance with the revised ISCO. ${ }^{73}$ The mapping contains definitions of the occupation groups active in health care and examples of occupations classified thereunder, divided in five broad groupings:

- health professionals (e.g. general practitioners, cardiologists, psychiatrists, but also including traditional and paramedical practitioners);

- health associate professionals (e.g. medical laboratory technicians, radiation therapists, assistant nurses);

- personal care workers in health services (e.g. birth assistants, medical imaging assistant, sterilization aide);

- Health management and support personnel (e.g. health service managers, social work and counselling professionals, medical secretaries); and

- Health service providers not elsewhere classified (e.g. armed forces occupations).

The ISCO classification forms the basis of many national occupational classifications. It also forms the basis for the WHO's standard classification of health workers. Hence, the categorization shown above proves useful for forming an idea of typical health care suppliers operating in EU Member States for the purpose of this research.

\footnotetext{
${ }^{71}$ World Health Organization, 2006, The World Health Report 2006: working together for health, WHO, p. 4.

${ }^{72}$ ISCO is a tool for organizing occupations into a clearly defined set of groups according to the tasks and duties undertaken in the job and is retrievable via: http://www.ilo.org.

${ }^{73}$ WHO template on classifying health workers, retrievable via: http://www.who.int/hrh/statistics/workforce_ statistics/en.
} 
I started this section with the definition of a health care provider from the Oxford dictionary of Public Health and compared it to definitions used by the WHO. In the following section I will analyse definitions used by the OECD. Thereafter, based on these findings, I will provide a definition of health care suppliers for the purpose of this research.

\subsubsection{OECD definition of health workforce and health care providers}

In this section, reference is made to the OECD report 'Health at a glance (2013)'. ${ }^{74}$ The reason that reference is made to the OECD report and the underlying statistics is that it contains useful information on typical health care suppliers. In the database providing health statistics, 'resources of health care' are indicated. ${ }^{75}$ These resources are not limited to suppliers. For example, also hospital beds are seen as health resources. The OECD, whose mission is to promote policies that globally improve economic and social well-being, applies economic analysis to health policies. In its report, the OECD presents comparable data on different aspects of the performance of health systems in OECD countries. As such, the report does not contain a definition of 'health workforce' or 'health care suppliers'. The report does contain, however, a chapter on the 'health workforce', with data on the supply and the remuneration of doctors and nurses in OECD countries. ${ }^{76}$ The data in the report is taken from the OECD Health Statistics Database. ${ }^{77}$ This database contains comparable statistics on health systems and is hence a tool used to carry out a comparative analysis. From the Health at a Glance Report (2013) ${ }^{78}$ and the resources of health care included in the OECD Health Statistics Database, I infer that the following occupations in any case exist in the 34 OECD Member States and thus the majority of EU Member States:

- (general) practicing medical doctors;

- physicians;

- midwifes;

- nurses;

- medical health nurses;

- caring personnel (personal care workers);

- dentists;

- pharmacists;

- physiotherapists;

- gynecologists;

- obstetricians; and

- psychiatrists.

\footnotetext{
74 OECD, 2013, Health at a Glance 2013: OECD Indicators, OECD Publishing, retrievable via: http://dx.doi.org/10.1787/health_glance-2013-en.

${ }^{75}$ OECD Health Statistics 2014, retrievable via: http://www.oecd.org/health/healthdata.

${ }^{76}$ Also the number of graduates are analysed in order to monitor the future workforce.

${ }^{77}$ Retrievable via: http://www.oecd.org/els/health-systems/health-data.htm.

78 OECD, 2013, Health at a Glance 2013: OECD Indicators, OECD Publishing, p. 63-81, retrievable via: http://dx.doi.org/10.1787/health_glance-2013-en.
} 
These occupations can be exercised either inside or outside a hospital setting. It is evident that this list is by no means exhaustive, but it does provide a number of typical and frequently occurring occupations. This is reinforced by the fact that the OECD uses the International Standard Industrial Classification of all Economic Activities ${ }^{79}$ (ISIC). ${ }^{80}$ The ISIC is a different standard qualification than the one applied by the WHO for the health care workforce. The ISIC, in contrast with the ISCO, contains a detailed section for human health and social work activities. ${ }^{81}$ It is actually not a classification of occupations, but of activities. Therefore, the classification, as such, is less useful in the search for a definition or typical examples of health care suppliers.

As was shown in section 2.2.1.1, the 2011 OECD SHA Manual provides a standard for classifying health expenditures according to the three axes of consumption, provision and financing. In that section, the SHA categorization of health care transactions (provision of goods and services) that lead to consumption has been discussed. The SHA manual also includes the providers of those goods and services. The definition of 'health care providers' in the OECD SHA Manual is the following: "organisations and actors that deliver health care goods and services as their primary activity, as well as those for which health care provision is only one among a number of activities". ${ }^{82}$ The scope of this definition is rather broad. The first group is referred to as 'primary providers' and the latter as 'secondary providers'. The categories of health care providers that are distinguished in the SHA Manual are derived from the ICHA-HP classification. This is another system for standard classifications. The system is, however, not intended for occupations or activities but specifically for the classification of providers. It classifies all organisations that contribute to the provision of health care goods and services, by arranging country specific provider units into common, internationally applicable categories. ${ }^{83}$ Figure 2.3 contains the ICHA-HP Classification of Health Care Providers, as was included in the OECD System of Health Accounts (2011).

\footnotetext{
${ }^{79}$ This is a UN system for classifying data. For a detailed structure and explanatory notes see: International Standard Industrial Classification of all economic activities (ISIC), Statistical Paper Series M, No. 4, Rev. 4, United Nations, New York 2008, p. 252-257, retrievable via: http://www.unstats.un.org.

${ }^{80}$ OECD, Definitions, Sources and Methods - Total health and social employment, OECD Health Statistics 2014.

81 ISIC (2008), p. 59-60; The ISCO (International Standard Classification of Occupations) forms the basis of the WHO definition of the health work force.

${ }^{82}$ Idem, p. 122. Hereby is noted that the organizations and actors very in their legal, accounting and operating structures.

83 Ibid.
} 


\begin{tabular}{|c|c|c|}
\hline Code & Description & SHA 1.0 codes \\
\hline HP.1 & Hospitals & HP.1.0 \\
\hline HP.1.1 & General hospitals & HP.1.1 \\
\hline HP.1.2 & Mental health hospitals & HP.1.2 \\
\hline HP.1.3 & Specialised hospitals (other than mental health hospitals) & HP.1.3 \\
\hline HP.2 & Residential long-term care facilitites & HP.2 \\
\hline HP.2.1 & Long-term nursing care facilities & HP. 2.1 \\
\hline HP. 2.2 & Mental health and substance abuse faclitities & HP. 2.2 \\
\hline HP.2.9 & Other residential long-term care facilities & HP. $2.3,2.9$ \\
\hline HP.3 & Providers of ambulatory health care & HP.3 \\
\hline HP.3.1 & Medical practices & HP.3.1 \\
\hline HP.3.1.1 & Offices of general medical practitioners & HP.3.1 \\
\hline HP.3.1.2 & Offices of mental medical specialists & HP.3.1 \\
\hline HP.3.1.3 & Offices of medical specialists (other than mental medical specialists) & HP.3.1 \\
\hline HP.3.2 & Dental practice & HP.3.2 \\
\hline HP.3.3 & Other health care practitioners & HP.3.3 \\
\hline HP.3.4 & Ambulatory health care centres & HP.3.4 \\
\hline HP.3.4.1 & Family planning centres & HP.3.4.1 \\
\hline HP.3.4.2 & Ambulatory mental health and substance abuse centres & HP.3.4.2 \\
\hline HP.3.4.3 & Free-standing ambulatory surgery centres & HP.3.4.3 \\
\hline HP.3.4.4 & Dialysis care centres & HP.3.4.4 \\
\hline HP.3.4.9 & All other ambulatory centres & HP.3.4.5, 3.4.9 \\
\hline HP.3.5 & Providers of home health care services & HP.3.6 \\
\hline HP.4 & Providers of ancillary services & \\
\hline HP.4.1 & Providers of patient transportation and emergency rescue & HP.3.9.1 \\
\hline HP.4.2 & Medical and diagnostic laboratories & HP.3.5, 3.9.2 \\
\hline HP. 4.9 & Other providers of ancillary services & HP.3.9.9 \\
\hline HP.5 & Retailers and other providers of medical goods & HP.4 \\
\hline HP.5.1 & Pharmacies & HP.4.1 \\
\hline HP. 5.2 & Retail sellers and other suppliers of durable medical goods and medical appliances & HP.4.2, 4.3, 4.4 \\
\hline HP. 5.9 & All other miscellaneous sellers and other suppliers of pharmaceuticals and medical goods & HP.4.9 \\
\hline HP.6 & Providers of preventive care & HP.5 \\
\hline HP.7 & Providers of health care system administration and financing & HP.6 \\
\hline HP.7.1 & Government health administration agencies & HP.6.1 \\
\hline HP.7.2 & Social health insurance agencies & HP.6.2 \\
\hline HP.7.3 & Private health insurance administration agencies & HP. $6.3,6.4$ \\
\hline HP.7.9 & Other administration agencies & HP.6.9 \\
\hline HP.8 & Rest of economy & HP.7 \\
\hline HP.8.1 & Households as providers of home health care & HP.7.2 \\
\hline HP.8.2 & All other industries as secondary providers of health care & $\begin{array}{l}\text { HP.2.3, 2.9, 7.1, } \\
7.9\end{array}$ \\
\hline HP.8.9 & Other industries n.e.c. & \\
\hline HP.9 & Rest of the world & HP.9 \\
\hline
\end{tabular}

Figure 2.3: Classification of health care functions (Source: SHA 2011, p. 83)

Note that the classification shown above only includes health care providers who supply goods and services directly to final consumers. After all, the SHA focuses on the final consumption of these goods and services by residents.

In this section, I analysed the definitions of health care providers used by the OECD. In that regard, I analysed the SHA Manual with the purpose of identifying what is to be understood as a common health care supplier. In the following section, I will demonstrate the conclusions I made with regard to the definitions of health care suppliers that have been analysed. Moreover, I will present a definition of health care suppliers for the purpose of this research. 


\subsubsection{Definition of health care suppliers for the purpose of this research}

In the previous sections, various definitions of health care suppliers were explored. As a starting point, the definition of health care provider in the Oxford dictionary of Public Health was taken. This definition has been compared to definitions used by the WHO and OECD for the purpose of data collection and analysis. The definitions of health care suppliers and health care supplies show a lot of resemblance, as they both relate to the purpose with which activities are carried out. I deduce from the WHO definition for health workers that a supplier is considered a health worker supplier if it carries out activities with a primary aim to enhance a person's health status. A health worker is either a health service provider or health management and support worker occupied in the health sector or a health service provider occupied in another sector. From the OECD definition of health care provider, it follows that a health care supplier can be a natural person but can also be an organisation. Furthermore, the OECD definition - like the WHO definition of health workers - concerns both primary and secondary providers. This means that suppliers for which the supply of health care goods and services is not the primary activity also fall under the OECD definition of health care providers.

In section 2.2.1.1, I noted that I conclude from the SHA Manual that, according to the OECD, the prerequisite of a basic level of medical, paramedical and nursing knowledge (on the basis of national standards of accreditation) is required to qualify certain activities as health care activities. In my view this requirement relates to the subject (the health care provider) and should, therefore, be included in a common definition of a health care provider. This is confirmed in the definition included in the Oxford Dictionary of Public Health: it refers to "professional person[s]". I realize that this may not be considered in to be keeping with the fact that the WHO includes health management and support workers in the health workforce as these workers may not have the medical knowledge to independently exercise a medical profession. Furthermore, it seems to contrast the inclusion of administrative activities in the health care functions distinguished by the OECD in the SHA Manual (2011). Nevertheless, like pointed out above in relation to health care supplies, one has to distinguish on the one side (core) health care activities and on the other side all kinds of related or supportive health services which can be part of a composition of services that does qualify as health care. All in all, I therefore deduce that the definition of health care provider should contain a qualitative element. Whereas a definition of a health service provider should, in my view, not contain such an element.

In conclusion, for the purpose of coming to common denominators of an EU health care system, I consider a health care supplier to be:

'natural persons or organisations carrying out activities with a primary intent to enhance a person's health status, provided that the activities are carried out by persons with sufficient level of medical, paramedical and nursing knowledge (according to national accreditation standards).' 


\subsubsection{Definitions of Health Systems}

In the previous sections, I analysed the definitions of health care activities and health care suppliers. As indicated in section 2.1, the purpose of analysing common definitions of health care was to be able to come to useful definitions for the purpose of this research but also to be able to draw up a model health care system. The model health care system is discussed in the following section. Before discussing the model health care system, this section serves to bring definitions of health systems used by the WHO into focus. An analysis of these definitions helps to be able to make remarks on the tenability of the model heath care system.

The WHO maintains the following definition of a 'health system':

"[a] health system consists of all organizations, people and actions whose primary intent is to promote, restore or maintain health. This includes efforts to influence determinants of health as well as more direct health-improving activities. A health system is therefore more than the pyramid of publicly owned facilities that deliver personal health services." 84

In a glossary published by the WHO Regional Office for Europe, the following definition of a health system is given:

"A formal structure for a defined population, whose finance, management, scope and content is defined by law and regulations. It provides for services to be delivered to people to contribute to their health and health care, delivered in defined settings such as homes, educational institutions, workplaces, public places, communities, hospitals and clinics, and may affect the physical and psychosocial environment. A health system is usually organized at various levels, starting at the most peripheral to the state government, known as the community or primary level." 85

These WHO definitions of health systems include, like the definitions for health care suppliers and health care supplies, include the purpose or aim of the activities carried out. I deduce from the definitions that a health system is a structure which includes activities with the primary intent to contribute to a person's health. This structure seems to both include the activities as well as the suppliers carrying out activities with that purpose. It also emerges from the definitions that the exact interpretation is a national issue and that care is provided in several settings and that it is organized on various levels.

For the purpose of this research, I consider a health system to be a framework within which the health care suppliers operate and health care is being supplied. This supports my

\footnotetext{
${ }^{84}$ World Health Organization, 2007, Everybody's business: Strengthening health systems to improve health outcomes: WHO's framework for action, WHO, p. 2.

${ }^{85}$ Roberts, J. L. and World Health Organization, 1998, Terminology: a glossary of technical terms on the economics and finance of health services, Doc. Nr. EUR/ICP/CARE 94 01/CNO1, retrievable via: http://www.euro.who.int.
} 
assumption that health care suppliers and health care supplies are common denominators of health systems worldwide.

\subsection{The model health care system}

In the previous sections, definitions of health care supplies, suppliers and health systems were explored. This led to the introduction of definitions of health care activities and health care suppliers for the purpose of this research. I consider the health care activities and health care suppliers, as defined in the previous section, as common denominators of an average EU health care system.

Every EU Member State has its own health care system and therefore has a different interpretation of health care, the extent of the health care transactions and health care suppliers. As health care systems are a national issue, it is impossible to provide one single definition of a EU health care system (see also section 2.2.3). On the basis of the common denominators of EU health care systems, I will introduce a model health care system for the purpose of this research. This model will serve as a framework, covering common types of health care transactions and operators, taking in account various contractual (or legal) ways to provide health care to patients. The model health care system gives the opportunity to observe the consequences of the application of positive EU VAT law in several common types of situations. It can provide for insights on both the application of positive EU VAT law and suggestions for a proposed application of VAT. In the following section, I will discuss the requirements for a successful model health care system.

\subsubsection{Requirements of the model health care system from a VAT perspective}

In order to be practicable, the model has to be of a general nature, has to be convenient and has to cover common EU health care transactions and suppliers. Since the model has to provide insights on how and in which specific situations the application of positive EU VAT law impedes access to health care, it is important to take a closer look at how the levying of VAT is actually affected and which elements are of key importance in order to determine the taxability and influence on the cost price of health care. This starts - in advance of the following chapter (chapter 3) on substantive EU VAT law - with an analysis of the requirements for a taxable transaction under positive EU VAT law. From the EU VAT Directive, the following requirements or factors that are of importance for the taxable event or otherwise the cost price of health care can be determined as follows (in the order provided in the Directive):

- Taxable person

- Taxable transaction

- Place of taxable transaction

- Taxable amount
- Rates

- Exemptions

- Deductions 
The above concepts are discussed in more detail in chapter 3. In this section, it will be considered which conditions the model health care system must satisfy in order to determine the consequences of the application of positive EU VAT law on health care transactions and the effect on the accessibility of health care. For each requirement (or factor), it will be briefly outlined what capabilities the model should provide for.

Taxable person. The definition of a taxable person in the EU VAT Directive is considerably broad, as can be understood from the terms 'any person' in Article 9 of the EU VAT Directive. ${ }^{86}$ A taxable person for VAT purposes can thus be a natural person (i.e. an independent health care supplier), an institution (i.e. hospital), a collaboration (i.e. between doctors), etc. ${ }^{87}$ What follows from the foregoing is that the model has to be able to cover different sorts of legal forms of suppliers. The broad scope of VAT even covers governmental bodies and bodies governed by public law. ${ }^{88}$ The suppliers in the model, therefore, have to be interchangeable and not limited to natural persons and certain legal forms of organizations.

Taxable transaction. Taxable transactions are described in Article 2 of the EU VAT Directive. These are supplies of goods and services, Intra Community acquisitions of goods and importation. The transactions in the model system hence must be interchangeable in order to cover the different types of transactions. As will be discussed in chapter 3, the nature of a transaction is decisive for many aspects of the imposition of VAT. For example, the place of supply of a service may differ from the place of supply of a good. This may even result in a shift in the liability and hence the obligation to remit the VAT to the tax authorities from the supplier to the recipient of the transaction at issue. The nature of the transaction can also be decisive for the application of an exemption or a reduced rate.

Place of taxable transaction. The place of the taxable transaction determines which Member State has the power to tax. The model that will be used in this research represents an average EU health care system. In relation to the place, it is therefore in any case important that the model is general enough to be applicable in all EU Member States, and it may even involve transactions to or from third countries.

Taxable amount. The taxable amount is not important for determining the taxability of a supply as such. It determines the basis for the calculation of the actual amount of VAT due.

\footnotetext{
${ }^{86}$ See section 3.5 .

${ }^{87}$ This refers to the principle of legal form neutrality according to which the legal form of a supplier may not be relevant for the VAT treatment of the transactions it provides.

${ }^{88}$ This directly follows from the explicit exceptions to the taxable person status made in Article 13 of EU VAT Directive.
} 
Rates. Next to the application of a standard VAT rate, Member States may apply one or two reduced rates. $^{89}$ Reduced VAT rates apply for example on the supply of certain 'pharmaceutical products', 'medical equipment' and 'medical and dental care and thermal treatment'. ${ }^{90}$ The application of rates must be clarified in the health care system model, as it directly influences the cost price of health care. This is not only the case in the ultimate supply of the chain but also in supplies preceding that ultimate supply.

Exemptions. This is a crucial factor. An exemption is an exception to the general rule that taxable events are subject to VAT. If an exemption applies, no VAT is due in relation to the transaction at issue. A further consequence of the application of an exemption is that it relates directly to the right to deduct input VAT. Exemptions for medical services are socalled exemptions without a right to deduct input tax. A supplier cannot deduct the VAT on goods and services that were purchased in relation to an exempt supply. It is generally conceived that the non-deductible VAT results in a cost component for the supplier and will, consequently, become part of the price charged by the recipient for his supplies. If an exempted transaction in the chain is followed by a taxed transaction, there might even be cascading of tax. The application of exemptions for medical services mainly depends on the nature of the taxable supply and the taxable person providing it. The model must be capable of showing effects of an exempt supply in the last link but also upstream, depending on the nature of the service provider and the nature of the (health care) transaction.

Deduction. The right to deduct ensures that the levying of VAT is neutral and that VAT does not remain a burden for taxable persons in the chain. As mentioned, the right to deduct is restricted in case exemptions apply, since a deduction of input VAT is only possible in so far as the costs relate to taxed output transactions. It is generally considered that a supplier will pass on the non-deductible VAT to the recipient of his supplies. If the supplier would not pass on the non-deductible VAT, it would lower his profit margin. The (absence of) the right to deduct input VAT thus influences the costs of health care. The analysis of the effects on the price of health care, as a result of the application of the (absence of) the right to deduct, requires a model that contains multiple levels of transactions.

The elements that may ultimately affect the cost price of health care have to be identified in the model health care system, otherwise the effect of the VAT on the (financial) access to health care can simply not be observed. As is apparent from the foregoing, it is necessary to work with multiple levels of transactions within the (production) chain. This also fits with the method of assessment of VAT. The common system of EU VAT is a multi-stage tax, applied up to and including the retail stage. It taxes (final) consumption by means of the application of a

\footnotetext{
${ }^{89}$ Articles 96 and 99 of EU VAT Directive.

${ }^{90}$ Point 3, 4 and 17 of Annex III to the EU VAT Directive.
} 
tax on transactions, proportional to the price of the goods and services provided. ${ }^{91}$ This requires the model to at least clarify the transactions provided to final consumers (health care seekers). As VAT is a multi-stage tax, it is also necessary to clarify to a certain extent the stages that precede the final transaction. In addition, the effects of the application of (different) VAT rates and exemptions within the chain become apparent.

The starting point of the model is a transaction between a (health care) supplier and the final consumer. That is an uncomplicated but most likely too brief transaction (chain). In many cases, a consumer can go directly to a health professional who can provide the required care. In those cases, the health professional will need to purchase goods and services (i.e. medicines, equipment, laboratory services) in order to provide the care, but then $\mathrm{s} / \mathrm{he}$ is able to directly provide the care to the patient. ${ }^{92}$ It is however quite conceivable that the contracted health professional himself is unable to provide the required care and has to make use of services of another party to be able to provide the care to the patient. These services could for instance be the hiring of staff or a general practitioner contracting a laboratory for the analysis of a blood sample. The professional could also refer the patient to a more specialized care provider who will enter into an agreement with the patient. The number of transactions and hence the length of a health care supply chain is thus dependent on the nature of the health care that is demanded by the recipient.

A model health care system - that is capable of providing useful information about the (legal) effect of the imposition of VAT on health care on the access to health care - is thus a model that is based on transactions and in principle does not exclude certain care providers, professions or institutions. Moreover, the number and complexity of the transactions in that model are dependent on the demand of health care by the recipient (consumption driven). ${ }^{93}$

\subsubsection{The model health care system for the purpose of this research}

With the aim of being able to establish the effect of the application of positive EU VAT law on health care transactions and its impact on the principle of access to health care in specific situations, common denominators of EU health care systems have been explored. In that regard, an analysis of the definitions of health care supplies and health care suppliers has been carried out. I consider these definitions to be the common denominators of health care systems. In order develop a model health care system, I established which elements are of key importance to determine the VAT taxability and, hence, which influence the cost price of health care transactions. The foregoing was necessary to come to a model health care system that: a) covers health care transactions that generally occur in EU Member States and b) contains the elements that are necessary to establish the VAT consequences of those

\footnotetext{
${ }^{91}$ Article 1 (2) of the EU VAT Directive.

92 A health care professional is mentioned here by means of example. It could as well be a hospital or a cooperation between doctors that directly provides health care to patients.

${ }^{93}$ The consumption driven approach is also used by the OECD as basis for the SHA, as was explained in section 2.2.2.
} 
transactions based on positive EU VAT law. I would like to point out that coming up with a model health care system is not an aim in itself, as it is not my intention to define or redefine model systems that may already exists. The model intends to serve as a means to determine the impact of the application of VAT on health care transactions.

On the basis of the previous sections, I conclude that the model health care system should at least contain the following information or requirements:

- Suppliers and supplies must be identifiable (who provides what to whom).

From the analysis of definitions of health care outside the field of VAT, it became clear that definitions used for health care suppliers and health care usually include, to a certain extent, a qualitative element. Obviously, the level of knowledge (according to national standards) has an influence on a person's status as a health care supplier (see section 2.2.1.1). Furthermore, transactions are only health care transactions if the intended aim is to improve the health status of the care recipient. As a result, both the quality or capacity of a supplier and the nature of the supply are relevant for determining whether transactions are generally considered health care transactions or not. As a matter of fact, this information is also required in relation to the imposition of VAT, as was shown in the previous section.

- Suppliers and supplies have to be variables in the model transactions.

The model has to work, irrespective of the quality of the supplier and the nature of the transactions carried out. This requirement is perhaps more VAT driven. The imposition of VAT is dependent on multiple elements. Both the nature of the supply (e.g. goods or services) and the quality of the supplier influence VAT taxability. Furthermore, these two elements should be interchangeable, as this offers the possibility to assess the application of positive VAT law as regards both intramural and extramural health care.

- The model transactions can take place in every EU Member State.

The model ultimately has to be able to provide information on the effects of the imposition of EU VAT on access to health care. Therefore, the transactions covered in the model should not be limited to transactions carried out within the territory of certain EU Member States.

- The model contains multiple (levels of) transactions and takes the demand of health care as a starting point.

The legal character of VAT demands that the model health care system at least includes transactions with the final consumer. The actual VAT burden may be influenced by the application of VAT or by the application of exemptions in transactions upstream in the supply chain. Therefore, the model should include 
multiple levels of transactions within the chain, starting with the basic situation (health care transactions directly rendered to final consumers). A multi-level model (involving multiple transactions in the supply chain) fits with the conclusions I made in the previous section, that health care is 'consumption driven', meaning that the number and complexity of health care transactions are dependent on the demand by the care seeker.

In its recent decision in Boehringer, the CJEU pointed out that there may be situations in which it is conceivable that a private medical insurance fund has to be considered the final consumer in a supply chain of medicinal products. ${ }^{94}$ As a result, discounts that were received by that medical insurance fund (on the basis of a national rule) from a supplier of medicinal products, upstream in the supply chain, were taken into account for the determination of the taxable amount of the supplies made by that supplier. In such a situation, the VAT burden for the supplier of medicinal products is reduced by the amount of the discount that it provides to the insurance company. The consumer price - i.e. the price that the patient has to pay in the pharmacy to obtain the medicinal product - is not affected by the discount. The VAT burden on the supply from the pharmacy to the patient, hence, remains the same. In my opinion, therefore, the fact that a private medical insurance fund is considered the final consumer in the supply chain does not have a direct effect on the VAT burden for the health care seeker. ${ }^{95}$ As a result, it does not directly affect the accessibility of health care for that person. Therefore, the model health care system in this research does not take into account the reimbursements made and discounts received by private medical insurance funds.

\subsubsection{Schematic overview of the model health care system}

Based on the foregoing, the model health care system should, at least, include the following transactions and actors (schematically):

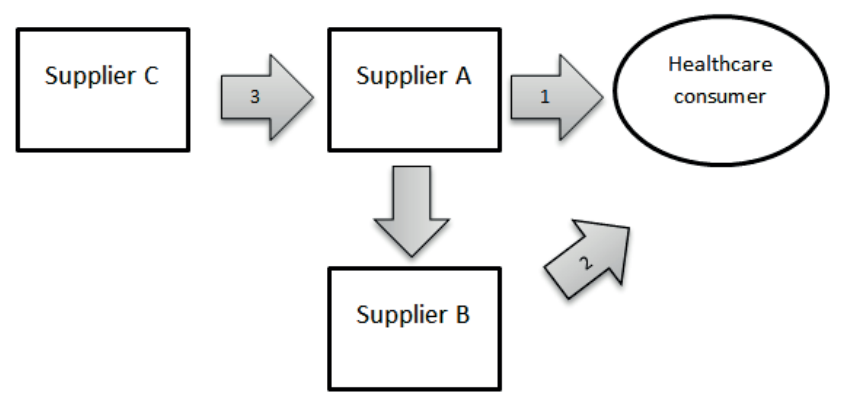

Figure 2.2 Model Health Care System

\footnotetext{
${ }^{94}$ CJEU 20 December 2017, Case C-462/16 Boehringer Ingelheim Pharma, ECLI:EU:C:2017:1006.

${ }^{95} \mathrm{I}$ am aware that there may be indirect effects, in case the reduction of the VAT burden on the level of the supplier of the medicinal products eventually results in a lower cost price of the medicinal products.
} 
The different transactions shown - by means of arrows - in figure 2.4 above and the considerations leading to this model lead me to conclude that the common health care transactions can basically be divided into three (main) types of situations. Below I will discuss these types of situations in more detail.

Basic situations: transactions made to final consumers by supplier A (ad. 1.)

The starting point in the model are the transactions between a supplier (supplier A) and the final consumer, also referred to as a 'basic situation'. Supplier A can have any legal form: it can be an independent health care professional, a hospital, a nursing home, etc., depending on the case that will be explored. Transactions in the basic situation are transactions in which health care is directly provided to health care consumers.

Parallel situations: transactions made to final consumers by supplier $B$ (ad. 2.)

These transactions involve supplies to final consumers that are provided in parallel to the (principal) health care service, provided in a basic situation. In order to examine the impediment of the application of VAT on supplies in parallel situations - on the access to health care - I distinguish the following two situations of parallel supplies: parallel one-onone situations and parallel two-on-one situations. In a parallel one-on-one situation, all supplies are carried out by one and the same health care supplier to one single recipient. In a parallel two-on-one situation, the supplies are carried out by different suppliers, while the recipient is the same person. For the application of VAT, this distinction is relevant, since, for example, the outcome of the application of VAT exemptions may differ depending on who performs the parallel supply.

A parallel situation can be illustrated by means of the following example. If a health care consumer is hospitalized, they receive health care directly from the (doctors employed by the) hospital. At the same time, the health care consumer may visit the hospital pharmacy in order to buy drugs. The supply of drugs is a supply, parallel to the supply of health care by the hospital. ${ }^{96}$ Depending on whether the hospital and the hospital pharmacy are, from a VAT point of view, to be considered as a single or as two different taxable persons, the example concerns a parallel one-on-one or a parallel two-on-one situation.

Successive situations: transactions made to supplier A by supplier C (ad.3)

These transactions are illustrated in the model by means of transactions between supplier $C$ and Supplier A. The health care consumer does not have a (direct) legal relationship with supplier $\mathrm{C}$. In general, these are transactions by means of which supplier A buys inputs (e.g. medical equipment or the services of a subcontractor) in order to be able to carry out the health care transaction demanded by the health care consumer. The difference with parallel situations lies in the legal relationships. In parallel situations, the 'other' supplier has a direct

\footnotetext{
${ }^{96}$ For the purpose of illustration, the supply of drugs is considered an independent supply for VAT purposes.
} 
legal relationship with the health care consumer, whereas in successive situations such a legal relationship is not present.

In practice it occurs, for example, that the health care consumer cannot be served by supplier A (e.g. a hospital) for the care (s)he demands. Perhaps supplier A does not have the required knowledge or resources to provide sufficient care. In that case, Supplier A can use the services of Supplier C (e.g. a self-employed medical professional) to provide the care. A variant of this example is the situation in which Supplier A (e.g. a hospital) hires staff from Supplier C (e.g. another hospital). In both these examples, the health care consumer does not have a (direct) contractual relationship with Supplier $C$. Despite the lack of the legal relationship, the health care consumer may in fact be treated directly by Supplier B (e.g. the hospitalized patient receives care from a staff member of another hospital, because this staff member is brought in by the hospital in which the health care consumer is hospitalized).

\subsection{The health care system in the Netherlands}

The previous section contains a presentation on the model health care system. So far, the input for this model was provided by means of a theoretical analysis of definitions used in relation to health care. In the end, a model is only an approach to reality. The purpose of this section is to establish whether the model health care system has practical value - with an eye on the application of VAT - and whether it covers relevant health care transactions that generally occur in EU Member States. Otherwise, the risk exists that this research on the application of EU VAT on health care would have an insufficient connection with reality.

For the reasons mentioned above, this section will provide for a basic understanding of the health care system as this is currently arranged in the Netherlands. Ideally, this results in insights on common health care transactions that take place in the Netherlands. After that, the model health care system, as presented in section 2.3, will be compared to the Dutch health care system. The purpose of this analysis is to establish whether the model has practical value and whether it covers relevant common health care transactions that occur in practice. This should also serve as a test to see whether no essential elements have been overlooked. The reason that the Dutch health care system has been chosen in this respect is that the Dutch system is a comprehensive and evolved system ${ }^{97}$ and reliable information on this system is relatively easily accessible. ${ }^{98}$

\footnotetext{
${ }^{97}$ See inter alia Kroneman, M., Boerma, W. et al., 2016, The Netherlands: health system review. Health Systems in Transition, vol. 18(2); Van den Berg, M.J., de Boer, D. et al., 2014, Zorgbalans 2014: De prestaties van de Nederlandse gezondheidszorg, RIVM rapport 2014-0038, Rijksinsituut voor Volksgezondheid en Milieu (RIVM), retrievable via: http://www.gezondheidszorgbalans.nl/rapporten.

${ }^{98}$ By means of publicly accessible documents and because I am a native speaker.
} 


\subsubsection{General information on the Dutch health care system}

According to the WHO Global Health Expenditure Database, ${ }^{99}$ in 2014 The Netherlands spent 96 billion USD on health care. In that year, it was the country with the second highest government expenditure on health care as a percentage of the GDP, compared to other countries of that region $\left(9 \%{ }^{100}\right)$. The Dutch health care system is based on the 'Bismarck model'. ${ }^{101}$ Other examples of EU Member States with health care systems based on the Bismarck models are France and Germany. Other countries have based their health care systems, for example, on the 'Beveridge model'. The Beveridge model is financed through taxation and is usually provided for free (public good). ${ }^{102}$ According to this model, health care is organised by the government. ${ }^{103}$ Examples of EU Member States with Beveridge models are Spain, Italy and the Scandinavian countries. ${ }^{104}$

The most recent major reform of the health care system took place in 2006 with the introduction of a unified compulsory insurance scheme. As a result of the reform, the focus has been shifted to the demand side, by introducing managed markets for universal health insurance packages, health care purchasing and provision. The government took a step back in terms of the control of volumes and prices and now it only takes the role of a supervisor of the markets in relation to health care. Before 2006, the system was based on social insurance in combination with private insurances for the better off. ${ }^{105}$ For the largest part, the current system is financed through compulsory health insurance contributions. Adults have to pay premiums to the insurer of their choice and an income dependent premium to a central fund. In return the insured citizens receive a basic benefits package containing, inter alia, GP care and hospital care. ${ }^{106}$

The General Practitioner (as a primary care provider) has a central role in the Dutch health care system. In the majority of cases, the GP is the first point of contact for health care consumers. A prescription or referral from a GP is required for certain medicines and medical

\footnotetext{
99 World Health Organisation, 2014, Health System Financing Profile by country, retrievable via: http://apps.who.int/nha/database/Country_Profile/Index/en.

100 Ibid.

${ }^{101}$ Lameire, N., Joffe, P. and Wiedemann, M., 1999, Healthcare systems - an international review: an overview, Nephrol Dial Transplant 14 [Suppl 6], p. 3.

${ }^{102}$ Econex, 2011, National Health Systems: Public Service vs. Insurance-Based Models, Health Reform Note 15, p. 1-4, retrievable via: http://www.econex.co.za.

${ }^{103}$ Van Veen, E., Hamilton, G., 2005, De Zorgverzekeringswet in Europees(rechtelijk) perspectief, Tijdschrift voor Gezondheidsrecht, 29:53-64.

104 Rutten, F.F.H. ,2012, The Impact of economic evaluation on healthcare decision-making, Valedictory Lecture of 4 October 2012 at Erasmus University Rotterdam, retrievable via: http://hdl.handle.net/1765/39519.

${ }^{105}$ Kroneman, M., Boerma, W. et al., 2016, The Netherlands: health system review, Health Systems in Transition, vol. 18(2), p. xxi.

106 Ibid.
} 
specialist care. There are other primary care providers that are directly accessible: midwives and dentists. $^{107}$

\subsubsection{Definitions and types of health care in the Netherlands}

In this section the types of care that are provided in the Netherlands are discussed in more detail. Before elaborating on the types of care, reference is made to common definitions for health care and health care system.

In a performance report on the Dutch health care system, reference is made to the following definition of health care:

"the entire field of health care providers, supporting staff, institutions, resources and activities whose direct aim is to maintain of improve people's health status of self-reliance and to prevent, resolve, alleviate or offset deficiencies I health and personal functioning". ${ }^{108}$

According to the report, the provision of health care by the health care provider to an individual patient or client is central to the definition, although activities of supporting staff are also considered part of health care. ${ }^{109}$ The report furthermore notes that health care providers have completed a medical, nursing or nursing care training that allows them to practice their profession. ${ }^{110}$ The definition used for health care system is broader than that for health care. A health care system also includes aspects from parties that are further away from the primary care process, such as health care insurance, health care inspection, government, supervising bodies, etc. ${ }^{111}$

In order the get an idea of what kind of health care transactions take place under the Dutch health care system and to compare these to the proposed model health care system, it is interesting to look at the health care transactions on the basis of the level of treatment. This provides insight into the number and nature of transactions and suppliers involved in the provision of health care in the Netherlands. The classification method of health care according to the level of treatment is one of the four classification methods mentioned by experts of the RIVM (the National Intitute for Public Helath and the Environment in the Nehterlands). ${ }^{112}$ The other methods involve classification of health care according to the need, the place of treatment and the target group.

\footnotetext{
${ }^{107}$ Idem, p. 129.

${ }^{108}$ Van den Berg, M.J., De Boer, D., Gijsen, R. et al. (Eds.), 2015, Dutch Health Care Performance Report 2014, National Institute for Public Health and the Environment (RIVM), p. 16, retrievable via: http://www.healthcareperformance.nl.

109 Ibid.

110 Ibid.

111 Post, N., Gijsen, R. et al., 2018, Wat is gezondheidszorg?, National Institute for Public Health and the Environment (RIVM), retrievable via: http://www.volksgezondheidenzorg.info.

112 Post, N., Gijsen, R. et al., 2018, Zorg: verschillende indelingen, National Institute for Public Health and the Environment (RIVM), retrievable via: http://www.volksgezondheidenzorg.info; see also Mackenbach, J.P., Van der Maas, J. (Eds.), 2008, Volksgezondheid en gezondheidszorg, Elsevier gezondheidszorg.
} 
A classification of the health care according to treatment level shows that, in the Netherlands, a distinction is made between zero-, first-, second- and third-line health care. This represents, in that same order, preventive care, care by generalists, by specialists, and top clinical care by academic hospitals. ${ }^{113}$ Zero-line care is care of a preventive nature which is granted to persons who do not require medical care (yet). ${ }^{114}$ First line care is the care that is directly accessible. It refers to the (first) level of treatment. In the Netherlands, first line care constitutes of, inter alia, general practice, first line psychological care, physiotherapy, dental care, and obstetrics. ${ }^{115}$ First line care is usually offered at home or close to the place where the person resides. The care is provided without being admitted to a hospital or other institution and a referral is not required. ${ }^{116}$ The first line care is strong in the Netherlands, as it is in Denmark and the United Kingdom. About 90\% of the Dutch health care demand is dealt with in the first line and accounts for only $4 \%$ of the total health care budget. ${ }^{117}$ In the Netherlands, second line care consists of, inter alia, mental health care and youth care. Second line care is offered in case first line care is inadequate and more specialized care is required. It is called 'second line' care if a reference from the first line is necessary to obtain the care. ${ }^{118}$ The care is usually provided in hospitals (general or specialized, including rehabilitation centres) or outpatient clinics, but it can also be provided in independent treatment centres or private hospitals. ${ }^{119}$ Third line care is available in case the care needed is highly specialized care. This kind of care is, for instance, offered by mental and somatic health care institutions. ${ }^{120}$

Apart from the 'regular' health care that is provided through the different lines, there is also complementary and alternative care. In the Netherlands, this care is provided by health care providers who are educated for regular health care. ${ }^{121}$ I have no reason to presume that this only occurs in the Netherlands. This phenomenon posed some problems in relation to VAT. ${ }^{122}$ It can be that a qualified health care provider generally provides services that are VAT

\footnotetext{
${ }^{113}$ Van der Burgt, M., Van Mechelen-Gevers, E., Te Lintel Hekkert, M., 2012, Introductie in de Gezondheidszorg, Bohn Stafleu van Loghum, p. 13.

${ }^{114}$ Idem, p. 14-15.

115 Post, N., Gijsen, R. et al., 2013, Wat is gezondheidszorg?, In: Volksgezondheid Toekomst Verkenning, Nationaal Kompas Volksgezondheid, Bilthoven: RIVM, retrievable via: http://www.nationaalkompas.nl;

${ }^{116}$ Van der Burgt, M., Van Mechelen-Gevers, E., Te Lintel Hekkert, M., 2012, Introductie in de Gezondheidszorg, Bohn Stafleu van Loghum, p. 13.

${ }^{117}$ Wiegers, T., Hopman, P., Kringos, D., De Bakker, D., 2011, NIVEL Overzichtstudies: de eerste lijn, NIVEL, p. 17.

118 Post, N., Gijsen, R. et al., 2013, Wat is gezondheidszorg?, In: Volksgezondheid Toekomst Verkenning, Nationaal Kompas Volksgezondheid, Bilthoven: RIVM, retrievable via: http://www.nationaalkompas.nl.

${ }^{119}$ Van der Burgt, M., Van Mechelen-Gevers, E., Te Lintel Hekkert, M., 2012, Introductie in de Gezondheidszorg, Bohn Stafleu van Loghum, p. 14.

${ }^{120}$ Post, N., Gijsen, R. et al., 2013, Wat is gezondheidszorg?, In: Volksgezondheid Toekomst Verkenning, Nationaal Kompas Volksgezondheid, Bilthoven: RIVM, retrievable via: http://www.nationaalkompas.nl.

${ }^{121}$ Van der Burgt, M., Van Mechelen-Gevers, E., Te Lintel Hekkert, M., 2012, Introductie in de Gezondheidszorg, Bohn Stafleu van Loghum, p. 14.

${ }^{122}$ As illustrated by CJEU 27 April 2006, Joined Cases C-444/04 and C-443/04 Solleveld, ECLI:EU:C:2006:257.
} 
exempt, whereas that same care provider also provides alternative or complementary care for which the VAT exemption is not applicable and VAT is due on those health care service. ${ }^{123}$

\subsubsection{Conclusions in relation to the model health care system}

The model health care system is based on transactions that ultimately lead to the final consumption of health care. Insight into the different types of health care transactions that are provided in the Netherlands has been provided by means of an analysis of health care according to treatment level.

It is obvious that the model health care system is capable of covering first line care. The same is true for second line care. These kinds of care, presumably, take place by means of a direct legal relationship between health care suppliers. This means that this kind of care would be covered in either the basic or parallel transactions included in the model health care system. Even if the second line care is provided by means of subcontracting through the primary care supplier, it is still covered under the model health care system as a successive transaction. In my view, the same is true for third line care. 'Third' in this regard refers to the complexity of the health care. Therefore, these kinds of transactions will also be included in the model health care system.

The Dutch health care system apparently also includes zero-line care. This is preventive care, which is provided to consumers, who, at that point, do not require care (yet). By creating the model health care system, the demand of care was taken as one of the basic assumptions. As a result, there is a risk that the model does not cover transactions in which this demand for care is missing. However, in case a consumer wishes to receive preventive care and consults a health care supplier, the relevant transaction falls under the basic situation. Another example is that a governmental institution provides preventive care to residents without the residents specifically demanding i, or perhaps without paying for it, for example vaccinations provided by the government. In my view, these transactions are also in principle covered by the model health care system.

\subsection{Interim conclusion}

In this chapter, a model EU health care system was introduced. The purpose of the model is to demonstrate the application of positive EU VAT law on health care transactions and to show the effect on access to health care in specific situations.

In order draw up the model health care system, definitions relating to health care have been explored. These definitions are also used by international organizations involved in qualitative and quantitative research in the field of health care (e.g. the WHO and the OECD). On the basis of my conclusions as regards the analysis of those definitions, I introduced definitions for health care activities and health care suppliers for the purpose of this research. It

\footnotetext{
${ }^{123}$ One of the criteria for application of the medical exemption in Article 132(1)(c) of the EU VAT Directive, is that the care provided has to fall within the profession for which the health care provider is registered.
} 
appeared that the aim of the transactions and the professional qualifications of the care providers are important indicators for activities qualifying as health care and suppliers qualifying as health care suppliers. I consider that the provided definitions for health care activities and health care suppliers are common denominators of EU health care systems.

Moreover, requirements of the model health care system have been set out in this chapter to ensure that the model would serve its purpose: providing information on the effect of the imposition of VAT on health care transactions and ultimately the effect on access to health care. Next to the requirements that followed from the analysis of the definitions, requirements derived from the VAT system have been formulated. The requirements have led to a multi-level and demand-driven model health care system, containing transactions in basic situations, parallel situations and successive situations. Within the parallel situation, a distinction is made between parallel one-on-one and parallel two-on-one situations.

The model health care system is illustrated in section 2.3.2. The different situations of transactions that arise in the model health care system serve as a basis for the assessment of the application of positive EU VAT law on health care transactions in chapter 7. 


\section{Legal framework as regards the application of VAT on health care transactions}

In the previous chapter, I explored terminology in the field of health care in order to determine the common denominators of health care systems in the EU. These common denominators where used to arrive at a model health care system. This model health care system serves to establish how and in which specific situations the application of exemption provisions on health care transactions hinders access to health care (chapter 7). In order to be able to determine the consequences of the application of positive EU VAT law, an understanding of several key elements that effect the VAT taxability of health care transactions is required. In this chapter, I will discuss these key elements in relation to health care transactions. Furthermore, I will discuss some fundamental principles and characteristics underlying the EU VAT system. This chapter, hence, serves as part of the legal framework of this research. In chapter 6, I will discuss the measures included in the EU VAT Directive that mitigate the VAT burden of health care supplies and their scope of application more comprehensively, in order to demonstrate how the application of positive EU VAT law on health care transactions hinders access to health care. Chapter 7, subsequently, demonstrates in which situations - i.e. where - the application of positive EU VAT law on health care transactions hinders access to health care.

\subsection{Introduction}

Before the entry into force of the European Directives on the application of an EU VAT System, national turnover tax systems were already present in Europe. The desire to come to an internal market without frontiers required a harmonization of indirect taxes in the EU. Article 113 of the TFEU requires the adoption of provisions for the harmonization of legislation concerning turnover taxes, to the extent necessary to ensure the establishment and functioning of the internal market. The adoption of a directive was chosen to achieve the objective of harmonization. ${ }^{124}$ The key provisions that govern the application of positive EU VAT law are laid down in the EU VAT Directive. ${ }^{125}$

The EU VAT Directive itself mentions the essential characteristics it possesses. The EU VAT is a general tax on consumption. ${ }^{126}$ Its legal character entails the aim to tax final consumption

\footnotetext{
${ }^{124}$ Articles $114-115$ of the TFEU.

${ }^{125}$ Council Directive 2006/112/EC of 28 November 2006 on the common system of value added tax, OJ L 347,11 December 2006.

${ }^{126}$ Article $1(2)$ of the EU VAT Directive.
} 
at the level of the final consumer. ${ }^{127}$ Furthermore, the tax is objective by nature (it is levied on the supply of goods and services) and proportionate (to the price). The levying of VAT takes is neutral. The right to deduct input VAT for suppliers in the supply chain is key in that regard, as businesses are not intended to bear the burden of the VAT. The common system of EU VAT ensures neutrality of the taxation of all economic activities, provided that those activities are themselves subject in principle to VAT. ${ }^{128}$ This includes neutrality in relation to international trade, which is reflected inter alia by the exemptions for export supplies. Neutrality also has to be ensured in relation to the legal form. This requires a similar VAT treatment of taxable persons, irrespective of their legal form. Also, there should be no discrimination between similar businesses as regards compliance requirements. The principle of fiscal neutrality, which is also inherent in the VAT system, means, according to settled case law, that supplies of goods or services which are similar, and which are therefore in competition with each other, may not be treated differently for VAT purposes. ${ }^{129}$

\subsection{Characteristics}

It can be deduced from the first article of the EU VAT Directive that the EU VAT System can be characterized as follows: ${ }^{130}$

- $\quad$ EU VAT is a general tax on consumption (see section 3.2.1).

- EU VAT is applied exactly proportional to the price of the goods and services (see section 3.2.3).

- EU VAT is levied at all stages of the production and distribution process (see section 3.2.2).

- $\quad$ The EU VAT system entitles taxable persons to the right to deduct input VAT (see section 3.2.4).

In the following subsections, the characteristics mentioned above will be discussed briefly.

\subsubsection{General consumption tax}

As indicated above, the EU VAT is a general tax on consumption. The tax is general, as it is not restricted to the taxation of specific goods and services. The EU VAT system intends to cover

\footnotetext{
${ }^{127}$ See section 3.2.2; see also Simons, A.L.C, 1996, EC Court of Justice recognizes the legal character of VAT, EC Tax Review, Volume 5, Issue 2, p. 87-90.

${ }^{128}$ CJEU 15 November 2012, Case C-174/11 Zimmermann, ECLI:EU:C:2012:716, para. 47; see inter alia, to that effect, CJEU 29 October 2009, Case C-174/08 NCC Construction Danmark, ECLI:EU:C:2009:669, para. 27; CJEU 22 December 2010, Case C-277/09 RBS Deutschland Holding, ECLI:EU:C:2010:810, para. 38.

${ }^{129}$ CJEU 15 November 2012, Case C-174/11 Zimmermann, ECLI:EU:C:2012:716, para. 48; inter alia, CJEU 17 February 2005, Joined Cases C-453/02 and C-462/02 Linneweber and Akritidis, ECLI:EU:C:2005:92, para. 24; CJEU 10 November 2011, Joined Cases C-259/10 and C-260/10 The Rank Group, ECLI:EU:C:2011:719, para. 32 and the case-law cited.

${ }^{130}$ See Van Doesum, A.J., Van Kesteren, H.W.M., Van Norden, G.J., 2016, Fundamentals of EU VAT Law, Kluwer Law International, para. 1.11 for a more comprehensive overview of the basic features of EU VAT law.
} 
all economic activities resulting in supplies of goods and services within the EU. As a result, the scope of application is broad. The broad scope of the EU VAT system required broad definitions for both taxable persons ${ }^{131}$ (the subject of taxation) and taxable transactions ${ }^{132}$ (the object of taxation). Hence, a large number of taxable persons are required to pay EU VAT due on their supplies of goods and services.

According to its legal character, the EU VAT System aims to tax final consumption at the level of the final consumer. ${ }^{133}$ As taxing consumption was, as such, not practically feasible, EU VAT took the form of a transaction tax. The object of taxation, as indicated above, is basically the supply of goods and services made by taxable persons. These transactions serve as a proxy for the expenditures that where required to purchase the goods and services, whereas the expenditures serve as a proxy for the consumption of those goods and services. ${ }^{134}$

It should be noted at this point that the broad scope of the EU VAT system also implies that the supply of health care is potentially included under the EU VAT system. Health care is, after all, something that can be 'consumed'. The provision of health care goods and services constitute transactions for which expenditure is incurred. Whether health care transactions are actually taxed with VAT depends on a number of other factors, i.e. the qualification of a health care supplier as a taxable person for VAT under Article 9 of the EU VAT Directive, or the application of an exemption provision. The application of exemption provisions actually constitutes an exception to the general character of EU VAT. Please note that, although it may be generally conceived that in relation to heath care transactions health care seekers are considered to be the final consumers, there are situations in which medical insurance funds are - for VAT purposes - considered to be the final consumers. In a recent case, the CJEU considered a private health insurance fund as the final consumer in a supply chain of pharmaceutical products. ${ }^{135}$ On basis of a national rule in Germany, the pharmaceutical company that manufactures and sells the medicinal products had to grant a discount to the private health insurance fund if an insured person had bought the medicinal product in a pharmacy and was entitled to a reimbursement of the costs by the insurance fund. Considering the insurance fund as the final consumer in that supply chain requires that the discount has to be taken into account while determining the taxable amount of the supply of the medicinal products at the level of the pharmaceutical company.

\subsubsection{All stages tax}

In section 3.2.1, it was explained that the legal character of the EU VAT System intends to tax final consumption at the level of the final consumer. Therefore, VAT is levied at all stages of

\footnotetext{
${ }^{131}$ Article 9 of the EU VAT Directive.

${ }^{132}$ Article 2 of the EU VAT Directive.

${ }^{133}$ Simons, A.L.C, 1996, EC Court of Justice recognizes the legal character of VAT, EC Tax Review, Volume 5, Issue 2.

${ }^{134}$ See Van Doesum, A.J., Van Kesteren, H.W.M., Van Norden, G.J., 2016, Fundamentals of EU VAT Law, Kluwer Law International, para. 1.11 for a more comprehensive overview of the basic features of EU VAT law, para. 1.3 and 1.11.1.

${ }^{135}$ CJEU 20 December 2017, Case C-462/16 Boehringer Ingelheim Pharma, ECLI:EU:C:2017:1006.
} 
the production and distribution process. Compared to a single stage tax, under the EU VAT system, a significant number of persons are liable to pay tax to the tax authorities. Under a single stage tax, this would be limited to, for example, operators active at the retail level. Van Doesum, Van Kesteren and Van Norden mention that the latter is considered an important drawback of a single-stage tax. A correct application would then depend heavily on the quality of the taxable persons at that stage in the supply chain. ${ }^{136}$

\subsubsection{Proportionality to the price}

The amount of VAT charged is calculated by means of the application of a rate. Member States have to apply a standard rate, fixed as a percentage of the taxable amount (which is in principle, the expense incurred by the recipient ${ }^{137}$ ) and which is the same for the supply of goods and the supply of services. ${ }^{138}$ Next to this standard rate, Member States may apply one or two reduced rates, but only in relation to the supply of goods in the categories specified under the EU VAT Directive. ${ }^{139}$ The application of a percentage ensures that the amount of VAT charged is proportionate to the price, regardless of which link in the supply chain the transaction takes place. This ensures legal neutrality. Another aspect that ensures the proportionality of the tax is the right to deduct input VAT (see section 3.2.4). The deduction of input VAT relieves a taxable person from the VAT that was incurred in the previous stage in the supply chain. In that way, the amount of VAT charged is not dependent on the length of a supply chain.

\subsubsection{The right to deduct input VAT}

A taxable person can only deduct the VAT he is liable to pay ('input VAT') on goods and services in so far as he uses them for the purpose of transactions that are subject to VAT. In order to safeguard neutrality of the EU VAT system, the right to deduct input tax is aimed at entirely relieving a taxable person of the VAT that is paid or payable in the course of all his economic activities, provided these are subject to VAT. ${ }^{140}$ This right may in principle not be limited and must be exercised immediately in respect of all taxes charged on transactions related to inputs. ${ }^{141}$

The provision concerning the right to deduct, can be found in Article 168 of the EU VAT Directive. It follows from that provision that a taxable person is entitled to deduct VAT

\footnotetext{
${ }^{136}$ Idem, para. 1.11.3.

${ }^{137}$ Article 73 of the EU VAT Directive.

${ }^{138}$ Article 96 of the EU VAT Directive.

${ }^{139}$ Article 98 of the EU VAT Directive.

140 CJEU 22 February 2001, Case C-408/98 Abbey National, ECLI:EU:C:2001:110, para. 24; CJEU 14 February 1985, Case C-268/83 Rompelman v Minister van Financiën, ECLI:EU:C:1985:74, para. 19; CJEU 15 January 1998, Case C-37/95 Belgische Staat v Ghent Coal Terminal, ECLI:EU:C:1998:1, para. 15; CJEU 21 March 2000, Joined Cases C-110/98 to C-147/98 Gabalfrisa and Others, ECLI:EU:C:2000:145, para. 44; CJEU 8 June 2000, Case C98/98 Midland Bank, ECLI:EU:C:2000:300, para. 19.

${ }^{141}$ CJEU 21 March 2000, Joined Cases C-110/98 to C-147/98 Gabalfrisa and Others, ECLI:EU:C:2000:145, para. 43; CJEU 6 July 1995, Case C-62/93 BP Soupergaz v Greek State, ECLI:EU:C:1995:223, para. 18.
} 
charged on the purchase of goods and services in so far as those goods and services are used for the purpose of carrying out transactions that are subject to VAT. ${ }^{142}$ This implies that the right to deduct input VAT cannot be enjoyed by persons acting in the capacity as a nontaxable person (e.g. a municipality acting as public authority). ${ }^{143}$

It is necessary to establish the nature of the outgoing transaction to determine whether and, if so, to what extent, taxable persons can deduct VAT. ${ }^{144}$ There is, after all, only a right to deduct VAT if incurred costs can be linked to transactions that are subject to VAT. For this reason, the application of exemption provisions on health care transactions has immediate consequences for the right to deduct the input VAT paid by the health care supplier, assuming that the supplier qualifies as a taxable person under Article 9 of the EU VAT Directive. The VAT charged to a health care supplier on the goods and supplies he has purchased in order to perform exempt health care services is not, or perhaps only partly, deductible.

The provision on the right to deduct in Article 168 of the EU VAT Directive, in principle, implies that there must be a direct and immediate link between a particular input transaction and a particular output transaction. ${ }^{145}$ From this rule, it follows, according to the CJEU, that the right to deduct VAT on acquired goods and supplies presupposes that the expenditure incurred in acquiring them was part of the cost components of the taxable transactions. ${ }^{146}$ For that reason, the expenditure must form part of the costs of the output transactions which use the acquired goods and services. ${ }^{147}$ In case a health care supplier performs outgoing health care supplies that are covered under an exemption for health care, it appears, on the basis of this reasoning, that the non-deductible input VAT becomes part of the costs of the output transactions. It is therefore, in my view, safe to conclude that nondeductible VAT - as a result of the application of an exemption provision - will be charged forward by the supplier in the price of the outgoing transactions. Therefore, in relation to health care, it can also be concluded that the denial of the right to deduct for a health care supplier leads to increased costs of health care for the consumer. This seems to be contrary to the aim of the exemption provisions for health care of ensuring that the accessibility of

\footnotetext{
${ }^{142}$ Article 168 of the EU VAT Directive.

${ }^{143}$ On basis of Article 13 of the EU VAT Directive, local government authorities shall not be regarded as taxable persons in respect of the activities engaged in as public authority.

${ }^{144}$ See also Gabriël, M.M. and Van Kesteren, H.W.M., 2011, Calculation of the (Pre-) Pro Rata under EU VAT Law, International VAT Monitor, Volume 22, No 5.

${ }^{145}$ CJEU 8 June 2000, Case C-98/98 Midland Bank, ECLI:EU:C:2000:300, para. 24; see also Van Doesum, A.J., Van Kesteren, H.W.M., Van Norden, G.J., 2016, Fundamentals of EU VAT Law, Kluwer Law International, para. 1.11 for a more comprehensive overview of the basic features of EU VAT law, para. 10.3.

${ }^{146}$ See, for example, CJEU 22 February 2001, Case C-408/98 Abbey National, ECLI:EU:C:2001:110, para. 28; CJEU 8 June 2000, Case C-98/98 Midland Bank, ECLI:EU:C:2000:300, para. 30; CJEU 6 April 1995, Case C-4/94 BLP Group, ECLI:EU:C:1997:107, para. 19.

147 Ibid.
} 
health care transactions is not hindered by increased costs which would occur if health care services are made subject to VAT.

For the purpose of the application of the right to deduct, a distinction needs to be made between direct costs and indirect costs. Direct costs are costs that are directly attributable to particular output transactions. These transactions are either subject to VAT or not. In case direct costs relate to transactions that are subject to VAT, the VAT incurred on those direct costs are, in principle, fully deductible for the taxable person who incurred the costs. If direct costs relate to transactions that are not subject to VAT, the VAT incurred on those direct costs is not deductible. Indirect costs (also: general costs) are costs that are not directly attributable to specific output transactions. These can, for example, be costs for cleaning services that a hospital incurs for cleaning rooms that are used by the hospital for performing health care services that are covered under the exemption provision for extramural health care, as well as for activities that are not covered under an exemption provision for health care (e.g. certain services by a plastic surgeon which does not constitute medical care).

Articles 173-175 of the EU VAT Directive contain provisions on a partial deduction of input VAT. These provisions determine the (extent of) the right to deduct input VAT on indirect costs. On the basis of these provisions, the deductible proportion of the VAT charged on the general costs of a taxable person is - under the main rule of Article 174 (1) of the EU VAT Directive - determined by applying a fraction based on turnover proportions. This is also referred to as a 'pro rata' calculation. In practice, it frequently occurs that the output of health care suppliers is a combination of exempt and taxed transactions (but predominantly exempt). Health care suppliers, therefore, often need to make pro rata calculations in order to determine to what extent they incur VAT on general costs (e.g. the costs of cleaning services, in the example given above) is deductible.

For suppliers who act in multiple capacities (both taxable and non-taxable) implementing the right to deduct is even more complicated. The pro rata calculation can only be used in respect of the economic activities. Therefore, a so-called 'pre pro rata' rate has to be applied if a person seeks to deduct VAT on costs that relate to both his taxable and non-taxable activities. ${ }^{148}$ Such a mechanism was not - and is still not - included in the EU VAT Directive. Its application, however, directly follows from the CJEU in Securenta. ${ }^{149}$ In that case, the CJEU ordered Member States to ensure that the calculation of the proportion of economic to noneconomic activities (the pre pro rata) objectively reflects the part of the input expenditure actually to be attributed to the respective two types of activities. ${ }^{150}$ As a result, VAT charged

\footnotetext{
148 The term 'pre pro rata' was introduced by Van Doesum; Van Doesum, A.J., 2009, Contractuele samenwerkingsverbanden in de BTW (diss.), p. 252.

${ }^{149}$ CJEU 13 March 2008, Case C-437/06 Securenta, ECLI:EU:C:2008:166.

${ }^{150}$ For more explanation on the (pre) pro rata mechanism, see Gabriël, M.M. and Van Kesteren, H.W.M., 2011, Calculation of the (Pre-) Pro Rata under EU VAT Law, International VAT Monitor, Volume 22, No 5.
} 
(on costs) is not deductible in so far it can be attributed to the non-taxable activities of a supplier.

\subsection{Neutrality principle}

While applying EU VAT law, one has to make sure the application is in line with certain fundamental principles. Neutrality is a key principle for the application of EU VAT law. Already in the preamble to the First EU VAT Directive, it was stated that the common system of VAT is bound to result in neutrality in competition. ${ }^{151}$ The neutrality principle combines elements of general law principles with system principles. ${ }^{152}$ The system element can be derived from Article 2 of the Second EU VAT Directive. From this article, it follows that VAT has to be:

"...exactly proportional to the price of the goods and services, whatever the number of transactions which take place in the production and distribution process before the stage at which tax is charged." 153

This aspect of neutrality is generally referred to as 'system neutrality', as it is closely related to the purpose and design of the EU VAT system. ${ }^{154}$ The application of exemption provisions can lead to an infringement of system neutrality. In the previous section, I demonstrated that the application of exemptions can lead to increased costs as a result of (charging forward) non-deductible input VAT. If non-deductible VAT becomes part of an outgoing supply in the ultimate link of a supply chain, this (only) affects the price for the health care consumer. If this, however, occurs earlier in the supply chain, it may happen that non-deductible VAT becomes a cost-component of a supply that is taxed with VAT (cascading). This results in an infringement of system neutrality. In such cases, VAT is not proportional to the price and, furthermore, the number of suppliers in a supply chain in that case influence the price of the supplied goods or services.

The principle of neutrality also contains a legal aspect. As indicated above, the First Directive demanded that the system of VAT has to result in neutrality of competition. In this regard, the CJEU has held in several cases that the principle of fiscal neutrality is actually a reflection of the principle of equal treatment in the field of VAT. ${ }^{155}$ The neutrality principle can be seen as a particular manifestation of the principle of equality. ${ }^{156}$ This legal aspect of neutrality applies in situations concerning competing taxable persons supplying similar goods or

\footnotetext{
${ }^{151}$ First Council Directive 67/227/EEC of 11 April 1967 on the harmonisation of legislation of Member States concerning turnover taxes, OJ 71, 14 April 1967.

${ }^{152}$ Van Doesum, A.J., Van Kesteren, H.W.M., Van Norden, G.J., 2016, Fundamentals of EU VAT Law, Kluwer Law International, para. 1.12.

${ }^{153}$ Article 2 of the Second EU VAT Directive; this principle is included in Article 1(2) of the EU VAT Directive.

${ }^{154}$ Van Doesum, A.J., Van Kesteren, H.W.M., Van Norden, G.J., 2016, Fundamentals of EU VAT Law, Kluwer Law International, para. 1.12 .

${ }^{155}$ See for example CJEU 27 April 2006, Joined Cases C-444/04 and C-443/04 Solleveld, ECLI:EU:C:2006:257, para. 36; CJEU 6 November 2003, Case C-45/01 Dornier, ECLI:EU:C:2003:595, paras. 42 and 69; CJEU 26 May 2005, Case C-498/03 Kingscrest Associates and Montecello, ECLI:EU:C:2005:322, paras. 29 and 52.

${ }^{156}$ Van Doesum, A.J., 2009, Contractuele samenwerkingsverbanden in de BTW (diss.), p. 32.
} 
services and are, as a result, in competition with each other. Van Doesum holds in this regard that the application of the neutrality principle as a particular manifestation of the principle of equality has as its purpose to ensure neutrality as regards competition. ${ }^{157}$ The application of the (general) principle of equality also covers other forms of equalities and is not restricted to situations in which persons are in competition with each other. ${ }^{158}$

CJEU cases on the application of exemption provisions for health care often contain references to legal neutrality (fiscal neutrality). The most prominent case in that regard is perhaps the Solleveld case. In that case, the CJEU held that a different treatment of an apparent similar service is only justified if the (professional) qualifications of the providers cannot ensure an equivalent level of quality of the service. ${ }^{159}$ In another (key) case on the application of health care exemptions, the CJEU held that the principle of fiscal neutrality would be frustrated if the possibility to rely on an exemption provision was dependent on the legal form in which the taxable person carries out its activity. ${ }^{160}$

\subsection{Ability to pay principle}

In chapter 4, I demonstrated that the element of access to health care - which is embedded in the human right to health - is based on the ability to pay principle (section 4.2.2). It entails that health care has to be accessible to everyone without discrimination. It was also demonstrated that the EU Health ministers consider accessibility of health care, taking into account the ability to pay, one of the overarching values that have to be taken into account when drafting specific proposals concerning health services (section 4.3.1). The foregoing shows that the ability to pay principle is one of the foundations within the principle of access to health care. Furthermore, within the EU it is recognized as a principle that has to be taken into account when drafting new legislation on health care services.

It seems that the EU VAT system values the ability to pay principle to a certain extent. This, in my view, can be derived from the (proclaimed) purpose of the exemption provisions for health care and the purpose of the application of reduced VAT rates. According to the EU, the purpose of exemption provisions for health care is the reduction of health care costs and making health care more accessible to individuals. ${ }^{161}$ The CJEU also held explicitly that the imposition of VAT on health care would hinder access to that care. ${ }^{162}$ Also, in relation to

\footnotetext{
${ }^{157}$ Idem, p. 33.

158 Bomer, A.H., 2012, De doorwerking van de algemene rechtsbeginselen in de BTW (diss.), Maastricht University, p. 125.

${ }^{159}$ CJEU 27 April 2006, Joined Cases C-444/04 and C-443/04 Solleveld, ECLI:EU:C:2006:257, para. 40.

${ }^{160}$ CJEU 7 September 1999, Case C-216/97 Jennifer Gregg and Mervyn Gregg v Commissioners of Customs and Excise, ECLI:EU:C:1999:390.

${ }^{161}$ See inter alia cases CJEU 20 November 2003, Case C-212/01 Margarete Unterpertinger, ECLI:EU:C:2003:625, para. 41; CJEU 8 June 2006, Case C-106/05 L.u.P., ECLI:EU:C:2006:380, para. 25; CJEU 6 November 2003, Case C45/01 Dornier, ECLI:EU:C:2003:595, para. 48; CJEU 10 September 2002, Case C-141/00 Kügler, ECLI:EU:C:2002:473, para. 29; CJEU 1 December 2005, Joined Cases C-395/04 and C-394/04 Ygeia, ECLI:EU:C:2005:734, para. 24.

${ }^{162}$ CJEU 11 January 2001, Case C-76/99 Commission vs. France, ECLI:EU:C:2001:12, para. 23.
} 
reduced rates, it appears that the EU VAT system values the principle of ability to pay. Reduced rates intend to make certain goods - regarded as being particularly necessary more accessible for the final consumer who ultimately pays the burden of VAT. ${ }^{163}$ The EU VAT system professes to value the ability to pay principle, while at the same time the VAT system does not take into account personal (financial) circumstances. Like Van Norden notes in this regard, the VAT system is not based on the ability to pay principle. ${ }^{164}$ Van Doesum notes that VAT is not a tax (based) on the ability principle but a tax on the ability to pay principle. $^{165}$

Considering the prominent place of the ability to pay principle in relation to the principle of access to health care, it is a good thing that the EU VAT system, as regards the application of exemption provisions for health care and the application of reduced rates (that also apply for e.g. pharmaceutical products and medical equipment), values the ability to pay principle to a certain extent. However - since the VAT system itself is not based on the ability to pay principle, as it does not take into account personal circumstances of health care consumers - the EU VAT system is, in my view, not the most efficient place to introduce measures with the purpose to safeguard ability to pay in relation to health care transactions.

\subsection{The subject of taxation: taxable persons}

This section serves to demonstrate, from a conceptual point of view, the scope of transactions that are covered under the EU VAT system. Considering the broad scope of EU VAT, which seeks to tax all consumption by final consumers, it includes a broad taxable person concept (see also section 3.2.1). It followed from the Second Council Directive that the concept is to be understood in a broad sense as covering all economic activities. ${ }^{166}$ This also emerges from the explanatory memorandum to the proposal for the Sixth Directive, where it is stated that the definition of taxable person "should be extended to cover all economic activities, wherever they take place and all activities which are in nature of such activities but which may be carried out separately or occasionally" ${ }^{167}$ Before elaborating on the definition of taxable persons under positive EU VAT law, I will address the role of a health care supplier in relation to the taxability of health care transactions under positive EU VAT law and on the consequences for health care suppliers if they qualify as a taxable person.

\footnotetext{
${ }^{163}$ CJEU 17 January 2013, Case C-360/11 Commission vs. Kingdom of Spain, ECLI:EU:C:2013:17, para. 48; CJEU 9 March 2017, Case C-573/15 Oxycure Belgium, ECLI:EU:C:2017:189, para. 22.

${ }^{164}$ Van Norden, G.-J., 2010, Het concern in de btw (diss.), Kluwer, p. 22.

${ }^{165}$ Van Doesum, A.J., 2009, Contractuele samenwerkingsverbanden in de BTW (diss.), p. 36.

${ }^{166}$ Second Council Directive 67/228/EEC of 11 April 1967 on the harmonisation of legislation of Member States concerning turnover taxes, OJ 71, 14 April 1967, Annex A, p. 2.

${ }^{167}$ Explanatory notes to Article 4 of the Proposal for a sixth Council Directive of 20 June 1973, COM(73)950; See also, for example, CJEU 20 June 2013, Case C-219/12 Finanzamt Freistadt Rohrbach Urfahr, ECLI:EU:C:2013:413, para. 17; CJEU 26 June 2007, Case C-284/04 T-Mobile Austria and Others, ECLI:EU:C:2007:381, para. 35; CJEU 26 June 2007, Case C-369/04 Hutchison $3 G$ and Others, ECLI:EU:C:2007:382, para. 29.
} 


\subsubsection{Role of a health care supplier in relation to the taxability of health care transactions under positive EU VAT law}

The quality and capacity in which the supplier acts while providing health care is crucial for the VAT treatment of the activities. If a health care supplier for example acts as a public authority it is not considered a taxable person. ${ }^{168}$ If a health care supplier is a taxable person but does not possess the medical qualifications required, a VAT exemption for the transactions that are carried out by that person may be denied. Although the EU VAT is an objective tax, taxing supplies of goods and services, it thus also imposes certain requirements on the object of taxation. For now, only the subject of taxation will be at issue. The object of taxation, the health care transactions, will be discussed in section 3.6 The question posed at this point is whether and to what extent health care suppliers come within the scope of VAT. This question is usually dealt with first when the tax liability has to be established, since it is the result of the way the taxable transactions are defined in Article 2 of the EU VAT Directive. Transactions are only taxable if carried out by a taxable person. Only the activities of a taxable person are referred to as taxable transactions. ${ }^{169}$ They are in principle taxed unless taxation is prevented as a result of the application of an exemption provision. By contrast, activities that cannot be qualified as taxable transactions are in principle not covered within the scope of the EU VAT Directive, which prevents exemptions from applying. Note that noneconomic activities differ from activities 'for purposes other than those of [his] business', as referred to in Articles 16 and 26 of the EU VAT Directive. The non-business activities referred to in those articles are the (non-business) activities of a taxable person.

Non-economic activities are by contrast carried out by persons in their capacity as nontaxable persons. ${ }^{170}$ The non-business activities of a taxable health care supplier (i.e. private use of a business asset) can thus - as a result of the application of the fictions in Articles 16 or 26 of the EU VAT Directive - be qualified as a taxable activity.

Based on the foregoing, as regards health care, it can be established that health care transactions potentially constitute taxable transactions if the health care supplier qualifies as a taxable person. The role of the supplier for the establishment of the taxability of health care transactions is therefore crucial. For the delineation of the scope of VAT as regards health care transactions, it is of great importance to establish whether the health care supplier is a taxable person or not. A health care supplier can even play a 'double role' in this regard. This applies e.g. for public bodies. They can be regarded as a taxable person for part of their activities and regarded as a non-taxable person for the other part of their activities.

\footnotetext{
${ }^{168}$ A minority of Member States treats hospital services, provided by public bodies, as non-taxable (also see section 6.1.1.2)

${ }^{169}$ Some exceptions apply, i.e. in case of importation of goods (Article 2(1)(d) of the EU VAT Directive).

170 CJEU 12 February 2009, Case C-515/07 Vereniging Noordelijke Land- en Tuinbouw Organisatie, ECLI:EU:C:2009:88.
} 


\subsubsection{Consequences of the taxable person status for health care suppliers}

The most important consequence was already mentioned in the previous section. Once a health care supplier qualifies as a taxable person, the activities carried out by that person are regarded as taxable transactions, provided that the other criteria of Article 2 of the EU VAT Directive are also fulfilled. The taxable person is in principle the person liable to pay the VAT due on the transactions that were provided by the person. ${ }^{171}$ This is a consequence of the indirect form of the tax. Also, a number of formal obligations are connected to the taxable person status, such as keeping accounts and complying with invoicing rules.

The status as a taxable person brings along the right to deduct input VAT. Being a taxable person brings with it a great advantage. In so far as a taxable person uses goods or services for taxed (output) transactions, the taxable person has a right to deduct the VAT that was charged to him on the costs incurred in relation to the taxed output taxations (see section 3.2.4). After all, in line with the neutral character of VAT, it should ultimately be borne by the end consumer to whom it is supplied. A taxable person has the right to label goods as either private or business goods ${ }^{172}$ and in that way can secure the right to an input deduction. This is something which is not possible for non-taxable persons (or end consumers). In that regard, it is very important to establish from which moment a person qualifies as a taxable person and from which moment the person no longer qualifies as a taxable person.

The transactions of taxable health care suppliers are often exempt due to the exemption provisions for health care activities in Article 132 of the EU VAT Directive. Therefore, they cannot benefit from the right to deduct input VAT, at least in so far as that input VAT was incurred in relation to exempt health care supplies. The 'advantage' for taxable persons performing taxed supplies hence turns out to be a disadvantage for taxable persons performing exempt supplies. This disadvantage manifests in multiple ways. On the input side, not being able to deduct leads to a bias to self-supply. While on the output side, it may frustrate competition where a competitor providing similar activities does have a right to deduct VAT.

\subsubsection{The definition of taxable person in positive EU Law}

The notion of a 'taxable person' is defined in Article 9 of the EU VAT Directive. It concerns 'any person who, independently carries out in any place any economic activity, whatever the purpose or results of that activity'. It is a Union law definition, requiring an autonomous and uniform application and interpretation. ${ }^{173}$ The conditions laid down in Article 9 of the EU VAT Directive and the consequences thereof for health care suppliers will be discussed in the following sections.

\footnotetext{
${ }^{171}$ Article 173 of the EU VAT Directive; see also Explanatory notes to Article 4 of the Proposal for a Sixth Council Directive of 20 June 1973, COM(73)950.

${ }^{172}$ CJEU 11 July 1991, Case C-97/90 Lennartz v Finanzamt München III, ECLI:EU:C:1991:315.

${ }^{173}$ CJEU 17 September 2014, Case C-7/13 Skandia America (USA), ECLI:EU:C:2014:2225, para. 23.
} 


\subsubsection{Any health care supplier acting independently}

\section{Any health care supplier}

What is most remarkable about the notion of a taxable person is that in fact 'any person' can qualify. Each health care supplier is a potential taxable person: hospitals, elderly homes, selfemployed medical specialists, alternative healers etc. There are no requirements as regards the legal form. Even a natural person can qualify as a taxable person. A profit-making goal is not required. The way in which the health care supplier acts or presents itself, by contrast, is important. It is required that the health care supplier acts independently, which excludes those working in employment.

In addition to legal and natural persons, all conceivable forms of cooperation, which present themselves as a unit to the public, can qualify as taxable persons. For example, a group practice of doctors, dentists and clinical services. The subject of taxation for VAT differs from the tax subject under direct taxes. It may well be that the lack of a legal form in the case of the group practice, given above as an example, prevents it from qualifying for tax purposes under, for example, corporate tax rules.

The term 'any person' reflects the neutrality of the tax in relation to legal form. Legal form neutrality not only plays a role in relation to the qualification as a taxable person. In relation to health care, the CJEU has confirmed the effect of legal form neutrality with regard to the application of (medical) VAT exemptions. The CJEU concluded in the Bulthuis-Griffioen case $(1995)^{174}$ that, where an exemption expressly refers to the concept of 'body', ${ }^{175}$ it may be claimed only by legal persons. Whereas, where a provision refers to 'organization', it can according to the CJEU - also be claimed by natural persons, including traders. Later, in Gregg\&Gregg (1999), the CJEU retracted its previous opinion. ${ }^{176}$ It held that the principle of fiscal neutrality would be frustrated if the possibility to rely on an exemption provision was dependent on the legal form in which the taxable person carries on his activity. The textual interpretation that was applied by the CJEU in Bulthuis-Griffioen had been put aside.

\section{Cooperation}

A taxable person is a person who acts independently. Particularly in situations where natural persons and/ or legal persons cooperate together, it may be hard to establish in which capacity the person or persons participating in the cooperation are acting. A group of dentists could for example cooperate together and present themselves as a cooperation to the public.

\footnotetext{
${ }^{174}$ CJEU 11 August 1995, Case C-453/93 Bulthuis-Griffioen v Inspecteur der Omzetbelasting, ECLI:EU:C:1995:265.

${ }^{175}$ As for instance in Article 132, paragraph 1, subsection, b of the EU VAT Directive.

${ }^{176}$ CJEU 7 September 1999, Case C-216/97 Jennifer Gregg and Mervyn Gregg v Commissioners of Customs and Excise, ECLI:EU:C:1999:390.
} 
This could emerge from the fact that they use one name. ${ }^{177}$ In this case, both the cooperation and the individual dentists can in principle be regarded as separate taxable persons depending on how the individual dentist acts on a specific occasion. If the independent dentist acts on behalf of the cooperation, it is the cooperation that is the taxable person. On the other hand, if the dentist acts in his own name and on his own behalf, this individual dentist is considered the taxable person. In this respect, the criteria of 'any person' and 'independently' are closely connected. ${ }^{178}$

Already in Heerma case, the CJEU held that one of the members of a cooperation (in that case a partner in a partnership) can in principle act independently from that cooperation and, therefore, be a distinct taxable person. ${ }^{179}$ It is thus important, in the particular case of cooperation, to determine the capacity in which a person acts: either independently or as (part of) the cooperation. As said, the name that is used can be an indicator. Furthermore, it has to be established which person or persons bear the economic risk of the activities carried out. Operating independently also implies that the person or entity bears the economic risk arising from its business. ${ }^{180}$

\section{Employed health care suppliers}

Health care suppliers that are under an employment contract or are in another way bound to an employer by legal ties are excluded from VAT. This follows directly from Article 10 of the EU VAT Directive, which further clarifies the term 'independently' in Article 9 of the EU VAT Directive. However, if these employees carry out activities outside the employment relationship, they may qualify as a taxable person for these activities if they act independently while carrying out these economic activities. At this point, it is important to note that the assessment of the application of VAT on the activities of a person has to be judged on its own merits, i.e. the application is not dependent on a possible subjection of that person to wage tax, for example, for the activities concerned.

By excluding employees, it is precluded that they have to deal with all kinds of administrative and financial obligations concerning the liability of VAT. The Advocate General in the Van der Steen case argued why it is beneficial that activities performed within the scope of an employment contract remain outside the scope of VAT. The AG indicated that, if included, VAT would have to be taxed on the salaries of employees and their employers making the taxable supplies would be able to deduct that VAT. If these employers, however, make exempt supplies, the VAT on the salaries would not be deductible. This would be

\footnotetext{
177 Using one name is not decisive and moreover is not required. See also CJEU 20 June 1991, Case C-60/90 Polysar Investments Netherlands v Inspecteur der Invoerrechten en Accijnzen, ECLI:EU:C:1991:268, para. 16-17 and Van Doesum, A.J., 2009, Contractuele samenwerkingsverbanden in de BTW (diss.), p. 137.

${ }^{178}$ Also Van Norden, G.-J., 2010, Het concern in de btw (diss.), Kluwer, p. 90.

${ }^{179}$ CJEU 27 January 2000, Case C-23/98 Heerma, ECLI:EU:C:2000:46.

180 CJEU 17 September 2014, Case C-7/13 Skandia America (USA), ECLI:EU:C:2014:2225, para. 25; CJEU 23 March 2006, Case 210/04 FCE Bank, ECLI:EU:C:2006:196, para. 35.
} 
burdensome for exempt suppliers and would distort the neutrality of the tax according to the Advocate General. ${ }^{181}$ This burdensome consequence of the application of exemption provisions also occurs in cases where labour is 'bought' from other (independent) parties, e.g. a health care supplier hiring in medical staff. In that case, the health care supplier is confronted with non-deductible input VAT on labour, which he would not have incurred if he 'used' employed staff. It may be expected that this non-deductible VAT is charged forward in the price of the health care supplied to the patient. Hence, this hinders access to health care. The non-deductible VAT may also be a reason for a health care supplier to alter his choices, i.e. preferring a less experienced employed doctor over hiring in a more experienced selfemployed doctor. This is an example of a side effect of the application of exemption provisions for health care. See also section 7.4.3, for the assessment of the application of health care exemptions in relation to hiring in staff. The position of a director and sole shareholder is somewhat more complex, as this is technically not an employee of the business. $^{182}$

In Asscher, a case concerning fundamental Treaty Freedoms, the CJEU did not consider a director and sole shareholder as a 'worker', since the activity of this person was not carried out in the context of a relationship of subordination. ${ }^{183}$ The director was therefore treated as a self-employed person. Yet, as a result of the application of Article 10 of the EU VAT Directive, the director may still be excluded from the scope of VAT. A director and sole shareholder of a company who is not acting in his own name, on his own behalf and own responsibility and is bound by a contract of employment of the company of which he is the sole shareholder the sole member of staff, is not himself a taxable person. ${ }^{184}$

\subsubsection{Economic activities}

\section{Continuity (and) obtaining income}

Only persons carrying out an economic activity are considered taxable persons. What the concept 'economic activity' entails cannot be found in the EU VAT Directive. Article 9(1), second subparagraph of the EU VAT Directive does provide some examples: the activity of producers, traders or persons supplying services, including mining and agricultural activities and activities of the professions. Furthermore, the exploitation of tangible or intangible property for the purpose of obtaining income therefrom on a continuing basis is explicitly mentioned as an economic activity.

\footnotetext{
${ }^{181}$ A-G Opinion 14 June 2007, Case C-355/06 J. A. van der Steen v Inspecteur van de Belastingdienst UtrechtGooi/kantoor Utrecht, ECLI:EU:C:2007:352, paras. 25-26.

182 Depending on the Member States national legislation.

${ }^{183}$ CJEU 27 June 1996, Case C-107/94 Asscher v Staatssecretaris van Financiën, ECLI:EU:C:1996:251, para. 26.

184 CJEU 18 October 2007, Case C-355/06 J. A. van der Steen v Inspecteur van de Belastingdienst UtrechtGooi/kantoor Utrecht, ECLI:EU:C:2007:615.
} 
In the past, the German Bundesfinanzhof argued that obtaining income on a continuing basis is only required for the exploitation of tangible or intangible property. This argument was based on the fact that the German version of the second sentence of Article 4(2) of the Sixth Directive contained the word 'auch' (also). ${ }^{185}$ The Bundesfinanzhof was of the opinion that the exploitation of tangible or intangible property for the purpose of obtaining income therefrom on a continuing basis was an addition to the activities mentioned in the first sentence, where the continuity criterion was not mentioned. The CJEU deduced in the Renate Enkler case, from the relationship with the provision of Article 12(1) of the EU VAT Directive (for this: Article 4(3) Sixth Directive), that an activity cannot be regarded as an economic activity if it is only performed occasionally. ${ }^{186}$ The current Article 12 of the EU VAT Directive gives Member States the possibility to qualify certain activities as an economic activity nevertheless, even though they are only carried out occasionally. An 'economic activity' thus presupposes continuity. In the current language versions of the EU VAT Directive, it is clear that the exploitation of tangible or intangible property for the purpose of obtaining income therefrom on a continuing basis is mentioned in Article 9(1) as an example of an economic activity, not as an addition like the Bundesfinanzhof has argued in the past. ${ }^{187}$ Occasional activities from taxable persons also fall within the scope of the EU VAT Directive, according to the CJEU in Kostov. ${ }^{188}$ These are the occasional activities of persons qualifying as 'taxable persons' on the basis of their core activity.

That an economic activity requires continuity can clearly be understood from the context. This does not, in my opinion, immediately imply that the continuity condition is related to the purpose of earning income. The continuous exploitation of activities is not the same as continuously earning income. Already in the Hong-Kong Trade case, it became clear that a taxable person has to aim for income. In that case, the CJEU interpreted the relevant provisions on taxable persons in the Second Directive and concluded that economic activities are activities necessarily incurred for the purpose of obtaining a payment or consideration. Persons that perform activities free of charge in all cases can, hence, not qualify as a taxable person. ${ }^{189}$ This confirms that the continuity criterion refers to the performance of activities and not (also) earning income. Also, the continuous performance of activities without continuously aiming for income qualifies as an economic activity. In relation to the exploitation of property, as referred to in Article 9(1), second subparagraph, the requirement

\footnotetext{
${ }^{185}$ Also, the English, Greek, Finnish, Portuguese and Swedish language version contained a word (equal to) 'also'. See A-G Opinion 28 March 1996, Case C-230/94 Renate Enkler $v$ Finanzamt Homburg, ECLI:EU:C:1996:145, para. 14.

${ }^{186}$ CJEU 26 September 1996, Case C-230/94 Renate Enkler v Finanzamt Homburg, ECLI:EU:C:1996:352, para. 20; the argument is brought foreward more clearly by the A-G: A-G Opinion 28 March 1996, Case C-230/94 Renate Enkler v Finanzamt Homburg, ECLI:EU:C:1996:145) paras. 14-15.

${ }^{187}$ E.i. the German language version the second sentence of the second subparagraph reads: "Als wirtschaftlige Tätigkeit gilt insbesondere...", and the English version reads "...shall in particular be regarded as an economic activity".

${ }^{188}$ CJEU 13 June 2013, Case C-62/12 Kostov, ECLI:EU:C:2013:391.

${ }^{189}$ CJEU 1 April 1982, Case C-89/81 Hong-Kong Trade, ECLI:EU:C:1982:121, paras. 11-12.
} 
of continuous income seems logical, because there is in fact only one action carried out, for example, the hiring of a dwelling. Here the 'extra' requirement of the continuous aim for income in order to be regarded as economic activity seems to be in place.

\section{Health care provided free of charge}

In general, it can be expected that health care workers receive a fee for the health care provided. There is however a large group of persons and organizations involved in volunteer aid or charity. They may either operate completely free of charge or may for example be financed by fund raising or subsidies.

Health care workers or organizations solely operating free of charge will not qualify as a taxable person under the EU VAT system, as was explained in the previous section. In cases of fund raising or subsidies this may be different. The question that is relevant in that regard is whether the sums received are to be seen as a consideration for the activities carried out by the health care workers. From Article 2 of the EU VAT Directive, it follows that the supply of services or goods are only considered taxable if they are carried out for consideration.

\subsubsection{Regardless of place, purpose and results}

\section{Any place}

Health care suppliers can, regardless of their nationality and regardless of where they are established, qualify as a taxable person under the EU VAT system. Their activities will be taxable for VAT purposes if they are carried out in one of the Member States. The text of Article 9 of the EU VAT Directive reads 'in any place'. The definition is not limited to the borders of the EU. In the explanatory memorandum to the proposal for a Sixth Directive, it was noted that this is done in order to make the tax more impartial with regard to the place where undertakings may be carrying out business. ${ }^{190}$

The territorial demarcation of EU VAT takes place at the object level. The supply of goods, intra-Community acquisition of goods, importation of goods, and the provision of services are only taxed when they take place within the territory of a Member State. For the determination of the place where the said transactions are taxed, the EU VAT Directive contains a multitude of rules and fictions. Given the nature of the tax, the place of taxation would have to be the place where the goods or services are consumed. Because the place of consumption is not always simple or straightforward, to establish the place of consumption, rules and fictions are necessary.

For the qualification as a taxable person, the nationality or place of establishment is thus not relevant. Health care suppliers worldwide can become a subject of EU Value Added Tax,

\footnotetext{
190 Proposal for a Sixth Council Directive on the harmonization of legislation of Member States concerning turnover taxes, Common system of value added tax: uniform basis of assessment, COM(73) 950, 20 June 1973.
} 
provided that their activities are carried out within the EU according to the rules and fictions laid down in the EU VAT Directive. The most appealing health care transactions take place in a B2C context. The main rule for the place of supply for B2C services determines that the service takes place there where the service provider is established. ${ }^{191}$ The services of hospitals and independent doctors established outside the EU will therefore not be taxable easily under the EU VAT system. If the services are, however, provided through fixed establishments of the health care supplier within the EU, the services are taxable under EU VAT. The majority of health care transactions that fall within the scope of the EU VAT Directive will most likely be carried out by EU Health care providers. Since the taxation of health care supplies in $\mathrm{B} 2 \mathrm{C}$ situations in principle takes place there where the supplier is established, it is extremely important for the uniform application of VAT that provisions regarding the taxation of health care are implemented and interpreted in a uniform manner in all Member States. If this is not the case, patients could take advantage of differences between the application of general and reduced rates or whether or not exemption provisions are applied. Clearly, this would be a distortion of fiscal neutrality. This is a plausible risk in border regions (or 'Euregions'), ${ }^{192}$ especially since EU citizens have rights to have the costs incurred across the border reimbursed. ${ }^{193}$ This is a consequence of the fundamental (EU) principle of the freedom to provide services.

\section{Whatever purpose or result}

In section 3.5.3.2 it was illustrated that an 'economic activity' requires continuity and an aim to obtain income. However, if one reads the first subparagraph of Article 9 of the EU VAT Directive carefully, one notes that the purpose and result of the activities are irrelevant. This seems to be contradictory at first. An aim to earn income is not necessarily the same as an aim for profit. In fact, in the health care sector, a lot of organisations do not aim for profit. These so-called 'non-profit organizations' ${ }^{194}$ (NPOs) primarily seek to have their costs recovered without realising profits. Since they carry out activities on a continuous basis and aim for income, they do qualify as a taxable person under the EU VAT system, provided the other relevant conditions are fulfilled. The wording of Article 4 of the Second Council Directive was perhaps even more clear in this respect. It described a taxable person as: 'any person who independently and habitually engages in transactions pertaining to the activities of producers, traders or persons providing services, whether or not for gain'.

\footnotetext{
${ }^{191}$ Article 45 of the EU VAT Directive.

192 Hermans, H.E.G.M., 2000, Cross-border health care in the European Union: recent legal implications of 'Decker and Kohll', Journal of Evaluation in Clinical Practice, vol.6, issue 4, p. 431-439, Blackwell Science.

193 Directive 2011/24/EU of the European Parliament and the Council of 9 March 2011 on the application of patients' rights in cross border health care.

${ }^{194}$ In my view 'non-profit organisations' are institutions that mainly carry out non-profit activities in the public interest. Compare e.g. Eicker, K., 2005, Do the basic freedoms of the EC Treaty also require an amendment to the national tax laws on charities and non-profit organisations?, EC Tax Review, Volume 14, Issue 3, p. 140 and Helios, M., 2007, Taxation of non-profit organizations and EC law, EC Tax Review, Volume 16, Issue 2, p. 65.
} 
Terra and Kajus note that this indifference is consistent with the nature of the tax, as it is the (private) expenditure incurred in order to attain consumption that is relevant. It is only for technical reasons that VAT is not levied directly on consumers. ${ }^{195}$ If organizations that do not aim for profit would be excluded, all consumption that takes place as a result of the activities of such organizations would remain out of the scope of VAT. That would clearly contradict the general character of the tax.

The addition 'whatever the purpose or result of that activity' in Article 9 of the EU VAT Directive hence does not bring along an excessive reduction of the number of health care suppliers qualifying as taxable persons. This is the case for health care workers and organisations who do not seek to recover their costs and do not ask for a fee or only charge a symbolic fee. ${ }^{196}$ These persons and organisations are not considered to carry out economic activities. In short, both profit, non-profit and charitable organizations in the field of health care in principle qualify as taxable persons, except for those only operating free of charge.

\subsection{The object of taxation: taxable transactions}

In section 3.5 I discussed the definition of taxable person. It appears that the scope of that definition, is rather broad. The definition intends to cover all economic activities. ${ }^{197}$ In chapter 2, I demonstrated that the scope of definitions for health care suppliers is also rather broad. As a result, a great number of health care suppliers is potentially covered within the scope of the definition of taxable persons.

Transactions of taxable persons are only covered under the EU VAT Directive if they constitute taxable transactions. This follows from the application of Article 2 of the EU VAT Directive. Transactions are, in principle, only covered within the scope of the EU VAT Directive if they can be qualified under one of the categories mentioned in that article. ${ }^{198}$ In the following sections, I will discuss the importance and the consequences of the qualification as taxable transactions in relation to the taxability of health care transactions under positive EU Law.

\footnotetext{
195 Terra, B. and Kajus, J., 2014, A Guide to the Recast VAT Directive, Chapter 3, p. 20, IBFD, retrievable via: http://online.ibfd.org.

${ }^{196}$ See section 3.5.3.2.

197 Second Council Directive 67/228/EEC of 11 April 1967 on the harmonisation of legislation of Member States concerning turnover taxes, OJ 71, 14 April 1967, Annex A, p. 2.; Explanatory notes to Article 4 of the Proposal for a sixth Council Directive of 20 June 1973, $\operatorname{COM}(73) 950$.

198 By means of fictions, the EU VAT Directive also considers some other transactions as 'taxable transaction', e.g. fictitious intra-community supplies (Article 17 of the EU VAT Directive) and supplies for purposes other than the business (Articles 16 and 26 of the EU VAT Directive).
} 


\subsubsection{Importance of the (right) qualification as taxable transactions in the relation to the taxability of health care transactions under positive EU Law}

Article 2 of the EU VAT Directive is generally considered the key article for delineating the scope of application of EU VAT law. It refers to the subject of taxation, the transactions covered and defines the territorial scope. Article 2 distinguishes 4 types of taxable events. The most important types are the supply of goods and the supply of services. Furthermore, it distinguishes intra-community supplies of goods and importation.

In relation to the application of positive EU VAT law on health care transactions, it is important to make the correct qualification. The qualification of a health care transaction as either a supply of a good or a supply of a service is important for determining the right VAT consequences. The exemption provisions for health care, for example, only apply to health care services. In that regard, a correct qualification is thus crucial for establishing the effect of the application of positive EU VAT law on the costs of health care. Especially, in case of composite supplies, the qualification of the (elements of a) supply may be complicated (see section 3.6.2). A correct qualification of supplies is also important for other reasons, like determining the place of supply and the application of VAT rates.

\subsubsection{Application of the doctrine of composite supplies in relation to health care transactions}

It occurs that formally distinct services, which could be supplied separately, must be considered to constitute a single transaction for VAT purposes when they are not independent. This is the case if one of the elements can be regarded as constituting the principal service, while the other element is to be regarded as ancillary to the principal service. ${ }^{199}$ Especially, in cases where one of the elements qualifies within the scope of application of one of the exemption, or the application of the reduced rate, the qualification of (the elements of) supplies important for determining the actual VAT burden of the supply or supplies. For that reason, the doctrine of composite supplies is of importance in relation to the qualification of health care supplies. The doctrine of composite supplies, therefore, has a prominent role in chapter 7, where the application of VAT exemptions for intramural and extramural care are assessed in order to demonstrate the hindering effect of the application of positive VAT law in specific situations. Especially in relation to the assessment of those exemption provisions in parallel situations, in which more than one (element of a) supply is supplied to a health care recipient.

In section 7.3.2.1, I demonstrate that, in case multiple elements of supplies are supplied, for VAT purposes they can either be qualified as:

\footnotetext{
199 CJEU 16 July 2015, Case C-584/13 Mapfre asistencia and Mapfre warranty, ECLI:EU:C:2015:488, para. 50; CJEU 17 January 2013, Case C-224/11 BGŻ Leasing, ECLI:EU:C:2013:15, para. 30 and the case-law cited.
} 
1. separate supplies;

2. a principle and an ancillary supply ('absorption'); or

3. a 'sui generis' supply.

In case of multiple element health care supplies, where one of the elements is covered under an exemption provision for health care, the question arises whether the other element(s) can also come within the scope of the exemption provision. This would be the case if the second element is 'absorbed' into the principal exempt health care supply. Absorption takes place if one of the elements can be regarded as constituting the principal service, while the other element is to be regarded as ancillary to the principal service. ${ }^{200}$ The supply is, in that case, exempt as a whole.

In case the elements cannot be split and none of the elements provided can be considered to constitute the principal element of the supply, absorption cannot take place. This occurs in case two or more elements supplied by the taxable person to the customer, being a typical consumer, are so closely linked that they form, objectively, a single, indivisible economic supply, which would be artificial to split. ${ }^{201}$ The elements together must be regarded as constituting a single supply of its own nature ('sui generis'). In case of a 'sui generis' supply, it has to be assessed on its own merits for determining the VAT consequences attached to this supply. ${ }^{202}$ If a multiple element health care supply, where one of the elements is covered under an exemption provision for health care, constitutes a 'sui generis supply', it is questionable whether that supply can be covered under a medical exemption provision. In Deutsche Bank, the CJEU held that the principle of fiscal neutrality cannot extend the scope of an exemption in the absence of clear wording. ${ }^{203}$ The exemption provisions, after all, have to be interpreted in a strict manner. It is therefore, in my view, not very likely that a 'sui generis' supply will come within the scope of application of a health care provision (see also section 7.3.2.1).

As indicated, the assessment of the application of exemption provisions in chapter 7 demonstrates that the application of the doctrine of composite supplies plays an important role in parallel situations of health care supplies. In that chapter, I demonstrate why, in my view, the doctrine should only play a role in case parallel supplies are made from the same health care supplier to a health care recipient (parallel one-on-one situations) and not in case the parallel supplies are made by different (health) care suppliers.

\footnotetext{
${ }^{200}$ CJEU 16 July 2015, Case C-584/13 Mapfre asistencia and Mapfre warranty, ECLI:EU:C:2015:488, para. 50; CJEU 17 January 2013, Case C-224/11 BGŻ Leasing, ECLI:EU:C:2013:15, para. 30 and the case-law cited.

${ }^{201}$ CJEU 27 October 2005, Case C-41/04 Levob Verzekeringen and OV Bank, ECLI:EU:C:2005:649, para. 23.

${ }^{202}$ CJEU 19 July 2012, Case C-44/11 Deutsche Bank, ECLI:EU:C:2012:484, para. 43.

${ }^{203}$ CJEU 19 July 2012, Case C-44/11 Deutsche Bank, ECLI:EU:C:2012:484, para. 45; CJEU 13 March 2014, Case C366/12 Klinikum Dortmund, ECLI:EU:C:2014:143, para. 40.
} 
At this point it is also useful to note the following. The application of the doctrine of composite supplies is used for the qualification of supplies as a result of the application of Article 2 of the EU VAT Directive. Therefore, the application of the doctrine of composite supplies in my view precedes the application of exemption provisions for health care (in Articles 132(1)(b) and 132(1)(c) of the EU VAT Directive). It appears, however, that the CJEU, in cases on the application of exemption provisions for health care often overlooks the application of the doctrine of composite supplies, while it immediately 'jumps' to the application of the exemption provision. It occurs, for example, that the application of the composite supply doctrine is in line with the application of the 'closely related' test, which has to be undertaken in order to establish whether a separate element of a supply can come within the scope of the exemption provision for intramural health care (see section 7.3.2.1).

\subsubsection{For consideration}

An important criterion for the qualification as a taxable transaction is that the supply is made for consideration. In order for a supply to be taxable, there must be a direct link between the service provided and the consideration received. ${ }^{204}$ In one of the key cases on the definition of consideration, the CJEU held that it requires a legal relationship between the provider and the recipient of the supplier, pursuant to which there is a reciprocal performance. That is, the remuneration is received by the provider and constitutes the value actually given in return for the supply to the recipient. ${ }^{205}$

In a case on health care services, the CJEU held that the payment of a lump sum, that was charged for the permanent availability of a health care supplier, who would health care services only if and at the time this was required by the patient, constitutes consideration. ${ }^{206}$ From this case, it follows that, for a payment to constitute consideration, the actual amount of care provided is not decisive.

In the field of health care, it often occurs that subsidies are granted to health care suppliers. In case of subsidies, it has to be determined whether there is a direct link between that subsidy and the goods or services provided by the beneficiary. Van Doesum, Van Kesteren and Van Norden note in this regard that, for the determination of a direct link between a service and a subsidy, one of the aspects that needs to be tested is whether there is an identifiable consumption by an identifiable consumer. ${ }^{207}$ Only in that case can there be a supply for consideration which is subject to VAT. For health care suppliers, a subsidy that is considered consideration for a taxable supply, can have negative consequences. It may lead to a situation where a health supplier has to pay the VAT he is liable for out of the subsidy

\footnotetext{
204 CJEU 5 February 1981, Case C-154/80 Staatssecretaris van Financiën v Coöperatieve Aardappelenbewaarplaats, ECLI:EU:C:1981:38, para. 12.

${ }^{205}$ CJEU 3 March 1994, Case C-16/93 Tolsma v Inspecteur der Omzetbelasting, ECLI:EU:C:1994:80, para. 14.

${ }^{206}$ CJEU 27 March 2014, Case C-151/13 Le Rayon d'Or, ECLI:EU:C:2014:185, para. 38.

${ }^{207}$ Van Doesum, A.J., Van Kesteren, H.W.M., Van Norden, G.J., 2016, Fundamentals of EU VAT Law, Kluwer Law International, p. 132.
} 
amount, and, as a result, a smaller part of the subsidy is left to be spent on health care activities. $^{208}$

\subsubsection{Consequences of the qualification as taxable transactions for health care transactions}

Transactions of taxable persons are only covered within the scope of the EU VAT Directive if they constitute taxable transactions. Article 2 of the EU VAT Directive thus delineates the scope of the Directive. Only the taxable transactions of a health care supplier, qualifying as a taxable person under Article 9 of the EU VAT Directive, are potentially taxed with VAT. As an exception, for the taxable event qualified as 'importation', it is not required that it is carried out by a taxable person. ${ }^{209}$

As indicated in section 3.2.4, the right to deduct input VAT cannot be enjoyed by persons acting in the capacity of a non-taxable person. Within the EU VAT system, the subject and the object of taxation are interrelated. Activities of a non-taxable person are non-taxable activities, ${ }^{210}$ and vice versa, a taxable person performing non-taxable activities is acting as a non-taxable person with regard to those activities. This entails that a taxable person is, in principle, not entitled to deduct input VAT on acquired goods and services that are used for the purpose of non-taxable activities.

\subsection{Reduced rates}

The previous sections concerned the delineation of the scope of the EU VAT Directive in terms of the persons and transactions covered. If a transaction is taxable, it is - as a general rule - taxed with VAT, according to the general VAT rate. ${ }^{211}$ Article 98 of the EU VAT Directive contains a provision on the application of reduced rates. Member States may apply either one or two reduced rates. The reduced rate may, however, only apply to supplies of goods and services listed in Annex III of the EU VAT Directive. The reduced rate may not be less than $5 \% .{ }^{212}$ The application of a reduced rate constitutes an exception to the principle that the standard rate applies and, therefore, has to be interpreted - like exemptions - in a strict manner. ${ }^{213}$

In section 3.4, I indicated that reduced rates have as their purpose to make certain goods regarded as being particularly necessary - more accessible for the final consumer who

\footnotetext{
208 Ibid.

${ }^{209}$ Article 2(1)(d) of the EU VAT Directive.

${ }^{210}$ Except for e.g. the importation of goods (Article 2(1)(d) of the EU VAT Directive).

${ }^{211}$ Article 96 of the EU VAT Directive.

${ }^{212}$ Article 98 of the EU VAT Directive.

213 CJEU 9 March 2017, Case C-573/15 Oxycure Belgium, ECLI:EU:C:2017:189, para. 35; CJEU 17 January 2013, Case C-360/11 Commission vs. Kingdom of Spain, ECLI:EU:C:2013:17, paras. 18-19; CJEU 18 March 2010, Case C-3/09 Erotic Center, ECLI:EU:C:2010:149, para. 15.
} 
ultimately pays the burden of VAT. ${ }^{214}$ I concluded in section 3.4 that, although the EU VAT system is not based on the ability to pay principle, in relation to health care - with the application of exemption provisions for health care and reduced rates for e.g. pharmaceutical products and medical equipment - it does value this principle to some extent.

An important difference between the application of reduced rates and the application of exemptions is that a supplier is entitled to deduct input VAT in relation to supplies that are subject to reduced rates. Therefore, the application of reduced rates brings along fewer side effects (i.e. bias to self-supply and cascading of VAT). The application of reduced rates may, however, bring with it other practical problems. Annex III, for example contains a reduced rate for medical equipment. Due to technological developments, new innovative medical products are constantly being introduced on the market. The exact purpose and features can often only be explained by experts in this field. It happens in practice that suppliers of those products, as well as the tax authorities, lack sufficient (medical technical) knowledge to establish the applicable VAT rate. This may result in increased compliance costs for suppliers, which will be passed on to their recipients. As a result, such increased costs constitute an impediment to the accessibility of health care.

In relation to health care transactions, both the application of reduced rates and the application of exemptions have as their purpose to make certain health care (related) supplies more accessible to individuals. I expect that the application of reduced rates comes closer to achieving that aim, as its direct effect (reduced taxation, but still a right to deduct input VAT) hinders access to health care less than the application of exemption provisions and causes fewer side effects. In chapter 8 , I discuss the application of reduced rates as an alternative to the application of VAT exemptions on health care supplies.

\subsection{Exemptions}

\subsubsection{General}

A significant number of health care transactions are exempt, others qualify for reduced rate as described in Annex III of the EU VAT Directive. The latter contains, inter alia, pharmaceutical products and medical equipment. The exemptions for health care transactions are exemptions under the category 'exemptions for activities in the public interest'. They do not result in deductions of input VAT.

I already referred to the fact that the application of reduced rates and exemptions constitute an exception to the general principle that all supplies of goods and services are taxed against the standard VAT rate. An exemption is firstly an exemption because the outgoing supply remains untaxed. Secondly, - and this is different compared to the application of reduced rates - if an exemption applies, the supplier is not entitled to the right to deduct input VAT

${ }^{214}$ CJEU 17 January 2013, Case C-360/11 Commission vs. Kingdom of Spain, ECLI:EU:C:2013:17, para. 48; CJEU 9 March 2017, Case C-573/15 Oxycure Belgium, ECLI:EU:C:2017:189, para. 22. 
(section 3.2.4). This, as such, distorts the system neutrality (see section 3.3). According to Van Hilten, exemption provisions are the most distortive elements of the VAT system. ${ }^{215}$ She refers in that regard to effects such as increased costs, cascading and distortions of neutrality. ${ }^{216}$

It is not always clear what the historical purpose of an exemption provision is. ${ }^{217}$ In relation to the application of exemption provisions for intramural and extramural health care in Articles 132(1)(b) and (c) of the EU VAT Directive, the CJEU made clear that they both aim at reducing the costs of medical care and making that care more accessible to individuals. ${ }^{218}$ The CJEU even extended this accessibility argument to the application of other exemption provisions. ${ }^{219}$ The reasoning of the CJEU in relation to the purpose of exemptions for medical care has never been justified from a human rights perspective. I demonstrated in chapter 4 that the intended purpose of the exemption provisions for health care corresponds to the principle of access to health care. See section 6.2.1 on the aim of exemption provisions for health care.

Exemptions are included under Title IX of the EU VAT Directive. The term exemption already suggests that, without its application, a certain transaction would be taxed. Transactions are exempt if they are explicitly mentioned in one of the exemption provisions included in the EU VAT Directive. The EU VAT Directive contains exemptions with a right to deduct (in some Member States referred to as 'zero rated supplies') and exemptions without a right to deduct. The first type of exemption is used to ensure the application of the destination principle within the European internal market. The supplies by a taxable person supplying a good to another taxable person within the EU are exempt under Article 138 of the EU VAT Directive. The supplier in that case is entirely relieved of his VAT burden, because he can deduct the VAT charged to him on his purchases and investments. Exemptions without a right to deduct do not offer that possibility.

\subsubsection{Types of exemptions}

The EU VAT Directive contains different types of exemptions under Title IX: 'exemptions for certain activities in the public interest', 'exemptions for other activities', 'exemptions for intra Community transactions', 'exemptions related to international transport and 'exemptions for

\footnotetext{
${ }^{215}$ Van Hilten, M.E., 2010, Over de neutraliteit van de omzetbelasting en het hellend vlak van de uitzonderingen, Kluwer, p. 29.

216 Ibid.

${ }^{217}$ Idem, p. 32-33.

${ }^{218}$ See inter alia cases CJEU 8 June 2006, Case C-106/05 L.u.P., ECLI:EU:C:2006:380, para. 25; CJEU 6 November 2003, Case C-45/01 Dornier, ECLI:EU:C:2003:595, paras. 43 and 48; CJEU 10 September 2002, Case C-141/00 Kügler, ECLI:EU:C:2002:473, para. 29; CJEU 20 November 2003, Case C-212/01 Margarete Unterpertinger, ECLI:EU:C:2003:625, para. 41; see also CJEU 1 December 2005, Joined Cases C-395/04 and C-394/04 Ygeia, ECLI:EU:C:2005:734, para. 24; A-G Opinion 10 September 2009, Case C-262/08 CopyGene, ECLI:EU:C:2009:541, para. 33.

${ }^{219}$ CJEU 5 October 2016, Case C-412/15 TMD, ECLI:EU:C:2016:738, para. 30.
} 
transactions relating to international trade'. Only the first two types do not give rise to a deduction of input VAT. The other exemptions mentioned do give rise to input VAT deductions and can hence be compared to 'zero rates' as applied in some Member States.

The exemptions 'in the public interest' aim at relieving certain sectors, for instance the medical sector, education and sports. The 'other exemptions' are the more technical exemptions (exemptions on financial services, real estate transactions, etc.). It is interesting to see that the formulation of the exemption provisions differs in a way that one provision puts more emphasis on the object of the transaction, while the other puts more emphasis on the subject of taxation (the taxable person).

\section{Objective exemption provisions}

Provisions that describe certain transactions that must be exempt, disregarding the qualities of the supplier, are objective exemption provisions, as they relate to the object. Examples of objective exemptions are the supply of human organs, blood and milk, most financial services, leasing or letting of immovable property, and the supply of 'new' land; etc. The definitions of the majority of the exemptions in the public interest seem to be more of a subjective nature, since there is a strong emphasis on the capacity or quality of the supplier. In order to ensure fiscal neutrality, it would perhaps be desirable if exemptions were only linked to the nature of the transactions and not to the person supplying those transactions. In such a scenario, a situation results where supplies of goods or services which are similar, and which are therefore in competition with each other, are treated in the same manner for VAT purposes.

The various definitions are interesting if we keep in mind that the value added tax focuses on the taxation of supplies of goods and services, intra-community acquisitions and imports. From a system perspective, one would expect the exemptions to solely describe the object.

\section{Subjective exemption provisions}

The exemptions for health care in Articles 132(1)(b) and 132(1)(c) of the EU VAT Directive are of a rather subjective nature. They both contain a reference to the status of the supplier. Article 132(1)(b) of the EU VAT Directive explicitly refers to hospitals, centers for medical treatment, etc. Article 132(1)(c) of the EU VAT Directive contains an indirect reference to the supplier. It refers to care that is rendered in the exercise of (medical and paramedical) professions, which implies that only certain suppliers are capable of providing that care.

A completely subjective exemption provision would describe a certain supplier and exempt all the services or goods supplied by this supplier. The EU VAT Directive does not contain such exemption provisions because most provisions start with phrases such as "the supply of..." or "transactions..." followed or preceded, in most cases, by a description of a supplier. The legislator seems to have followed an objective approach for exempting certain subjects. According to Denie, it follows from the structure of the law and the 'competition neutrality' 
that transactions should be exempted and not the person carrying them out. ${ }^{220}$ From a practical point of view it is after all not desirable to define two opposites in one law. Despite these potential impracticalities, exemptions in the public interest that are contained in the EU VAT Directive seem to have a strong subjective influence, although they are formulated as an objective exemption.

A good example of an exemption provision where the subjective element is dominant is the exemption for services by the public postal services. It appears from the text of that provision that its application has as its purpose exempting the public postal service in general, rather than exempting some services in particular. In Commission vs. Germany, the CJEU compared language versions of the exemption provision for postal services and concluded that the term 'public postal services' clearly refers to the actual organizations which engage in the supply of the services to be exempted. Thus, for a body to be exempted for its services, the body has to be the 'public postal service' of a Member State. According to the CJEU, the exemption could not be applied by bodies which pursue the same objective, as it would not be regarded as 'public postal services'. Following this judgment, the exemption for postal services could thus not be applied by German railway and airline companies in relation to their services rendered to Deutsche Post in accordance with the law. Later, in TNT Post UK Ltd., the CJEU seems to objectify the subjective exemption for postal services to a certain extent, but the exemption is still reserved for operators, public or private, who undertake to provide, in a Member State all or part of the national postal service. The objectification was thus only limited, while the emphasis is still on the qualities of the supplier.

The assessment of the application of the exemption for extramural care in basic situations shows that professional qualities of the health care supplier are a decisive criterion for the application of that provision (section 7.2.3). The exemption provision for extramural care in Article 132 (1)(c) of the EU VAT Directive, as such, does not mention a supplier but refers to the exercise of (para)medical professions, as defined by the Member States. I concluded that the reference to the professional qualifications of a service provider is understandable if compared to definitions for health care and health care suppliers used in practice by international organizations (i.e. the OECD and the WHO). In chapter 2, I demonstrated how the presence of a sufficient level of knowledge serves as a delineation criterion for determining the difference between health care services and other health services. In other words, I concluded that the quality of a service provider (in terms of professional knowledge and defined on a national level) is a criterion that is used to establish whether the supply made by that provider can be considered health care (see sections 2.2.1 and 2.2.4). Moreover, the requirement of sufficient professional knowledge ensures that services provided by unorthodox doctors or charlatans do not fall within the scope of the exemption

${ }^{220}$ Denie, A.H.R.M., 1987, De overheid in de omzetbelasting, Kluwer. 
provision for extramural care. This is completely justifiable on basis of the aim of the medical exemption provisions: making health care more accessible to individuals.

The exemption provision for intramural care in Article 132(1)(b) of the EU VAT Directive does not refer to medical or paramedical professions. It refers to public bodies - or similar bodies - hospitals, centres for medical treatment or diagnosis and other duly recognized establishments of a similar nature. If hospital or medical care is supplied by one of the qualified bodies or establishments, the hospital or medical care they provide may come within the scope of the exemption provision. The CJEU held in this regard that the exemption provision for intramural health care covers hospital and medical care carried out within a 'hospital environment', while the exemption for extramural health care covers medical care supplied outside such a framework, both at the private address of the person providing the care and at the patients home or at any other place. ${ }^{221}$ The criterion for drawing a distinction between those two provisions is thus less the nature or substance of the service than the place where it is provided. ${ }^{222}$ This is remarkable in my view. To apply the exemption provision for extramural health care, the professional qualifications of the health care supplier are decisive, whereas, in case of intramural care, the qualifications of the person actually providing the health care (i.e. the doctor employed by the hospital) are disregarded for the application of this exemption provision. If the place of the provision of the health care services is the only reason to maintain different exemption provisions, I do not see why their criteria for application and the scope of application should differ. The aim of health care exemptions, as well as the principle of access to health care, after all, do not make a distinction between intramural and extramural care. It may be that the legislator, for reasons of feasibility of the VAT system, assumed that all health care provided by establishments or bodies qualifying under the exemption provision for intramural care is in fact carried out by health care professionals with sufficient professional knowledge. Such an aim to keep the system feasible, in my view, is a good idea, as long as the criteria do not lead to differences in the scope of application. At this point, I refer to the assessment of the exemption provisions in chapter 7, where it is shown that, under positive EU law, the criteria and the scope of application for extramural and intramural health care differ.

From a legal neutrality point of view - equal products should be taxed against an equal percentage of VAT - objective exemptions could help to ensure equal treatment with regard to the supply of goods. For services, and in particular medical services, the equality or similarity is mainly determined by the quality of the supplier providing the service, thus here I tend to be in favour of subjective exemptions, although a mix between the different forms would probably be the best option.

\footnotetext{
${ }^{221}$ CJEU 10 September 2002, Case C-141/00 Kügler, ECLI:EU:C:2002:473, para. 36.

${ }^{222}$ CJEU 6 November 2003, Case C-45/01 Dornier, ECLI:EU:C:2003:595, para. 47.
} 


\subsubsection{Effects of the application of exemptions}

The direct effect of the application of exemption provisions is that the supplies that are covered under such an exemption remain untaxed. Another direct effect is that the supplier is not entitled to deduct input VAT on the goods and services incurred in relation to the exempt output suppliers. This follows directly from the application of Article 168 of the EU VAT Directive. As indicated, the application of exemption provisions, as a result, distorts the system neutrality of EU VAT.

At this point I refer to chapter 6 for an assessment of the application of exemption provisions from a conceptual point of view in order to establish how the application of exemptions hinders the principle of access to health. Chapter 7 contains a comprehensive assessment of the exemption provisions on health care in order to show in which situations the application of exemption provisions hinders access to health care. The assessment will show that the application of exemption provisions - which are distortive - not only distort system neutrality, but also bring with them many side effects (i.e. hidden VAT, cascading of VAT and potential changes in behaviour for suppliers or health care recipients).

\subsection{Conclusion}

In this chapter I discussed some fundamental principles and characteristics underlying the EU VAT system. In that regard, this chapter serves as part of the legal framework of this research on the application and hindering effect of positive EU VAT law on health care transactions. Such a framework is necessary to be able to comment on the hindering effect from a conceptual point of view. I showed in this chapter that the scope of EU VAT is rather broad and, as a result, potentially covers a significant number of health care transactions. A part of the health care activities is, however, outside the scope of VAT as a result of the application of exclusions. This may be the case in Member States where public health care providers provide public health care.

I also showed that the aim of VAT in some respects corresponds with the purpose of the principle of access to health care. This is the case for the application of exemption provisions for health care and the application of the reduced rates. They both constitute exceptions to the general principle that all supplies of goods and services by a taxable person are taxed against the standard VAT rate. The application of reduced rates seems to come closest to adhering to that aim, as the VAT on supplies is reduced as a result of the reduced rates, while the right to deduct remains intact. This is different for the application of the distortive exemption provisions. The application of exemption provisions brings along many side effects, as a result of which access to health care is still hindered.

In the following chapter, I will explore the human right to health and, more in particular, the issue of accessibility to health care. This is necessary to be able to establish whether the reasoning of the CJEU in relation to the purpose of exemption - i.e. making health care more accessible to individuals by reducing the costs of that health care - can be justified. 
Once this is established, I will investigate in chapter 5 whether the principle of access to health - like the CJEU suggests - has to be taken into account while applying EU law. 


\section{The principle of access to health care}

\subsection{Introduction}

The 'principle'223 of access to health care is often used by the Court of Justice EU ('CJEU') as an argument to apply a VAT exemption for health care. From the CJEU case law on VAT and health care, I concluded that the CJEU maintains the principle of access to health care as a standard in relation to the application of positive EU VAT law (see also section 1.1). Moreover, the CJEU seems to indicate that the imposition of EU VAT reduces access to health care and even hinders access in particular situations. This principle of access to health care is not defined in the context of EU VAT, nor is it reflected in the legislative history relating to the application of the EU VAT Directive. Nevertheless, as a result of the ex tunc effect of CJEU decisions on the interpretation of EU VAT Directive provisions, access to health care and the need to reduce costs of health care is to be treated as a justification for the application of VAT exemptions and reductions, at least in relation to positive EU VAT law.

I share the view of the CJEU that imposing a VAT burden on health care transactions reduces the accessibility of those transactions for consumers. Likewise, I accept that reductions of the VAT burden - i.e. reduced VAT rates, VAT exemptions and exclusions - can promote access to those transactions. The latter can be justified, for example, by the ability to pay principle. However, it appears that the CJEU interprets positive VAT law in such a way that account is taken of accessibility of health care. Since I have not found a basis for the application of this principle in positive EU VAT law, nor in any preparatory works of the EU VAT Directive, I chose to explore this principle from a human rights perspective and discovered that access to health care is, in that field, recognized as part of the more encompassing right to health.

In recent years, the right to health has gained more importance. It has been recognized in a number of human rights instruments and constitutions. ${ }^{224}$ The right to health is not to be confused with the right to be healthy. It is a right that contains both freedoms and entitlements ensuring the enjoyment of a variety of facilities, goods, services, and conditions that are necessary for the realization of the highest attainable standard of health. ${ }^{225}$ In 2006 , the 25 Health Ministers invited the European Institutions to ensure that their work will protect the overarching values of universality, access to good quality care equity and

\footnotetext{
${ }^{223}$ Access to health care is not explicitly recognized as a 'principle' in the EU VAT Directive or in any preparatory acts. I refer to access to health care as a 'principle', as I concluded from the considerations made by the CJEU that it takes account of the accessibility to health care while interpreting positive EU VAT law.

${ }^{224}$ In 2006 over 100 constitutional provisions included the right to health or health-related rights; Hunt, P., 2006, The Human Right to the Highest Attainable Standard of Health: New Opportunities and Challenges, Transactions of the Royal Society of Tropical Medicine and Hygiene, 100: 603-607, retrievable via: http://www.essex.ac.uk/hrc/research/projects/rth/docs/Paul_hunt_leading_article.pdf.

${ }^{225}$ UN Committee on Economic, Social and Cultural Rights (CESCR), General Comment No. 14: The Right to the Highest Attainable Standard of Health (Art. 12 of the Covenant), 11 August 2000, paras. 8-9.
} 
solidarity when drafting proposals concerning health services. ${ }^{226}$ In 2009 , together with the adoption of the Lisbon Treaty, the Charter of Fundamental Rights of the European Union entered in to force. This legally binding Charter contains a provision that explicitly refers to the right of access to health care. ${ }^{227}$ It appears that the argument of access to care is also used in relation to provisions in the Treaty on the Functioning of the European Union (TFEU).

In relation to this research on the interrelationship between VAT and health care, it is interesting to note that the right to health is considered to consist of several crucial elements, including the financial accessibility (affordability) of health care. ${ }^{228}$ It is, in particular, the element of financial accessibility that seems to be reflected in the reasoning of the CJEU in relation to the application of VAT exemptions on health care activities. In this chapter I will elaborate on the substance and normative content of the human right to health in order to see whether it supports the current EU VAT treatment of health care. I will also discuss the scope of the right to health in relation to positive EU VAT law.

\subsection{The human right to health in an international context}

The right to health is recognized in international human rights law. It is a fundamental human right to which increasing attention has been paid in recent years, inter alia, by human rights treaty monitoring bodies, the World Health Organization and the Human Rights Council. ${ }^{229}$ The right to health falls under the category of economic, social and cultural rights. This category is generally distinguished from the civil and political rights, a category of rights which is contrary to the former category, often invoked in national judicial proceedings and international complaint mechanisms which are designed to protect these rights on an international level. ${ }^{230}$ Harrington and Stuttaford noted that there has been a remarkable transformation in the last decade: many scholars now labour to develop the normative content, conceptualize the application and evaluate the right to health from the point of view of moral philosophy and theories of justice after having been long neglected. ${ }^{231}$

The right to health is a human right. Human rights are rights that a person has because he or she is a human being. The human right to health imposes binding obligations on the States that have ratified treaties containing a right to health. ${ }^{232}$ These rights apply to the

\footnotetext{
${ }^{226}$ Council Conclusions on Common values and principles in European Union Health Systems, OJ C 146, 22 June 2006.

${ }^{227}$ Article 35 of the Charter of Fundamental Rights of the European Union of 30 March 2010, 2010/C 83/02.

${ }^{228}$ UN Committee on Economic, Social and Cultural Rights (CESCR), General Comment No. 14: The Right to the Highest Attainable Standard of Health (Art. 12 of the Covenant), 11 August 2000, para. 12.

${ }^{229}$ UN Office of the High Commissioner for Human Rights (OHCHR), Fact Sheet No. 31, The Right to Health, June 2008, p. 1, retrievable via: http://www.ohchr.org.

${ }^{230}$ Toebes, B.C.A., 1999, The Right to Health as a Human Right in International Law, Intersentia/Hart, p. 6.

${ }^{231}$ Harrington, J. and Stuttaford, M. (Eds.), 2010, Global Health and Human Rights: legal and philosophical perspectives, Routledge, p. 1.

232 Toebes, B.C.A, Hartlev, M., Hendriks, A., Herrmann, J.R., 2012, Health and Human Rights in Europe, Intersentia, p. 97.
} 
relationship between human beings and States. ${ }^{233}$ This implies that these rights, in principle, cannot be invoked among human beings. Furthermore, the rights can only be invoked in the relationship between persons and States, if the latter is a State Party to the human rights treaty at issue. Not all aspects of the human right to health can be invoked against States. A person's health status is not solely dependent on health facilities that can be offered to that person by a State. In that regard it has been discerned that a right to health has to be distinguished from a right to be healthy (see also section 4.1). ${ }^{234}$

\subsubsection{Recognition of the right to health in international human rights law}

The 1946 Constitution of the World Health Organization ${ }^{235}$ for the first time secured a right to health. According to the preamble to the Constitution "[t]he enjoyment of the highest attainable standard of health is one of the fundamental rights of every human being without distinction of race, religion, political belief, economic or social condition". The adoption of the right in the WHO Constitution has been considered an important point of departure for the further elaboration of a right to health in human rights documents. ${ }^{236}$ Later, In the Universal Declaration of Human Rights of 1948 ('UDHR'), ${ }^{237}$ a right to "a standard of living adequate for the health and well-being of himself and of his family" was enshrined. ${ }^{238}$

The UDHR is part of the so-called 'International Bill of Human Rights', together with the International Covenant on Economic, Social and Cultural Rights of 1966 ('ICESCR') and the International Covenant on Civil and Political Rights ('ICCPR'). ${ }^{239}$ In contrast to the UDHR, the two covenants are legally binding on the States which have accepted the covenants by ratification or accession. ${ }^{240}$ The ICESCR ${ }^{241}$ is considered the central instrument of protection for the right to health. ${ }^{242}$ In Article 12 (1) of the ICESCR, the right to health is defined as "the right of everyone to the enjoyment of the highest attainable standard of physical and mental health". The right to health in the ICESCR will be discussed in more detail in section 4.2.2.

\footnotetext{
233 Donnelly, J., 2013, Universal Human Rights in Theory and Practice, Cornell University Press, p. 10; Mann, J. M. et al., 1994, Health and Human Rights, Health and Human Rights, Vol. 1, No. 1 Autumn, p. 10.

${ }^{234}$ UN Committee on Economic, Social and Cultural Rights (CESCR), General Comment No. 14: The Right to the Highest Attainable Standard of Health (Art. 12 of the Covenant), 11 August 2000, paras. 8-9.

${ }^{235}$ The WHO Constitution was adopted by the International Health Conference held in New York from 19 June to 22 July 1946, signed on 22 July 1946 by the representatives of 61 States (Off. Rec. Wld Hlth Org., 2, 100), and entered into force on 7 April 1948.

236 Toebes, B.C.A, Hartlev, M., Hendriks, A., Herrmann, J.R., 2012, Health and Human Rights in Europe, Intersentia, p. 87.

${ }^{237}$ UN General Assembly, Universal Declaration of Human Rights, 10 December 1948, 217 A (III), retrievable via: http://www.un.org/en/documents/udhr.

${ }^{238}$ Article 25 of the Universal Declaration of Human Rights.

${ }^{239}$ UN Office of the High Commissioner for Human Rights ('OHCHR'), Fact Sheet No. 2 (Rev.1), The International Bill of Human Rights, June 1996, No. 2 (Rev.1), retrievable via: http://www.ohchr.org.

${ }^{240}$ Idem, p. 8.

${ }^{241}$ UN General Assembly, International Covenant on Economic, Social and Cultural Rights, 16 December 1966, United Nations, Treaty Series, vol. 993, p. 3, entered into force on 3 January 1978, retrievable via: http://www.ohchr.org/ (hereafter: 'ICESCR').

242 UN Office of the High Commissioner for Human Rights ('OHCHR'), Fact Sheet No. 31, The Right to Health, June 2008, p. 9, retrievable via: http://www.ohchr.org.
} 
The right to health is later, in various ways, addressed in several international and regional human rights instruments such as the Convention on the Rights of the Child (1989) and the International Convention on the Protection of the Rights of All Migrant Workers and Members of Their Families (1990). The right is also recognized in several regional instruments and in numerous constitutions. ${ }^{243}$ See section 4.3 for a discussion on the right (of access) to health in an EU context.

Nevertheless, there is continuous attention for the further development and clarification of the right to health. The Commission on Human Rights created a mandate of Special Rapporteur on the right of everyone to the enjoyment of the highest attainable standard of physical and mental health. The Rapporteur presents, inter alia, annual reports to the Human Rights Council and the General Assembly, monitors the situation of the right to health around the world, communicates with States and other parties with regard to alleged cases of violation and promotes the full realization of the right to health through dialogue with relevant actors. ${ }^{244}$

\subsubsection{Definition of the right to health in the ICESCR}

As indicated, the right to health is explicitly recognized in the ICESCR. The ICESCR is an international human rights treaty that contains a number of economic, social and cultural human rights that bring about obligations for State Parties to this treaty. According to Kooijmans, the ICESCR presupposes an active government policy. The ICCPR - which is like the ICESCR, and also part of the International Bill of Human Rights - on the other hand requires direct application. The human rights in the ICESCR are not directly applicable. ${ }^{245}$ Kooijmans describes the rights in the ICCPR as obligations leading to results, whereas the rights in the ICESCR are obligations to perform to the best of one's ability. ${ }^{246}$ The realization of the right to health is monitored by independent experts (special rapporteurs) that are appointed by the Human Rights Council (see also section 4.2.1). Article 12 of the ICESCR defines the right to health as follows:

"Article 12

1. The States Parties to the present Covenant recognize the right of everyone to the enjoyment of the highest attainable standard of physical and mental health.

2. The steps to be taken by the States Parties to the present Covenant to achieve the full realization of this right shall include those necessary for:

\footnotetext{
243 Idem, p. 9-10; also WHO Fact sheet no. 323 of November 2013, The Right to Health, retrievable via: http://www.who.int. UN Committee on Economic, Social and Cultural Rights (CESCR), General Comment No. 14: The Right to the Highest Attainable Standard of Health (Art. 12 of the Covenant), 11 August 2000.

${ }^{244}$ UN Office of the High Commissioner for Human Rights ('OHCHR'), Fact Sheet No. 31, The Right to Health, June 2008, retrievable via: http://www.ohchr.org.

${ }^{245}$ Kooijmans, P.H., 2002, Internationaal publiekrecht in vogelvlucht, Kluwer, Deventer, 9th edition, p. 359.

246 Ibid.
} 
(a) The provision for the reduction of the stillbirth-rate and of infant mortality and for the healthy development of the child;

(b) The improvement of all aspects of environmental and industrial hygiene;

(c) The prevention, treatment and control of epidemic, endemic, occupational and other diseases;

(d) The creation of conditions which would assure to all medical service and medical attention in the event of sickness."

The definition of the right to health shown above is broad and includes freedom and entitlements. A better understanding of the broad Right to Health can be found in the comments provided by the Committee on Economic, Social and Cultural Rights ('CESCR'). The CESCR issues 'General Comments' on the interpretation of the provision of the Covenant. General Comments are not legally binding ('soft law'), but they are increasingly being referred to in legal scholarship and practice. According to Toebes, they can be considered influential and authoritative documents that can supersede the status of mere soft law. ${ }^{247}$

The CESCR is a body of independent experts, responsible for the monitoring functions that are assigned to the United Nations Economic and Social Council (ECOSOC) under Part IV of the Covenant. ${ }^{248}$ State Parties to the Covenant are obliged to submit reports to the Committee regularly on the implementation of the rights. Since May 2013, the CESCR has the competence to receive and consider communications from individuals who claim that their rights under the covenant have been violated. ${ }^{249}$

General Comment 14 provides an extensive and authoritative ${ }^{250}$ interpretation of the right to health defined in Article 12 ICESCR. At a fist glance the definition of the right resembles the definition in the preamble to the 1946 WHO Constitution. According to General Comment 14, the Third Committee of the UN General Assembly did not take over the definition in the preamble to the WHO Constitution, because the Right to Health in Article 12 of the Covenant should not be confined to the right to health care. It is broader and it also includes the right to the underlying determinants of health "such as food and nutrition, access to safe and potable water and adequate sanitation, safe and healthy working conditions, and a healthy environment". 251

Compared to the definition 'right to health care', the wording of 'right to health' may be considered to imply a right to be healthy as it seems to refer to the status of a person's

\footnotetext{
247 Toebes, B.C.A, Hartlev, M., Hendriks, A., Herrmann, J.R., 2012, Health and Human Rights in Europe, Intersentia, p. 92.

${ }^{248}$ Economic and Social Council resolution 1985/17 of 28 May 1985.

249 Optional Protocol to the International Covenant on Economic, Social and Cultural Rights, entered into force on 5 May 2013; Information retrievable via: http://www.ohchr.org/EN/HRBodies/CESCR.

250 Harrington, J. and Stuttaford, M. (Eds.), 2010, Global Health and Human Rights: legal and philosophical perspectives, Routledge, p. 2.

${ }^{251}$ UN Committee on Economic, Social and Cultural Rights (CESCR), General Comment No. 14: The Right to the Highest Attainable Standard of Health (Art. 12 of the Covenant), 11 August 2000, para. 4.
} 
wellbeing. ${ }^{252}$ General Comment 14 is very clear on this matter: "the right to health is not to be understood as a right to be healthy". Although it can be required from a State to provide for the necessary facilities and equal access thereto, a State cannot ensure good health. The ICESCR therefore describes the right to health as "a right to the enjoyment of a variety of facilities, goods, services and conditions necessary for the realization of the highest attainable standard of health". ${ }^{253}$ In her study (1999), Toebes gives three reasons to justify the term 'right to health': "1) the fact that the term is best in line with the character of the international treaty provisions, 2) the fact that this term is most commonly used at the international level, and 3) the importance of recognizing not only a right to health care, but also a right to a number of underlying preconditions for health such as access to safe drinking water and environmental health". 254

In General Comment 14, the following interrelated and essential elements of the right to health are distinguished:

"(a) Availability. Functioning public health and health-care facilities, goods and services, as well as programmes, have to be available in sufficient quantity within the State party. The precise nature of the facilities, goods and services will vary depending on numerous factors, including the State party's developmental level. They will include, however, the underlying determinants of health, such as safe and potable drinking water and adequate sanitation facilities, hospitals, clinics and other health-related buildings, trained medical and professional personnel receiving domestically competitive salaries, and essential drugs, as defined by the WHO Action Programme on Essential Drugs.

(b) Accessibility. Health facilities, goods and services have to be accessible to everyone without discrimination, within the jurisdiction of the State party. Accessibility has four overlapping dimensions:

Non-discrimination: health facilities, goods and services must be accessible to all, especially the most vulnerable or marginalized sections of the population, in law and in fact, without discrimination on any of the prohibited grounds.

Physical accessibility: health facilities, goods and services must be within safe physical reach for all sections of the population, especially vulnerable or marginalized groups, such as ethnic minorities and indigenous populations, women, children, adolescents, older persons, persons with disabilities and persons with HIV/AIDS. Accessibility also implies that medical services and underlying determinants of health, such as safe and potable water and adequate sanitation facilities, are within safe physical reach, including in rural areas. Accessibility further includes adequate access to buildings for persons with disabilities.

Economic accessibility (affordability): health facilities, goods and services must be affordable for all. Payment for health-care services, as well as services related to the underlying determinants of health, has to be based on the principle of equity, ensuring that these services, whether privately or publicly provided, are affordable for all, including socially disadvantaged groups. Equity demands that poorer households should not be disproportionately burdened with health expenses as compared to richer households.

\footnotetext{
${ }^{252}$ Hessler, K., Buchanan, A., 2002, Specifying the Content of the Human Right to Health Care, In: Medicine and Social Justice: Essays on the Distribution of Health Care, Oxford University Press, p. 84-101.

${ }^{253}$ UN Committee on Economic, Social and Cultural Rights (CESCR), General Comment No. 14: The Right to the Highest Attainable Standard of Health (Art. 12 of the Covenant), 11 August 2000, paras. 8-9

${ }^{254}$ Toebes, B.C.A., 1999, The Right to Health as a Human Right in International Law, Intersentia/Hart, p. 17.
} 
Information accessibility: accessibility includes the right to seek, receive and impart information and ideas concerning health issues. However, accessibility of information should not impair the right to have personal health data treated with confidentiality.

(c) Acceptability. All health facilities, goods and services must be respectful of medical ethics and culturally appropriate, i.e. respectful of the culture of individuals, minorities, peoples and communities, sensitive to gender and life-cycle requirements, as well as being designed to respect confidentiality and improve the health status of those concerned.

(d) Quality. As well as being culturally acceptable, health facilities, goods and services must also be scientifically and medically appropriate and of good quality. This requires, inter alia, skilled medical personnel, scientifically approved and unexpired drugs and hospital equipment, safe and potable water, and adequate sanitation." 255

Accessibility is obviously an essential element of the right to health. "Health facilities, goods and services have to be accessible to everyone without discrimination" is how 'accessibility' is defined. ${ }^{256}$ The non-discrimination provision is mentioned as one of the dimensions of accessibility. Accessibility should especially be secured for "the most vulnerable and or marginalized sections of the population". ${ }^{257}$ In paragraph 19 of General Comment 14, this is further specified as "a special obligation to provide those who do not have sufficient means with the necessary health insurance and health-care facilities". ${ }^{258}$

Economic accessibility is another dimension of accessibility mentioned in General Comment 14. "Payment for health-care services, as well as services related to the underlying determinants of health, has to be based on the principle of equity" ${ }^{259}$ Equity demands that less fortunate households should not be disproportionately burdened. ${ }^{260}$ Payment on the basis of the equity principle has to ensure that these services are affordable for all, whether privately or publicly provided. Tobin notes in this regard that a "health system that is beyond the financial means of people cannot be said to promote the effective enjoyment of the right to health". ${ }^{261}$

The other dimensions of accessibility are also of great importance, but they are however less relevant for discussions on the taxation of health care. General Comment 14 does not contain any explicit remarks on the effects of taxation on the accessibility of health facilities, goods and services. Yet, the elements of accessibility are clearly relevant for this study.

\footnotetext{
${ }^{255}$ UN Committee on Economic, Social and Cultural Rights (CESCR), General Comment No. 14: The Right to the Highest Attainable Standard of Health (Art. 12 of the Covenant), 11 August 2000, para. 12; See also Toebes, B.C.A., 1999, The Right to Health as a Human Right in International Law, Intersentia/Hart, p. 114-122.

${ }^{256}$ UN Committee on Economic, Social and Cultural Rights (CESCR), General Comment No. 14: The Right to the Highest Attainable Standard of Health (Art. 12 of the Covenant), 11 August 2000, para. 12.

257 Ibid.

${ }^{258}$ Idem, para. 19.

${ }^{259}$ Idem, para. 12

${ }^{260}$ Idem, para. 12

${ }^{261}$ Tobin, J., 2012, The Right to Health in International Law, Oxford University Press, p. 169.
} 


\subsubsection{Binding character of the right to health in the ICESCR}

In the foregoing paragraphs I established that the human right to health is a fundamental right that is included in a number of international human rights treaties, widely supported by States. This is already obvious from the fact that in December 2013 the ICESCR had 160 State Parties, ${ }^{262}$ including all the current EU Member States.

The question is if and in how far the right is legally binding for State Parties. The right to health is for instance not included in The Convention for the Protection of Human Rights and Fundamental Freedoms ${ }^{263}$ ('ECHR'). In case of a violation of the rights and guarantees set out in this convention or its protocols, an application may be lodged with the European Court of Human Rights. Since the right to health is not as such included in the ECHR, it cannot be invoked before this Court.

The ICESCR does contain some binding obligations for States Parties in relation to the right to health. General Comment 14 (which has to be read in conjunction with General Comment 3 on 'progressive realisation' ${ }^{264}$ ) describes these obligations. ${ }^{265}$ The ICESCR strives for a progressive realization. 'Progressive realization' is referred to in General Comment 14 as a "continuing obligation to move as expeditiously and effectively as possible towards the full realization of article 12". There are also various obligations for States Parties which are of immediate effect. ${ }^{266}$ In relation to the right to health, State Parties have the obligation to exercise the rights in the covenant without discrimination of any kind. ${ }^{267}$ There is also an obligation to take deliberate, concrete and targeted steps towards the full realization of the rights in the covenant. ${ }^{268}$

General Comment 14 distinguishes, in this regard, three types or levels of obligations for State Parties:

- the obligation to respect (i.e. States refrain from interfering directly or indirectly with the enjoyment of the right to health);

\footnotetext{
${ }^{262}$ Status as at 30 December 2013, retrievable via: https://treaties.un.org.

${ }^{263}$ Council of Europe, European Convention for the Protection of Human Rights and Fundamental Freedoms, as amended by Protocols Nos. 11 and 14, 4 November 1950, ETS 5.

264 UN Committee on Economic, Social and Cultural Rights (CESCR), General Comment No. 3: The Nature of States Parties' Obligations (Art. 2, para. 1 of the Covenant), 14 December 1990.

${ }^{265}$ Part II of UN Committee on Economic, Social and Cultural Rights (CESCR), General Comment No. 14: The Right to the Highest Attainable Standard of Health (Art. 12 of the Covenant), 11 August 2000; See also Toebes, B.C.A, Hartlev, M., Hendriks, A., Herrmann, J.R., 2012, Health and Human Rights in Europe, Intersentia, p. 97.

${ }^{266}$ UN Committee on Economic, Social and Cultural Rights (CESCR), General Comment No. 14: The Right to the Highest Attainable Standard of Health (Art. 12 of the Covenant), 11 August 2000, para. 30.

${ }^{267}$ Article 2(2) of the ICESCR.

${ }^{268}$ Article 2(1) of the ICESCR; UN Committee on Economic, Social and Cultural Rights (CESCR), General Comment No. 14: The Right to the Highest Attainable Standard of Health (Art. 12 of the Covenant), 11 August 2000, para. 30.
} 
- the obligation to protect (i.e. States take measures that prevent third parties from interfering with that right); and

- the obligation to fulfil (i.e. appropriate legislative, administrative, budgetary, judicial, promotional and other measures towards full realization of the right). ${ }^{269}$

It is interesting to note that an example of the obligations to protect mentioned in the Comment is "to ensure that privatization of the health sector does not constitute a threat to the availability, accessibility, acceptability and quality of health facilities, goods and services". 270

Next to specific obligations, General Comment 14 also describes 'International Obligations' and 'Core Obligations'. Toebes describes the international obligations as the obligation for States to respect the right to health in other countries and to prevent third parties from violating the right in other countries. ${ }^{271}$ The core obligations mentioned in General Comment 14 imply "that State Parties have a certain minimum obligation to ensure, under all circumstances, the delivery of minimum basic levels of, in this case, essential health services" ${ }^{272}$ Violations of the right to health can occur either through direct action or through the omission or failure of States to take necessary steps arising from the legal obligations. ${ }^{273}$ The Special Rapporteur noted in his 2011 report that an increasing number of individuals are bringing cases before the national courts claiming breaches of the right to health. ${ }^{274}$ This has led to success in particular in relation to the access to essential medicines. Also, Toebes notes that International and domestic courts have increasingly enforced access to health-related services, although mostly in lower and middle-income countries. ${ }^{275}$

From the foregoing, I conclude that, as regards the right to health, State Parties to the ICESCR have the obligation of progressive realization and some other obligations with immediate effect. Progressive realization still leaves room for retroactive measures taken in the relation to the right to health, but only if a State Party can prove that the measure has been introduced after the most careful consideration of all alternatives and that they are

\footnotetext{
${ }^{269}$ UN Committee on Economic, Social and Cultural Rights (CESCR), General Comment No. 14: The Right to the Highest Attainable Standard of Health (Art. 12 of the Covenant), 11 August 2000, para. 33.

270 Idem, para. 35.

271 Toebes, B.C.A, Hartlev, M., Hendriks, A., Herrmann, J.R., 2012, Health and Human Rights in Europe, Intersentia, p. 99.

272 Ibid.

${ }^{273}$ UN Committee on Economic, Social and Cultural Rights (CESCR), General Comment No. 14: The Right to the Highest Attainable Standard of Health (Art. 12 of the Covenant), 11 August 2000, paras. 48-49.

${ }^{274}$ UN Human Rights Council, Report of the Special Rapporteur on the Right of Everyone to the Enjoyment of the Highest Attainable Standard of Physical and Mental Health, Anand Grover: addendum, 21 March 2011, A/HRC/17/25/Add.3.

275 Toebes, B.C.A, Hartlev, M., Hendriks, A., Herrmann, J.R., 2012, Health and Human Rights in Europe, Intersentia, p. 102-103.
} 
justified. ${ }^{276}$ Since all current EU Member States are party to the ICESCR, I conclude that the ICESCR brings about that the right to health has to be safeguarded while revising or drafting EU legislation. Coomans notes that, although the realization of economic, social and cultural rights normally takes place in the territory of States, States do not exist in isolation. ${ }^{277}$ In this regard he also discusses the legal obligations for the European Communities. Neither the European Community nor the European Union are a party to the ICESCR, while all the EU Member States are. According to Coomans, it can be argued that the Community is obliged to respect human rights in all its internal and external activities. ${ }^{278}$ Ahmed and De Jesús Butler set out that the present nature of human rights protection in the EU is essentially 'negative', as the EU is under a duty not to violate human rights while obeying the Treaty obligations. They illustrate that if it would be accepted that the EU is under direct obligations as a result of international law, the issue of enforcement would still have to be considered as monitoring bodies such as the UN Human Rights Committee have no jurisdiction to review claims against the EU as such. ${ }^{279}$

In this and the previous subsections, the right to health has been discussed in an international context. Hereafter I will discuss the right to health - and the accessibility of health care - in an EU context.

\subsection{Recognition of the human right to health in an EU context}

As noted before, all EU Member States are party to most of the 'core' international human rights treaties, such as the ICESCR. The EU itself has not ratified or acceded to a UN human rights treaty, except for the Convention on the Rights of Persons with Disabilities (CRPD). ${ }^{280}$ The EU did develop its own international mechanisms to protect human rights. Individuals living in EU Member States therefore face a so-called two-tier system for the protection of their human rights. ${ }^{281}$ On the one hand, their own Member States has to safeguard their rights as a result of being party to human rights treaties. On the other hand, it is the EU as a whole that has to carry out obligations in relation to EU citizens. ${ }^{282}$

\footnotetext{
${ }^{276}$ UN Committee on Economic, Social and Cultural Rights (CESCR), General Comment No. 14: The Right to the Highest Attainable Standard of Health (Art. 12 of the Covenant), 11 August 2000, para. 32.

${ }^{277}$ Coomans, A.P.M., 2007, Application of the International Convenant on Economic, Social and Cultural Rights in the Framework of International Organisaztions. In: Von Bogdandy, A., Wolfrum, R. (Eds.), Max Planck Yearbook of United Nations Law (11), p. 359-390.

278 Ibid.

279 Ahmed, T., De Jesús Butler, I., 2006, The European Union and Human Rights: An International Law Perspective, In: European Journal of International Law, Vol. 17 No.4, p. 771-801.

${ }^{280}$ Europe Regional Office for the UN High Commissioner for Human Rights, The European Union and International Human Rights Law, p. 8, retrievable via: http://www.europe.ohchr.org/Documents/Publications/ EU_and_International_Law.pdf.

${ }^{281}$ Ibid.

282 Idem, p. 9.
} 


\subsubsection{The 2006 statement of EU Health Ministers}

Also, specifically in relation to ensuring access to health, the EU took fundamental steps. Common challenges like population ageing, increased health care costs and interdependence of EU health care systems called for closer cooperation. Moreover, the economic crisis has led to a limitation of the availability of financial resources and hence a difficulty for Member States to maintain fiscal sustainability. ${ }^{283}$ The need for closer cooperation resulted in 2006 in a joint statement on the common values and principles that underpin Europe's health systems by the 25 Health Ministers of the European Union. ${ }^{284}$ With this statement, they invited the European institutions to ensure that their work will protect the common values and principles contained in the statement when drafting specific proposals concerning health services. In the statement, the Health Ministers recall that the overarching values of "universality, access to good quality care, equity and solidarity have been widely accepted in the work of the different EU institutions". They briefly describe these values as follows: "[u]niversality means that no-one is barred access to health care; solidarity is closely linked to the financial arrangement of our national health systems and the need to ensure accessibility to all; equity relates to equal access according to need, regardless of ethnicity, gender, age, social status or ability to pay". ${ }^{285}$ The invitation of the Health Ministers has been respected and has played a significant role in the enforcement of the overarching values.

\subsubsection{Directive $2011 / 24 / E U$}

The statement of the EU Health Ministers has played an important role in the realization of Directive 2011/24/EU on the application of patients' rights in cross border health care. ${ }^{286}$ The enforcement of this Directive was considered a key step in providing a legal framework for the interaction of EU health systems. ${ }^{287}$ In the preamble to Directive 2011/24/EU, reference is made to the fact that "the court of justice has laid down that public health protection is among the overriding reasons of general interest that can justify restrictions to the freedom of movement envisaged in the Treaties". ${ }^{288}$ The concept of 'overriding reasons of general interest' was developed in the CJEU case law in relation to Articles 49 (freedom of establishment) and 56 of the TFEU (freedom to provide services). ${ }^{289}$ Next to the overriding reasons of general interest, developed in case law, the TFEU mentions specific justifications for the restriction of treaty freedoms. The protection of public health is explicitly mentioned

\footnotetext{
${ }^{283}$ Communication from the Commission on effective, accessible and resilient health systems, $\operatorname{COM}(2014) 215$ final, 4 April 2014.

${ }^{284}$ Council Conclusions on Common values and principles in European Union Health Systems, OJ C 146, 22 June 2006.

${ }^{285}$ Ibid; Preamble to Directive 2011/24/EU of the European Parliament and of the Council of 9 March 2011 on the application of patients' rights in cross-border healthcare, OJ L 88, 4.4, 2011, p. 45.

${ }^{286}$ Directive 2011/24/EU of the European Parliament and of the Council of 9 March 2011 on the application of patients' rights in cross-border healthcare, OJ L 88, 4.4, 2011, p. 45.

${ }^{287}$ European Commission, European Semester Thematic Factsheet: Health Systems, 14 November 2016, retrievable via: https://ec.europa.eu.

${ }^{288}$ Preamble, para. 11.

${ }^{289}$ Preamble, para. 12.
} 
in the TFEU as a possible justification for derogations to the freedom of establishment. The CJEU ruled that the "objective of maintaining a balanced medical and hospital service open to all may also fall within one of the derogations, on grounds of public health, provided for in Article 52 TFEU, in so far as it contributes to the attainment of a high level of health protection". ${ }^{290}$

I did not investigate whether and in how far 'grounds of public health' protection correspond to or stray from the human right to health. However, the CJEU explained that it is one of the objectives of the TFEU to safeguard access to a balanced medical and hospital service to all. This demonstrates that access to health is a principle that cannot be ignored when applying and drafting EU legislation and policies. In chapter 5, I will discuss in more detail the balance between the application of EU VAT and the principle of access to health care.

\subsubsection{The Charter of Fundamental Rights of the European Union}

Already in 2000, the European Parliament, the Council and the Commission established a 'Charter of Fundamental Rights of the European Union' ('EU Charter'). ${ }^{291}$ The EU Charter had the purpose to set out clearly, as general principles of EU Law, fundamental rights, freedoms and procedural rights guaranteed by the EU Convention and the rights derived from constitutional traditions common to the Member States. ${ }^{292}$

The EU Charter contains a provision on health care. According to Article 35 of the EU Charter, everyone has the right of access to preventive health care and the right to benefit from medical treatment under the conditions established by national laws and practices. The provision also demands ensuring a high level of human health protection in the definition and implementation of all Union policies and activities.

With the entry into force of the Lisbon Treaty, ${ }^{293}$ the EU Charter gained the same legal value as the EU Treaties. In the EU Charter, fundamental rights of EU citizens have been clarified, updated and brought together in a single document. The EU Charter is consistent with the European Convention on Human Rights, meaning that the application and scope of rights that are also mentioned in that convention are the same. ${ }^{294}$ Where human rights treaties apply to State Parties, the EU Charter is addressed to the institutions and bodies of the EU with due regard for the principle of subsidiarity. Furthermore, the EU Charter applies to Member States only when they are implementing Union law. The EU bodies and institutions and

\footnotetext{
290 Preamble, para. 12; derived from CJEU 16 May 2006, Case C-372/04 Watts, ECLI:EU:C:2006:325, paras. 103106; see also CJEU 28 April 1998, Case C-158/96 Kohll v Union des caisses de maladie, ECLI:EU:C:1998:171, para. 50 and CJEU 12 July 2001, Case C-157/99 Smits and Peerbooms, ECLI:EU:C:2001:404, para. 73.

${ }^{291}$ Charter of Fundamental Rights of the European Union of 30 March 2010, 2010/C 83/02.

292 Egholm Elgaard, K., 2016, The Impact of the Charter of Fundamental Rights of the European Union on VAT Law, World Journal of VAT/ GST Law, vol. 5, issue 2.

293 Treaty of Lisbon amending the Treaty on European Union and the Treaty establishing the European Community, signed at Lisbon, 13 December 2017, 2007/C 306/01.

${ }^{294}$ Article 52(3) EU Charter
} 
Member States have to respect the rights, observe the principles and promote their application in accordance with their respective powers. ${ }^{295}$ No new power or task for the European Community or the EU was established with the enforcement of the EU Charter, nor are their powers and tasks, as defined by the EU Treaties, modified. ${ }^{296}$

As said, the EU Charter - which explicitly recognizes a right (of access) to health - has become an integral part of primary EU law. Herewith, it is established that the right to health also has to be taken into account in relation to the application of EU VAT law. Egholm Elgaard comprehensively studied the impact of the EU Charter on the application of EU VAT law. One of her conclusions is that 'any impact of the Charter on VAT-related matters must be considered in connection with legislation, case law, administrative practice and guidelines etc., in order to comply with the Charter with its status as EU Primary Law'. ${ }^{297}$ In chapter 5, the balance between the right to health and more specifically the principle of access to health care and the application of EU VAT law is discussed in more detail.

\subsection{Conclusion}

In the beginning of this chapter I stated that the CJEU maintains the principle of access to health care as a standard in relation to the application of positive EU VAT law. This principle is, however, not defined in the context of EU VAT. Therefore, in this chapter, I explored the principle from a human rights perspective and discovered that access to health care is recognized as part of the more encompassing right to health in international human rights law. I showed that the right to health consists of several interrelated essential elements, of which accessibility is one. I also showed that the element of accessibility has four overlapping dimensions. One of these dimensions is 'economic accessibility', implying that health facilities, goods and services should be affordable for all and payments have to be based on the principle of equity. Furthermore, I showed in this chapter that the ICESCR contains some binding obligations for States Parties in relation to the right to health. This obligation covers all elements and dimensions of the right to health. Therefore, all States that acknowledge the right to health have to take progressive measures in this regard. In my view, therefore, this progressive approach to improving the enjoyment by all people of the right to health entails - specifically in relation to the dimension of economic accessibility - that obstacles that affect the affordability of health care have to be abolished or diminished. This also includes obstacles in the form of measures that are in conflict with the equity principle.

Within the EU, a right to (access to) health is included in the EU Charter, which is legally binding and part of primary EU law. The recognition of the right to health and more specifically the principle of access of health care in both an international and EU context lead

\footnotetext{
${ }^{295}$ Article 51(1) EU Charter.

${ }^{296}$ Article 51(2) EU Charter; see also Article 6 of the EU Treaty (as amended by the Lisbon Treaty).

297 Egholm Elgaard, K., 2016, The Impact of the Charter of Fundamental Rights of the European Union on VAT Law, World Journal of VAT/ GST Law, vol. 5, issue 2.
} 
me to conclude that it cannot be ignored while applying, interpreting and drafting (EU) legislation. Furthermore, the recognition of the principle of access to health care supports the reasoning of the CJEU in several cases on VAT and health care, where it considered that the principle provides a justification for the application of VAT exemptions and reductions. The balance between the principle of access to health care and the application of EU VAT law will be discussed in more detail in the following chapter. 


\section{Balance between the application of VAT and the principle of access to health care}

\subsection{Introduction}

In chapter 3, I discussed the purpose and functioning of the EU VAT system. It was shown that EU VAT, by its nature affects health care consumption. In chapter 4 the substance and content of the principle of access to health care have been discussed both from an EU and international human rights law perspective. Access to health care proves to be a principle that must be adhered to while applying, interpreting and drafting (EU) legislation.

Already in section 1.1, reference was made to the aims of the human right to health and the VAT as a general tax on consumption, as being two averting 'forces'. The figure 1.1 shows that the general character of the EU VAT system aims to include a large part of health care consumption within its scope. The right to health, on the other hand, requires the accessibility of health care to be ensured by relieving health care consumption from burdens like a value added tax that may have the effect of increasing the cost price of that health care or making it less affordable.

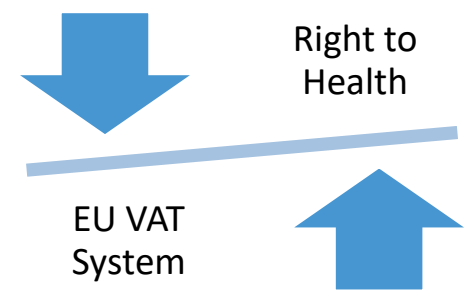

Figure 5.1 How are the EU VAT system and the right to health balanced?

The CJEU appears to hold the opinion that the application of positive EU VAT law hinders access to health care. ${ }^{298}$ This presumes a relationship between the EU VAT system and the right to health. The reasoning of the CJEU has - so far - not been justified from a human rights perspective. It would be interesting to see what would happen if the two 'forces' would

\footnotetext{
${ }^{298}$ CJEU 1 December 2005, Joined Cases C-395/04 and C-394/04 Ygeia, ECLI:EU:C:2005:734, para. 23; CJEU 11 January 2001, Case C-76/99 Commission vs. France, ECLI:EU:C:2001:12, para. 23; CJEU 20 June 2002, Case C287/00 Commission vs. Germany, ECLI:EU:C:2002:388, para. 47 (as regards education services, however in the same line); CJEU 6 November 2003, Case C-45/01 Dornier, ECLI:EU:C:2003:595, para. 40.
} 
put be on a scale. Would one of the forces simply out-weigh the other? Or are they of an equal hierarchical level? These are questions that are central in this chapter. This allows for a conclusion on the relevance of the principle of access to health care in relation to the application of EU VAT. In figure 5.1, the opposing objectives of the EU VAT system and the right to health are illustrated once more, this time with the purpose to show the possible consequences of the (counter)balance of these two 'forces'.

If it would be assumed that it is possible that an assessment of the application of, on the one hand, EU VAT and, on the other hand, the right to health leads to the conclusion that one force takes precedence over the other, this could in an extreme case infer that the application of one of the forces needs to be abolished in order to ensure the correct application of the other force. For example, if one would conclude that the application of EU VAT would prevail over the application of the right to health, this could mean that the latter is not supposed to hinder the application of EU VAT. Conversely, if one concludes that the application of the right to health overrules the application of EU VAT, this could infer that the current EU VAT system has to be abolished. The latter (and also the first) is not foreseeable - for sure not in the near future - considering that the EU VAT system is embedded in primary EU law and has a good reputation with regard to revenue raising for Member States and the Union's own resources. The TFEU contains an assignment to harmonize indirect taxation within the EU in order to facilitate the internal market (see section 5.2.2). This shows that the existence of indirect taxes is, as such, accepted. The goal was, however, a uniform application and interpretation within the EU. A possible abolition of the current EU VAT system is, therefore, not an option I will consider within this study.

\subsection{The conflicting objectives of the right to health and the application of EU VAT}

This study departs from the hypothesis that the application of positive EU VAT law on health care transactions hinders the access to health care. The basic idea underlying this hypothesis is the reasoning of the CJEU on the of application of VAT on certain health care and health care related supplies and the effect on access to health care for consumers. As I indicated earlier, the CJEU also seems to accept that VAT hinders access to health care. However, this idea, so far, has never been justified. Checking the validity of this hypothesis is one of the major goals of this research. The hindering effect implies that the EU VAT system and the principle of access to health care pursue diverse interests. In this section, I will discuss in more detail the objectives of positive EU VAT law on the one hand and the (principle of) access to health care on the other.

\subsubsection{Objectives of the right to health in relation to health care consumption}

The statement that the application of EU VAT law hinders access to health care lead me to explore the basis for accessibility of health care within human rights law (chapter 4). The human right to health is comprehensive. The comprehensiveness of the right to health at the 
same time makes it abstract. The ICESCR ${ }^{299}$ - an international human rights treaty - defines the right to health as "the right of everyone to the enjoyment of the highest attainable standard of physical and mental health". ${ }^{300}$ Interpretative commentary shows that the right to health must be understood as "a right to the enjoyment of a variety of facilities goods, services and conditions necessary for the realization of the highest attainable standard of health". ${ }^{301}$

In my view, the right to health is defined in such a way that it describes an ideal. The recognition of this right - within human rights law - brought with it freedoms and entitlements for humans. States undertook obligations to take steps towards the full (progressive) realization of the right to health. The obligation for a progressive realization entails the continuing obligation to move as expeditiously and effectively as possible to the full realization of the right to health. ${ }^{302}$ One could thus say that the objective of the right to health is in fact the objective of progressively improving the enjoyment by all people of the right to health. ${ }^{303}$

In chapter 4, it was shown that the right to health consists of several interrelated essential elements, of which accessibility is one. ${ }^{304}$ It was also shown that the element of accessibility has four overlapping dimensions. One of these dimensions is 'economic accessibility', implying that health facilities, goods and services should be affordable for all. ${ }^{305}$ Furthermore, payment for health care services has to be based on the principle of equity. As the obligation of a progressive realization of the right to health covers all its elements and dimensions, all States that acknowledge the right to health have to take progressive measures in this regard. In my view, therefore, this progressive approach to improving the enjoyment of all people to the right to health entails - specifically in relation to the dimension of economic accessibility - that obstacles that affect the affordability of health care have to be abolished or diminished. This also includes obstacles in the form of measures that are in conflict with the ability to pay principle.

\footnotetext{
${ }^{299}$ UN General Assembly, International Covenant on Economic, Social and Cultural Rights, 16 December 1966, United Nations, Treaty Series, vol. 993, p. 3, entered into force on 3 January 1978.

${ }^{300}$ UN General Assembly, International Covenant on Economic, Social and Cultural Rights, 16 December 1966, United Nations, Treaty Series, vol. 993, p. 3, Article 12.

${ }^{301}$ UN Committee on Economic, Social and Cultural Rights (CESCR), General Comment No. 14: The Right to the Highest Attainable Standard of Health (Art. 12 of the Covenant), 11 August 2000, para. 10.

${ }^{302}$ UN Committee on Economic, Social and Cultural Rights (CESCR), General Comment No. 14: The Right to the Highest Attainable Standard of Health (Art. 12 of the Covenant), 11 August 2000, para. 31.

${ }^{303}$ See also WHO Media centre, WHO Health and Human Rights Fact Sheet N ${ }^{\circ} 323$, December 2015, retrievable via: http://www.who.int/mediacentre/factsheets/fs323/en.

${ }^{304}$ From General Comment No. 14 (11 Augustus 2000) it follows that the right to health contains the following interrelated and essential elements: availability, accessibility, acceptability, and quality, see section 4.2.2.

${ }^{305}$ See section 4.2.2; See also UN Committee on Economic, Social and Cultural Rights (CESCR), General Comment No. 14: The Right to the Highest Attainable Standard of Health (Art. 12 of the Covenant), 11 August 2000, para. 12.
} 
In the following section, I will discuss the objectives of the EU VAT system in relation to health care consumption.

\subsubsection{Objectives of the EU VAT system in relation to health care consumption}

In chapter 3 , the purpose and functioning of the EU VAT system were discussed. It was demonstrated that the EU VAT aims to tax consumption at the level of the final consumer. In order to pursue this aim and, at the same time, keep the application of the system feasible, the EU VAT was designed as a tax on transactions. Therefore, in relation to health care, the health care transactions are potentially covered within the scope of VAT. It was also shown in chapter 3 that another characteristic of the EU VAT system is that it is a general tax with a broad scope of application. Therefore, many health care suppliers will be confronted with EU VAT while performing their health care activities, either as a result of their activities being taxed or exempted within the scope of EU VAT.

The EU VAT system can be perceived as regressive. ${ }^{306}$ By applying a general or reduced rate to the taxable amount of transactions, the tax is charged proportionately to the price charged for those transactions. This does not take into account the financial position of the (final) consumer of those transactions. One could argue that only the application of a reduced rate to certain 'basic needs' (e.g. foodstuffs and books) contributes to a certain extent and takes into account the ability to pay principle.

The presence of exemption provisions and provisions that require the application of a reduced rate on certain supplies show the apparent objective of the EU legislator to relieve the VAT burden on certain transactions. Therefore, in addition to an objective to tax supplies in as general a manner as possible, there is also an objective to not tax certain supplies or simply to reduce the tax burden on those supplies. It should be noted that these exceptions to the general application of the VAT system always have to be interpreted in a strict manner. ${ }^{307}$ At the same time, a strict interpretation does not mean that terms used in exemption provisions should be construed in such a way as to deprive the exemptions of their intended effect. ${ }^{308}$ With regard to health care transactions, it is the aim of the EU VAT system - by applying exemptions - to reduce health care costs and make it more accessible to individuals. ${ }^{309}$ The objective of the EU VAT in relation to health care consumption seems

\footnotetext{
${ }^{306}$ Commission Staff Working Document, Accompanying document to the Green Paper on the future of VAT, SEC (2010) 1455 final, para. 3.1; see also section 6.2.6.

${ }^{307}$ CJEU 15 June 1989, Case C-348/87 Stichting Uitvoering Financiële Acties, ECLI:EU:C:1989:246, para. 13; CJEU 11 January 2001, Case C-76/99 Commission vs. France, ECLI:EU:C:2001:12, para. 21; CJEU 20 November 2003, Case C-8/01 Taksatorringen, ECLI:EU:C:2003:621, para. 36.

${ }^{308}$ E.g. CJEU 28 January 2010, Case C-473/08 Eulitz, ECLI:EU:C:2010:47, para. 27.

${ }^{309}$ See inter alia CJEU 20 November 2003, Case C-212/01 Margarete Unterpertinger, ECLI:EU:C:2003:625, para. 41; CJEU 8 June 2006, Case C-106/05 L.u.P., ECLI:EU:C:2006:380, para. 25; CJEU 6 November 2003, Case C45/01 Dornier, ECLI:EU:C:2003:595, para. 48; CJEU 10 September 2002, Case C-141/00 Kügler, ECLI:EU:C:2002:473; CJEU 1 December 2005, Joined Cases C-395/04 and C-394/04 Ygeia, ECLI:EU:C:2005:734, para. 24; A-G Opinion 10 September 2009, Case C-262/08 CopyGene, ECLI:EU:C:2009:541, para. 33.
} 
twofold. On the one hand, the general character of EU VAT seeks to include all transactions leading to final consumption, including health care consumption. On the other hand, the EU VAT system relieves the VAT burden on (certain) health care transactions, as it aims to make health care more accessible to individuals.

\subsection{Different hierarchies of the right to access to health care and the application of VAT}

\subsubsection{Different hierarches in relation to sources of EU law}

The right to health has been recognized within the scope of international human rights law and has been addressed in several international and regional human rights instruments. The right is codified in the ICESCR, which is considered the central instrument for the protection of the right to health (see section 4.2.1). The ICESCR contains some binding obligations for State Parties in relation to the right to health - with the objective of a progressive realization of that right - as was also discussed in section 5.2.1. ${ }^{310}$ All current EU Member States are a State Party to the ICESCR. Within the EU, a right to health has been included in the Charter of Fundamental Rights of the European Union ('EU Charter'). ${ }^{311}$ Moreover, access to care has been recognized by the EU Health Ministers as one of the 'overarching values' that forms a basis for the further development of EU health systems and policies. ${ }^{312}$

With the entry into force of the Lisbon Treaty on 1 December 2009, the EU Charter became an integral part of primary EU law. As a result, the EU Charter - and hence the right (of access) to health, which it contains - gained the same legal value as the EU Treaties. As was explained in section 4.3.3, the EU Charter applies to EU Member States when implementing Union law. As a result, it is certain that the right to health, and also accessibility to health care, have to be taken into account while drafting and implementing EU law and national legislation, for example provisions concerning VAT Law.

The provisions that concern the application of positive EU VAT law are laid down in the EU VAT Directive. This directive constitutes secondary EU law and is binding upon each Member State to which it is addressed as to the result to be achieved. ${ }^{313}$ The status of secondary law includes that provisions in the EU VAT Directive always have to be interpreted in line with primary EU law. ${ }^{314}$ The basis for the EU VAT system in primary EU law can be found in Article 113 of the TFEU. Article 113 of the TFEU does not contain an assignment to adopt a Value

\footnotetext{
${ }^{310}$ See also section 4.2.3 on the binding character of the right to health in the ICESCR.

${ }^{311}$ See section 4.3.3.

${ }^{312}$ See section 4.3.1 and 4.3.2.

${ }^{313}$ Article 249 of the TFEU (Consolidated Version of the Treaty on the Functioning of the European Union, O.J., C 202, 7 June 2016).

${ }^{314}$ See for example CJEU 15 November 2012, Case C-174/11 Zimmermann, ECLI:EU:C:2012:716, para. 50; CJEU 29 October 2009, Case C-174/08 NCC Construction Danmark, ECLI:EU:C:2009:669, para. 44; CJEU 19 July 2012, Case C-44/11 Deutsche Bank, ECLI:EU:C:2012:484, para. 45; CJEU 13 March 2014 A-G Opinion 26 September 2013, Case C-366/12 Klinikum Dortmund, ECLI:EU:C:2013:618, para. 53.
} 
Added Tax within the EU. It does, however, require the adoption of provisions for the harmonization of legislation concerning turnover taxes, to the extent necessary to ensure the establishment and functioning of the internal market. Obviously, at that point, indirect taxation as such was accepted. There was, however, a need for harmonization and uniform application. The adoptions of a directive was chosen to achieve the objective of harmonization. $^{315}$

From the foregoing, it follows that the right to health has become an integral part of primary EU law and has the same legal value as the EU Treaties. The TFEU is the main source of primary EU law in the field of VAT, containing an assignment to harmonize indirect taxes within the Union. ${ }^{316}$ In terms of hierarchy, the provisions in the EU Charter are, hence, on the same level as the assignment for a harmonized EU VAT system in the TFEU (see figure 5.2). The EU VAT Directive is secondary EU law, but it has to be interpreted in line with primary EU law, meaning it has to be in line with both the TFEU as well as the EU Charter. As a result, the provisions in the EU Charter are capable of affecting the application and interpretation of positive EU VAT law. National VAT legislation has to be consistent with the EU VAT Directive. Member States are, however, free to determine the text and form of the national VAT Act used to transpose the Directive into national law. ${ }^{317}$ Yet, national courts are required to interpret domestic law, in so far as possible, in the light of the wording and the purpose of the EU VAT Directive. ${ }^{318}$ Since the EU VAT Directive has to be in line with the EU Charter, this also means that national VAT legislation is capable of being affected by the application of the provisions in the EU Charter. Expressed in more concrete terms, the right to (access to) health, as recognized in the EU Charter, cannot be denied in relation to the interpretation of the application of positive EU VAT law. In my view, this is not only the direct consequence of the enforcement of the EU Charter, but also the result of the obligation to respect the application of international human rights law, since all current EU Member States are a State Party to the ICESCR that explicitly recognizes the right to health (see section 4.2.3). In the figure below, a schematic overview of the hierarchy of relevant EU law in the field of VAT and the EU Charter is provided. ${ }^{319}$

\footnotetext{
${ }^{315}$ Article $114-115$ of the TFEU (Consolidated Version of the Treaty on the Functioning of the European Union, O.J., C 202, 7 June 2016).

${ }^{316}$ For a concise introduction to EU law, with a focus on the domain of VAT, reference is made to Van Doesum, A.J., Van Kesteren, H.W.M., Van Norden, G.J., 2016, Fundamentals of EU VAT Law, Kluwer Law International, para. 1.10, p. 20-32.

317 CJEU 19 January 1982, Case 8/81 Becker, ECLI:EU:C:1982:7, para. 17; See also Van Doesum, A.J., Van Kesteren, H.W.M., Van Norden, G.J., 2016, Fundamentals of EU VAT Law, Kluwer Law International, p. 23.

${ }^{318} \mathrm{Idem}$, para. 1.10.2.2.1.; Article 288 of the TFEU (Consolidated Version of the Treaty on the Functioning of the European Union, O.J., C 202, 7 June 2016).

319 Under 'secondary EU VAT law' I only referred to the EU VAT Directive. In the field of EU, VAT also other EU Directives (e.g. the Refund Directive) and the EU VAT Regulation are considered secondary EU VAT law. I only referred to the EU VAT Directive as it contains the key provisions and is most relevant for the purpose of this research.
} 


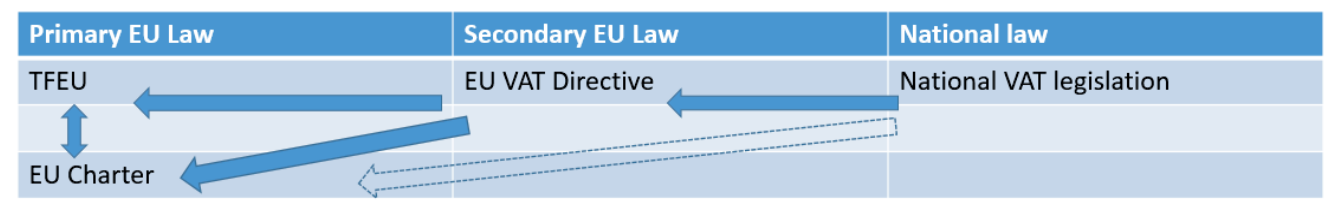

Figure 5.2 Schematic overview of the hierarchy of relevant EU law in the field of VAT and the EU Charter

\subsubsection{Role of the EU Charter in CJEU cases on EU VAT law}

It is the task of the CJEU to observe the law in the interpretation and application of the Treaties. ${ }^{320}$ In the previous chapter, I already briefly referred to the study by Egholm Elgaard on the impact of the EU Charter on the application of EU VAT law. ${ }^{321}$ Part of her study focused on considerations made by Advocates General and the CJEU in relation to provisions of the EU Charter in cases on EU VAT. She indicates that the Charter is an integral part of EU law and therefore an integral part of the legal basis for analysing EU VAT law. ${ }^{322}$ With her case law study, she demonstrated that the EU Charter has already proven to play an important role in both formal and substantive aspects of VAT Law. This includes the application of VAT Exemptions. ${ }^{323}$

Until now, the CJEU did not have to give its decision in cases concerning the application of the VAT exemptions for medical care in Articles 132(1)(b) or (c) of the EU VAT Directive in relation to Article 35 of the EU VAT Charter, the provision containing the right (of access) to health care. To be able to give an idea of the possible impact of this provision in the EU Charter on the application of positive EU VAT law on health care transactions, it is useful to take a closer look at CJEU case law on the imposition of VAT on the services of lawyers. The reason for this is that, in these cases, remarks are made on the effect of the imposition of VAT in relation to the access to justice, as laid down in Article 47 of the EU Charter.

In that regard I refer, in the first place, to Commission vs. France ${ }^{324}$ on the application of a reduced rate to the supply of services by lawyers under the legal aid scheme in France. ${ }^{325}$ The Commission brought an infringement procedure against the French Republic, as it was of the opinion that it failed to comply with the provisions in the EU VAT Directive by maintaining a reduced rate on those services. The French Republic claimed that the application of a standard VAT rate to services by lawyers would jeopardize access to justice for the most

\footnotetext{
${ }^{320}$ Article 19 of the TFEU (Consolidated Version of the Treaty on the Functioning of the European Union, O.J., C 202, 7 June 2016).

${ }^{321}$ Egholm Elgaard, K., 2016, The Impact of the Charter of Fundamental Rights of the European Union on VAT Law, World Journal of VAT/ GST Law, vol. 5, issue 2, p. 63-91.

322 Ibid.

${ }^{323}$ Ibid.

${ }^{324}$ CJEU 17 June 2010, Case C-492/08 Commission vs. France, ECLI:EU:C:2010:348.

${ }^{325}$ Services of lawyers under the French legal aid scheme are services that are paid in full or in part by the State (CJEU 17 June 2010, Case C-492/08 Commission vs. France, ECLI:EU:C:2010:348, para. 8).
} 
disadvantaged persons. ${ }^{326}$ The CJEU considered that the pursuit of access to justice is not a valid reason for failing to comply with the provisions of the EU VAT Directive. ${ }^{327}$ The French Republic apparently also submitted a remark on the fact that access to justice is recognized as a fundamental right in the EU Charter inter alia. ${ }^{328}$ That remark was, however, made to support the reasoning that lawyers providing services under the legal aid scheme are engaged in welfare or security work. The reason for that was that the French were seeking to find a way to apply the VAT exemption for the supply of services and goods closely linked to welfare and social security work, laid down in Article 132(1)(g) of the EU VAT Directive. Although the CJEU rejected the arguments provided by the French Republic, unfortunately it did not directly react to the statement made by the French Republic on the application of the EU Charter. The CJEU also did not take over considerations made by AG Jääskinen in that regard in his opinion on this case. The AG literally posed the following question: "would application of the standard rate of VAT result in limiting access to justice, as the French Republic claims?" ${ }^{329}$ The AG supports the vision of the Commission on this matter. The Commission had apparently argued that the application of a standard VAT rate has no effect on the financial situation of recipients where legal aid is paid in full by the State. Furthermore, if the French would want to give financial support to those individuals who are not entitled to a full contribution from the State, they would have to amend their rules with regard to partial legal aid. ${ }^{330}$ As mentioned above, the CJEU did not take over these arguments in this case, nor did it refer to the application of the EU Charter in relation to the imposition of VAT on the services of lawyers under the legal aid regime.

The second CJEU case I would like to refer to at this point is Ordre des barreaux francophones et germanophone. ${ }^{331}$ Belgium applied an exemption for services supplied by lawyers on the basis of a transitional provision. The provision ended with effect from 1 January 2014, meaning that, as of that date, the services provided by lawyers are taxed against the general VAT rate. ${ }^{332}$ The abolition of the VAT exemption was challenged by a number of Belgian bar councils together with several human rights and humanitarian associations and a number of individuals having incurred lawyers' fees subject to VAT. ${ }^{333}$ In its preliminary questions, the Belgian Constitutional Court asked, inter alia, whether the imposition of VAT on services by lawyers, without taking account of the fact whether the client qualifies for legal aid, is in line with the right to an effective remedy and the principle of equality of arms under Article 47 of the EU Charter.

\footnotetext{
${ }^{326}$ CJEU 17 June 2010, Case C-492/08 Commission vs. France, ECLI:EU:C:2010:348, para. 21.

327 Idem, para. 21.

${ }^{328}$ Idem, para. 26.

${ }^{329}$ A-G Opinion 11 February 2010, Case C-492/08 Commission vs. France, ECLI:EU:C:2010:72, para. 34.

330 Idem, para. 36.

${ }^{331}$ CJEU 28 July 2016, Case C-543/14 Ordre des barreaux francophones et germanophone, ECLI:EU:C:2016:605.

332 Idem, para. 18.

333 A-G Opinion 10 March 2016, Case C-543/14 Ordre des barreaux francophones et germanophone, ECLI:EU:C:2016:157, para 2.
} 
According to CJEU case law in other areas than VAT, the imposition of costs arising from legal proceedings can be challenged in the light of the right to an effective remedy where those costs represent an 'insurmountable obstacle' or where they make it impossible in practice or excessively difficult to exercise the rights conferred by the EU legal order. ${ }^{334}$ The CJEU clarifies that the doubts of the referring court with regard to this matter only concern the situation of clients who do not qualify for legal aid under the relevant provisions of national law, meaning that they might be directly affected by an increase of those costs. ${ }^{335}$ For that reason, the CJEU went on to establish whether the imposition of VAT on the services supplied by lawyers could by itself create such an insurmountable obstacle to access to justice or make it in practice impossible or excessively difficult to exercise the rights conferred by the EU legal order. The CJEU started with referring to the claims made by the applicants that the imposition of the standard VAT rate to services supplied by lawyers, in respect of individuals who do not qualify for legal aid, causes a significant increase in costs arising from legal proceedings. ${ }^{336}$ Directly after that, the CJEU noted that the imposition of VAT, however, brings along with it the right to deduct input VAT, which is, according to the CJEU, likely to reduce the lawyers' fees. Moreover, it held that the extent to which lawyers are financially obliged to pass on the cost resulting from the VAT in their fees is uncertain. ${ }^{337}$ The level of a possible increase of fees is even more uncertain according to the CJEU, given the fee scheme for lawyers in Belgium, which apparently requires lawyers to take into account the financial situation of their clients. ${ }^{338}$ The foregoing lead the CJEU to conclude that there is no close or mechanical correlation between the charging of VAT on the services supplied by lawyers and an increase of the price of those services. ${ }^{339}$ The CJEU added to that that the amount of VAT at issue is far from constituting the largest part of the costs of legal proceedings and, as a result, is argues that it cannot hold that the imposition of VAT on services by lawyers creates by itself an 'insurmountable obstacle' to access to justice or that it makes it in practice impossible or excessively difficult to exercise the rights conferred by the EU legal order. ${ }^{340}$ Hence, the protection conferred by the right to an effective remedy was not found to extend to the imposition of VAT on the services supplied by lawyers. ${ }^{341}$

In relation to the principle of equality of arms, the CJEU sought to establish whether the charging of VAT at the rate of $21 \%$ on the services supplied by lawyers puts non-taxable individuals at a disadvantage compared to individuals who have the status of taxable persons,

\footnotetext{
${ }^{334}$ CJEU 28 July 2016, Case C-543/14 Ordre des barreaux francophones et germanophone, ECLI:EU:C:2016:605, para. 31.

${ }_{335}$ Idem, para. 25.

${ }^{336}$ Idem, para. 32.

${ }^{337}$ Idem, para. 33.

338 Idem, para. 34.

339 Idem, para. 35.

${ }^{340}$ Idem, para. 36.

${ }^{341}$ Idem, para. 37.
} 
as only the latter enjoy the right to deduct input VAT. ${ }^{342}$ Also in relation to this principle, the CJEU rejected the arguments of the applicants. It held that, as a result of the Belgian fee scheme - where legal fees are freely negotiated - lawyers can take into account the financial situation of their clients and ask their non-taxable clients to pay fees, including VAT, which are lower than those asked of their taxable clients. ${ }^{343}$

As indicated, I addressed the two abovementioned cases to be able to present an idea of how the provisions in the EU Charter are put against provisions of the EU VAT Directive. Furthermore, I found these cases interesting as the AGs and the CJEU paid attention to the question whether the imposition of VAT on certain services would impede the access to justice and/ or the right to an effective remedy and the principle of equality of arms under Article 47 of the EU Charter. Like in this study, it also concerns accessibility in the context of a human right. In both CJEU cases that have been discussed in this section, the CJEU concluded that the imposition of VAT on services of lawyers did not constitute a distortion in relation to the application of the rights laid down in the EU Charter.

It is clear that the EU Charter does have an impact on the application of EU VAT law. ${ }^{344}$ The CJEU has to make sure the EU Directive is interpreted and applied in accordance with primary EU law, which includes the EU Charter. In the two CJEU cases that were discussed in this section, (one of) the parties based their arguments on provisions included in the EU Charter. In the first case that was discussed, the CJEU did not explicitly refer to arguments based on the application of the EU Charter. What it did rule in relation to access to justice is that the pursuit of that access is not a valid reason for failing to comply with the provisions of the EU VAT Directive. ${ }^{345}$ In the second case, the CJEU did refer to the EU Charter and mainly investigated - on the basis of previous case law in fields other than VAT - whether the imposition of VAT on the services by lawyers would constitute an insurmountable obstacle or whether it makes it impossible in practice or excessively difficult to exercise the rights conferred by the EU legal order. ${ }^{346}$ Only in that case the imposition of VAT on those services can possibly be put aside.

In my opinion, the outcome and the considerations put forward by the CJEU cannot simply be taken over and be applied to the imposition of VAT on health care transactions. The CJEU already made clear in relation to the exemptions on health care that these exemptions aim to ensure that the accessibility of health care transactions is not hindered by increased costs, which would occur if those services would be made subject to VAT. In this sense, health care

\footnotetext{
342 Idem, para. 39.

${ }^{343}$ Idem, para. 45

${ }^{344}$ For a more comprehensive study of this impact, reference is made to: Egholm Elgaard, K., 2016, The Impact of the Charter of Fundamental Rights of the European Union on VAT Law, World Journal of VAT/ GST Law, vol. 5, issue 2, p. 63-91.

${ }^{345}$ Idem, para. 21.

${ }^{346}$ CJEU 28 July 2016, Case C-543/14 Ordre des barreaux francophones et germanophone, ECLI:EU:C:2016:605, para. 31
} 
differs from the application of the reduced rate for lawyers' services. This proves that, within the VAT system, measures have been taken to stimulate the accessibility of health care. For lawyers' services, this is not the case, as the EU VAT Directive does not contain any VAT exemptions for those services. These services are thus meant to be covered under the broad scope of VAT. The two CJEU cases on lawyers' services that were discussed in this section concerned bringing the French and Belgium national VAT legislation in line with the EU VAT Directive, which implies taxation against the general rate. Having the hierarchy of sources of law in mind (figure 5.2), the harmonization of indirect taxes (following from the TFEU) and the rights laid down in Article 47 of the EU Charter are on the same level: the level of primary law. In other words, harmonizing the national VAT legislation (e.g. abolishing reduced rates or exemptions for the lawyers' services in order to comply with the provisions laid down in the EU VAT Directive) is, in principle, equally important as access to justice, the right to an effective remedy and the principle of equality of arms, following from the application of Article 47 of the EU Charter, as they constitute primary EU law. Furthermore, fiscal neutrality requires an equal VAT treatment of equivalent services. This is another argument for the abolishing the transitional national provisions that deviated from the general rule of the full taxation of lawyers' services in the EU VAT Directive. In contrast to these services, health care transactions are supposed to be exempt on the basis of the EU VAT Directive. Therefore, the starting point differs. In addition, I would like to add that the principle of fiscal neutrality constitutes secondary EU law and can, therefore, in general not be invoked to test the validity of exemption provisions provided for in the EU VAT Directive. ${ }^{347}$

It is clear that the levying of VAT in principle increases the price of a transaction. It can be deduced from Ordre des barreaux francophones et germanophone that the CJEU also acknowledges that fact and also acknowledges that charging VAT on lawyers' services can potentially affect the right to justice. ${ }^{348}$ The main reason for the CJEU to reject the arguments made by the applicants in that regard was that the CJEU had established that in the circumstances of the case, the imposition of VAT did not create an insurmountable obstacle to access to justice or make it impossible in practice or excessively difficult to exercise the rights conferred by the EU legal order. In my view, this is not an assessment that needs to be made in relation to the application of EU VAT on health care transactions in order to establish whether the access to health care can be affected by the imposition of VAT. That criterion was after all - as can be deduced from the case - a criterion that needs to be fulfilled specifically in relation to challenging the right to an effective remedy, guaranteed by Article

\footnotetext{
${ }^{347}$ CJEU 15 November 2012, Case C-174/11 Zimmermann, ECLI:EU:C:2012:716, para. 50; CJEU 29 October 2009, Case C-174/08 NCC Construction Danmark, ECLI:EU:C:2009:669, para. 44; CJEU 19 July 2012, Case C-44/11 Deutsche Bank, ECLI:EU:C:2012:484, para. 45; A-G Opinion 26 September 2013, Case C-366/12 Klinikum Dortmund, ECLI:EU:C:2013:618, para. 53.

${ }^{348}$ I deduce this inter alia from the fact that the CJEU in para. 37 leaves an opening for taking account of the right to legal aid in cases where the charging of VAT were to create, by itself, an insurmountable obstacle to access to justice or make it in practice impossible or excessively difficult to exercise the rights conferred by the EU legal order. See also para. 37 of the case where the CJEU refers to 'increased costs'.
} 
47 of the EU Charter. ${ }^{349}$ Moreover, in relation to the application of VAT exemptions on health care, the CJEU already acknowledged that the imposition of EU VAT as such reduces the accessibility of health care.

\subsection{Conclusions}

\subsubsection{Conclusions on the conflicting objectives}

In section 5.2.1, I referred to the definition of the right to health as a definition of an ideal. It is the objective of the right to health to progressively improve the enjoyment by all people of the right to health. ${ }^{350}$ The aspiration of this objective obliges States to take progressive steps towards the full realization of that right. More specifically - in relation to economic accessibility - this entails that measures that affect the affordability of health care have to be avoided and, furthermore, payment for health care services has to be based on the equity principle.

According to its legal character, EU VAT aims to tax consumption at the level of the final consumer, as was discussed in section 5.2.2. Furthermore, its broad scope intends to cover all transactions leading to that consumption, including health care consumption. I already stipulated that the objective of EU VAT in relation to health care consumption seems twofold. In order to make health care more accessible to individuals, which is also an objective of EU VAT, the VAT system relieves the VAT burden on (certain) health care transactions that are included in its scope.

The objective of EU VAT to make health care more accessible to individuals seems to correspond to the issue of accessibility, which is an important element of the human right to health (see section 5.2.1). I therefore concur with the considerations the CJEU put forward on the importance of the accessibility of health care. However, I do not agree with the CJEU that the VAT system is pursuing that objective by applying exemption provisions. The application of VAT exemptions still hinders access to health care. This is a result of denying an input VAT deduction. The extent of the distortive effect of the exemption provisions is discussed in more detail in chapters 6 and 7. Furthermore, the application of reduced rate also does not ensure a full relief of VAT on health care transactions, as there is still partial taxation.

As regards the objectives of the right to health and the EU VAT system, I conclude that, by nature, they conflict, as was already expected at the outset of this study. The right to health requires progressive measures towards economic accessibility of health care transactions. The general character of EU VAT, however, tends to include all health care transactions under its scope. Furthermore, the right to health demands that payment for health care services is

\footnotetext{
${ }^{349}$ CJEU 28 July 2016, Case C-543/14 Ordre des barreaux francophones et germanophone, ECLI:EU:C:2016:605, para. 31.

${ }^{350}$ See also WHO Media centre, WHO Health and Human Rights Fact Sheet N ${ }^{\circ} 323$, December 2015, retrievable via: http://www.who.int/mediacentre/factsheets/fs323/en.
} 
based on the principle of equity. The general application of EU VAT does not take that principle into account, as VAT is levied proportional to the price of transactions.

The right to health and the EU VAT system also have corresponding objectives. They both aim to make health care more accessible to individuals. In the context of VAT, that aim is pursued by including exemption provisions and provisions for reduced rates. The application of these provisions in relation to health care transactions is discussed in more detail in the following chapter. At this point, however, it is already clear that, despite those provisions, the imposition of VAT on health care transactions reduces access to health care merely because of the fact that the cost price of health care transactions increases.

\subsubsection{Conclusions on the hierarchy and the role of the CJEU}

In section 5.3, I demonstrated that the provisions of the EU VAT Directive need to be in line with primary EU law. This implies that it also must comply with the provisions in the EU Charter and, hence, also the right to health as laid down in Article 35 of the Charter. As Egholm Elgaard correctly notes in this regard:

"any impact of the Charter on VAT-related matters must be considered in connection with legislation, case law, administrative practice and guidelines etc., in order to comply with the Charter with its status as EU Primary Law". ${ }^{351}$

The right to health not only has to be taken into account because of its inclusion in the EU Charter, it also has to be taken into account as it is recognized in a number of an international human rights treaties. The ICESCR - to which all current EU Member States are a State Party - puts on all State Parties the obligation for a progressive realization of the right to health. Therefore, the right to health cannot be denied while applying EU VAT law. The same is true - as a consequence - for the principle of access to health care, of which financial access is one dimension.

The right to health and the desire for a harmonized EU VAT system are on the same hierarchical level. It is, therefore, in my view, safe to say that the presence of a harmonized VAT in the EU is accepted within the context of primary law. The rules of application of the harmonized VAT system (the EU VAT Directive) are, however, part of secondary EU Law and have to take into account the application of the right to health, as was shown above.

In section 5.3.2, I explored the role of the CJEU in this regard. In order to illustrate that role in relation to the application of the EU Charter concerning the application of VAT exemptions, I discussed two CJEU cases that dealt with the taxation of lawyers' services. Although there has not been a CJEU case yet on the balance between the right to health and the application of EU VAT on health care transactions, I believe that the application of the right to health in

\footnotetext{
${ }^{351}$ Egholm Elgaard, K., 2016, The Impact of the Charter of Fundamental Rights of the European Union on VAT Law, World Journal of VAT/ GST Law, vol. 5, issue 2, p. 63-91.
} 
Article 35 of the EU Charter may have a greater impact on the imposition of VAT on health care transactions than the impact the application of Article 47 of the EU Charter has on the imposition of VAT on the lawyers' services. The main reason for this conclusion is that the CJEU already acknowledged in relation to health care that the imposition of VAT on health care transactions reduces the accessibility of health care, whereas, in the field of access to justice, the CJEU uses other criteria to establish reduced accessibility.

In chapter 4, I established that the proclaimed aim of the medical exemptions - i.e. to ensure that the accessibility of health care transactions is not hindered by increased costs, which would occur if those services would be made subject to VAT - seems to correspond to the element of accessibility, which is an important element of the human right to health. The principle of access to health care, hence, justifies the considerations made by the CJEU in cases on the application of medical exemptions on health care transactions. In this chapter, I explored the relationship between the principle of access to health care and EU VAT. I concluded, like the considerations of the CJEU suggest, that the principle of access to health care indeed has to be taken into account for the application of EU VAT on health care transactions. In the following chapter, I will discuss the measures that are currently embedded within the EU Directive with a view to mitigating the VAT burden on health care transactions. This is necessary to answer the first central research question on how the application of positive EU VAT law on health care transactions impedes the principle of access to health care. 
Part III How the Application of Positive EU VAT Law Impedes Access to Health Care 


\section{Elements of positive EU law that may mitigate the VAT burden on health care transactions}

In chapter 3, I discussed the characteristics and some fundamental principles of positive EU VAT law. Moreover, I discussed several key elements that affect the VAT taxability of health care transactions. Such a legal framework is necessary in order to be able to address the application of positive EU VAT law on health care transactions from a conceptual point of view. In chapter 4, I explored the right to health and more in particular the element of accessibility to health care in order to justify the stated aim of EU VAT, which is to make health care more accessible to individuals, by reducing the costs of that care. I concluded that that aim corresponds to the principle of access to health care. In chapter 5, I concluded that the right to health must be taken into account while applying and interpreting positive EU VAT law. After having established that the principle of access to health can indeed be regarded as a standard in relation to the application of positive EU VAT law, in this chapter I will - in order to answer the central research question - establish how the access to health care is impeded as a result of the application of positive EU VAT law. In the following chapter, I will focus on the specific situations (where) the access to health care is hindered.

In this chapter I will discuss measures within the EU VAT Directive that may mitigate the VAT burden on health care transactions. In the following sections, at first the exclusions will be discussed. These are provisions that result in transactions being excluded from the scope of application of the EU VAT Directive (delineation). As such, these are not elements that specifically aim to exclude health care transactions from the scope of VAT. The result of their application is, however, that health care transactions are excluded. After the exclusions, the function and functioning of the application of VAT exemptions will be discussed to establish the (general) effect of the application of VAT on health care in relation to the right to care. 


\subsection{Exclusions in relation to health care transactions}

In some Member States, public supplies of health care are considered non-taxable events (see section 6.1.3). As a result - on the basis of the national equivalent of Article 13 of the EU VAT Directive - these health care transactions are excluded from the scope of EU VAT. This is the result of delineation, i.e. a system consequence. In this section, I will discuss the application of exclusion provisions. I will also demonstrate how the application of exclusions for public bodies on the basis of Article 13 of the EU VAT Directive and the exemption provisions for health care may result in a differential treatment of public and private sector bodies (section 6.1.2).

In section 3.2.1, I demonstrated that the scope of application of the EU VAT system is broad. It, in principle, covers all activities of taxable persons that ultimately lead to consumption. Some activities or persons are, however, explicitly excluded from the scope of European VAT. These are referred to as 'exclusions'. There are basically two types of exclusions: exclusions on the subject level and exclusions on object level. An example of an exclusion on the subject level can be found in Article 13 of the EU VAT Directive. This article is included in the EU VAT Directive under Title III 'Taxable Persons' and mentions bodies that "shall not be regarded as taxable persons". The EU VAT Directive, on the other hand, does not contain an exclusion provision specifically for transactions. Examples of excluded transactions are, according to case law, transactions for free and transactions provided in the common interest. ${ }^{352}$

It is impossible to treat these two types of exclusions as independent concepts. This already follows from a closer reading of Article 13 of the EU VAT Directive. The exclusion of the subject (public body) from the scope of VAT only applies:

"in respect of the activities or transactions in which they engage as public authorities". 353

Within the EU VAT system, the subject and the object are interrelated. Activities of a nontaxable person are in principle non-taxable activities ${ }^{354}$ and, vice versa, a taxable person performing excluded activities is acting as a non-taxable person with regard to those activities. A clear distinction between exclusions on a subject level and exclusions on object level can, therefore, not be made.

Note that 'exclusions' are not similar to 'exemptions'. As a result of an exclusion, a certain transaction is outside the scope of VAT and thus not taxable. As a result of an exemption, transactions remain within the scope of VAT and are thus taxable, however, they are not taxed. For the exempt transactions, a supplier is considered to be a taxable person, whereas for its non-taxable transactions, the supplier is not considered a taxable person.

\footnotetext{
${ }^{352}$ See for example CJEU 1 April 1982, Case C-89/81 Hong-Kong Trade, ECLI:EU:C:1982:121 and CJEU 8 March 1988, Case C-102/86 Apple and Pear Development Council, ECLI:EU:C:1988:120.

${ }^{353}$ Article 13 of the EU VAT Directive.

${ }^{354}$ Except for e.g. the importation of goods (Article 2(1)(d) of the EU VAT Directive) and intra-community acquisitions of new means of transport (Article 2(1)(b)(ii) of the EU VAT Directive).
} 
Article 13 of the EU VAT Directive excludes states, regional and local government authorities and other bodies governed by public law. Bodies that qualify under Article 13(1) of the EU VAT Directive are not regarded as taxable persons for the activities or transactions in which they engage as public authorities. In some Member States certain health care services are also considered to fall under this provision. The result is that the health care supplier is, for the activities concerned, regarded as a non-taxable person for VAT purposes. Consequently, the activities are not subject to VAT. On the other hand, the health care supplier does not have the right to deduct input VAT incurred in relation to those activities. In section 6.1.2, the VAT treatment of public sector bodies will be discussed in more detail. Public sector bodies are not only possibly confronted with the exclusion in Article 13 VAT, it can also be that the body is considered a taxable person, yet an exemption applies for the (health care) activities that it carries out. In the latter situation, not the subject but the object is excluded from taxation. The application of VAT exemptions for activities 'in the public interest' ${ }^{355}$ is therefore discussed in section 6.2, concerning health care supplies.

The VAT treatment of public sector bodies has caused a lot of discussion on EU-level. Problems that have been an issue in this regard are: the lack of neutrality, the lack of harmonization and complexity. ${ }^{356}$ In order to give a better idea of these issues, I will first outline the conditions laid down in Article 13 of the EU VAT Directive.

\subsubsection{The exclusion in Article 13 of the EU VAT Directive}

\subsubsection{General}

The first paragraph of Article 13(1) of the EU VAT Directive reads as follows:

"States, regional and local government authorities and other bodies governed by public law shall not be regarded as taxable persons in respect of the activities or transactions in which they engage as public authorities, even where they collect dues, fees, contributions or payments in connection with those activities or transactions."

Bodies governed by public law are not regarded as taxable persons in so far as they act as a public authority. The negative formulation of this provision shows that, without this exclusion, the said public bodies would fall under the broad notion of taxable person. This is important for a better understanding of the interpretation of Article 13 of the EU VAT Directive in relation to Article 9 of the EU VAT Directive. If the public body would not as such qualify as a taxable person, ${ }^{357}$ the application of Article 13 of the EU VAT Directive would be unnecessary. In other words, the exclusion in Article 13 of the EU VAT Directive only plays a

\footnotetext{
${ }^{355}$ Art. $132-134$ of the EU VAT Directive.

${ }^{356}$ Copenhagen Economics, 2013, VAT in the public sector and exemptions in the public interest, Final report for TAXUD/2011/DE/334, p. 50.

${ }^{357}$ See also CJEU 26 June 2007, Case C-284/04 T-Mobile Austria and Others, ECLI:EU:C:2007:381, para. 48 where the CJEU held that the application of Article 4(5) Sixth Directive [now: Article 13 of the EU VAT Directive] "implies a prior finding that the activity considered is of an economic nature".
} 
role after it has been established that the public body qualifies as a taxable person under Article 9 of the EU VAT Directive. In that regard, I do not immediately see the need for the last part of the first paragraph of Article 13 (1) of the EU VAT Directive: "even where they collect dues, fees, contributions or payments in connection with those activities or transactions". If the (public) body does not obtain any fee for performing the activities mentioned in that same paragraph, the activities would probably not even qualify as taxable activities under Article 2 of the EU VAT Directive, as consideration is missing. Moreover, the activities are economic activities in the first place.

In section 3.5.3.1 the exclusion of employees has been discussed. Henkow calls the exclusion for employees the only explicit exclusion, since all other persons engaged in any kind of economic activity are taxable persons for the purposes of European VAT, with the exception of public bodies when their activities are covered by Article 13 of the EU VAT Directive. ${ }^{358}$ । agree that employees are the only group of persons that are explicitly and fully excluded as a subject from the scope. Yet, I believe the exclusions for employees and public bodies are not similar. As was explained above, the exclusion in Article 13 of the EU VAT Directive only plays a role after it has been established that a person qualifies as a taxable person under Article 9 of the EU VAT Directive. The criterion of independence in Article 9 of the EU VAT Directive excludes employees from the notion of taxable persons, where the exclusion is actually an (ex post) adjustment of the broad tax base.

Article 13 of the EU VAT Directive constitutes an exception to the general character of the European VAT as a general tax on consumption including all consumptive expenditure. Therefore, the provision has to be interpreted in a strict manner. ${ }^{359}$ Van Doesum, Van Kesteren and Van Norden suggest that national courts should take the underlying objective of the VAT system - taxing private consumption - into account when assessing whether an activity of a public body is covered by Article 13 of the EU VAT Directive and hence excluded from the scope of VAT. ${ }^{360}$ After all, one could question whether there is still 'consumption' in case a citizen involuntarily pays for goods or services (i.e. a driving licence). At the same time, they admit that consumption can hardly be denied if a citizen pays for goods and services supplied by a public body, while those same goods could also be bought from private operators. $^{361}$

\footnotetext{
${ }^{358}$ Henkow, O., 2013, The VAT/GST Treatment of Public Bodies, Kluwer Law International, p. 30.

359 See inter alia CJEU 26 March 1987, Case 235/85 Commission vs. Netherlands, ECLI:EU:C:1987:161, para. 17.; CJEU 4 June 2009, Case C-102/08 SALIX Grundstücks-Vermietungsgesellschaft, ECLI:EU:C:2009:345, paras. 67-68 and CJEU 16 September 2008, Case C-288/07 Isle of Wight Council, ECLI:EU:C:2008:505, para. 60.

${ }^{360}$ Van Doesum, A.J., Van Kesteren, H.W.M., Van Norden, G.J., 2016, Fundamentals of EU VAT Law, Kluwer Law International, p. 94.

${ }^{361}$ Ibid.
} 


\subsubsection{Public bodies acting as public authorities}

The exclusion in Article 13 of the EU VAT Directive concerns 'bodies governed by public law'. This phrase is not further specified in the EU VAT Directive. The article gives the following examples: states and regional and local government authorities. What can be inferred from the text is that the exclusion in any case does not cover private bodies. ${ }^{362}$ Henkow compared the phrase 'bodies governed by public law' in several language versions of the EU VAT Directive. He concluded that the versions are not entirely consistent, and the expressions used do not necessarily have a meaning under national law. However, the wording does imply that the legal regime applicable to the body determines whether a body is public or not. ${ }^{363}$ The various interpretations of the terms 'public body' and 'public law' is also mentioned in the 2013 report 'VAT in the public sector' as one of the factors complicating the VAT treatment of public sector activities in the EU. ${ }^{364}$ In Saudaçor, the CJEU held, in relation to the first condition, that the fact that a body in question has, under national law, powers conferred by public law is not decisive for the purposes of the qualification as body governed by public law. ${ }^{365}$ According to the CJEU, it does, however, constitute a factor of definite importance in determining that the body must be classified as a body governed by public law. ${ }^{366}$

The second condition that must be fulfilled in order for the exclusion to apply, resulting in the treatment as a non-taxable person, is that the activities or transactions must be carried out by that body while acting 'as [a] public authority'. ${ }^{367}$ In Carpaneto Piacentino and Rivergaro, the CJEU expressed itself on the meaning of the wording 'as a public authority'. It held that activities pursued as public activities are those activities engaged in by bodies governed by public law under the special regime applicable to them. It does not include activities pursued under the same legal conditions as those that apply to private traders. ${ }^{368}$ As a result, the VAT treatment of public bodies is dependent on applicable national law. This is for example reflected in the inconsistent VAT treatment of hospital services in the different Member States (see section 6.1.2). In the First Report from the Commission to the Council of 14 September 1983 on the application of the VAT system, the Commission already noted that

\footnotetext{
${ }^{362}$ As is confirmed by the CJEU in CJEU 17 October 1989, Joined Cases C-231/87 and C-129/88 Ufficio distrettuale delle imposte dirette di Fiorenzuola d'Arda e.a v Comune di Carpaneto Piacentino and Others, ECLI:EU:C:1989:381, para. 15.

${ }^{363}$ Henkow, O., 2013, The VAT/GST Treatment of Public Bodies, Kluwer Law International, p. 38.

${ }^{364}$ Copenhagen Economics, 2013, VAT in the public sector and exemptions in the public interest, Final report for TAXUD/2011/DE/334, p. 23, 50.

${ }^{365}$ CJEU 29 October 2015, Case C-174/14 Saudaçor, ECLI:EU:C:2015:733, para. 58 366 Ibid.

367 Inter alia CJEU 14 December 2000, Case C-446/98 Fazenda Pública v Câmara Municipal do Porto, ECLI:EU:C:2000:691, para. 15; CJEU 25 July 1991, Case C-202/90 Ayuntamiento de Sevilla v Recaudadores de Tributos de las Zonas primera y segunda, ECLI:EU:C:1991:332, para. 18; CJEU 11 July 1985, Case C-107/84 Commission vs. Germany, ECLI:EU:C:1985:332 and CJEU 26 March 1987, Case 235/85 Commission vs. Netherlands, ECLI:EU:C:1987:161.

368 CJEU 17 October 1989, Joined Cases C-231/87 and C-129/88 Ufficio distrettuale delle imposte dirette di Fiorenzuola d'Arda e.a v Comune di Carpaneto Piacentino and Others, ECLI:EU:C:1989:381, para. 19
} 
that the wide divergences between Member States on this point gives rise to a number of difficulties. $^{369}$

\subsubsection{Exceptions to the exclusion}

There are two important exceptions to the exclusion for public bodies. The exclusion does not apply and the body concerned is hence regarded as a taxable person, if:

A. the treatment as a non-taxable person would lead to significant distortions in competition; or

B. the activities concerned are listed in Annex I, provided that those activities are not carried out on such a small scale as to be negligible. ${ }^{370}$

The need for a strict interpretation of the exclusion itself brings about that these exceptions are to be interpreted in a broad manner. The CJEU confirmed this and recalled that the aim of the exception is to restore the general rule according to which any activity of an economic nature is in principle subject to VAT. ${ }^{371}$

\section{A: Significant distortions in competition}

From Isle of Wight it follows that distortions in competition both entail actual and potential competition, provided that the possibility must be real and not purely hypothetical. ${ }^{372}$ The mere presence of private operators on a market cannot as such demonstrate the existence either of actual or potential competition or of a significant distortion of competition. ${ }^{373}$ The CJEU held in Salix that a significant distortion in competition not only concerns distortions in competition that are disadvantageous to (taxable) competitors of the supplier. It also concerns competition distortions that affect the supplier as a result of its treatment as a nontaxable person. ${ }^{374}$ The latter refers for example to cases in which there are negative effects as a result of not taxing certain transactions with VAT. The recipient of transactions performed by a non-taxable supplier will not be able to deduct any input VAT, even in cases where the recipient is a taxable person, which is entitled to an input tax deduction. If a supplier that is in competition with the aforementioned non-taxable supplier does charge VAT on similar transitions, the non-taxed supplier will find itself at a disadvantageous position. The recipient with a right to deduct input VAT will, then, prefer to buy goods or

\footnotetext{
${ }^{369}$ First Report from the Commission to the Council on the application of the common system of value added tax of 14 September 1983, COM(83) 426 final, p. 30.

${ }^{370}$ Second and third subparagraph of Article 13(1) of the EU VAT Directive.

${ }^{371}$ CJEU 4 June 2009, Case C-102/08 SALIX Grundstücks-Vermietungsgesellschaft, ECLI:EU:C:2009:345, paras. 67-68; CJEU 16 September 2008, Case C-288/07 Isle of Wight Council, ECLI:EU:C:2008:505, para. 60.

${ }^{372}$ CJEU 16 September 2008, Case C-288/07 Isle of Wight Council, ECLI:EU:C:2008:505, para. 65.

${ }^{373}$ CJEU 19 January 2017, Case C-344/15 National Roads Authority, ECLI:EU:C:2017:28, para. 44.

374 CJEU 4 June 2009, Case C-102/08 SALIX Grundstücks-Vermietungsgesellschaft, ECLI:EU:C:2009:345, paras. 62-76.
} 
services on which VAT is charged to them, as non-taxed supplies are likely to contain hidden VAT, as a result of accumulation.

\section{B: Activities listed in Annex I}

For the activities mentioned in Annex I to the EU VAT Directive, the public bodies have to be treated as taxable persons, unless they are negligible. The activities mentioned are:

(1) Telecommunications services;

(2) supply of water, gas, electricity and thermal energy;

(3) transport of goods;

(4) port and airport services;

(5) passenger transport;

(6) supply of new goods manufactured for sale;

(7) transactions in respect of agricultural products, carried out by agricultural intervention agencies pursuant to Regulations on the common organisation of the market in those products;

(8) organisation of trade fairs and exhibitions;

(9) warehousing;

(10) activities of commercial publicity bodies;

(11) activities of travel agents;

(12) running of staff shops, cooperatives and industrial canteens and similar institutions;

(13) activities carried out by radio and television bodies in so far as these are not exempt pursuant to Article 132(1)(q).

\section{Exempt instead of non-taxable}

Next to the two imperative exceptions to the exclusion for public bodies, there is an optional exception in Article 13(2) of the EU VAT Directive. The definition of the provision in 13(2) of the EU VAT Directive demonstrates a clear distinction between, on the one hand, exceptions and exemptions. It is remarkable that he CJEU, in its own case law, uses the term 'exempt' while referring to the exclusion of Article 13 of the EU VAT Directive. ${ }^{375}$ Member States may treat activities that are covered under Article 132, 135, 136, and 371, Articles 374 to 377, Article 378(2), Article 379(2), or Articles 380 to 390b as exempt instead of non-taxable if they are carried out by bodies governed by public law as activities in which those bodies engage as public authorities.

The scope of application of Article 13(2) of the EU VAT Directive also concerns health care transactions, as these are listed under Article 132 of the EU VAT Directive. Implementation of this provision in national law has the effect that public hospitals that act as a public authority for the hospital services that they carry out, are considered a taxable person for the services

375 CJEU 29 October 2015, Case C-174/14 Saudaçor, ECLI:EU:C:2015:733, para. 41. 
covered by the exemption for hospital services. ${ }^{376}$ Theoretically, such hospitals can perform both VAT exempt and non-taxable activities. For services that are normally taxed because they do not fall under the exemption for hospital services, the exception to the exclusion in Article 13 (2) Directive VAT does after all not apply.

\subsubsection{Differential treatment of public and private sector bodies}

The exclusion for public bodies in Article 13 of the EU VAT Directive and the exemptions for activities in the public interest in Articles 132-134 of the EU VAT Directive result in a differential treatment of public and private bodies or activities under the EU VAT system, leading to distortions of competition between exempt, non-taxable and taxable services, ${ }^{377}$ especially since privatization and deregulation of former public sector activities has increased. ${ }^{378}$ The European Commission has addressed the problems that this differential treatment may cause already several times.

In the 2010 Green Paper, the Commission addressed the differential treatment as a key issue to be tackled in order to make the VAT system more solid, simple and efficient. The Green Paper was used as a means to invite all stakeholders (i.e. businesses, academics, citizens, and tax authorities) to take a critical look at all aspects of the EU VAT system which has now been in place for over 40 years. In the Green Paper, the Commission emphasizes that nondeductible VAT becomes a factor influencing investment and spending decisions of public bodies that are outside the scope of VAT. As a result, they have an incentive to limit outsourcing as opposed to public and private bodies that fall within its scope and are entailed to deduct input VAT. The Commission Staff Working Document accompanying the Green Paper is more extensive. ${ }^{379}$ It mentions three (types of) shortcomings in relation to the VAT treatment of the public sector. ${ }^{380}$ This is firstly the distortion of competition between public and private bodies and the bias towards the self-supply of inputs that results therefrom ('neutrality'). The wide discretion that is left to the Member States to define 'public bodies' is seen as another shortcoming ('lack of harmonisation'). Finally, the Commission staff mentions the 'complexity' of the current VAT regime for public bodies, as they can either be within the scope and taxed, within the scope and exempt or be outside the scope. The qualification is complicated by the difficulty to determine the right of deduction, the exemptions that are not defined precisely and the different options available to the Member States in Articles 13 and $132-134$ of the EU VAT Directive. ${ }^{381}$ Public health care suppliers may

\footnotetext{
${ }^{376}$ Article 132(1)(b) of the EU VAT Directive.

${ }^{377}$ Communication from the Commission to the Council and the European Parliament of 7 May 2000, A strategy to improve the operation of the VAT system within the context of the internal market, $\operatorname{COM}(2000) 348$ final, $p$. 11. See also Commission Staff Working Document, Accompanying document to the Green Paper on the future of VAT, SEC (2010) 1455 final, p. 10.

378 Ibid.

${ }^{379}$ Commission Staff Working Document, Accompanying document to the Green Paper on the future of VAT, SEC (2010) 1455 final, p. 10.

${ }^{380}$ Idem, p. 10, 24.

${ }^{381}$ Idem, p. 24-26.
} 
be confronted with these complex matters and, as a result, incur substantial compliance costs. These increased costs may put them in a worse position compared to private hospitals which could lead to an infringement of fiscal neutrality or - if they are not considered to be in competition - with the general principle of equality. ${ }^{382}$

The conclusions of the public consultation, initiated by the Green Paper, have led to a careful consideration of a gradual phasing out of existing exemptions, such as on education or health. In other words, a broadening of the tax base is encouraged as a means to diminish the shortcomings of the current VAT rules as regards public bodies. ${ }^{383}$ Ultimately, this would lead to a situation where all public bodies are taxed and are hence entitled to claim an input VAT deduction. This is comparable to the system in force in New Zealand and Australia. ${ }^{384}$ Nevertheless, up until now, no concrete changes to the EU VAT treatment of public bodies has been presented.

\subsubsection{Differential treatment of (bodies involved in) health care activities}

The provision of health care is generally considered to be a public service. It is mostly offered to the public through public sector bodies. Most Member States, however, have a tendency to liberalize former exclusively public sectors, ${ }^{385}$ allowing more and more private competitors to enter the market. Aujean, Jenkins and Poddar distinguish three categories of government activities, including the provision of public goods and services. Health care supplies are considered public goods. This category is then sub-divided into the provision of goods and services on a collective basis to the public at large and the supply of goods and services where it may be feasible to measure individual consumption. The latter concerns goods and services for which it is not socially desirable to charge any price or to charge a price which reflects the full costs of providing them. These goods and services are referred to by the authors as 'merit goods'. Health care and education are mentioned as examples of 'merit goods'. ${ }^{386}$

The study shows in the first place that the provision of hospital services occurs in all the surveyed Member States. It also appears that the VAT treatment differs. Hospital services are

\footnotetext{
382 Bomer, A.H., 2012, De doorwerking van de algemene rechtsbeginselen in de BTW (diss.), Maastricht University, p. 125.

${ }^{383}$ Communication from the Commission to the European Parliament, the Council and the European Economic and Social Committee of 6 December 2011, COM(2011) 851 final (otherwise referred to as the 'White Paper').

${ }^{384}$ Vyncke, K., Cordewener, A. and De Broe, L., 2011, Towards a Simpler, More Robust and Efficient VAT System by levying VAT at EU Level, International VAT Monitor July/August 2011, IBFD, p. 245. See also Aujean, M., Jenkins, P. and Poddar, S., 1999, A new approach to public sector bodies, International VAT Monitor vol. 10, no. 1, July/ August 1999, IBFD, p. 147.

${ }^{385}$ Copenhagen Economics, 2013, VAT in the public sector and exemptions in the public interest, Final report for TAXUD/2011/DE/334, p. 50.

${ }^{386}$ Aujean, M., Jenkins, P. and Poddar, S., 1999, A new approach to public sector bodies, International VAT Monitor vol. 10, no. 1, July/ August 1999, IBFD, p. 144. See also Gendron, P.P., 2005, Value Added Tax Treatment of Public Sector Bodies and Non-profit Organizations: A Developing Country Perspective, Bulletin for International Taxation, Volume 59, No. 12, IBFD, p. 515, who refers to health care and education as 'quasi-public goods'.
} 
not subject to VAT across the EU, except for private health care services in Austria. This is because either the subject (the hospital) is excluded from the scope of VAT or because the hospital services themselves qualify as VAT exempt services. The VAT treatment of hospital services within the EU is apparently not uniform and apparently the EU VAT Directive allows a lot of room for discretion in this respect to the Member States. In my view, these problems, are due to the fact that health care systems are not harmonized within the EU. As a result, it is necessary, at least under positive EU law, to leave discretion to the Member States when it concerns the qualification of medical professions or qualifying health care bodies. In the end, as followed from the analysis of definitions for health care in chapter 4, the quality aspect remains decisive for distinguishing health care from other health-related services. This is also in line with the aim of VAT to make health care more accessible to individuals. The differential VAT treatment of hospital services may be problematic from a neutrality point of view. In my view, a differential treatment between Member States can, to a certain extent, be justified on the basis of the destination principle. It may be expected that hospital services are by nature mainly consumed locally. Furthermore, numbers in cross-border patient mobility show that the actual number of patients seeking treatment cross border is still relatively small. ${ }^{387}$

At the time the conclusions of the public consultation following the release of the Green Paper were presented (2011), a more detailed comprehensive study on the economic consequences and possible reforms of the EU VAT treatment of the public sector, also initiated by the Commission, had been carried out. ${ }^{388}$ This study, which was expanded in $2013,{ }^{389}$ involved, inter alia, a comparison of the (national) VAT treatment of public bodies in the different Member States. To gain insight into the national VAT treatment, Member States were asked to fill out a questionnaire. The questionnaire also included a number of specific questions about the VAT treatment of the provision of hospital services. The study shows that, in nearly all Member States, hospital services are assigned to public bodies. To the question "If there is a public service offering, is it treated as taxable?" nineteen of the twenty-six Member States that filled out the questionnaire answered in the affirmative. One of the Member States (Poland) actually indicated that both options are possible. Under Polish national law, the public hospital service is treated as taxable if it is performed directly to a consumer who pays remuneration on the basis of a civil law agreement. The other six Member States treat hospital services provided by public bodies as non-taxable.

\footnotetext{
${ }^{387}$ Footman, K., Knai, C., Baeten, R. et al., 2014, Cross border health care in Europe, Policy Summary 14, WHO; Legido-Quigley, H., Passarani, I., Knai, C. et al., 2011, Cross-border healthcare in Europe: clarifying patients' rights, BMJ, 342(7793):364-7.

${ }^{388}$ Copenhagen Economics, 2011, VAT in the public sector and exemptions in the public interest, Final report for TAXUD/2009/DE/316.

${ }^{389}$ Copenhagen Economics, 2013, VAT in the public sector and exemptions in the public interest, Final report for TAXUD/2011/DE/334.
} 
Private health care offerings are considered taxable in all Member States. All Member States, except for Austria, at the same time treat these health care offerings as tax exempt. The latter implies that the public bodies assigned to provide health care in those Member States are not considered to engage in those activities 'as public authorities'. Otherwise, those health care suppliers would not be regarded as taxable persons because of the exclusion in Article 13 of the EU VAT Directive (see section 6.1.1 for a more detailed explanation of the exclusion provision). Austria is the only Member State that does not exempt private health care offerings, but it applies a reduced rate.

The fact that health care is considered a public good, or more specifically a merit good, and it is either provided by public or private bodies, complicates the levying of VAT. Already on the subject level, the distinction between private and public bodies is of importance for the VAT consequences. Public health care suppliers are either included or excluded from the scope of VAT. The ongoing discussions on the EU level as regards the (diverse) VAT treatment of public sector bodies is in any case of importance for bodies involved in health care activities.

\subsubsection{Effects of non-economic activities of health care suppliers}

The previous sections concerned the exclusions that are present in the EU VAT Directive. The EU VAT Directive contains exclusions on the subject level and the object level. These types of exemptions are, in fact, interrelated, as was explained in section 6.1. If transactions are excluded from the scope of EU VAT, as a result of the application of these exclusions, they are not taxable. These activities are usually referred to as 'out-of-scope' activities. Examples of such activities are activities of charity organizations that exclusively perform activities free of charge or the activities of public bodies that act in their capacity as government. The direct and most obvious consequence of a transaction falling outside the scope of EU VAT is that there is no VAT charged in relation to these activities. In the following sections, the effects of the supply of out-of-scope activities by health care suppliers will be discussed in more detail.

\subsubsection{Health care suppliers as 'non-taxable persons'}

Article 13 of the EU VAT Directive defines the persons that are excluded from the scope of EU VAT. Article 13 is placed under Title III of the Directive, which is called 'Taxable Persons'. Yet, the exclusion clearly focusses on activities, for it states: "in respect of those activities or transactions". The result is, however, that the person carrying out these activities should not be regarded a taxable person. The type of activities undertaken are obviously decisive for the qualification as falling within or outside the scope of VAT and even overrule the qualification of the subject under Article 9 of the EU VAT Directive as regards the activities concerned. What should be kept in mind is that the person in question as such (purely on basis of the nature of the subject) qualifies as a taxable person on the basis of the criteria in Article 9 of the EU VAT Directive. If that were not the case, an application of Article 13 of the EU VAT Directive would after all not be at issue, because the person would already be outside the scope as a result of the application of Article 9 of the EU VAT Directive. If the exclusion of 
Article 13 of the EU VAT Directive applies, the person performing the activities concerned is, as a result, a non-taxable person in respect of those activities.

I showed in the previous sections that the application of Article 13 of the EU VAT Directive is not always straightforward and leads to a differential treatment of public and private bodies and, consequently, a differential treatment of (bodies involved in) health care activities. In the 2013 report on the study on VAT in the public sector and exemptions in the public interest, it is shown that Article 13 of the EU VAT Directive is capable, theoretically, of avoiding unfair competition caused by treating public transactions in the same was as those of private competitors. However, as is pointed out in the report, the success of this greatly depends on its proper transposition and application by Member States. Furthermore, it is noted that the distortion clause in Article 13 of the EU VAT Directive disregards problems a public body might face in relation to its (non-deductible) input VAT. ${ }^{390}$ For example, it seems that an excluded public body cannot make any VAT claims on the basis of the rules concerning the adjustment of input VAT for the goods that are acquired in their capacity as a non-taxable person and that are later used for tax purposes (in the capacity as taxable person). ${ }^{391}$

\subsubsection{No or reduced input VAT deduction}

The right to deduct input VAT is a right that is reserved for taxable persons, as can be understood from Article 168 of the EU VAT Directive. It was shown in section 3.2.4 that the right to deduct is aimed at entirely relieving a taxable person of the VAT that is paid or payable in the course of all his economic activities, provided that they are subject to VAT.

If a health care supply is provided as a non-taxable activity (e.g. public hospital care), the health care provider cannot deduct the VAT charged on costs or investments made in relation to that activity. As a result, the non-deductible VAT may become part of the cost price of that health care and will increase the price of health care offered to health care seekers. This shows that, despite the application of exclusions, the application of positive EU VAT law still hinders access to health care. The non-deductibility of input VAT will not only influence the (cost) price of health care, it will also influence choices made by, for example, the body providing that public health care. If possible, the body will avoid investments in relation to which VAT is charged. It can, after all, not deduct that VAT and will prefer VAT-free investments.

These effects might be diminished in case the Member State concerned would for example have a VAT compensation scheme in place. VAT compensation schemes are often in place to compensate public bodies for the inability to deduct input VAT. Some Member States limit

\footnotetext{
${ }^{390}$ Copenhagen Economics, 2013, VAT in the public sector and exemptions in the public interest, Final report for TAXUD/2011/DE/334, p. 60-61.

${ }^{391}$ Cf. CJEU 11 July 1991, Case C-97/90 Lennartz v Finanzamt München III, ECLI:EU:C:1991:315, para. 17.
} 
the benefits of such schemes for operators in specific sectors. ${ }^{392}$ It should be noted that such VAT compensation schemes are not a result of implementation of the EU VAT Directive. In the 2013 report on the study on VAT in the public sector and exemptions in the public interest, a comprehensive analysis was carried out on the compensation systems present in different Member States and their effects. ${ }^{393}$ In the report, compensation systems are referred to as a means to address VAT issues, "such as a compensation for expected hidden VAT included in the price of an exempt transaction, which is provided by a private entity to a public body". ${ }^{394}$ The presence of such systems alone already demonstrates that VAT exclusions hinder access to health care and that there is an apparent need or desire to mitigate the hindering effect.

The effects that occur as a result of the inability to deduct input VAT in the case of exclusions are, in principle, similar to the effects of non-deductible VAT in the case of the application of exemption provisions. I, therefore, refer at this point to section 7.2.2.2 on the consequences of the application of an exemption for medical care in the basic situation.

\subsubsection{Acting in multiple capacities}

It is possible that this person also performs other activities that also qualify as economic activities but are not subsequently excluded by the application of Article 13 of the EU VAT Directive. As a result, the person can act in two capacities: as a taxable person and a nontaxable person. Also, health care suppliers can act in different capacities. In the previous section it was shown that a number of Member States consider hospitals to be non-taxable persons under their national VAT system for the public hospital services they provide. If such a hospital would, for example, also offer non-public hospital services, or services as a result of which competition distortions occur, the hospital acts not only as a non-taxable person, but also as a taxable person for VAT.

The possibility of being able to act in multiple capacities brings with it additional burdens. In the first place, it requires a certain level of knowledge from the supplier on the criteria for qualifying transactions as taxable or non-taxable. I expect this is more likely to occur in Member States that treat certain forms of (public) health care as non-taxable for VAT purposes. Moreover, as a result of the inability to deduct input VAT in relation to excluded transactions, the supplier will be required to keep an administration of the amount of turnover related to non-economic activities and economic activities. The reason for this is that only the taxed economic transactions give rise to an input tax deduction, based on the application of Article 168 of the EU VAT Directive. The substantial costs for administration may be expected to be charged forward in the prices of the health care provided by the supplier and, hence, may impede access to health care.

\footnotetext{
392 Ibid.

393 Ibid.

${ }^{394}$ Idem, para. 94.
} 
A taxable person that carries out both taxed and exempt transactions is usually confronted with the provisions on proportional VAT deductions, as laid down in Articles 173-175 of the EU VAT Directive. In practice, it rarely happens that the transactions carried out by a taxable person are fully taxed or fully exempt. The provisions on proportional VAT deductions are relevant for determining the deductible VAT on a taxable person's general costs. With general costs I refer to costs that relate to the economic activities of the taxable person but that cannot be attributed to the taxed or to the exempt transactions. The main rule for determining a proportional deduction is to use a fraction ('pro rata') based on the amount of turnover resulting from those activities (see also sections 3.2.4 and 7.2.2.2). The periodical calculation of this partial deduction is, as such, already an administrational burden. For suppliers who act in multiple capacities (both economic and non-economic) this administrative exercise becomes even more complicated. They have to apply a 'pre pro rata' for determining the deductible VAT on general costs that relates both to the activities in the capacity as a taxable person, as well as to the activities in the capacity as a non-taxable person (see also section 3.2.4). ${ }^{395}$ VAT charged on (costs) is not deductible in so far as it can be attributed to the non-taxable activities of a supplier. As a result of these complex regulations, health care suppliers whose activities are excluded from the scope of EU VAT may thus face a substantial administrative burden, compared to (health care) suppliers who only perform activities covered within the scope of EU VAT.

\subsubsection{Interim conclusion}

As a result of the application of the provision for exclusions, in Article 13 of the EU VAT Directive, public health care suppliers may be excluded from the scope of VAT. As a result, there activities are considered outside the scope. This entails that the health care supplier has no right to deduct input taxation, as this right is reserved for taxable persons in relation to their taxed supplies. As an exception to the exclusion, Member States may consider the health care services of, for example, a public hospital as exempt.

The application of the exclusion provision in Article 13 of the EU VAT Directive, on the one hand, and the application of the exemption provisions for health care, on the other hand, may lead to a differential treatment of public and private sector bodies. I demonstrated that, especially for public sector bodies, the application of positive EU law is rather complex. They can be either excluded from or included in the scope of VAT. Within the scope, their transactions can either be taxed or exempt. As a result, they may have difficulties, for instance to determine their right to deduct. The foregoing shows that the application of exclusions hinders access to health care. The complexity of the application of VAT brings along substantial compliance costs, leading to increased costs of health care and, hence, impedes access to health care. The same is true for the negative side effects of the inability

\footnotetext{
395 The term 'pre pro rata' was introduced by Van Doesum; Van Doesum, A.J., 2009, Contractuele samenwerkingsverbanden in de BTW (diss.), p. 252.
} 
to deduct input VAT (e.g. the bias to self-supply) (see also section 6.2.6 on the effects of the application of exemption provisions).

Exclusions are the mere result of a delineation of the scope. They follow directly from the system of VAT. From the purpose of exemption provisions, it follows, however, that it is an aim of the VAT system to make health care more accessible to individuals. I do not see any reason why the VAT system should disregard this aim if the health care transactions concerned are outside the scope. Furthermore, the principle of access to health care, from a human rights perspective, also does not make any distinctions between public and private health care suppliers that would justify a differential VAT treatment.

\subsection{The application of VAT exemptions in relation to health care transactions}

In section 3.8, I provided a general introduction to the concept of exemption provisions. The application of exemptions and exclusions have in common that the transactions to which they apply are not taxed with VAT. Yet, there are important differences. Excluded transactions, in principle, do not fall within the scope of application of the EU VAT Directive, whereas, exempt transactions do. Exemption provisions in the EU VAT Directive can only apply to taxable activities.

Unlike the exclusions that have been discussed in section 6.1, the exemptions for medical care are measures that have been included in the VAT with the specific aim to relieve the VAT burden on health care transactions. This section serves to provide a conceptual analysis of the application of VAT exemptions in relation to health care transactions by discussing their application criteria and effects. This should provide insights with regard to the question of how the application of EU VAT hinders the access to health care. Chapter 7, subsequently, contains comprehensive assessments on the application of the VAT exemptions for medical care, in order to make it clear in which specific situations the access to health care is hindered as a result of the application of EU VAT.

In a number of cases, the CJEU held that the VAT exemptions for medical care have the objective of reducing the costs of health care and of making health care more accessible to individuals. ${ }^{396}$ It therefore wishes to ensure that the benefits flowing from hospital and medical care: "are not hindered by the increased costs of providing it that would follow of it, or closely related activities were subject to VAT". 397

\footnotetext{
${ }^{396}$ See inter alia CJEU 20 November 2003, Case C-212/01 Margarete Unterpertinger, ECLI:EU:C:2003:625, para. 41; CJEU 8 June 2006, Case C-106/05 L.u.P., ECLI:EU:C:2006:380, para. 25; CJEU 6 November 2003, Case C45/01 Dornier, ECLI:EU:C:2003:595, para. 48 and CJEU 10 September 2002, Case C-141/00 Kügler, ECLI:EU:C:2002:473; see also CJEU 1 December 2005, Joined Cases C-395/04 and C-394/04 Ygeia, ECLI:EU:C:2005:734, para. 24 and A-G Opinion 10 September 2009, Case C-262/08 CopyGene, ECLI:EU:C:2009:541, p. 33.

${ }^{397}$ CJEU 11 January 2001, Case C-76/99 Commission vs. France, ECLI:EU:C:2001:12, para. 23.
} 
This suggests that the application of VAT exemptions in fact results in VAT relief for those individuals, the consumers of that health care.

This suggestion is interesting because exemptions, as such, infringe the general and neutral character of the EU VAT system (see also section 3.3). ${ }^{398}$ The application of exemptions can even lead to a cascading of VAT within the production chain, a consequence that has been recognized from the beginning. ${ }^{399}$ Under the main rule of this general and neutral VAT system, all supplies of goods and services are taxed and the taxable persons carrying out the taxed supplies are entitled to a deduction of the VAT that was charged to them on their inputs. It is for this reason that exemptions are exemptions to the main rule and that they have to be interpreted in a strict manner. This by no means proves to be an easy task, judging from the number of cases decided by the CJEU concerning the interpretation of exemption provisions. That is not surprising, considering that the terms used in the exemption provisions are not further defined in the EU VAT Directive. Moreover, terms such as 'medical care' and 'hospital care' can have a various interpretations in different Member States, since health care systems are a national matter. ${ }^{400}$

In chapter 2, I explored definitions and common denominators of EU health care systems. I demonstrated that the health care sector entails a great number of transactions, not only those limited to the actual provision of health care but also supporting transactions. In section 3.2, I demonstrated that the EU VAT Directive potentially covers a large part of the health care provided by health care providers as a result of the broad scope of the concept of the taxable person. Consequently, the potential area of application of VAT exemptions for hospital and medical care on health care transactions is significant.

The VAT exemptions for hospital and medical care are included in Article 132 of the EU VAT Directive. Article 132(1)(b) of the EU VAT Directive contains an exemption for ('intramural') hospital and medical care, while Article 132(1)(c) of the EU VAT Directive exempts medical care provided by (para)medical professionals ('extramural' care). In the following sections, the scope of application of these exemption provisions, as regards health care transactions, will be discussed. It follows from the case law on the exemption provisions on hospital and medical care that they actually aim to cover the same kinds of services: services with as their purpose diagnosing and treating and, in so far as possible, curing diseases or health disorders. ${ }^{401}$ Therefore, the exemption provisions will be analysed together. Before discussing the conditions for the application of the exemption provisions for intramural and

\footnotetext{
${ }^{398}$ Article 1 (2) of the EU VAT Directive.

${ }^{399}$ It was therefore that the number of exemptions was limited and that the application of a reduced rate was preferable to exemptions; see also the preamble to Second Council Directive 67/228/EEC of 11 April 1967 on the harmonisation of legislation of Member States concerning turnover taxes, OJ 71, 14 April 1967.

${ }^{400}$ See also Chapter 2.

${ }^{401}$ CJEU 6 November 2003, Case C-45/01 Dornier, ECLI:EU:C:2003:595, para. 48; CJEU 14 September 2000, Case C-384/98 D., ECLI:EU:C:2000:444, para. 18; CJEU 10 September 2002, Case C-141/00 Kügler, ECLI:EU:C:2002:473, para. 38.
} 
extramural health care, I will discuss their joint objective, i.e. making health care more accessible to individuals.

\subsubsection{Making health care more accessible to individuals by reducing costs}

Within this study, I frequently referred to considerations made by the CJEU on the (apparent) aim of the exemptions for medical care under positive EU VAT law. It is, as a result of those considerations, commonly accepted that the exemption provisions in Article 132(1)(b) and (c) of the EU VAT Directive both aim at reducing the costs of medical care and making that care more accessible to individuals. ${ }^{402}$ The CJEU even extended this accessibility argument to the application of other exemption provisions. In the TMD case, the CJEU held that:

"as regards the purpose of the provisions of Article 132 of Directive 2006/112, it must be recalled that that article aims to exempt from VAT certain activities in the public interest with a view to facilitating access to certain services and the supply of certain goods by avoiding the increased costs that would result if they were subject to VAT". 403

From the foregoing it can be deduced that the accessibility argument is a valid argument while interpreting the scope of the other exemption provisions included in Article 132 of the EU VAT Directive. The argument of access to health care was brought up by the CJEU for the first time in Commission vs. France. ${ }^{404}$ Moreover, Advocate General Saggio, already referred to a need to reduce medical costs in the opinion on the $D$. case (2000). ${ }^{405}$ The Advocate General stated the following:

"Next, if one considers the reasons why the provision of medical care is exempt from VAT, the references to care of the person which feature in the provision at issue make it fairly clear that the exemption is justified by the need to reduce medical costs and thus to promote access to health-care. Were a different approach to be taken, if, in other words, the exemption were to be considered applicable to all professional activities carried out by doctors, the scope of application of the provision would broaden in favour of activities which have no connection with the health of human beings and quite different situations and interests would be treated in the same way without good reason."

\footnotetext{
${ }^{402}$ See inter alia cases CJEU 8 June 2006, Case C-106/05 L.u.P., ECLI:EU:C:2006:380, para. 25; CJEU 6 November 2003, Case C-45/01 Dornier, ECLI:EU:C:2003:595, para. 43,48 and CJEU 10 September 2002, Case C-141/00 Kügler, ECLI:EU:C:2002:473; CJEU 20 November 2003, Case C-212/01 Margarete Unterpertinger, ECLI:EU:C:2003:625, para. 41; see also CJEU 1 December 2005, Joined Cases C-395/04 and C-394/04 Ygeia, ECLI:EU:C:2005:734, para. 24 A-G Opinion 10 September 2009, Case C-262/08 CopyGene, ECLI:EU:C:2009:541, para. 33.

${ }^{403}$ CJEU 5 October 2016, Case C-412/15 TMD, ECLI:EU:C:2016:738, para. 30.

${ }^{404}$ CJEU 11 January 2001, Case C-76/99 Commission vs. France, ECLI:EU:C:2001:12, para. 23.

${ }^{405}$ A-G Opinion 27 January 2000, Case C-384/98 D., ECLI:EU:C:2000:55.

${ }^{406}$ Idem, para. 16.
} 
The Advocate General was - unfortunately, without making a reference to legal sources of the opinion that the reasons for the exemption for medical care are based on the need to reduce medical costs and the promotion of access to health care. The CJEU in that case did not take over that reasoning, nor did it give a reaction to it. As indicated, it introduced the objective of accessibility to health care for the first time in Commission vs. France. In that case, how the concept of activities 'closely related to hospital and medical care' must be interpreted was at issue. The case concerned a hospital laboratory that transferred blood samples to other laboratories to be analysed. According to the CJEU, taking the sample and transferring the sample to a specialized laboratory constitute services which are closely related to that analysis, since the patient is indifferent as to whether the laboratory which takes the samples also carries out the analysis or not. ${ }^{407}$ The CJEU emphasized, in line with the opinion of the Advocate General in that case, that the concept of activities 'closely related to hospital and medical care' does not call for an especially narrow interpretation, since the exemption of activities closely related to hospital and medical care is designed to ensure that benefits flowing from such care are not hindered but the increased costs of providing it that would follow if it, or closely related activities, were subject to VAT. ${ }^{408}$ It must be noted that the analysis itself must have a therapeutic aim. The CJEU referred in this respect to its decision in the $D$. case, where it considered that medical interventions which do not have a therapeutic aim must be subject to VAT. ${ }^{409}$

As indicated, the CJEU frequently referred to the accessibility of health care as an argument for applying VAT exemptions. The CJEU, unfortunately, does not refer to (legal) sources for applying that argument. Furthermore, it appears that the argument of accessibility of health care in the Commission vs. France case was actually discussed in relation to the scope of application of the notion of 'closely related activities' and not to the scope of application of the exemption provision in general. From paragraphs 22 to 23 of the CJEU decision, it may be deduced that the CJEU was seeking to answer the question whether services rendered by a specialized laboratory to a hospital laboratory could fall under the definition of the concept of 'closely related services':

"22. It must be pointed out, second, that Article 13(A)(1)(b) of the Sixth Directive does not include any definition of the concept of activities 'closely related' to hospital and medical care.

23. As the Advocate General noted in point 23 of his Opinion, that concept does not, however, call for an especially narrow interpretation since the exemption of activities closely related to hospital and medical care is designed to ensure that the benefits flowing from such care are

\footnotetext{
${ }^{407}$ CJEU 11 January 2001, Case C-76/99 Commission vs. France, ECLI:EU:C:2001:12, paras. 28-30.

408 Idem, para. 23.

${ }^{409}$ CJEU 14 September 2000, Case C-384/98 D., ECLI:EU:C:2000:444.
} 
not hindered by the increased costs of providing it that would follow if it, or closely related activities, were subject to VAT." 410

The same line of reasoning can be found in the Commission vs. Germany case (2002). ${ }^{411}$ In that case, the CJEU also discussed the argument of accessibility, however, this time in relation to the application of the VAT exemption for educational services, as currently included in Article 132(1)(i) of the EU VAT Directive. In that case the CJEU stated that:

"[n]evertheless, that concept does not require an especially strict interpretation since the exemption of the supply of services closely related to university education is designed to ensure that access to the benefits of such education is not hindered by the increased costs of providing it that would follow if it, or the supply of services and of goods closely related to it, were subject to VAT (see, by analogy, in relation to Article 13(A)(1)(b) of the Sixth Directive, Case C-76/99 Commission v France [2001] ECR 1-249, paragraph 23). However, if the undertaking by State universities of research projects for consideration is made subject to VAT, that does not have the effect of increasing the cost of university education." 412

It seems that the CJEU in its decision in Dornier (2003), extended the scope of the accessibility argument to the general application of the exemption provision in Article 132(1)(b) of the EU VAT Directive, without restricting its relevance to the interpretation of the concept of closely related services. ${ }^{413}$ Later, in Unterpertinger (2003), the CJEU considered that examinations or other medical interventions of a prophylactic nature carried out for persons not suffering from any disease or health disorder may even fall under Article 132(1)(c) of the EU VAT Directive, while referring to the objective of accessibility to health care. It considered the following:

"41. On the other hand, medical services effected for a purpose other than that of protecting, including maintaining or restoring, human health may not, according to that same case-law, benefit from the exemption under Article $13 A(1)(c)$ of the Sixth Directive. Having regard to their purpose, to make those services subject to VAT is not contrary to the objective of reducing the cost of health care and of making it more accessible to individuals." 414

From this consideration, it can be concluded that the exemption provision for extramural health care in Article 132(1)(c) of the EU VAT Directive also has as its objective to make health care more accessible to individuals by reducing the costs of health care. In later cases - i.e. TMD, to which reference was made in the beginning of this section - the CJEU explicitly confirmed that the objective to make health care accessible is a common objective of both of the exemption provisions for medical care.

\footnotetext{
${ }^{410}$ CJEU 11 January 2001, Case C-76/99 Commission vs. France, ECLI:EU:C:2001:12, paras. 22-23.

${ }^{411}$ CJEU 20 June 2002, Case C-287/00 Commission vs. Germany, ECLI:EU:C:2002:388.

412 Idem, para. 47.

${ }^{413}$ CJEU 6 November 2003, Case C-45/01 Dornier, ECLI:EU:C:2003:595, para. 48.

${ }^{414}$ CJEU 20 November 2003, Case C-212/01 Margarete Unterpertinger, ECLI:EU:C:2003:625, para. 41.
} 
As was demonstrated, the objective of accessibility to health care gained a prominent place in CJEU case law on the application of health care exemptions. Obviously, the objective of the VAT exemptions for health care is to reduce health care costs and make health care more accessible to individuals. The CJEU maintains the accessibility to health care as a standard while applying positive EU VAT law in relation to health care transactions. This objective cannot be justified on the basis of legislative history in the field of EU VAT. In order to find other arguments to justify the reasoning of the CJEU, I explored, in chapter 4 , the human right to health. The recognition of the right to health, and more specifically the principle of access of health care in both an international and EU context, lead me to conclude that this principle has to be taken into account while applying, interpreting and drafting (EU) legislation. Furthermore, the recognition of the principle of access to health care supports the reasoning of the CJEU in cases on the application of VAT in health care, where it considered that the principle forms a justification for the application of VAT exemptions.

In the following sections, the requirements for the application of the exemption provisions for intramural health care will be discussed in relation to the subject (the health care supplier).

\subsubsection{Requirements as regards the health care supplier under the exemption provision for intramural care}

The exemption provision for intramural care in Article 132(1)(b) of the EU VAT Directive, reads as follows:

"(b) hospital and medical care and closely related activities undertaken by bodies governed by public law or, under social conditions comparable with those applicable to bodies governed by public law, by hospitals, centres for medical treatment or diagnosis and other duly recognised establishments of a similar nature;". ${ }^{415}$

The provision concerns services that are carried out in a hospital environment. This does not directly follow from the text of the provision, which only describes the service provider, without explicitly referring to a specific place. This differs, for example, from the corresponding national provisions in the Netherlands and the United Kingdom that both refer to the place where the service has to be carried out. For the exemption on intramural care to apply, it is in the first place required that the service supplier is a hospital, a body governed by public law, a centre for medical treatment or diagnosis or an establishment of a similar nature. The latter three can only qualify under the exemption if the activities are undertaken under social conditions comparable to those applicable to bodies governed by public law.

$\overline{{ }^{415} \text { Article 132(1)(b) of the EU VAT Directive. }}$ 
Moreover, if the service is carried out by an establishment of a similar nature it has to be 'duly recognised'.

In 1985, the Commission proposed a so-called 'blank exemption' for hospital services, meaning that the exemption would apply to all forms of hospital care, without requiring any recognition. ${ }^{417}$ In the preamble to the proposal, the Commission pointed out that this was necessary with a view to ensuring the uniform application of the exemption in the Member States. Another concern were the difficulties that had apparently arisen with regard to the calculation of the Community's own resources. Under the proposed replacement of Article 13(1)(b) of the Sixth Directive, hospital and medical care and closely related activities were exempt if undertaken by hospitals, centres for medical treatment or diagnosis and other duly recognized establishments of a similar nature. ${ }^{418}$ It was not required that services were carried out by public bodies or under social conditions comparable to those applicable to public bodies. The Economic and Social Committee ('Ecosoc') expressed its concerns. According to the Ecosoc, the imprecise term in the 'blanket exemption' may give rise to difficulties as regards its practical application. It would, for example, not be easy to draw the line between therapeutic treatment and purely cosmetic treatment. A dividing line should, according to the Ecosoc, continue to be drawn between those services liable to taxation and the exempted services, the distinction being based on the criteria established hitherto. ${ }^{419}$ The proposal of the Commission was withdrawn in 1993.

\subsubsection{Legal form neutrality}

Whereas interpreting terms such as 'hospital', 'body governed by public law' and 'centre for medical care or diagnosis' seems pretty straightforward, the term 'other duly recognized establishments of a similar nature' is rather vague. In Gregg\&Gregg (1999) the CJEU had to interpret the term 'establishments', which can still be found in the current Article 132(1)(b) of the EU VAT Directive. ${ }^{420}$ The case concerned two natural persons carrying on a business

\footnotetext{
${ }^{416}$ The current Article 132(1)(b) of the EU VAT Directive differs from the exemption provision for hospital care as was included in the Proposal for a Sixth Directive of 20 June 1973, COM(73)950, in the proposal for the provision, the supply of hospital and medical services, and supplies of goods incidental thereto, by medical establishments run by: bodies governed by public law, non-profit making organizations or private charitable organisations was exempt. Conditions such as 'duly recognised' and 'under social conditions comparable to...' were not included in the proposed provision.

The scope of application of Article 132(1)(b) of the EU VAT Directive is set out in a very clear way by the AG in its conclusion on case CopyGene (A-G Opinion 10 September 2009, Case C-262/08 CopyGene, ECLI:EU:C:2009:541).

${ }^{417}$ Proposal for a $19^{\text {th }}$ Council Directive on the harmonization of the laws of the Member States relating to turnover taxes, amending Directive 77/388/EEC - common system of value added tax, COM(84) 648 final, 5 December 1984.

${ }^{418}$ Idem, Article 1, point 3(a) of the proposal.

${ }^{419}$ Economic and Social Committee Opinion on the proposal for a 19th Council Directive on the harmonization of the laws of the Member States relating to turnover taxes, amending Directive 77/388/EEC, OJ 85/C 218/07, 29 August 1985.

${ }^{420}$ CJEU 7 September 1999, Case C-216/97 Jennifer Gregg and Mervyn Gregg v Commissioners of Customs and Excise, ECLI:EU:C:1999:390.
} 
together, as partners. The dispute concentrated on the question whether the exemption on intramural care applied only to activities carried on by legal persons or whether these two natural persons could also benefit from the exemption. ${ }^{421}$

Four years before the decision in the Gregg\&Gregg case, the CJEU had been very strict in interpreting a similar term, 'bodies', as used in the exemption provision for services and goods closely linked to welfare and social security work. ${ }^{422}$ The CJEU concluded in the Bulthuis-Griffioen case $(1995)^{423}$ that, where an exemption expressly refers to the concept of 'body', ${ }^{424}$ it may be claimed only by legal persons. The decisions at the time led to a situation in which it was conceivable that two similar services were treated differently for VAT purposes, simply because of the fact that the legal form of the service suppliers differs.

In its decision in Gregg\&Gregg, the CJEU retracted its previous opinion. The CJEU did consider the principle of neutrality this time and stated that:

"[i]t cannot be inferred from the fact that Article 13A(1) of Sixth Council Directive 77/388 [Article 132(1) of the EU VAT Directive] [...] mentions different categories of economic operators that the exemptions provided for thereunder are confined to legal persons where it refers expressly to activities undertaken by 'establishments' or 'organisations', whilst in other cases an exemption may also be claimed by natural persons".

One or more natural persons running a business can still form an individualized entity. A textual interpretation had been put aside, in favour of a teleological interpretation. The Gregg\&Gregg case can be considered a landmark case as regards the condition of legal form neutrality in connection to exemption provisions. Frequent reference to this case has been made by the CJEU concerning several exemption provisions. ${ }^{425}$

\subsubsection{2. 'Duly recognised establishments of a similar nature'}

For an 'establishment of a similar nature' to qualify under Article 132(1)(b) of the EU VAT Directive, it has to be duly recognized. It is up to the Member States to establish a procedure for recognition. In order to be duly recognized, a formal recognition procedure is not essential. The limits of the discretion conferred on Member States are the Community

\footnotetext{
${ }^{421}$ See also CJEU 10 September 2002, Case C-141/00 Kügler, ECLI:EU:C:2002:473, in which the relevance of the legal form of the service provider was at issue.

${ }^{422}$ Article 132, paragraph 1, subsection g of the EU VAT Directive.

${ }^{423}$ CJEU 11 August 1995, Case C-453/93 Bulthuis-Griffioen v Inspecteur der Omzetbelasting, ECLI:EU:C:1995:265.

${ }^{424}$ As for instance in Article 132, paragraph 1, subsection, b of the EU VAT Directive.

${ }^{425}$ Inter alia CJEU 10 September 2002, Case C-141/00 Kügler, ECLI:EU:C:2002:473, para. 30; CJEU 17 February 2005, Joined Cases C-453/02 and C-462/02 Linneweber and Akritidis, ECLI:EU:C:2005:92, para. 25; CJEU 16 October 2008, Case C-253/07 Canterbury Hockey Club and Canterbury Ladies Hockey Club v The Commissioners for Her Majesty's Revenue and Customs, ECLI:EU:C:2008:571, paras. 30-31.
} 
principles, in particular the principle of equal treatment (fiscal neutrality). ${ }^{426}$ It is for the national authorities to take into consideration a number of factors which include: the public interest of the activities of the taxable person in question, the fact that other taxable persons carrying on the same activities already have similar recognition, and the fact that the costs incurred for the treatment in question may be largely met by health insurance schemes or other social bodies. ${ }^{427}$

Another case in which the CJEU provided guidance on the limits of discretion conferred on Member States is the L.U.P. case. ${ }^{428}$ L.u.P. is a private company which carries out medical tests for companies operating laboratories. These companies are affiliated with general practitioners who prescribed those tests. After the Court had established that the medical tests may constitute (the provision of) medical care, it considered the conditions imposed by the Member State on the basis of the national equivalent of the exemption for medical care provided for in Article 132(1)(b) of the EU VAT Directive.

The relevant provision under the national law of the Member State concerned (Germany) contained two conditions for medical tests to be exempt. The first condition was that the medical tests must be provided under the supervision of a doctor. The Court referred to the Dornier case in this respect and held that this first condition goes beyond the limits of the discretion allowed to the Member State, since the term 'medical care' also includes treatment given under the sole responsibility of persons who are not doctors. ${ }^{429}$ The second condition under the national law of the Member State required that at least $40 \%$ of the medical tests carried out must relate to persons insured by a social security authority. According to the CJEU, it is within their limits of discretion that the national authorities:

"take into consideration, inter alia and in addition to the public interest of the activities of the taxable person in question and the fact that other taxable persons carrying out the same activities already have similar recognition, the fact that the costs incurred for treatment in question may be largely met by health insurance schemes or other social security bodies". ${ }^{430}$

\footnotetext{
${ }^{426}$ CJEU 10 June 2010, Case C-262/08 CopyGene, ECLI:EU:C:2010:328, para. 64; CJEU 6 November 2003, Case C45/01 Dornier, ECLI:EU:C:2003:595, para. 69; CJEU 8 June 2006, Case C-106/05 L.u.P., ECLI:EU:C:2006:380, para. 48.

${ }^{427}$ CJEU 10 June 2010, Case C-262/08 CopyGene, ECLI:EU:C:2010:328, para. 65; CJEU 10 September 2002, Case C-141/00 Kügler, ECLI:EU:C:2002:473, paras. 57-58; CJEU 6 November 2003, Case C-45/01 Dornier, ECLI:EU:C:2003:595, paras. 72-73; CJEU 8 June 2006, Case C-106/05 L.u.P., ECLI:EU:C:2006:380, para. 53.

${ }^{428}$ CJEU 8 June 2006, Case C-106/05 L.u.P., ECLI:EU:C:2006:380.

${ }^{429}$ CJEU 6 November 2003, Case C-45/01 Dornier, ECLI:EU:C:2003:595, paras. 70, 71 and 80.

${ }^{430}$ CJEU 8 June 2006, Case C-106/05 L.u.P., ECLI:EU:C:2006:380, para. 53; These factors were earlier mentioned in the Dornier case (ECLI:EU:C:2003:595) and in the Kügler case (ECLI:EU:C:2002:473), in relation to the recognition of charitable organizations within the meaning of Article 132(1)(g) of the VAT Directive.
} 
In CopyGene, a Danish case, the dispute concerned the possible exemption of the services provided by a stem cell bank. ${ }^{431}$ As this was a body governed by private law, the question arose whether it was a 'duly recognised establishment of a similar nature'. What followed from the national procedure was that the services were provided by professional medical staff. ${ }^{432}$ The CJEU noted that this is, as such, not relevant for the recognition. ${ }^{433}$ What it did consider relevant was that the services carried out were not covered by the public social security scheme, ${ }^{434}$ although this does not in itself justify a difference in the treatment of providers for VAT purposes. ${ }^{435}$ The application of the principle of fiscal neutrality in this case was frustrated by the fact that there was, at the time, no other stem cell bank in Denmark besides CopyGene. A comparison to the VAT treatment of a similar establishment was therefore impossible. Another relevant fact in the case was that CopyGene was authorized by the competent health authorities to handle cord stem cells under the national legislation implementing Directive 2004/23. ${ }^{436}$ However, this fact also should, according to the CJEU, not automatically lead to recognition for the authorization was a necessary condition for carrying out the activities of a private stem cell bank. ${ }^{437}$ The national court has to determine, if the competent authorities refuse recognition described in Article 132(1)(b), whether the refusal of that recognition complies with the principle of fiscal neutrality. The CJEU pointed out that, for that to be established it would be appropriate to take into consideration, for example, established administrative practice and other practices adopted as regards the status of paramedical establishments and exemptions from VAT in sectors comparable to the establishment in question in the main proceedings. ${ }^{438}$

\subsubsection{Requirements as regards the health care supplier for the exemption provision for extramural care}

Article 132(1)(c) of the EU VAT Directive, contains an exemption for the provision of medical care in the exercise of the medical and paramedical professions as defined by the Member State concerned. Like the exemption provision for intramural care in Article 132(1)(b) of the EU VAT Directive, the exemption provision for extramural care has the objective of reducing costs of medical care and making that care more accessible for individuals. ${ }^{439}$ Contrary to the exemption provision for intramural care, the exemption provision for extramural care does not refer to a subject such as a 'person', 'body' or something like that specified. It can be derived from the text of the exemption provision that the medical care must be provided by a

\footnotetext{
${ }^{431}$ CJEU 10 June 2010, Case C-262/08 CopyGene, ECLI:EU:C:2010:328.

${ }^{432}$ It was however not clear whether the staff was 'professionally qualified'.

${ }^{433}$ CJEU 10 June 2010, Case C-262/08 CopyGene, ECLI:EU:C:2010:328, para. 68.

${ }^{434}$ Idem, para. 69.

${ }^{435}$ Idem, paras. 71 and 75.

${ }^{436}$ Directive 2004/23/EC of the European Parliament and of the Council on setting standards of quality and safety for the donation, procurement, testing, processing, preservation, storage and distribution of human tissues and cells, OJ L 102/48, 31 March 2004.

${ }^{437}$ CJEU 10 June 2010, Case C-262/08 CopyGene, ECLI:EU:C:2010:328, para. 75.

${ }^{438}$ Idem, para. 79.

${ }^{439}$ CJEU 13 March 2014, Case C-366/12 Klinikum Dortmund, ECLI:EU:C:2014:143, para. 28.
} 
supplier while exercising a medical or paramedical profession. The supplier, hence, had to act in a certain capacity. This can be deduced from the wording of the CJEU in Kügler. The CJEU applied a textual interpretation and held that, for the application of the exemption provision for extramural care: "medical services must be involved and they must be supplied by persons who possess the necessary professional qualifications". ${ }^{440}$ The CJEU concluded in that case that the application of the exemption provision for extramural care cannot be made dependent on the legal form of the medical service provider. This is only logical since this provision does not refer to the form of a provider at all. ${ }^{441}$

The VAT treatment of medical care - and the application of either the exemption provision for intramural health care or the exemption provision extramural health care - is particularly dependent on the question of where the services are carried out. The CJEU held in this regard that both exemption provisions intend to cover all services which have as their purpose the diagnosing and treating and, in so far as possible, curing diseases or health disorders. ${ }^{442}$ The provisions intend to regulate all exemptions of medical services in the strict sense, however, their field of application differs. ${ }^{443}$ It seems to me that the legislator chose to adopt two different exemption provisions only for practical reasons. Perhaps, with the aim of maintaining a feasible VAT system, they preferred to exempt all health care activities that take place in a hospital or similar health care facility, instead of making the exemption provision for intramural care dependent on the professional qualities of employees of those facilities, performing the health care concerned. A possible differential VAT treatment of intramural and extramural care can, at least, not be explained on the basis of the objective of the exemption provisions, as that objective is the same for both the provisions. Moreover, this joint objective, in my view, requires that the criteria of application for both the individual exemption provisions are similar. This also follows from the application of the principle of access to health care which is embedded in the human right to health. It follows from the assessment of that principle - in section 4.2 - that it does not contain a distinction on the basis of the type of health care (intramural or extramural) provided. The presence of two distinct exemption provisions for health care in the EU VAT Directive is, in my view, understandable on the basis of practical reasons but it should not, at the same time, lead to a differential VAT treatment of intramural health care and extramural health care. In section 7.3, the scope of application of the exemption provisions in parallel situations is assessed. This assessment shows, inter alia, that the application of different exemption provisions does

\footnotetext{
${ }^{440}$ CJEU 10 September 2002, Case C-141/00 Kügler, ECLI:EU:C:2002:473, para. 27.

${ }^{441}$ Idem, para. 30.

${ }^{442}$ CJEU 10 June 2010, Case C-262/08 CopyGene, ECLI:EU:C:2010:328, para. 28; CJEU 6 November 2003, Case C45/01 Dornier, ECLI:EU:C:2003:595, para. 48; CJEU 8 June 2006, Case C-106/05 L.u.P., ECLI:EU:C:2006:380, para. 27; etc.

${ }^{443}$ CJEU 10 June 2010, Case C-262/08 CopyGene, ECLI:EU:C:2010:328, para. 27; CJEU 10 September 2002, Case C-141/00 Kügler, ECLI:EU:C:2002:473, para. 36; CJEU 8 June 2006, Case C-106/05 L.u.P., ECLI:EU:C:2006:380, para. 26; etc.
} 
lead to a differential VAT treatment of intramural and extramural health care. For that reason, I proposed the adoption of a 'general exemption for health care supplies' in section 8.2.4.

As indicated earlier, in order to come within the scope of the exemption provision for extramural care, the health care supplier has to act in a certain capacity: i.e. in the exercise of a medical or paramedical profession. In the following section, this condition will be discussed.

\subsubsection{The exercise of medical and paramedical professions}

The exemption provision for extramural health care in Article 132(1)(c) of the EU VAT Directive does not specify a subject. As a result, extramural health care in the exercise of a (para)medical profession care provided by any person or entity - qualifying under the broad 'taxable person' definition laid down in Article 9 of the EU VAT Directive - may come within the scope of the exemption provision. The Member States enjoy discretion to set out criteria for defining the medical and paramedical professions. It is obvious that this discretion is not unlimited. As was shown earlier, with regard to questions concerning the relevance of the legal form of the provider and the place where the services are carried out for the application of the exemption provisions for health care, the CJEU uses a teleological interpretation method while safeguarding the principles of Community law, the principle of fiscal neutrality in particular.

Safeguarding the principle of fiscal neutrality would, in principle, entail that taxable persons supplying similar goods or services are treated the same for VAT purposes. There is a connection between the principle of fiscal neutrality and the principle of equal treatment, and this follows, inter alia, from the following consideration by the CJEU in Solleveld (see also section 3.3):

"the requirement of a correct and straightforward application of the exemptions does not allow the Member States to prejudice the objectives of the Sixth Directive or the principles of Community law, in particular the principle of equal treatment, which is reflected, in the field of VAT, by the principle of fiscal neutrality". ${ }^{444}$

This, however, does not imply that the qualities of a service provider do not influence the VAT treatment of the services. This is the area for which discretion is afforded to the Member States, as they can define the medical and paramedical professions referred to in Article 132(1)(c) of the EU VAT Directive. In Solleveld, the CJEU indicated that the abovementioned objectives serve as the limits of the discretion. In case both the service provided and the professional qualities of the service provider are similar, it is clear that the VAT treatment of these services should also be similar. However, what happens if the services provided by two

${ }^{444}$ CJEU 27 April 2006, Joined Cases C-444/04 and C-443/04 Solleveld, ECLI:EU:C:2006:257, para. 35. 
different health care suppliers are equal, while their professional qualifications differ? The CJEU provided for guidance on this matter in Solleveld. The CJEU held in this case that:

"where [the qualifications] [are] not identical, medical care can be regarded as similar only to the extent that it is of equivalent quality from the point of view of the recipients" ${ }^{445}$

The CJEU seems to draw a parallel with the CPP case (on composite supplies) by involving the perception of the recipients. ${ }^{446}$ I wonder in how far this could be considered a reliable tool to establish the (medical) quality standards of a service (provider). Since the similarity of two medical extramural services depend on the professional qualifications of the health care provider providing those services, the CJEU concluded that once it is established that services are similar, a deviating VAT treatment is not justified if the professional qualifications of the providers ensure an equivalent level of quality of the service. ${ }^{447}$ Quality, here, clearly forms the boundary for the - relatively - broad application of the fiscal neutrality principle. The consequences of the CJEU decision in Solleveld on the application of the exemption provision for extramural care in the basic situations is discussed extensively by means of the assessment of the exemption provision in section 7.2.3.1.

Rephrasing this complex matter in other words brings me to the following. As regards medical services, that come within the scope of Article 132(1)(c) of the EU VAT Directive, the organizational form of the health care supplier, as such (natural person or entity), is irrelevant. What is relevant are the professional qualifications of the supplier that are used to carry out the medical service. These professional qualifications have to adhere to national standards. In case the professional medical qualifications of health care suppliers guarantee a similar level of quality of the health care provided, the health care activities carried out have to be subject to an equal VAT treatment as a result of the application of the principle of fiscal neutrality.

\footnotetext{
${ }^{445}$ Idem, para. 40.

${ }^{446}$ CJEU 25 February 1999, Case C-349/96 Card Protection Plan Ltd (CPP) v Commissioners of Customs \& Excise, ECLI:EU:C:1999:93; In this case the viewpoint of a customer was held to be an important factor for determining whether a certain transaction consists out of one or more services.

${ }^{447}$ CJEU 27 April 2006, Joined Cases C-444/04 and C-443/04 Solleveld, ECLI:EU:C:2006:257, para. 41.
} 


\subsubsection{Relationship with criteria for health care suppliers under Article 132(1)(b) of the EU VAT Directive}

The CJEU made clear that the criterion for drawing a clear distinction between Articles 132(1)(b) and (c) of the EU VAT Directive is less the nature or substance of the service than the place where it is provided. ${ }^{448}$ The application of the exemption provisions is, hence, dependent on the type of care - i.e. intramural health care or extramural health care provided. For the application of the exemption provision for intramural care, it appears that the individual professional qualifications of the health care professional are disregarded. For the application of the exemption provision for extramural care, those professional qualifications are relevant. This may result in a differential VAT treatment of intramural and extramural health care. I.e. it may occur that an employee of a hospital does not (if assessed individually) have the appropriate professional medical knowledge. However, since that employee is employed in a hospital that qualifies under the exemption provision for intramural care, the health care may still be exempt. A self-employed health care supplier is as a result confronted with a larger degree of legal uncertainty, see also section 7.2.3.2.

It appears that fiscal neutrality is safeguarded within the scope of application of the individual exemption provisions for health care, however, not between them. Where it comes to intramural care, the exemption provision applies regardless of the legal form of the service provider. This is also true for the exemption on extramural care. As regards extramural care, the CJEU in Solleveld even added that, as a result of the application of the principle of fiscal neutrality, the scope of the exemption provision may be extended in case a similar level of (professional) quality can be guaranteed (see sections 6.2.2.1 and 7.2.3.1).

It seems that fiscal neutrality is, however, not safeguarded between the areas of application of the exemption provisions included in Articles 132(1)(b) and (c) of the EU VAT Directive. In section 6.2.2 I already made reference to the fact that this does not correspond to the joint aim of the exemption provisions for health care, nor to the application of the principle of access to health care. Perhaps, this does not bring along an infringement of the principle of fiscal neutrality, as intramural and extramural health care are not in competition with each other. In that case, it does at least, in my view bring along an infringement of the (general) principle of equality. See to that regard section 3.3.

\footnotetext{
${ }^{448}$ CJEU 6 November 2003, Case C-45/01 Dornier, ECLI:EU:C:2003:595, para. 47, where the CJEU follows the AG in its conclusion; see also case CJEU 10 September 2002, Case C-141/00 Kügler, ECLI:EU:C:2002:473, para. 36; CJEU 23 February 1988, Case 353/85 Commission vs. United Kingdom, ECLI:EU:C:1988:82, paras. 32-33.
} 


\subsubsection{Requirements of the health care activities provided}

In the previous section, the conditions for the application of the exemption provision for medical care were discussed in relation to the subject, i.e. the health care supplier. In this section, I will discuss the application criteria in relation to the object, i.e. the health care activities. The application of these criteria will be discussed in more detail in chapter 7 , which contains an assessment of the exemption provisions for medical care in specific situations, departing from a basic situation.

\subsubsection{Covered medical and hospital care}

In the previous sections, I already demonstrated that, according to the CJEU, both exemption provisions for medical care intend to cover all services which have as their purpose the diagnosing and treating and, in so far as possible, curing diseases or health disorders, only their field of application differs. ${ }^{449}$ The text of the individual exemption provisions slightly differs at this point. The exemption provision for intramural health care in Article 132(1)(b) of the EU VAT Directive refers to 'hospital or medical care'. The exemption provision for extramural health care in Article 132(1)(c) of the EU VAT Directive refers to 'the provision of medical care'. The term 'hospital care' appears straightforward, i.e. referring to it as being health care provided in a hospital. ${ }^{450}$ Far more important is the term 'medical care' which is included in both exemption provisions and gave rise to a number of CJEU decisions. In the following section, I will discuss the notion of medical care in relation to the exemption provisions for extramural and intramural health care.

\subsubsection{2. 'Medical care' under Articles 132(1)(b) and (c) of the EU VAT Directive}

In Commission vs. United Kingdom, the CJEU for the first time indicated the distinction between the notion of 'medical care' under Articles 132(1)(b) and (c) of the EU VAT Directive. ${ }^{451}$ From the considerations of the CJEU in this case, it can be understood that 'medical care' is the (common) denominator of the two exemption provisions and that it is the location where this care is provided that is decisive for the application of either the exemption provision included in Article 132(1) (b) or (c) of the EU VAT Directive. According to the CJEU, the care referred to in Article 132(1) (b) encompasses a whole range of medical care normally provided on a non-profit-making basis in establishments pursuing social purposes such as the protection of human health. ${ }^{452}$ The CJEU held that - taking into account the position of indent (c) and the context - indent (c) involves services provided outside hospitals and similar establishments and within the framework of a confidential relationship which is normally established in the consulting room of that person. ${ }^{453}$

\footnotetext{
449 CJEU 10 June 2010, Case C-262/08 CopyGene, ECLI:EU:C:2010:328, paras. 27-28; CJEU 6 November 2003, Case C-45/01 Dornier, ECLI:EU:C:2003:595, para. 48; CJEU 8 June 2006, Case C-106/05 L.u.P., ECLI:EU:C:2006:380, paras. 26-27; etc.

${ }^{450}$ Although a discussion at this point is conceivable it has not lead to many questions.

${ }^{451}$ CJEU 23 February 1988, Case 353/85 Commission vs. United Kingdom, ECLI:EU:C:1988:82.

${ }^{452}$ Idem, para. 32.

${ }^{453}$ Idem, para. 33.
} 
Later, in its judgement in Dornier, concerning the distinction between the exemptions provided for in sub (b) and (c), the CJEU confirmed that the criterion for drawing a clear distinction between the two exemptions is less the nature of the service than the place where it is provided. ${ }^{454}$ Furthermore, the CJEU held that:

"...the principle of fiscal neutrality precludes, inter alia, economic operators carrying on the same activities from being treated differently as far as the levying of VAT is concerned." ${ }^{455}$

From the foregoing, it can be deduced that both exemption provisions aim to exempt the same kind of care. It is the place in which the care is provided to a patient that is decisive for determining which one of the exemption provisions for health care in the EU VAT Directive is applicable.

\subsubsection{Interpreting the term 'medical care'}

The CJEU has confirmed the assumption that can be made on the basis of a textual interpretation of the exemption provisions, i.e. that the notion 'medical care' in the exemption provisions for extramural and intermural care refers to the same kind of activities. This is in line with the common objective of these exemption provisions of making health care more accessible to individuals by reducing the costs of that care. ${ }^{456}$ The CJEU held that the concept of 'medical care' intends to cover:

"services that have as their aim the diagnosis, treatment and, in so far as possible, cure of diseases or health disorders" 457

Moreover, the CJEU indicated that it follows from the foregoing that medical services effected for the purpose of protecting, maintaining or restoring human health may come within the scope of either one of the exemption provisions for medical care. ${ }^{458}$ Despite the common objective of the exemption provisions for medical care in the EU VAT Directive, the VAT treatment of (health care) activities falling within the scope of the exemption provisions

\footnotetext{
${ }^{454}$ CJEU 6 November 2003, Case C-45/01 Dornier, ECLI:EU:C:2003:595.

455 CJEU 6 November 2003, Case C-45/01 Dornier, ECLI:EU:C:2003:595, para. 44; CJEU 10 September 2002, Case C-141/00 Kügler, ECLI:EU:C:2002:473, para. 30.

${ }^{456}$ CJEU 20 November 2003, Case C-212/01 Margarete Unterpertinger, ECLI:EU:C:2003:625, para. 41; CJEU 8 June 2006, Case C-106/05 L.u.P., ECLI:EU:C:2006:380, para. 25; CJEU 6 November 2003, Case C-45/01 Dornier, ECLI:EU:C:2003:595, para. 48; CJEU 10 September 2002, Case C-141/00 Kügler, ECLI:EU:C:2002:473, para. 29; CJEU 1 December 2005, Joined Cases C-395/04 and C-394/04 Ygeia, ECLI:EU:C:2005:734, para. 23; A-G Opinion 10 September 2009, Case C-262/08 CopyGene, ECLI:EU:C:2009:541, para. 33.

${ }^{457}$ CJEU 13 March 2014, Case C-366/12 Klinikum Dortmund, ECLI:EU:C:2014:143, para. 29; CJEU 6 November 2003, Case C-45/01 Dornier, ECLI:EU:C:2003:595, para. 48; CJEU 8 June 2006, Case C-106/05 L.u.P., ECLI:EU:C:2006:380, para. 27; CJEU 10 June 2010, Case C-262/08 CopyGene, ECLI:EU:C:2010:328, para. 28.

${ }^{458}$ CJEU 13 March 2014, Case C-366/12 Klinikum Dortmund, ECLI:EU:C:2014:143, para. 30; CJEU 20 November 2003, Case C-212/01 Margarete Unterpertinger, ECLI:EU:C:2003:625, para. 40-41; CJEU 20 November 2003, Case C-307/01 d'Ambrumenil and Dispute Resolution Services, ECLI:EU:C:2003:627, paras. 58-59; CJEU 8 June 2006, Case C-106/05 L.u.P., ECLI:EU:C:2006:380, para. 29.
} 
may, however, differ depending on the health care exemption that is applicable. The scope of the exemption provision for intramural care in Article 132(1)(b) of the EU VAT Directive appears to be broader as it also involves closely related activities, whereas the scope of the exemption provision in Article 132(1)(c) of the EU VAT Directive does not contain such an extension.

An interpretation of terms and conditions in legal provisions must, in principle, be consistent with the objectives pursued by the exemptions and principles of Community law. ${ }^{459}$ The CJEU repeated several times that the purpose of exemptions is decisive for the question whether a medical service should be exempt. ${ }^{460}$ A literal interpretation is in my view not sufficient especially if it is not certain that the exemption provisions are still adequate to date, as a textual interpretation may exclude new kinds of medical services that are in effect perhaps similar to established forms of health care. As indicated in the beginning of this section, the exemption provisions obviously have a joint objective. This objective of making health care more accessible to individuals by reducing costs has been discussed in section 6.2.1.

\subsubsection{Therapeutic aim}

Austrian national legislation used to exempt all turnover from the activity as a doctor. It did not provide for any criteria related to the services the doctor should provide. The exemption was generally applied on all the activities provided by the doctor (subjective exemption). In the $D$. case, the CJEU made clear that medical interventions that do not have a therapeutic aim must be excluded from the scope of Article 13A(1)(c) of the Sixth Directive (now: Article 132(1)(c) of the EU VAT Directive). ${ }^{461}$ The governments of Austria, the Netherlands, as well as the United Kingdom argued in that case that the exemption applies to medical services, irrespective of the purpose for which they are provided. Those governments claimed that every medical or paramedical activity provided to persons should be VAT exempt. The services at issue in the case concerned services of a medical expert, who, on the instructions of a court, had to establish, on the basis of a genetic test, whether the plaintiff in the main proceedings could be the child of the defendant. The CJEU held that these services are not aimed at diagnosing, treating and, in so far as possible, curing diseases or health disorders. Therefore, and in having regard to the strict interpretation of exemption provisions, the CJEU decided that the services had to be excluded from the scope of application of the exemption provision for extramural care. ${ }^{462}$

\footnotetext{
${ }^{459}$ See for example CJEU 18 November 2010, Case C156/09 Verigen, ECLI:EU:C:2010:695, para. 23.

460 Inter alia CJEU 20 November 2003, Case C-212/01 Margarete Unterpertinger, ECLI:EU:C:2003:625, para. 42 and CJEU 20 November 2003, Case C-307/01 d'Ambrumenil and Dispute Resolution Services, ECLI:EU:C:2003:627, para. 60 (with reference to the AG).

${ }^{461}$ CJEU 14 September 2000, Case C-384/98 D., ECLI:EU:C:2000:444.

${ }^{462}$ Idem, para. 19.
} 
Another CJEU case that concerned the therapeutic aim of health care activities is Margarete Unterpertinger. ${ }^{463}$ The referring court wished to know whether services provided by medical experts are exempt from VAT where the medical examinations by the expert intend to establish or to exclude disability or unfitness for work. The Landesgericht Innsbruck referred to the $D$. case and asked whether that case is interpreted correctly as meaning that medical examinations and expert opinions based thereon, for the purpose of establishing or excluding disability or unfitness to work, do not fall within the scope of application of Article $13 \mathrm{~A}(1)(\mathrm{c})$ of the EU VAT Directive, regardless of whether or not the doctor who acts as an expert is instructed by a court or a pension insurance institution.

Again, the CJEU emphasized that Article 13(1)(c) of the EU VAT Directive does not exempt all services, only the 'provision of medical care'. As in cases D. and Ambulanter Pflegedienst Kügler, the concept of medical care does not lend itself to an interpretation which includes medical interventions carried out for a purpose other than that of diagnosing, treating and, in so far as possible, curing diseases or health disorders. This, according to the Court, does not mean that the therapeutic aim must be confined within an especially narrow compass. Even medical services affected for prophylactic purposes may benefit from the exemption. ${ }^{464}$ It is clear, once again, that, according to the Court, the purpose of the service is relevant. If an expert is asked to make a report, the purpose is not directly the protection of health (curing, diagnosing, etc.) but it will support another person's or institution's decision-making process. Perhaps it is not necessary to note the fact that the report prepared on the request of the court is, from a neutrality perspective, is not relevant.

The decision in Margarete Unterpertinger was delivered on at the same day as $d^{\prime}$ Ambrumenil. ${ }^{465}$ There is also a joint conclusion of the Advocate General in these cases. The CJEU's reply to the questions referred in both cases is almost entirely equal. The considerations made in d'Ambrumenil may be considered more relevant, as the VAT and Duties Tribunal specifically addressed the scope of application of Article 13A(1)(c) of the EU VAT Directive. The CJEU indicated with respect to some of the services provided by d'Ambrumenil, whether the exemption provision for extramural health care in Article $13 A(1)(c)$ of the EU VAT Directive may apply.

According to the CJEU, the services consisting of the following may be exempt under Article $13 \mathrm{~A}(1)(\mathrm{c})$ of the EU VAT Directive:

- conducting medical examinations of individuals for employers or insurance companies;

\footnotetext{
${ }^{463}$ CJEU 20 November 2003, Case C-212/01 Margarete Unterpertinger, ECLI:EU:C:2003:625.

${ }^{464}$ CJEU 14 September 2000, Case C-384/98 D., ECLI:EU:C:2000:444; CJEU 10 September 2002, Case C-141/00 Kügler, ECLI:EU:C:2002:473.

${ }^{465}$ CJEU 20 November 2003, Case C-307/01 d'Ambrumenil and Dispute Resolution Services, ECLI:EU:C:2003:627.
} 
- the taking of blood or other bodily samples to test for the presence of viruses, infections or other diseases on behalf of employers or insurers; or

- certification of medical fitness, for example, as to fitness to travel;

where those services are intended principally to protect the health of the person concerned. ${ }^{466}$

Whether the certification of medical fitness falls within the scope of the exemption provision depends, according to the CJEU, on the principal purpose of the certification. If the certificate is required by a third party, as a condition precedent to the exercise by the person concerned of a particular activity, the principal purpose of the service is to provide the third party with a necessary element for taking a decision and not the protection of the health of the person. In that case, it cannot be exempt under Article 13A(1)(c) of the EU VAT Directive. ${ }^{467}$ The same assessment should be made with regard to services consisting of conducting medical examinations of individuals for employers or insurance companies and taking blood or other bodily samples to test for the presence of viruses, infections or other diseases on behalf of employers or insurers.

The CJEU explicitly held that the exemption does not apply to:

- giving certificates as to a person's medical condition for purposes such as entitlement to a war pension;

- medical examinations conducted with a view to the preparation of an expert medical report regarding issues of liability and the quantification of damages for individuals contemplating personal injury litigation;

- the preparation of medical reports following examinations referred to in the previous indent and medical reports based on medical notes without conducting a medical examination;

- medical examinations conducted with a view to the preparation of expert medical reports regarding professional medical negligence for individuals contemplating litigation; and

- the preparation of medical reports following examinations referred to in the previous indent and medical reports based on medical notes without conducting a medical examination. ${ }^{468}$

The purpose of these services is, according to the CJEU, to provide expert reports concerning a person's state of health and covering, in particular, the injuries or disabilities by which he or she is affected, in order to treat administrative applications, such as applications for the payment of a war pension or for the purposes of court proceedings for compensation, such

\footnotetext{
${ }^{466}$ Idem, para. 68.

${ }^{467}$ Idem, para. 61

${ }^{468}$ Idem, p. 96.
} 
as claims for damages for medical negligence. ${ }^{469}$ As a result, they do not constitute 'medical care'.

In this section I demonstrated that, in order for health care activities to qualify within the scope of the exemption provisions for medical care, the care has to be provided with a therapeutic aim.

\subsubsection{Closely related activities}

In the previous sections, the medical care that is referred to in the exemption provisions for health care was discussed. It occurs that activities related to the medical care provided (the principal service) may also come within the scope of an exemption. The scope of the exemption provision for intramural care explicitly covers activities that are closely related to that care. The provision for extramural care in Article 132(1)(c) of the EU VAT Directive does not contain such an extension. ${ }^{470}$ From a textual interpretation of the exemption provisions for health care activities, it can thus be concluded that the legislator only intended to extend the scope of the exemption provision for intramural health care. Perhaps the legislator - for practical reasons - chose to exempt all kinds of related activities that a patient receiving health care in a hospital environment usually requires.

In contrast to the Sixth Directive and the EU VAT Directive, the definition of the exemption provision for intramural care in the proposal for a sixth Council Directive did not contain an extension to closely related activities. ${ }^{471}$ It is not clear why these wordings were added at a later stage. ${ }^{472}$ Although in its reports to the Council, the Commission foresaw some difficulties as regards the interpretation of the terms referring to private hospitals and the other establishments mentioned, there were no remarks made on possible interpretation (difficulties) as regards the notion of 'closely related', ${ }^{473}$ neither in relation to the exemption for intramural health care, nor in relation to other exempt activities mentioned in 132 of the EU VAT Directive. In its Second Report, the Commission did note that:

\footnotetext{
${ }^{469}$ CJEU 20 November 2003, Case C-307/01 d'Ambrumenil and Dispute Resolution Services, ECLI:EU:C:2003:627, p. 62.

${ }^{470}$ The CJEU explicitly confirmed this in the Commission vs. United Kingdom case (CJEU 23 February 1988, Case 353/85 Commission vs. United Kingdom, ECLI:EU:C:1988:82). The UK drew a parallel between Article 132(1)(b) and (c) of the EU VAT Directive and argued that the supply of a good could also be exempt under Article $132(1)(c)$ of the EU VAT Directive if that good was supplied in connection with the medical care referred to in that article. The CJEU pointed out that Article 132(1)(b) concerns intramural care, where Article 132(1)(c) of the EU VAT Directive concerns extramural care.

${ }^{471}$ Proposal for a sixth Council Directive on the harmonization of Member States concerning turnover taxes, COM(73) 950 of 20 June 1973.

472 The same is true for the exemption provision for services closely linked to the protection of children and young persons in Article 132(1)(h) of the EU VAT Directive.

${ }^{473}$ Reports on the application of the common system of Value Added Tax: First Report from the Commission to the Council from 14 September 1983, $\operatorname{COM}(83) 426$ final and the Second Report from the Commission to the Council from 20 December 1988, COM(88) 799 final.
} 
"[t]he expression "closely related activities" [...] seemed to be interpreted in a fairly restrictive manner by Member States". ${ }^{474}$

This was confirmed by a VAT Committee study. The report also mentions a Community list that was drawn up, containing the transactions referred to and the usefulness of adding this list to the proposed amendment extending the exemption to the entire hospital sector. This list, regretfully, has not been made public. Since it is impossible to trace the exact meaning of the expression 'closely related', a literal interpretation would be reasonable. It implies that the activity must have a certain relationship to the principal service and, since it must be 'closely' related, it also seems to insinuate a certain necessity to carry out this 'extra' service. In the case law of the CJEU, certain criteria were developed to establish whether activities can be qualified as being 'closely related' to a principal, exempt, service.

In chapter 7, in which I have assessed the application of the exemption provisions, the consequences of the extension of the exemption provisions for intramural health care to closely related activities will be discussed in more detail. In that chapter, it is also demonstrated what the scope of application of that extension is and in which situations (within the model health care system) it plays a role. The application of the notion of closely related activities often concurs with the application of the doctrine of composite supplies (section 7.2.3.1). In that regard, I demonstrated in section 7 why I hold the opinion that the extension to closely related activities is superfluous with regard to the provision of intramural health care in parallel one-on-one situations (see also sections 7.3.2.3).

As indicated earlier, on basis of a textual interpretation, closely related activities can only be absorbed within the scope of the exemption provision for intramural care. In section 6.2.3 I already noted in that respect that the presence of two distinct exemption provisions for health care in the EU VAT Directive is, in my view, understandable for practical reasons. However, considering their joint objective, this should not lead to a differential VAT treatment of health care and health care related supplies. The exploration of the principle of access to health care in relation to the human right to health in chapter 4 supported this view. In the context of access to health care, no distinction is made as regards the type of health care carried out (intramural or extramural health care). The assessment in chapter 7 will show that, despite the joint objective of the exemption provisions, a differential VAT treatment of intramural and extramural health care occurs. Moreover, it appears that the CJEU attempts to introduce 'new' criteria in order to include (closely) related activities also within the scope of the exemption provision for extramural care. See for example section 7.3.2.3 on the 'therapeutic continuum' criterion.

\footnotetext{
${ }^{474}$ Second Report from the Commission to the Council from 20 December 1988, COM(88) 799 final p. 32.
} 


\subsubsection{The temporal requirement}

In this section I will discuss possible temporal restrictions, i.e. whether the amount of time between the principal health care service and the related activity is relevant for applying the exemption on the related service. On basis of a literal interpretation I believe that the time is not an issue. The objective of the related activity appears to be decisive, not the time it takes. With one of the preliminary questions submitted to the Court in CopyGene, the Danish $\varnothing$ stre Landsret wished to find out whether the term closely related in Article 132(1)(b) is to be interpreted as implying a temporal requirement between the hospital care and a service closely related thereto. ${ }^{475}$ In this case, a private stem cell bank collects, transports, analyses, and stores umbilical cord blood from new-borns, so that these cells are available for a possible treatment of the child in the event of subsequent serious disease. There is thus an interval of time between the collection of the blood and the possible future medical service to the child. The CJEU in that case held that the exemption provision for intramural care does not impose a 'temporal requirement'. ${ }^{476}$ It held that:

"there could be a long period of time between the collection of the cord stem cells concerned and their possible future use for the purposes of hospital or medical care does not, as such, preclude activities such as those at issue in the main proceedings from coming within that exemption, all the more so since, as the referring court points out in the second part of the first question, it is impossible to collect blood containing cord stem cells otherwise than at birth." 477

The time that elapsed between the related and the principal health care service does as such not seem to influence the applicability of the exemption provision on the related activity. The CJEU did, however, stipulate in that case that a merely potentially related activity cannot come within the scope of the exemption provision in case the hospital and medical care have not been performed, commenced or yet envisaged. ${ }^{478}$

The CopyGene case is not only interesting because of the question referring to the temporal requirement. It is also a nice example of the social changes after the enforcement of the Sixth Directive. The use of stem cells for the purposes described in the underlying case is relatively new. It would be interesting to see whether the CJEU will take this into account, like the AG did, ${ }^{479}$ and will argue analogously that these kinds of services should be exempt, just like the supply of human organs, blood and milk (Article 132(1)(d) of the EU VAT Directive).

\footnotetext{
${ }^{475}$ CJEU 10 June 2010, Case C-262/08 CopyGene, ECLI:EU:C:2010:328.

${ }^{476}$ Idem, para. 45.

477 Ibid.

478 Idem, para. 52.

${ }^{479}$ A-G Opinion 10 September 2009, Case C-262/08 CopyGene, ECLI:EU:C:2009:541, p. 48.
} 


\subsubsection{The functioning and effects of exemptions under EU VAT}

In the previous sections I discussed the exemption provisions for health care transactions and their conditions for application in order to define the legal framework. An actual assessment of the exemption provisions for health care transactions will be made in chapter 7 . In that chapter, different situations have been distinguished (derived from the model health care system which was introduced in chapter 2 ) in order to be able to demonstrate how and in which specific situations the imposition of VAT on health care transactions hinders accessibility of health care. In this section, I will discuss the functioning and effects of the health care exemptions under positive EU Law from a conceptual point of view.

In section 3.2, the characteristics of the EU VAT system have been set out. In short, the EU VAT can be described as a general tax on consumption. The application of exemptions under the EU VAT system is contrary to the aforementioned principle as a broad-based tax. ${ }^{480}$ As a main rule, the EU VAT Directive subjects the supply of all goods and services made by a taxable person to VAT. At the same time, this taxable person is entitled to deduct the input VAT paid by him in the course of his taxed output transactions. ${ }^{481}$ This makes the system neutral. VAT paid by a taxable person within the supply chain is eligible for deduction up until the final stage of that chain, where the supply to the final consumer takes place. By definition, the application of exemptions ${ }^{482}$ therefore infringes the neutral character of the tax. Nevertheless, the EU VAT system contains a number of exemptions with and without a right to deduct input VAT.

The application of the exemptions is only required to be tested once it is established that the transactions concerned fall within the scope of the Directive and are 'taxable transactions' ${ }^{483}$ transactions outside the scope remain per definition untaxed. The exemptions are included in Title IX of the EU VAT Directive. It contains exemptions 'in the public interest', 'exemptions for other activities', 'exemptions for Intra-Community transactions', 'exemptions on importation', 'exemptions on exportation', 'exemptions related to international transport', and 'exemptions relating to international trade'. Most of these exemptions do not entail a right to deduct input VAT, among them the exemptions for medical and hospital care. For the purpose of discussion, I will therefore focus on the functioning and effects of the exemptions without a right to deduct input VAT.

In the figure below, the (direct) effect of the application of an exemption provision is shown.

\footnotetext{
${ }^{480}$ Green Paper on the future of VAT: Towards a simpler, more robust and efficient VAT system, COM(2010) 695 final p. 10.

${ }^{481}$ Article 168 of the EU VAT Directive (general rule on input VAT deduction).

${ }^{482}$ The same goes for exclusions, the application of which has a similar effect compared to exemptions without deduction right.

${ }^{483}$ Article 2 of the EU VAT Directive.
} 


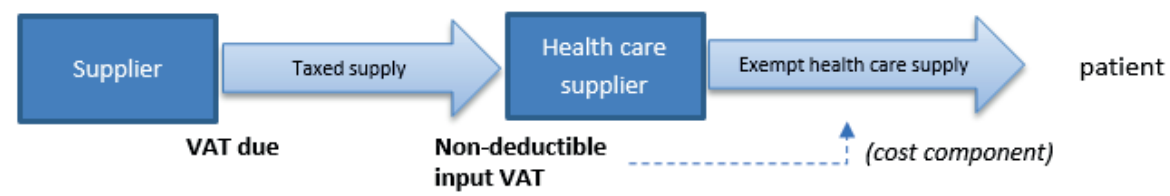

Figure 6.1 The direct effect of the application of an exemption provision

The most straightforward consequence of the exemption is that the transaction that is provided to the end consumer remains untaxed, at least if the (end) consumer is presumed to be a non-taxable person (B2C-transaction). The fact that the transaction as such is not taxed and the supplier does not have to charge any VAT in relation to that supply does not mean that there is no VAT burden in relation to that supply. The reason for that is that the fundamental right to an input tax deduction only applies in so far as goods and services are purchased in the course of a taxable person's taxed activities. In the example shown in figure 6.1, the supplier carrying out the exempt service cannot deduct any VAT that was charged to him on his 'input costs' that directly relate to the exempt supply. As a result, the VAT that the supplier once paid on his purchases becomes an extra cost component, which probably will become part of the purchase price (at least partly) that is charged to the consumer. It is after all safe to assume that taxable persons in principle seek to maximize their profit. The input VAT that has become part of the purchase price is referred to as 'hidden VAT'.

If the exemption applies in a B2B-transaction - an exempt supply is made by a taxable person to another taxable person - the direct effect of the application of the exception is again that the transaction as such remains untaxed. The supplier does not charge any VAT as regards that transaction to the taxable person receiving the good or service. Like in $\mathrm{B} 2 \mathrm{C}$ situations, there is still a VAT burden, as the supplier is not entitled to input VAT deduction in relation to the exempt supply. The effect of the application of the exemption in a B2B situation may however be more significant as the recipient of the supply is in principle not the end consumer in the supply chain. The application of an exemption becomes more problematic if an exempt supply is followed by a taxed supply. See the following figure:

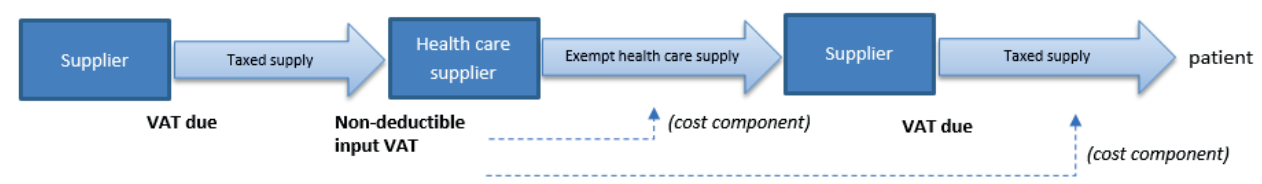

Figure 6.2 The forwarding of hidden VAT and cascading of VAT.

The figure above shows an exempt transaction followed by a taxed transaction. It illustrates one of the negative effects of the application of VAT exemptions. In the second transaction, VAT is charged in relation to an amount containing the 'hidden VAT' supplier A was not 
allowed to deduct. The result is that in fact VAT is charged on top of (hidden) VAT, otherwise referred to as cascading of VAT or the cascade effect. ${ }^{484}$ This is a clear distortion of the neutral character of the VAT. Both figures show the effect of the so-called 'VAT paradox'. The taxable person performing exempt supplies in fact pays VAT as a result of the inability to deduct input VAT, whereas a taxable person supplying taxed supplies is relieved from the input VAT he incurred in the course of his taxed supplies.

The effects of the application of exemption provisions may be justified to a certain extent. From a historical point of view, one of the reasons for applying VAT exemptions is that they sustain distributional and social objectives and compensate for the perceived regressive nature of the VAT system. ${ }^{485}$ Another rationale for the application of VAT exemptions is the 'difficult to tax' argument (for exemptions relating to gambling, real estate, financial transactions, etc.). ${ }^{486}$ In relation to health care, the purpose of the application of the exemption provisions - making health care more accessible to individuals by reducing the costs of that health care - can be justified on the basis of the application of the principle of access to care. The reasoning of the CJEU in relation to the purpose of exemptions for medical care has never been justified from a human rights perspective. I demonstrated in chapter 4 that the proclaimed purpose of the exemption provisions for health care corresponds to the principle of access to health care.

In this chapter, the function and functioning of VAT exemptions is therefore discussed in order to establish the (general) effect of the application of VAT on health care in relation to the right to care. Chapter 7 provides for a more detailed illustration of the effect of the application of VAT Exemptions for medical care, as it is linked to specific themes that appear to typically occur in the health care sector.

\subsection{Conclusions}

Even though the VAT exemptions for health care intend to facilitate access to health care I demonstrated in chapter 6 that, from a conceptual point of view, exemptions are by definition distortive and hinder access to health care, for example in case exempt transactions in a supply chain are followed by taxed transactions and an accumulation of VAT occurs. This leads to the paradoxical situation in which medical VAT exemptions have the objective of reducing the cost of health care and of making it more accessible to individuals, while at the same time the application of VAT exemptions hinders access to health care. ${ }^{487}$ In that regard, it is important to acknowledge the various factors that cause an exemption to hinder such access to health care. First of all, a factor causing exemptions to hinder access to health care is the amount of input VAT incurred by the health care supplier. If the health care

\footnotetext{
${ }^{484}$ Commission Staff Working Document, Accompanying document to the Green Paper on the future of VAT, SEC (2010) 1455 final, p. 29.

${ }^{485}$ Idem, p. 27.

486 Ibid.

${ }^{487}$ See section 6.2.3.4. on the objective of reducing health care costs.
} 
provider incurs a substantial amount of VAT, which he cannot deduct, the costs of the health care, and therefore the prices and thus the access to health care, are likely to be affected. Another factor to take into account is that an exemption in the health care sector, connected with the absence of a right of deduction, may result in a health care supplier making economically inefficient decisions. A hospital, for example, generally provides services that are VAT exempt. As a result, only a small part of the VAT that is charged to the hospital on the goods and services that it purchases ('input VAT') is deductible. If only the VAT consequences are taken into account and this hospital has the choice between performing certain services in-house, or hiring a third party, it will choose the first option in case the third-party charges VAT on its services and the hospital is not entitled to deduct this input VAT. This phenomenon is referred to as the bias towards insourcing. In practice, this leads to situations in which a health care supplier makes certain choices driven by the VAT consequences attached to the available options, with a risk of denying economic efficiency. 


\section{How VAT exemptions impede access to health care in specific situations}

\subsection{Introduction}

The purpose of this chapter is to show the application of positive EU VAT law on health care transactions in specific situations in order to be able to answer the first research question, i.e. in which situations the imposition of VAT impedes access to health care. The ultimate goal is to be able to show the implications of the two exemption provisions in different situations and the differences between their application in exactly the same situations. In chapter 6, I discussed elements of positive EU VAT law that are intended to mitigate the VAT burden on health care transactions from a conceptual point of view. In particular, I discussed exclusions - in particular in relation to public bodies - and VAT exemptions for health care transactions. I concluded that the application of these measures - besides the reduced rates - do not have the intended effect and may even be counterproductive.

In order to understand and demonstrate in which situations the application of exemption provisions hinders access to health care, common types of situations in which health care can be provided are distinguished. These common types of situations are derived from the analysis of definitions and common denominators of EU health care systems (chapter 2) and health care transactions that were the subject in the CJEU cases in the field of VAT exemptions on health care. It is therefore ensured that these typical situations occur in the EU and can be used for the purpose of demonstrating EU VAT consequences. The aforementioned analysis led to a model health care system (figure 7.1).

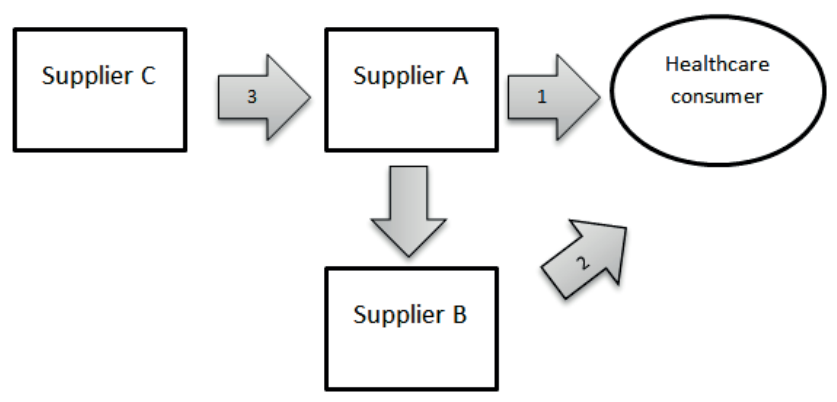

Figure 7.1 Model health care system

This model health care system - that was discussed in more detail in chapter 2 - is consumption driven and based on transactions. The transactions in the model health care system can be carried out in three main categories of situations. It contains transactions made to final consumers by supplier A, as shown in figure 7.1 (arrow 1). These transactions are referred to as transactions in a basic situation. The model also contains transactions 
made to final consumers by supplier B (arrow 2), referred to as transactions in parallel situations. Furthermore, it contains transactions by supplier C to supplier A (arrow 3), referred to as transactions in successive situations.

It appears that the scope of application of health care exemptions differs depending on the situation and relationship in which the health care is provided. Moreover, the scope of application might also differ within the same situation, depending on which exemption provision for health care is applicable. To be able to show these differences and to determine in which types of situations the application of VAT exemptions hinders access to health care, I will investigate a) what the scope of the exemption provisions for health care is in basic, parallel, and in successive situations and b) to what extent the application of exemption provisions hinder the access to health care in basic, parallel, and in successive situations.

In the previous chapter, I pointed out that, unlike exclusions, the VAT exemptions for medical care have the objective to make health care more accessible to individuals by reducing the costs of health care. ${ }^{488}$ Exclusions may also mitigate the VAT burden of health care transactions - especially there where it concerns public health care - yet this is the mere result of the delineation of the scope of EU VAT. The same is true for exclusions from the scope of EU VAT as a result of the lack of consideration (e.g. the provision of free health care by doctors conducting voluntary work). The effects of applying exemptions and exclusions, nevertheless, are similar to a large extent. The effects of applying exclusions in basic, parallel and successive situations will therefore be touched upon as well, while discussing the application of VAT exemptions in those situations.

Reduced rates have been included in the EU VAT system to reduce the costs of - and improve the access to - essential goods for final consumers. ${ }^{489}$ From a conceptual point of view, this objective seems to work, if compared to full taxation. Unlike the application of exemptions and exclusions, the application of reduced rates respects the system neutrality of the EU VAT System, as the right to deduct input taxation can still be exercised. As a result, less distortions occur. From the conceptual analysis, I concluded that - next to the increasing of the cost price of health care - the application of reduced rates hinders access to health care mainly as a result of delineating the scope of application of reduced rates. Reduced rates are, after all, exceptions to the general rule, i.e. the application of the standard VAT rate.

\footnotetext{
${ }^{488}$ See section 6.2.1 on the objective of reducing health care costs.

489 CJEU 17 January 2013, Case C-360/11 Commission vs. Kingdom of Spain, ECLI:EU:C:2013:17, paras. 48 and 65; CJEU 9 March 2017, Case C-573/15 Oxycure Belgium, ECLI:EU:C:2017:189, para. 22.
} 


\subsection{The hindering effect of VAT exemptions in the health care sector in basic situations}

To be able to demonstrate the scope of the application of exemption provisions for health care and to analyse the hindering effect of these exemptions, I will discuss several situations in which health care is ultimately supplied to patients. In this section, I will discuss the application of the exemptions for health care in the basic situation, where health care supplies are made directly to the patient (see figure 7.2).

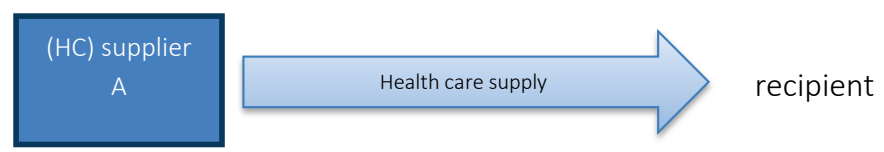

Figure 7.2 Health care supply in a basic situation

In order to demonstrate the effects of exemption provisions for health care, this 'simple' situation serves as a starting point as it concerns supplies made in the ultimate link of the supply chain involving only one single health care supplier. This basic situation may be extended with other elements or suppliers in the other situations that are discussed in this chapter. In that way - i.e. step by step extending the basic situation - the differences in the effect of the application of the exemption can be observed more easily. The effect of the application of VAT exemptions in the health care sector in parallel situations and successive situations will be demonstrated in sections 7.3 and 7.4). Section 7.5 contains an overview of the conclusions per situation and per type of medical exemption provision.

\subsubsection{Introduction}

Figure 7.2 shows an example of a health care supply in a basic situation. In this situation, there is one supply from the supplier directly to the health care consumer, whereas in the parallel and the successive situation, supplies are added in order to examine the effects of the application of VAT on those supplies and to be able to compare that effect to the effect of the application of VAT on health care transactions in a basic situation. The arrows that are drawn in the different situations represent supplies. Those supplies consist - from a VAT point of view - of only one element ('single element supply'). Supposedly, in practice, almost every supply made by a supplier consists of multiple elements. For example, a service provided by a tax advisor may consist of conducting a literature study, writing a tax advice on a computer, printing the advice, and finally sending the advice by letter to the customer. For the purpose of illustration, however, the supply made by the health care supplier to the health care recipient in the basic situation is assumed to contain only one element. For example, a general practitioner can diagnose a patient with skin disease simply by observing the patients skin. While using 'single element supplies', I assume that, if the supply would contain other elements, they would lack a sufficient degree of independence for the application of VAT. Hence, the supplies in the basic situation are supplies of which it is 
beyond discussion that the elements of which it consists shall be considered as one single supply from a VAT perspective. The doctrine of composite supplies, therefore, does not play a role in the basic situation. This differs from parallel situations in which there is at least one separate element that contains a sufficient degree of independence, as a result of which it has to be taken into account for the determination of the VAT implications. As will be shown in the assessment of the application of health care in parallel situations, the separate element can either be regarded as part of the principle supply (by means of absorption or together with the other elements as a 'sui generis supply') or as a separate supply, depending on the nature of the supply provided (see also section 7.3.2.1).

In figure 7.2 an example of a basic situation is drawn. Figure 7.3 , below, shows where in the model health care system, this basic situation occurs.

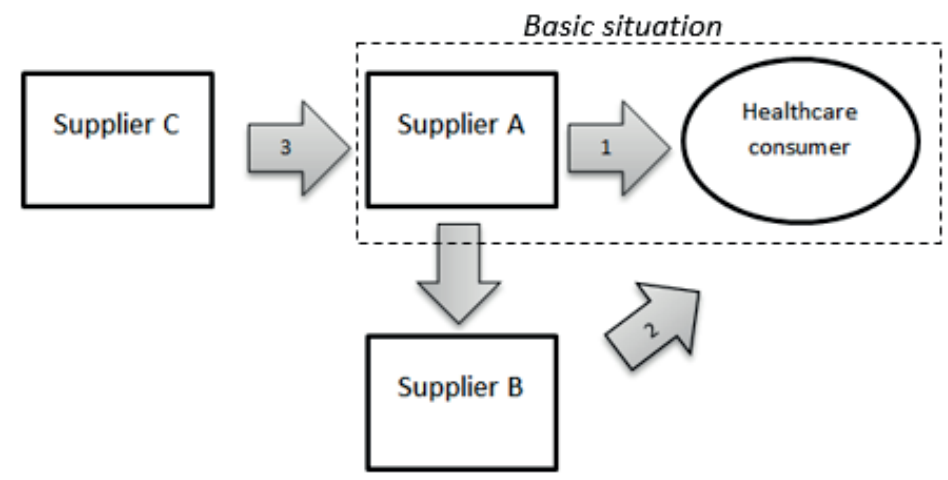

Figure 7.3 Basic situation in the model health care system

In the basic situation, only one supplier is involved. The supplier directly supplies health care to the health care consumer (patient), for example, periodically provided dental treatment by a dentist to a patient, or the services provided by the general practitioner mentioned before. The supply in these basic situations does not contain any element that has such a degree of independence that it should be assessed separately.

The application of an exemption provision for health care is dependent on the nature of the supply provided, as well as the quality of the (health care) supplier. ${ }^{490}$ In order to demonstrate the scope of the application of health care exemptions in the basic situation, I will - hereafter - assess the relevant criteria for the application of the exemptions if health care is provided in a basic situation. For the purpose of discussion, it is assumed that the

\footnotetext{
490 It follows from the text of the Articles 132(1)(b) and (c) of the EU VAT Directive, together with case law on the application and interpretation of these provisions that the application of the exemptions for medical care is dependent on both the nature of the services provided, as well as the quality of the provider. For intramural care it is even important in which capacity a health care professional is operating (see for example CJEU 27 April 2006, Joined Cases C-444/04 and C-443/04 Solleveld, ECLI:EU:C:2006:257, para. 30).
} 
service provided in the example drawn above constitutes 'medical care'. Articles 132 (1)(b) and $132(1)(c)$ of the EU VAT Directive intend to regulate all exemptions of medical services in the strict sense. ${ }^{491}$ Their individual application is, however - in addition to the nature of the supply and the quality and capacity of the health care supplier - mainly dependent on the place in which the medical care is provided. The basic situation does not refer to such a specific place. Therefore, for each situation I will assess both exemption provisions individually. By doing so it will become clear to what extent the effect of the application of exemption provisions differs in each situation, solely as a result of providing the same care in a different place (i.e. intramural vs. extramural care). In section 7.2.2.1, the application of the exemption provision for intramural care in the basic situation is assessed. Section 7.2.3.1 contains an assessment of the application of the exemption provision for intramural care in the basic situation. It is assumed that the supplier ('Supplier A') qualifies as a taxable person under Article 9 of the EU VAT Directive and the services provided are not covered under the exclusion of Article 13 of the EU VAT Directive. Hence, the services Supplier A provides fall within the scope of the EU VAT System and constitute economic activities.

\subsubsection{Basic situations under Article 132(1)(b) of the EU VAT Directive}

The previous subsection showed what is to be understood as a supply in a basic situation. The supply in that situation is in fact the last link in a supply chain through which health care is supplied to a patient (see also figure 7.3). Figure 7.2 shows an example of a health care supply in a basic situation. In this section, the scope of the exemption provision for intramural care in basic situations of supplies will be assessed. The purpose of this assessment is to establish under which circumstances medical care in a basic situation is exempt from VAT (according to Article 132(1)(b) of the EU VAT Directive). The outcome of the assessment can be compared to the outcome in the other situations that have been distinguished in this chapter. This facilitates an illustration of which situations the application of health care exemptions hinders access to health care and in which situations an impediment of the principle of access to health care is most likely to occur.

\subsubsection{Assessment of the application of the exemption provision for intramural care in the basic situation}

Article 132(1)(b) of the EU VAT Directive contains an exemption provision for intramural care. It exempts:

"hospital and medical care and closely related activities undertaken by bodies governed by public law or, under social conditions comparable with those applicable to bodies governed by public law, by hospitals, centres for medical treatment or diagnosis and other duly recognised establishments of a similar nature". ${ }^{492}$

\footnotetext{
${ }^{491}$ See, for example, CJEU 13 March 2014, Case C-366/12 Klinikum Dortmund, ECLI:EU:C:2014:143, para. 31.

${ }^{492}$ Article 132(1)(b) of the EU VAT Directive.
} 
In section 6.2.2, the conditions were discussed. For the application of this exemption provision, the legal form of the supplier is irrelevant. ${ }^{493}$ The procedures and conditions for recognition are a national matter, as a result of which those procedures differ per Member State. The discretion conferred on Member States to set up a national recognition procedure for suppliers that are allowed to apply the health care exemption for intramural care is limited by the application of Community principles, in particular the principle of equal treatment which, in the field of VAT, takes the form of the principle of fiscal neutrality. ${ }^{494}$ The principle of fiscal neutrality demands that all the categories of establishments governed by private law referred to in Article 132(1)(b) of the EU VAT Directive are subject to the same conditions for recognition if they provide similar services. The CJEU has repeatedly stated that a national rule precluding the exemption from applying to treatment given under the sole responsibility of members of paramedical professions goes beyond the limits of the discretion granted to the Member States. ${ }^{495}$

The fact that the recognition takes place on a national level is, on the one hand, logical and a mere result of the fact that health care systems are a national matter. Other than the VAT system, health care systems are not harmonized throughout the EU, a quality requirement can therefore only be safeguarded on a national level. On the other hand, there may be an unequal VAT treatment of the services between the Member States. This raises the question whether there are valid justification grounds for such a different treatment in the various Member States. The application of VAT is (largely) based on the destination principle. This principle reflects the legal character of the VAT to tax consumption at the level of the (end) consumer. At the same time, it is safe to say that, in general, the place where the health care supplier is established and the place where the consumption of the care takes place correspond. It can be expected that health care transactions are, by their nature, supplied at the place where consumption takes place. A German citizen will usually visit a German hospital for example. Both the service supplier (the hospital) and the place where the service is consumed is Germany in that case. If the German citizen, however, regularly visits a hospital in the Netherlands for treatment, the question may arise whether the medical treatment or hospital care is not actually consumed in Germany. The VAT treatment of a service, if taxed according to the origin principle on the basis of Article 45 of the EU VAT Directive, may lead to a distortion of fiscal neutrality between Member States. As said, this phenomenon occurs especially in border regions. In section 1.2, I already indicated that cross-border patient mobility has increased exponentially increased over the past two decades in the EU, although the absolute volumes of patients seeking treatment across

\footnotetext{
${ }^{493}$ CJEU 7 September 1999, Case C-216/97 Jennifer Gregg and Mervyn Gregg v Commissioners of Customs and Excise, ECLI:EU:C:1999:390, para. 20.

${ }^{494}$ CJEU 8 June 2006, Case C-106/05 L.u.P., ECLI:EU:C:2006:380, para. 48; CJEU 6 November 2003, Case C-45/01 Dornier, ECLI:EU:C:2003:595, para. 69; CJEU 10 June 2010, Case C-262/08 CopyGene, ECLI:EU:C:2010:328, para. 64.

${ }^{495}$ CJEU 8 June 2006, Case C-106/05 L.u.P., ECLI:EU:C:2006:380, para. 51; CJEU 6 November 2003, Case C-45/01 Dornier, ECLI:EU:C:2003:595, para. 70.
} 
European borders is relatively small. Although a lack of harmonization is problematic, the effect seems to be relatively small. The same is true, for example, for supplies related to real estate. They are also generally consumed at the place where the real estate is situated.

In most of the EU Member States, health care activities provided by a qualified public body are treated as activities that fall within the scope of the EU VAT System. They constitute economic activities. The establishments providing the health care are considered to be persons aiming for income on a continuing basis. Yet, the hospital and medical care they provide is exempt from VAT. In the example provided above, the application of the VAT exemption results in a VAT-free supply of health care by supplier A to the recipient. Supplier A cannot deduct any input VAT that was charged to him in connection with the exempt health care he provided. That non-deductible VAT (or at least a part of it), which forms part of the cost price, will be charged forward to the recipient.

In some Member States, for example Cyprus, Greece and Poland, public hospital care provided by public bodies is not covered under the EU VAT Directive (see also section 6.1.3) ${ }^{496}$ These services are considered non-taxable in those Member States. Article 13 of the EU VAT Directive excludes bodies governed by public law from the scope in respect of their activities or transactions in which they engage as public authorities. Consequently, if supplier A in the example drawn in figure 7.1 is a public body and its services qualify under the national equivalent of Article 13 of the EU VAT Directive, the health care provided does not constitute a taxable transaction for VAT. The supply is outside the scope and supplier A, hence, does not charge VAT on the supply. Since supplier $A$ is not operating as a taxable person as regards the supply of the (public) health care, it is not entitled to deduct any input VAT in relation to that supply. The deduction of VAT is, according to Article 168 of the EU VAT Directive, only possible for taxable persons. Like in the previous example, where the supply was VAT exempt, the supplier will pass on (part of) the non-deductible input VAT to the recipient.

The exemption provision of Article 132(1)(b) of the EU VAT Directive covers hospital and medical care carried out within a 'hospital environment', while Article 132(1)(c) of the EU VAT Directive covers medical care supplied outside such a framework, both at the private address of the person providing the care and at the patients home or at any other place. ${ }^{497}$ The criterion for drawing a distinction between those two provisions is thus less the nature or substance of the service than the place where it is provided. ${ }^{498}$ In the example of the basic situation that was provided above, it was assumed that the health care provided constituted medical care in the light of one of the exemption provisions. It is the place in which the health care is provided that is decisive for which the exemption provision applies. The distinction is

\footnotetext{
${ }^{496}$ Copenhagen Economics, 2013, VAT in the public sector and exemptions in the public interest, Final report for TAXUD/2011/DE/334, p. 83.

${ }^{497}$ CJEU 10 September 2002, Case C-141/00 Kügler, ECLI:EU:C:2002:473, para. 36.

${ }^{498}$ CJEU 6 November 2003, Case C-45/01 Dornier, ECLI:EU:C:2003:595, para. 47.
} 
of importance, as the exemption provisions contain different criteria as regards the supplier. The scope of Article 132(1)(b) of the EU VAT Directive is in that sense broader compared to the scope of Article 132(1)(c) of the VAT. The former provision not only includes medical care provided directly by doctors or other health professionals under medical supervision, but also paramedical services provided in hospitals under the sole responsibility of persons who are not doctors. ${ }^{499}$

Another difference between the two medical exemption provisions is that Article 132(1)(b) of the EU VAT Directive also exempts closely related activities undertaken by the bodies referred to in that provision. In case of single element supplies, similar to the supply in the example of a basic situation, this extension of the exemption provision to closely related activities is irrelevant, as explained in section 7.3.2.1. For the purpose of illustration, I assumed that none of the elements present in the basic supply have enough substance to take them into account separately for the assessment of the VAT consequences of the supply. A closely related activity can only be distinguished if it constitutes an activity actually supplied as a service ancillary to the hospital or medical care by the patients in question and constituting the principal service. ${ }^{500}$ In case of a single element supply in the basic situation - as shown above - a separate ancillary activity is not present.

In conclusion, it is the place or environment in which the medical care in this basic situation is carried out that dictates which exemption provision is applicable. Article 132 (1)(b) of the EU VAT Directive concerns medical care that is supplied in a hospital environment. The exemption is applicable in the basic situation if the (single element supply of) health care provided qualifies as hospital or medical care and the supplier qualifies, according to national standards, as one of the bodies referred to in the exemption provision. The single element supply, as such, cannot constitute a closely related service, as in the basic situation there is no (other) supply rendered to which it relates or is ancillary to. In parallel and successive situations, this is different, since one or multiple elements are added (see sections 7.2.2.1 and 7.2.3.1). In those situations, they may be closely related to the principal health care service.

\footnotetext{
499 CJEU 6 November 2003, Case C-45/01 Dornier, ECLI:EU:C:2003:595, para. 70; CJEU 8 June 2006, Case C106/05 L.u.P., ECLI:EU:C:2006:380, para. 51.

${ }^{500}$ CJEU 10 June 2010, Case C-262/08 CopyGene, ECLI:EU:C:2010:328, para. 39; CJEU 1 December 2005, Joined Cases C-395/04 and C-394/04 Ygeia, ECLI:EU:C:2005:734, para. 18.
} 


\subsubsection{Consequences of the application of the exemption provision for intramural care in the basic situation}

In section 6.2.6, I discussed the consequences of the application of exemption provisions from a conceptual point of view. See below the example of a supply made in the basic situation:
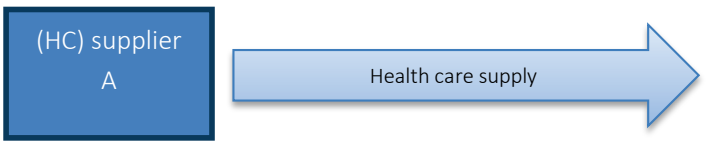

recipient

The direct effect of the application of the VAT exemption for intramural care on health care transactions in the basic situation is that there is no VAT due on the supply. This is an exception to the general principle that VAT is to be levied on all services supplied for consideration by a taxable person. ${ }^{501}$ As a consequence, Supplier A does not charge any VAT to the patient as regards the supply and is not liable for paying any VAT to the tax authorities.

Taxable persons who carry out exempt transactions are not allowed to deduct any VAT charged to them in relation to those exempt supplies. ${ }^{502}$ The limitations on the right to deduct input tax for a supplier will most likely result in the inclusion of (part of) the nondeductible VAT in the price of the health care transaction for the final consumer (the patient), i.e. increased health care costs. ${ }^{503}$ Since Supplier A cannot deduct any input VAT that was charged to him in relation to the health care he supplies to the patient, it is expected that Supplier A passes on the non-deductible tax to the patient. This implies that the health care supply is, despite the application of the exemption provision for intramural care, not entirely VAT free. In case Supplier A does not pass on any of the non-deductible input VAT to the patient, it will reduce his profit margin. The non-deductible input VAT then becomes a burden for the supplier. The latter is contrary to the legal character of the VAT System, being a tax on (private) consumption.

The application of an exemption provision in the basic situation also brings along side effects. As a result of the non-deductible input VAT, Supplier A may face a reduced incentive to

\footnotetext{
${ }^{501}$ CJEU 15 June 1989, Case C-348/87 Stichting Uitvoering Financiële Acties, ECLI:EU:C:1989:246; CJEU 5 June 1997, Case C-2/95 Sparekassernes Datacenter (SDC), ECLI:EU:C:1997:278; CJEU 6 November 2003, Case C-45/01 Dornier, ECLI:EU:C:2003:595; CJEU 3 March 2005, Case C-472/03 Arthur Andersen, ECLI:EU:C:2005:135; CJEU 2 October 2009, Case C-242/08 Swiss Re Germany Holding, ECLI:EU:C:2009:647; CJEU 28 January 2010, Case C473/08 Eulitz, ECLI:EU:C:2010:47; CJEU 18 December 2010, Case C-175/09 AXA UK, ECLI:EU:C:2010:646.

${ }^{502}$ This follows directly from the application of Article 168 of the EU VAT Directive.

${ }^{503}$ See also section 1.5 on the assumption that the imposition of VAT on health care transactions can be expected to lead to an increase of health care costs.
} 
outsource services that are taxed with VAT (for example cleaning services or IT services). ${ }^{504}$ The VAT burden can, consequently, force Supplier A to make economically inefficient decisions. Furthermore, as explained in the previous subsection, Member States enjoy a discretion to set up a national recognition procedure for suppliers that are allowed to apply the health care exemption for intramural care. Due to the lack of harmonization at this point, fiscal neutrality is only ensured within Member States, however, not between them. In the example given, in which Supplier A supplies only one recipient, it only has to consult the applicable VAT legislation of the Member State in which the service takes place. If a health care supplier would be liable for VAT in multiple Member States, the complexity of the rules, due to the deviating national rules, leads to a degree of legal uncertainty. As was noted earlier, this may be justified by the fact that the majority of intramural health services is expected to be consumed locally (there where the consumer resides), which safeguards the destination principle.

As regards the example of a health care supply in a basic situation provided in figure 7.2, I made the assumption that Supplier A qualifies as a taxable person under Article 9 of the EU VAT Directive and that he is - for the activities concerned - not excluded from the scope of VAT on the basis of Article 13 of the EU VAT Directive. As a result, the supplies are considered economic (taxable) activities. In section 6.1.3, I showed that certain Member States, however, exclude public health care from the application of VAT, because the supplier operates as a government public authority in relation to those supplies. It may thus be that the medical care supplied by Supplier A in a certain Member State falls within the application of the exclusion of Article 13 of the EU VAT Directive. In that case, Supplier A is not considered to be a taxable person in relation to those services. This results in a situation similar to the application of a VAT exemption on those services.

\subsubsection{Basic situations under Article 132(1)(c) of the EU VAT Directive}

In section 7.2.2, I discussed the scope of the exemption provision for intramural care in basic situations. In this section, the scope of the exemption provision for extramural care in basic situations of supplies will be discussed and assessed. The purpose of this assessment is to establish under which circumstances medical care in a basic situation is exempt from VAT according to Article 132(1)(c) of the EU VAT Directive.

\subsubsection{Assessment of the application of the exemption provision for extramural care in the basic situation}

The exemption provision for extramural health care covers medical care supplied outside a hospital environment, both at the private address of the person providing the care and at the

\footnotetext{
${ }^{504}$ Copenhagen Economics, 2013, VAT in the public sector and exemptions in the public interest, Final report for TAXUD/2011/DE/334, p. 109.
} 
patient's home or at any other place. ${ }^{505}$ Article $132(1)(c)$ of the EU VAT Directive contains the exemption provision for extramural care, it reads as follows:

"(c) the provision of medical care in the exercise of the medical and paramedical professions as defined by the Member State concerned". ${ }^{506}$

The provision contains conditions as regards the supply, as well as the supplier. The exemption for extramural care has as an objective to ensure that the exemption applies solely to services provided by persons with the required professional qualifications. ${ }^{507}$

In their national legislation, Member States have to define these medical and paramedical professions. The exact scope of the application of the exemption for extramural medical care is therefore dependent on the Member States where the services are carried out in accordance with the rules of the EU VAT Directive. In the previous section, I also showed that the definition of bodies that can provide exempt intramural care is a national matter. The result is that the scope of the exemption provisions differs per Member State. This is in my view only problematic and perhaps not in line with the principle of fiscal neutrality if the service providers in different Member States compete with each other. As regards health care and education, this is less likely than for instance for financial services, ${ }^{508}$ since health care and education are services presumably rather consumed locally. See also section 7.2.2.1.

The discretion for Member States to define the medical and paramedical professions does not only cover the power to define the required qualifications to carry out the said professions, it also covers the power to define the specific medical care activities which are covered by such professions. A Member State may even specify the care in respect of which they are qualified in the context of those professions. ${ }^{509}$ As stated, the ways in which the Member States use their discretionary power to define the professions or professional qualifications differ. Germany for example in its national Value Added Tax Act (UStG ${ }^{510}$ ) exempts medical care that is carried out in the exercise of the activities as a doctor, dentist, an alternative medicine practitioner, a physiotherapist, midwife, or by similar health service provider. ${ }^{511}$ In the UK Value Added Tax Act 1994, reference is made to statutory registers. Only the medical services within the profession in which a provider is registered to practice

\footnotetext{
${ }^{505}$ CJEU 10 June 2010, Case C-262/08 CopyGene, ECLI:EU:C:2010:328, para. 36.

${ }^{506}$ Article $132(1)$ (c) of the EU VAT Directive.

${ }^{507}$ CJEU 27 April 2006, Joined Cases C-444/04 and C-443/04 Solleveld, ECLI:EU:C:2006:257, para. 37; CJEU 10 September 2002, Case C-141/00 Kügler, ECLI:EU:C:2002:473, para. 27.

508 PwC, 2011, How the EU VAT Exemptions impact the Banking Sector (retrievable via: http://www.pwc.nl/nl/assets/documents/pwc-db-vat-study-final-report-fo3.pdf).

${ }^{509}$ CJEU 27 April 2006, Joined Cases C-444/04 and C-443/04 Solleveld, ECLI:EU:C:2006:257, para. 30.

${ }^{510}$ German Value added tax Act (UStG), as amended by the notice of 21 February 2005 (BGBI. I S. 386), most recently by aricle 11 of the law of July 18, 2017 (BGBI. I p. 2417) is changed.

${ }^{511} \S 4, \mathrm{nr}$. 14a UStG.
} 
are exempt. ${ }^{512}$ The latter is also the case, for example, in the Netherlands, where medical care is only exempt if carried out by practitioners who completed training designed for the profession they carry out and for which rules have been imposed in or due to the Act regarding professions in individual health care, to the extent that these services belong in the field of expertise of this profession and constitute part of specified training. ${ }^{513}$

The application of the exemption provision for extramural care thus depends on the professional qualities of the supplier providing the care and whether the profession that is exercised by the supplier qualifies as a medical or paramedical profession according to national VAT legislation. It occurs that health care suppliers, whose professions are excluded from the definition of the medical and paramedical professions, supply services that are similar to those of health care suppliers whose profession is covered under the exemption provision. This situation is illustrated in figure 7.4.

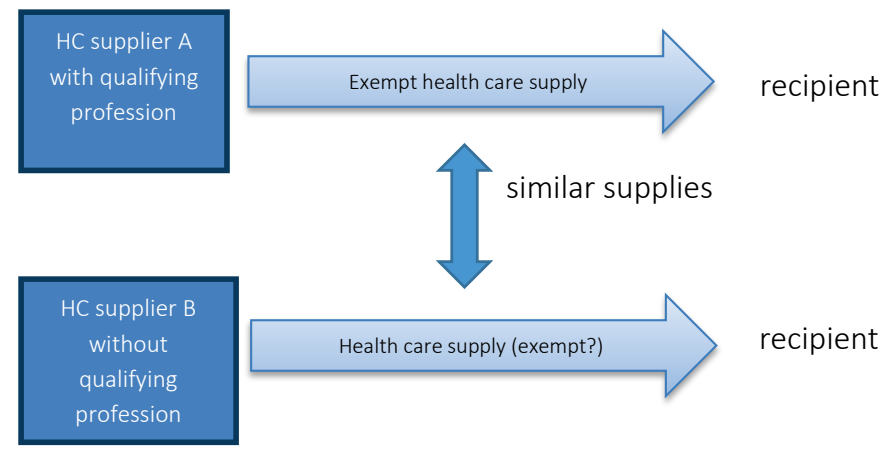

Figure 7.4

Supplier A and Supplier B in figure 7.4 are supplying similar health care services to patients. Yet, only supplier A's profession is covered under the national definition of 'medical and paramedical professions'. As a result, the supply made by supplier $B$, in principle, does not qualify under the exemption provision for extramural care and should, therefore, be taxed. Whereas, supplier A does possess the required professional qualifications, as a result of which his services are exempt, assuming that the care provided falls within the area of expertise of his profession (see below).

The CJEU held that, in these situations, in line with the aim of the exemption provision and the application of the principle of fiscal neutrality, the national authorities will have to ensure that health care services, performed by persons with professional qualifications that can be regarded as being of an equivalent value compared to those of persons exercising

\footnotetext{
${ }^{512}$ Schedule 9, Group 7, Items 1 to 3 of the Value Added Tax Act 1994; see also HM Revenue \& Customs, 2014, Health professionals and pharmaceutical products, VAT Notice 701/57 of 28 July.

${ }^{513}$ Article 11(1)(g) Wet op de omzetbelasting 1968.
} 
professions, are also covered within the scope of the exemption. ${ }^{514}$ This means that, in case the professional qualifications of supplier B in figure 7.4 are of equivalent value compared to those of supplier A - i.e. according to national standards - the health care provided by supplier B should also be exempt. The quality of the professional qualification is used in this regard as a standard to safeguard a correct application of the principle of fiscal neutrality. This might seem out of place in an objective tax system. The quality of the professional qualification, by definition, concerns the subject of taxation. The question arises whether this is the right method to ensure the correct application of the exemption provision for extramural health care. A strict application of exemption provisions requires a strict definition of extramural health care. As noted before, in relation to the exemption provision for extramural care, there is no clear-cut definition of the health care that is covered under Article 132(1)(c) of the EU VAT Directive, nor in other primary or secondary EU legislation (see also section 2.2.1). There is also no harmonized health care system in the EU that defines the professional qualifications for medical and paramedical professions in the Member States. This justifies, in my view, that the definition of the extramural care, for VAT purposes, is at the discretion of the Member States. However, it does not, by definition, justify that the required quality is related to the knowledge of the subject. Yet, the human component in extramural care is of such importance that, in my view, it is logical to presume that the professional quality of a health care supplier is decisive for the quality of the health care supply. I have found support for this view in my conclusions as regards the exploration of common definitions of health care activities and providers (chapter 2). In section 2.2.2.3, I defined a health care supplier for the purpose of this research as follows:

"natural persons or organisations carrying out activities with a primary intent to enhance a person's health status, provided that the activities are carried out by persons with sufficient level of medical, paramedical and nursing knowledge (according to national accreditation standards)".

This definition contains a qualitative element, i.e. it requires a sufficient level of knowledge of the person or organization carrying out the services. I demonstrated in section 2.2.1.1 how the presence of a sufficient level of knowledge serves as a delineation criterion for determining the difference between health care services and other health services. In other words, I concluded that the quality of a service provider (in terms of professional knowledge and defined on a national level), is a criterion that is used to establish whether the supply made by that provider can be considered health care. The fact that Article 132(1)(c) of the EU VAT Directive contains a reference to the professional qualifications of the service provider, which has to be recognized on a national level, is thus completely understandable and in line with the definitions used in practice by international organizations. Moreover, the

${ }^{514}$ CJEU 27 April 2006, Joined Cases C-444/04 and C-443/04 Solleveld, ECLI:EU:C:2006:257, para. 41; CJEU 8 June 2006, Case C-106/05 L.u.P., ECLI:EU:C:2006:380, para. 32; CJEU 14 April 2016, Case C-555/15 Gabarel, ECLI:EU:C:2016:272, p.38. 
requirement of sufficient professional knowledge ensures that services by unorthodox doctors or charlatans do not fall within the scope of the exemption provision for extramural care. This is justifiable on basis of the aim of the medical exemption provisions, to make health care more accessible to individuals.

In figure 7.4 a situation was illustrated in which two suppliers with different professional qualifications provide similar services. It can also occur that suppliers with similar professional qualifications, both qualifying as a medical professional under national legislation, provide different services (see figure 7.5).

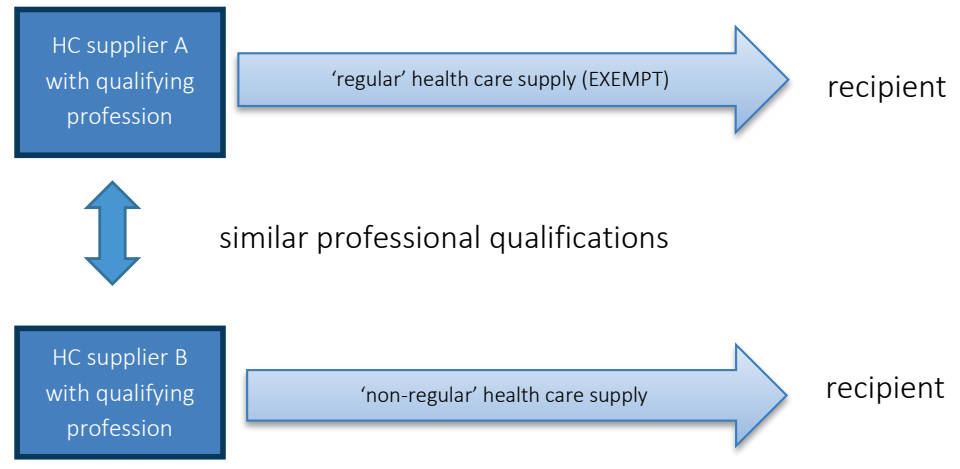

Figure 7.5

As noted before in this section, supplies are only exempt if the qualified health professional providing them is operating within the field of expertise of the medical profession ('regular health care supplies'). As a result, 'non-regular' health care provided by a medical professional may fall outside the scope of the exemption provision. Supplier A and B in figure 7.5 may have obtained the exact same professional qualifications and exercise a similar medical profession. If the treatment that supplier B provides, however, does not fall within the area of expertise of his profession, the treatment is not exempt. An interesting example in this regard is the VAT treatment of acupuncture treatment. Acupuncture treatment is a traditional procedure-based therapy. These kinds of therapies use various techniques, primarily without the use of education, to provide health care. ${ }^{515}$ The WHO considers traditional medicine, like acupuncture treatment, health care. Acupuncture treatment is increasingly used and recognized around the globe. In 2012, at least 18 countries had health care coverage for acupuncture treatment. ${ }^{516}$ In a VAT Notice of HM Revenue \& Customs, it is

\footnotetext{
515 World Health Organisation (2000), General Guidelines for Methodologies on Research and Evaluation of Traditional Medicine, WHO/EDM/TRM/2000.1, p. 9 (retrievable via: http://apps.who.int/iris/bitstream/10665/ 66783/1/WHO_EDM_TRM_2000.1.pdf).

${ }^{516}$ World Health Organisation (2013), WHO Traditional Medicine Strategy 2014-2023, p. 22 (retrievable via: http://www.who.int/medicines/publications/traditional/trm_strategy14_23/en).
} 
explicitly stated that, in the UK, the services of acupuncturists do not fall within the scope of the exemption provision for extramural health care, as there are (currently) no statutory registers in this field. The services of health professionals are only in the UK exempt if the professional is enrolled or registered on the appropriate statutory register. ${ }^{517}$ The question arises whether acupuncture services of a registered health professional - whose 'regular' services do qualify under the exemption provision (i.e. a professional enrolled or registered on an appropriate statutory register) - are exempt. This is not clear from the VAT Notice. It became clear in the Solleveld case that the discretion conferred on Member States to define, in national law, the paramedical professions as regards the exemption provision of extramural care, also covers the power to define the specific medical care activities which are covered by such professions. ${ }^{518}$ In the Netherlands, it was explicitly noted in a Decree issued by the State Secretary of Finance that acupuncture treatment given by registered health professionals is per definition 'non-regular' health care and does not fall within the scope of the exemption provision. ${ }^{519}$ This Decree has been repealed after a decision of the Dutch Court of Appeal according to which the acupuncture treatment by a health professional did fall within the area of expertise of the profession of the service provider and was therefore exempt under the exemption provision for extramural health care. ${ }^{520}$ The Court of Appeal stated that the field of expertise of the health professional - i.e. a doctor - encompassed all acts in the field of medicine. In the Netherlands, the education to become a doctor does not contain a clear-cut curriculum defined by law, whereas for other professions (e.g. obstetricians) there is. The area of expertise of the profession of doctor is hence not defined in the Netherlands. The Court of Appeal held in that particular case that the health professional who provided acupuncture treatment, alongside the health care he regularly provides, operates in his capacity as doctor and it was safeguarded that the quality of the treatment is at least similar to that of the care he regularly provides. In other words, according to that reasoning, the acupuncture is considered part of the regular activities of a doctor. The reasoning of the Court of Appeal is logical in my view. It was largely based on the CJEU in the Solleveld case and therewith on the principle of fiscal neutrality. As the supplier had sufficient professional qualifications for its regular medical activities, the Court of Appeal held that he was supposed to understand and apply the correct assessments to either provide regular health care or acupuncture treatment. According to the Court of Appeal, the health care supplier therefore makes a diagnosis in his capacity as a doctor. In line with the principle of fiscal neutrality, services similar to the regular services of a doctor therefore have to be VAT exempt. The acupuncture services were considered similar to the regular services

\footnotetext{
${ }^{517}$ HM Revenue \& Customs, 2014, Health professionals and pharmaceutical products, VAT Notice 701/57 of 28 July 2014.

${ }^{518}$ CJEU 27 April 2006, Joined Cases C-444/04 and C-443/04 Solleveld, ECLI:EU:C:2006:257, para. 30.

519 Decree of the State Secretary of Finance of 14 May 2013, nr. BLKB2013/810M, Stcrt.nr. 2013/13136 (repealed on 2 April 2016 by Decree of the State Secretary of Finance of 29 March 2016, BLKB2016/433MStcrt. 2016, 17339).

${ }^{520}$ Court of Appeal Den Bosch, 11 September 2015, nr. 14/00971, ECLI:NL:GHSHE:2015:3527.
} 
of a doctor by the Court of Appeal, because acting in the capacity of a doctor brings along with it that the quality of those services is at least similar to that of the regular health care a doctor provides. ${ }^{521}$

The example of acupuncture services shows the potential differential VAT treatment of these services within the EU. In the UK, services by acupuncturists are explicitly excluded from the exemption provision for extramural care, whereas the Netherlands includes acupuncture services if they are provided by qualifying health professionals next to the regular care they provide. This is, in my view, not a contradiction as I do not consider the treatment by an acupuncturist who is not a qualifying health professional similar to that of a qualifying health professional providing acupuncture treatment as an extension to his regular activities. The reason is that the CJEU held that, in order to determine the similarity of health care services, it is appropriate to take into account the professional qualifications of the supplier. ${ }^{522}$ Moreover - as was explained before - the exploration of the definitions of EU health care transactions and providers showed that it is commonly accepted that the quality of knowledge of a service provider (on the basis of national standards of accreditation) serves as an indication to determine whether the services of that provider constitute health care (see also sections 2.2.1.1). This, in my view, justifies that acupuncture services are excluded from the application of the exemption provision for extramural care in case these services are performed by non-qualifying health professionals. Those service providers lack the prerequisite of a basic level of professional medical knowledge. Furthermore, the principle of fiscal neutrality and the strict interpretation of exemption provisions justifies the deviating VAT treatment of acupuncture treatment between a qualifying care provider and a nonqualifying care provider. Also, with regard to the destination principle, a possible deviating VAT treatment of these services in the Member States can be justified.

Unlike in the situation illustrated in figure 7.4 - where similar health care services are provided by a qualifying health care provider and a non-qualifying health care provider - the principle of fiscal neutrality obviously does not serve as a means to broaden the scope of the exemption provision for extramural care in situations where a qualifying health professional provides 'non-regular care' and is thus acting outside the field of expertise of his profession. This is understandable in my view. The level of quality of care is only guaranteed as long as the (required medical knowledge for that) care is part of the requirements of the medical profession of the service provider and the care is within the field of expertise of the medical professional. Since the Court of Appeal in the Netherlands had established that the acupuncture services are, from a quality point of view, similar to the regular health care provided by a doctor, if carried out by a doctor, it makes sense to exempt these services; the reasoning of that court makes sense. Perhaps the outcome would have been different if, in

\footnotetext{
${ }^{521}$ CJEU 27 April 2006, Joined Cases C-444/04 and C-443/04 Solleveld, ECLI:EU:C:2006:257, para. 40.

${ }^{522}$ Compare CJEU 27 April 2006, Joined Cases C-444/04 and C-443/04 Solleveld, ECLI:EU:C:2006:257, para. 40.
} 
the Netherlands, the education to become a doctor did contain a clear-cut curriculum defined by law, that would explicitly exclude acupuncture. If a health care supplier operates outside his field of expertise, and thus supplies 'non-regular care', this care is different from a quality point of view - from the care he obtained his professional qualifications for. Therefore, it is appropriate and in line with the aim of the VAT exemptions for medical care - i.e. to make health care more accessible to individuals - to exclude this 'non-regular' care from the scope of the exemption provision in Article 132(1)(c) of the EU VAT Directive.

Different from the exemption for intramural care in Article 132(1)(b) of the EU VAT Directive, the exemption provision for intramural care does not contain an extension of the exemption to closely related activities. The interpretation of that concept is therefore not relevant for the interpretation of the exemption provision in Article 132(1)(c) of the EU VAT Directive. ${ }^{523}$ As I explained in the previous section, in case of a singular supply, the concept of closely related services is not relevant as the nature of a singular supply already implies that it does not contain any elements with a sufficient degree of independence which would require an assessment of the possible VAT consequences of that particular element. Minor provisions of goods which are strictly necessary at the time when the care is provided, for example a bandage, are considered to be economically indissociable from the service and hence absorbed in the exempt supply of the health care. In this basic situation with only one (singular) supply, there is thus no need to consider any potentially related supplies that can possibly come within the scope of the exemption.

In this section, an assessment of the application of the exemption provision for extramural care in the basic situation is addressed. I concluded that - assuming the health care supply provided by Supplier A, in the example given in figure 7.2, qualifies as medical care - the application of the exemption provision depends in the first place on the professional qualifications of Supplier A. The profession of the supplier needs to fall under the Member State's definition of medical and paramedical professions. Furthermore, the health care provided needs to fall under the regular exercise of the medical or paramedical profession of the supplier. The exemption provision for extramural care thus contains qualitative requirements with regards to:

a. the supplier (i.e. the supplier has to exercise a paramedical or medical profession, as defined by the Member State);

b. the supply (i.e. the supply has to be medical care); and

c. the relationship between the supplier and the supply (i.e. the care has to be provided in the exercise of the profession of the supplier).

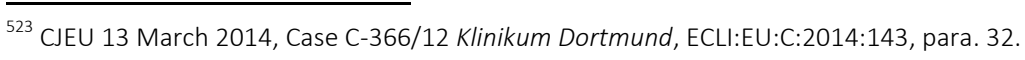


These three criteria have been discussed in this section and also situations in which suppliers provide similar services, whereas only one of those providers exercises a profession that falls under the national definition of medical and paramedical professions, qualifying under the exemption provision for extramural care (see figure 7.4). A supplier can still benefit from the exemption provision for extramural care, although its professional qualifications do not fall under the national definition of (para)medical professions, if it provides care similar to that of persons that do have the required professional qualifications. In that case, the supplier will have to demonstrate that its professional qualifications are of an equivalent value to that of a qualifying health care professional. In the basic situation, the medical services of a nonqualifying health care provider can thus only come within the scope of the exemption provision on the basis of quality aspects of the education or profession of the supplier. In this way, fiscal neutrality is safeguarded. Furthermore, this seems to be in line with the aim of the medical exemption provisions of making health care more accessible to individuals. It was already shown in chapter 2 that commonly used definitions of health care contain a qualitative requirement in relation to the (medical knowledge of) the service provider in order to distinguish health care from other health services. ${ }^{524} \mathrm{I}$ also discussed the situation in which a qualifying medical professional provides services outside its area of expertise ('nonregular supplies'). I concluded that the application of the principle of fiscal neutrality does not extend the application of the exemption for extramural care in the basic situation to supplies that are made outside the exercise of the profession - i.e. outside the area of expertise - of a qualifying medical professional. A Member State enjoys the discretion to define the specific medical care activities covered by the qualifying (para)medical professions. I believe that the exclusion of 'non-regular' services of qualifying health care professionals is in line with the aim of the exemption provisions for medical care. Furthermore, as noted above, using a qualitative criterion for distinguishing health care from other health services is commonly accepted. I am, however, aware of the fact that VAT is a transaction-based tax. On that ground, it could be argued that the assessment of the application of a VAT exemption should only relate to the service itself. Therefore, one should only consider the quality of the service instead of also taking into account the professional knowledge of a supplier. In my view, an individual VAT assessment for each individual service of a supplier would be impractical and time and cost consuming. It may, therefore, be that the legislator - by choosing to consider the professional qualifications of the supplier as starting point - intended to maintain a feasible system, while at the same time intending to only exempt health care. This is understandable, especially since the quality of extramural care services seems to be particularly dependent on the medical knowledge of the health care professional. As a result of the choice for a feasible VAT system, a qualifying health professional who starts exploring new types of health (care) services outside his original field

${ }^{524}$ See section 2.2.1.1. 
of expertise may, however, run the risk that his services fall outside the scope of the exemption provision. ${ }^{525}$

\subsubsection{Consequences of the application of the exemption provision for extramural care in the basic situation}

The consequences of the application of the exemption provision for extramural care obviously resemble those described in section 7.2.2.2 in relation to the exemption for intramural care. In my view, the application of the exemption for extramural care, however, brings along even more legal uncertainty for the health care suppliers supplying services in basic situations, compared to the application of the exemption provision for intramural care. This follows from the way the exemption provision is defined. As was shown in the assessment in the previous section, the exemption provision for extramural care in Article 132(1)(c) of the EU VAT Directive contains qualitative requirements as regards the supply, the (professional qualifications of the) supplier and the relationship between the supplier and the supply (by demanding that the health care provided is within the area of expertise of the medical profession). For the application of VAT, health care suppliers not only need to make sure whether they are a qualifying medical professional (i.e. according to national accreditation), they also need to assess whether the medical care they provide falls within their area of expertise. Furthermore, as was shown in the previous section, situations may occur in which a non-qualifying health care provider has to make sure whether he exercises a profession with a similar quality of a qualifying service provider. In that case, the services of the former supplier may fall within the scope of the exemption provision for extramural care, provided the service constitutes medical care and falls within the area of expertise of the supplier. For intramural care providers, the legal uncertainty as a consequence of the application of the exemption provision in Article 132(1)(b) of the EU VAT Directive is less in my view. If the supplier (usually not a natural person) qualifies under the definition of that provision (i.e. recognized under national law), the medical and hospital services by that supplier are, in principle, automatically exempt, without the need to assess the professional qualities or the area of expertise of employees of the supplier (e.g. doctors employed by the hospital). In the basic situation, the requirements as regards the health care supplier therefore bring along more legal uncertainty for health care suppliers providing extramural care than for health care suppliers providing intramural health care.

The discretion for Member States to define paramedical and medical professions, and the power to define the specific medical care activities which are covered by such professions may lead to a deviating VAT treatment of similar services among Member States. Fiscal neutrality can thus not be guaranteed between Member States. In that regard, I refer to the

\footnotetext{
${ }^{525}$ The only escape for him to be able to apply the exemption, could perhaps be the principle of fiscal neutrality, if it can be proven that these 'new' health services are of a qualitative point of view similar to the 'regular services' the supplier provides in the exercise of his profession (in line with the reasoning of the Court of appeal in the Netherlands on acupuncture services). For 'non-regular services' this will not work, in my opinion.
} 
example given in section 7.2.3.1 on the application of VAT on acupuncture services in the UK and the Netherlands. As was noted in section 1.2, cross-border patient mobility has increased exponentially in the EU, although the absolute volumes of patients seeking treatment across the border is relatively small. The impact of such a differential VAT treatment as regards patients seeking extramural care of a health care supplier in the basic situation across the border seems thus small. Moreover, as was discussed in section 7.2.2.2 in relation to the application of the exemption provision for intramural health care in the basic situation, the fact that the majority of health care is consumed locally (within the Member State of residence) is in line with the destination principle.

\subsection{The hindering effect of VAT exemptions in the health care sector in parallel situations}

In the previous section I assessed the scope of the exemption provisions for intramural and extramural care for supplies in the basic situation. In that situation, singular supplies are provided directly to a patient. These singular supplies took place in the ultimate link of the health care supply chain. In this section, and the following sections, the example of the supply in the basic situation is extended with extra (elements of) supplies that are provided either in parallel to the basic supplies or prior to this ultimate supply (section 7.4). This is useful for demonstrating the scope of the exemption provisions in relation to the related (elements of) supplies.

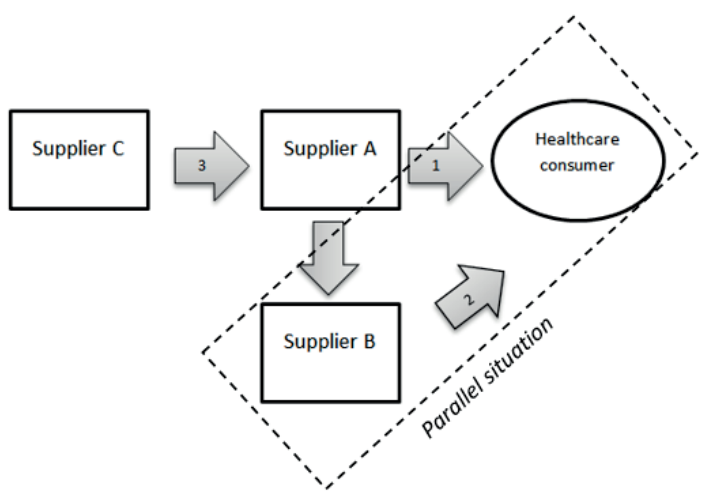

Figure 7.6 Paralle/ situation in the model health care system.

Figure 7.6 above shows where supplies in parallel situations can occur. As will be shown in the next subsection, supplies in a parallel situation occur in the relationship between the principal health care provider and the health care consumer or between another supplier that the principal health care provider and the health care consumer. 


\subsubsection{Introduction}

Supplies in a parallel situation are two (or more) (elements of) supplies that are provided directly by the supplier ${ }^{526}$ to the final consumer. This differs from the examples of single element supplies in the basic situation (section 7.2), which did not contain elements with a sufficient degree of independence that required an assessment of those elements separately from the principal service in order to determine the VAT consequences of the supply. In order to examine the impediment of the application of VAT - on supplies in parallel situations - on the access to health care, I distinguish the following two situations of parallel supplies: parallel one-on-one situations and parallel two-on-one situations. The following examples of supplies in parallel one-on-one and parallel two-on-one situations will be used:

\section{A. Parallel one-on-one situation}

In a parallel one-on-one situation, all supplies are carried out by one and the same health care supplier to one single recipient. The supplies do not have to be carried out simultaneously in time. They can also be carried out in succession. The term 'parallel' thus refers to the legal relationship (in all cases between the same supplier and the recipient) and not to the time on which the supplies take place.

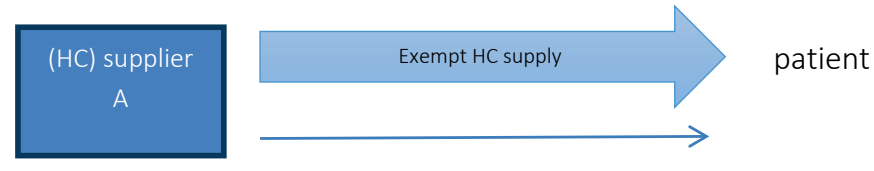

Figure 7.7 Example of supplies in a parallel one-on-one situation.

Figure 7.7 shows an example of a parallel one-on-one situation in which supplier A carries out two supplies to the recipient (i.e. a doctor that provides the patient with a plaster during a consultation). In order to illustrate if and to what extent the application of health care exemptions hinder access to health care, it is assumed that supplier A carries out a health care supply that qualifies under one of the exemptions for health care. The other arrow represents the related supply. This related supply is assumed to contain such a degree of independence that it should be assessed separately for VAT purposes. It is furthermore assumed that Supplier A qualifies as a taxable person under Article 9 of the EU VAT Directive and that he is not excluded from the scope of VAT for the activities concerned on the basis of Article 13 of the EU VAT Directive.

\section{B. Parallel two-on-one situation}

In a parallel two-on-one situation, the supplies are carried out by different suppliers, whereas the recipient is the same person. They are referred to as parallel, because both the suppliers have a legal relationship with the same recipient. The suppliers are not legally related as

\footnotetext{
${ }^{526}$ In the examples provided, the HC supplier is presumed to qualify as a taxable person under Article 9 of the EU VAT Directive, unless stated otherwise.
} 
regards the supplies carried out for the recipient. Also, in this situation, the supplies do not necessarily have to be carried out simultaneously in time.

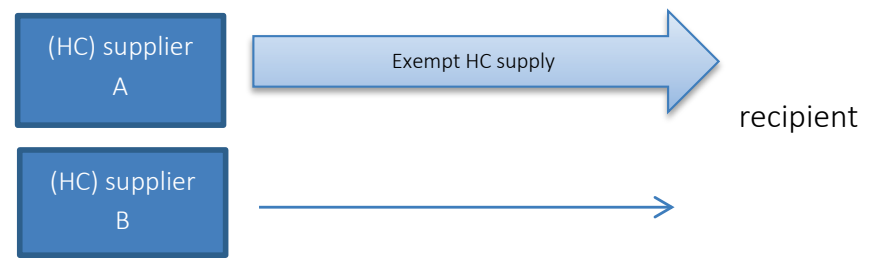

Figure 7.8 Example of supplies in a parallel two-on-one situation

Figure 7.8 shows an example of supplies in a parallel two-on-one situation. In this example, both supplier A and supplier B carry out a supply to the same recipient. This situation can be characterized as a parallel situation, because supplier A and supplier B both have a legal relationship with the same recipient as regards their individual supply. The suppliers do not have to be legally related to each other as regards the supplies carried out for the recipient. For the purpose of illustration, it is assumed that the supply carried out by supplier A qualifies under one of the exemption provisions for health care. Furthermore, it is assumed that both Supplier A and Supplier B qualify as taxable persons under Article 9 of the EU VAT Directive. The supplies that are drawn in the figure above by means of the two arrows are not necessarily two distinct supplies from a VAT perspective.

In CJEU cases that concern multiple element health care supplies, like the parallel one-on-one and parallel two-on-one situations illustrated above, I noted that, in its argumentation, the CJEU uses both the doctrine of 'composite supplies' and the test whether the elements are 'closely related'. This 'closely related' test is used where it concerns the exemption provision for intramural care, as this exemption is extended to activities that are closely related to the principal medical care qualifying under Article 132(1)(b) of the EU VAT Directive, whereas the exemption for extramural care does not contain such an extension. In the next subsections it will become clear that the CJEU, in case of multiple element supplies, sometimes applies both the doctrine of 'composite supplies' and the 'closely related' test simultaneously. In my view, it seems that the CJEU, in cases on the application of the medical exemption provisions, often overlooks the application of the doctrine of composite supplies, while it immediately jumps to the 'closely related' test. For the purpose of an assessment of the exemption provisions for medical care in parallel situations, the following section starts with a discussion of the doctrine of 'composite supplies'. 


\subsubsection{Parallel one-on-one situations}

The first parallel situation that I have distinguished is a parallel one-on-one-situation. In figure 7.7, the following example of a supply in a parallel one-on-one-situation was shown (figure 7.7):

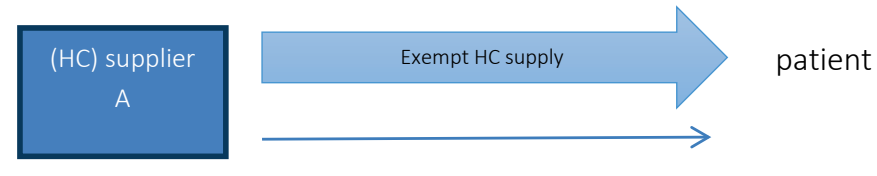

The following subsections contain an assessment of the application of the exemption provision for medical care in parallel one-on-one situations in relation to intramural and extramural care.

\subsubsection{Assessment of the application of the exemption provisions for medical care in parallel one-on-one situations}

It appears that in parallel situations, the doctrine of composite supplies has to be consulted in order to establish whether the two (elements of) supplies are - from a VAT point of view - to be qualified as single or as multiple supplies. It occurs that the application of the composite supply doctrine often concurs with the application of the 'closely related' test. At first sight, this seems inconceivable, as the qualification of supplies as one or single supplies in my view takes place before one assesses the application of exemption provisions. Yet, the CJEU qualifies the supplies and assesses the application of exemption provisions at the same time. Hereafter, this approach is discussed in more detail in relation to supplies in parallel one-on-one situations.

\section{Composite supplies}

The singular supply in the basic situation, described in section 7.2.1, did not contain any element that had such a degree of independence that it should be assessed separately in order to establish the VAT consequences. In a parallel situation, there is at least one element that does have such a degree of independence. In figure 7.7 this distinctive element is drawn as the smaller arrow. In situations like these, the primary question which needs to be answered is whether this distinctive element is also covered within the scope of the exemption provision that applies to the principal service (the larger arrow). Furthermore, it has to be established if, and in what way, the application of the exemption provisions for medical care hinder the access to health care in parallel two-on-one situations. For the assessment of the qualification of the principal service under the exemption provision for intramural care, I refer to section 7.2.2.1. The assessment of the qualification of the principal service under the exemption provision for extramural care was discussed in section 7.2.3.1.

In the examples in figures 7.7 and 7.8 , it is assumed that the principal health care supply provided by Supplier A (qualifying as a taxable person for VAT) is covered under one of the 
exemption provisions for medical care. More specifically, for the assessment of the application of the exemption provision for intramural care, the principal service is assumed to fall within the scope of Article 132(1)(b) of the EU VAT Directive. For the assessment of the application of the exemption provision for extramural care, the principal service is assumed to fall within the scope of Article 132(1)(c) of the EU VAT Directive.

Apart from and before the application of the exemption provisions, another fundamental question needs to be answered. It has to be established whether the distinctive element (the service illustrated by means of the smaller arrow in figures 7.7 and 7.8) can be qualified as a separate supply for VAT purposes or whether it is actually absorbed in or part of the principal service provided. In that regard, the doctrine of composite supplies needs to be consulted. According to the CJEU, each supply of a service or a good must be regarded as distinct and independent. ${ }^{527}$ This means that both (distinctive) supplies have to be assessed individually in order to determine their VAT consequences. The CJEU, however, indicated that there are situations in which the supplies cannot be split. If that is the case, there is only one relevant transaction for VAT purposes.

It occurs that formally distinct services, which could be supplied separately, must be considered to constitute a single transaction for VAT when they are not independent. This is the case if one of the elements can be regarded as constituting the principal service, while the other element is to be regarded as ancillary to the principal service. ${ }^{528}$ For example, supplier $A$ is a hospital and one of the doctors attaches a plaster on the wound of a patient during the patient's treatment. From the viewpoint of a 'typical consumer', the treatment will (still) be regarded as constituting the principal health care service, despite the supply of the plaster. The supply of the plaster (which, if assessed individually would qualify as a supply of a good according to the definition of Article 14 of the EU VAT Directive) will be considered ancillary to the principal health care service provided by the hospital. The supply of the plaster is, from a VAT perspective, absorbed by the supply of health care. ${ }^{529}$ Supplier A, in this example, carries out one single supply of a service which is exempt from VAT.

Theoretically, situations can occur in which, from the viewpoint of a typical customer, the transaction provided in parallel is of such importance that it is actually considered predominantly over the exempt health care supply. For example, a medical professional qualifying under Article 132(1)(c) of the EU VAT Directive provides services in the field of hypnotherapy. The hypnotherapy may be preceded by a number of preparatory acts, like

${ }^{527}$ CJEU 16 July 2015, Case C-584/13 Mapfre asistencia and Mapfre warranty, ECLI:EU:C:2015:488, para. 49; CJEU 29 March 2007, Case C-111/05 Aktiebolaget NN, ECLI:EU:C:2007:195, para. 22; CJEU 27 September 2012, Case C-392/11 Field Fisher Waterhouse, ECLI:EU:C:2012:597, para. 14; CJEU 17 January 2013, Case C-224/11 BGŻ Leasing, ECLI:EU:C:2013:15, para. 29; CJEU 25 February 1999, Case C-349/96 Card Protection Plan Ltd (CPP) $\checkmark$ Commissioners of Customs \& Excise, ECLI:EU:C:1999:93, para. 29.

${ }^{528}$ CJEU 16 July 2015, Case C-584/13 Mapfre asistencia and Mapfre warranty, ECLI:EU:C:2015:488, para. 50; CJEU 17 January 2013, Case C-224/11 BGŻ Leasing, ECLI:EU:C:2013:15, para. 30 and the case-law cited).

${ }^{529}$ CJEU 23 February 1988, Case 353/85 Commission vs. United Kingdom, ECLI:EU:C:1988:82. 
(medical) research ${ }^{530}$ which is similar to the research carried out by that medical professional in the course of the 'regular care ${ }^{531}$ he provides. In that case, it may well be assumed that, from the viewpoint of the typical consumer, the hypnotherapy and the research are regarded as one single supply, while the hypnotherapy service constitutes the principal element of the supply and the preparatory research constitutes the ancillary service. As a result, this composite service does not qualify within the scope of the exemption provision in Article 132(1)(c) of the EU VAT Directive, as hypnotherapy is a form of alternative treatment which is not exercised in the field of qualifying medical professions.

In case the elements cannot be split, however, none of the elements provided can be considered to constitute the principal element of the supply and absorption cannot take place. This occurs where two or more elements supplied by the taxable person to the customer, being a typical consumer, are so closely linked that they form, objectively, a single, indivisible economic supply, which would be artificial to split. ${ }^{532}$ The elements together must be regarded as constituting a single supply of its own nature ('sui generis'). For the VAT consequences attached to this supply, it has to be assessed on its own merits. ${ }^{533}$ Furthermore, since the service has to be taken into account as a whole for VAT purposes, it is questionable whether it can be covered under a medical exemption provision. The exemption provisions, after all, have to be interpreted in a strict manner. In Deutsche Bank, the CJEU held that the principle of fiscal neutrality cannot extend the scope of an exemption in the absence of clear wording. ${ }^{534}$ As the CJEU pointed out:

"[t]hat principle is not a rule of primary law which can condition the validity of an exemption, but a principle of interpretation, to be applied concurrently with the principle of strict interpretation of exemptions". 535

In conclusion, in case multiple elements of supplies are supplied in parallel, they can, for VAT purposes, either be considered as:

4. separate supplies;

5. a principle and an ancillary supply ('absorption'); or

6. a 'sui generis' supply.

\footnotetext{
${ }^{530}$ This example is given in a Dutch Decree in relation to acupuncture services; Decree of the State Secretary of Finance of 14 May 2013, nr. BLKB2013/810M, Stcrt.nr. 2013/13136 (repealed on 2 April 2016 by Decree of the State Secretary of Finance of 29 March 2016, BLKB2016/433MStcrt. 2016, 17339).

${ }^{531}$ See section 7.2.3.1. on the distinction between regular and non-regular health care.

${ }^{532}$ CJEU 27 October 2005, Case C-41/04 Levob Verzekeringen and OV Bank, ECLI:EU:C:2005:649, p. 23.

${ }^{533}$ CJEU 19 July 2012, Case C-44/11 Deutsche Bank, ECLI:EU:C:2012:484, para. 43.

${ }^{534}$ CJEU 19 July 2012, Case C-44/11 Deutsche Bank, ECLI:EU:C:2012:484, para. 45; CJEU 13 March 2014, Case C366/12 Klinikum Dortmund, ECLI:EU:C:2014:143, para. 40.

535 Ibid.
} 
In the sphere of taxed supplies, the outcome will be less interesting, assuming that all the elements, whether provided separately or together, are taxed against the standard VAT rate. If, however, one of the elements or the elements together qualify within the scope of application of one of the exemption provisions or the application of the reduced rate, the outcome is of importance for the actual VAT burden of the supply or supplies.

In this section, I demonstrated that, prior to the assessment of the application of medical exemption provisions on supplies in parallel situations, the doctrine of composite supplies has to be consulted. This is necessary in order to establish whether the two (elements of) supplies are - from a VAT point of view - to be qualified as single or multiple supplies. It occurs that the application of the composite supply doctrine often concurs with the application of the 'closely related' test. In the following section, I will discuss the 'closely related' test in more detail.

\section{Closely related supplies}

In the previous paragraph, I demonstrated that, for the assessment of the application of the exemption for intramural care, the qualification of the supply is an essential step. I will explain in this section why it is incorrect in my view that the CJEU sometimes seems to overlook this fundamental step when assessing the exemption provision for intramural care in parallel one-on-one situations.

The demand for the qualification of a supply as one of the 'taxable events' follows already from the application of Article 2 of the EU VAT Directive. At that point, the doctrine of composite supplies is already relevant. In cases on medical care, the CJEU also applied the criteria for composite supplies. ${ }^{536}$ What is striking is that the CJEU also uses these criteria, or criteria derived therefrom, in order to establish whether (elements of) supplies are closely related to medical care. The exemption for intramural care in Article 132(1)(b) of the EU VAT Directive also includes, unlike Article 132(1)(c) of the EU VAT Directive, closely related activities. In practice this has proven to be a grey area. An extension to (closely) related activities is also included in other VAT exemption provisions, e.g. the exemption provisions for education and for insurance services.

The CJEU uses criteria it developed as regards the doctrine of composite supplies and criteria derived therefrom in case law concerning transactions that are potentially related to health care. From a textual interpretation, it seems that the legislator, with the inclusion of related transactions under the exemption provisions aimed to create a broader scope with regard to those provisions, as opposed to exemption provisions without such an inclusion. Apparently, again on the basis of a textual interpretation, it was not desired to also include closely related transactions under the exemption provision for extramural care. Transactions can, according to the CJEU, only be closely related to intramural care if they are actually supplied ancillary to

${ }^{536}$ E.g. CJEU 23 February 1988, Case 353/85 Commission vs. United Kingdom, ECLI:EU:C:1988:82, para. 33. 
the hospital or medical care received by the patients in question and constituting the principal service. ${ }^{537}$ The term 'ancillary' is also used in the context of composite supplies in order to determine whether one of the (elements of) supplies is absorbed into the other. In order for a supply to be closely related under the intramural health care referred to in Article 132(1)(b) of the EU VAT Directive, it needs to be more than ancillary. According to the CJEU, that supply should not only facilitate the exempt principal service, it has to be logically part of the provision of hospital and medical care services and constitute an indispensable stage in the process of the supply of those services to achieve their therapeutic objectives. ${ }^{538}$ Furthermore, the supply has to be essential to achieve the therapeutic objectives pursued by the hospital services and medical care in connection with which they have been supplied. ${ }^{539}$

I agree with Van Norden that the test that is applied by the CJEU in order to determine whether transactions fall under the notion of 'closely related' is more strict than the application of the criteria of 'ancillary', which is used to determine if one element of the supply is absorbed by the other, principal (element of the) supply. ${ }^{540}$ Especially the criterion of being essential excludes a lot of ancillary services from the scope of 'closely related'. Considering, for example, the matter in the Ygeia case, one could argue that the provision of telephone services and the hiring out of televisions to in-patients are supplies ancillary to the hospital care that is provided to those patients. ${ }^{541}$ The services do not constitute an end in itself but a means of enhancing the enjoyment or benefit of the hospital care. ${ }^{542}$ The provision of those services are, however, in my view not essential to achieving the therapeutic objectives of (regular) hospital care. This means, according to the criteria formulated by the CJEU, that the provision of those services is not considered closely related to hospital care and hence are subject to VAT. However, if one would consider a possible absorption of the services provided by the hospital, the outcome may be completely different. If the provision of telephone services and hiring out of televisions (the ancillary service) is absorbed by the provision of hospital care (the principal service), there is only one single service left according to the criteria that the CJEU maintains in case of composite

\footnotetext{
${ }^{537}$ CJEU 1 December 2005, Joined Cases C-395/04 and C-394/04 Ygeia, ECLI:EU:C:2005:734, para. 18; CJEU 6 November 2003, Case C-45/01 Dornier, ECLI:EU:C:2003:595, para. 35.

${ }^{538}$ CJEU 1 December 2005, Joined Cases C-395/04 and C-394/04 Ygeia, ECLI:EU:C:2005:734, para. 25.

539 Idem, para. 29. The CJEU based its reasoning on the Commission vs. Germany case in which it was at issue whether university research could qualify as a service closely related to university education (CJEU 20 June 2002, Case C-287/00 Commission vs. Germany, ECLI:EU:C:2002:388, paras. 48-49).

${ }^{540}$ Van Norden, G.-J., 2010, Het concern in de btw (diss.), Kluwer, p. 308.

${ }^{541}$ In case Ygeia the CJEU had to give its opinion on whether inter alia the provision of telephone services and the hiring out of televisions to in-patients was subject to VAT.

${ }^{542}$ CJEU 1 December 2005, Joined Cases C-395/04 and C-394/04 Ygeia, ECLI:EU:C:2005:734, para. 19: It is apparent from the case-law that a service can be considered to be ancillary to a principal service where it constitutes not an end in itself but a means of enhancing the enjoyment or benefit of the principal service supplied by the provider (see, to this effect, in particular, CJEU 22 October 1998, Joined Cases C-308/96 and C94/97 Madgett and Baldwin, ECLI:EU:C:1998:496, para. 24; CJEU 6 November 2003, Case C-45/01 Dornier, ECLI:EU:C:2003:595, para. 34).
} 
supplies. That service is the provision of hospital care and falls within the scope of Article 132(1)(b) of the EU VAT Directive.

It is understandable that the CJEU had to come up with criteria to define the grey area of 'closely related' supplies. It is also understandable that these criteria show similarities with those used for establishing whether multiple (elements of) supplies form a single supply or separate supplies for the application of VAT. In my view, however, the assessment of composite supplies as multiple or single transactions under Article 2 of the EU VAT Directive fundamentally differs from the assessment of transactions as being '(closely) related' to exempt transactions under Articles 132 or 135 of the EU VAT Directive. I believe that in parallel one-on-one situations, it first has to be established whether there is a single supply or separate supplies on basis of the criteria for composite supplies. That implies that, in those situations, the 'closely related' test becomes superfluous. In case of absorption, the ancillary element 'disappears'. In case of separate supplies, none of the supplies can be considered closely related, as this requires one of the supplies to be ancillary to the other (principal) supply. Also, in case of a sui generis supply, there is no 'closely related' test as there is only one supply that has to be taken into account as a whole for VAT purposes. It seems contrary to the order of provisions in the EU VAT Directive to reconsider the qualification of the supply (based on Article 2 of the EU VAT Directive), in case it turns out that an exemption provision (based on Article 132 of the EU VAT Directive) applies. The 'closely related' test is still applicable in other situations with multiple (elements of) supplies. Although, in my view the criteria it is based on - the criteria for composite supplies - were not intended to cover supplies in parallel two-on-one situations and supplies in successive situations.

\subsubsection{Assessment of the application of the exemption provision for intramural care in parallel one-on-one situations}

In this section, I will assess the application of the exemption provision for intramural care in parallel one-on-one situations. In section 7.2.2.1, the application of the exemption provision for intramural care in the basic situation has been assessed. I concluded that the application of the exemption provision in Article 132(1)(b) of the EU VAT Directive depends on the qualification of the health care supplier under national law, the nature of the supply (hospital or medical care) and the place in which the provision of the care takes place.

In comparison to the basic situation, the parallel one-on-one situation contains an extra element of a supply that is provided to the recipient of the care by the same health care supplier as in the basic situation, parallel to the provision of medical care. In section 7.3.1, the following example of a supply in a parallel one-on-one situation was given (figure 7.7):

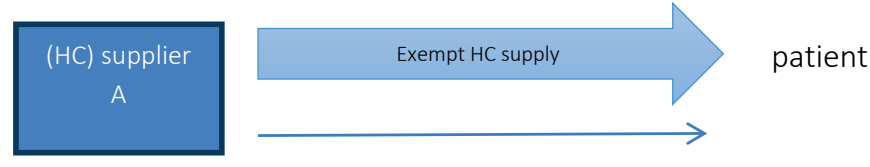


For the purpose of the assessment of application, it is assumed that the principal service (illustrated by means of the larger arrow in figure 7.7) is exempt under Article 132(1)(b) of the EU VAT Directive. This assumption is made in order to establish what the effect is of the supply of a substantial element (illustrated by means of the smaller arrow) in this parallel one-on-one situation on the application of the said exemption provision.

In the previous section, it was discussed that the presence of distinctive elements of supplies calls for the application of the doctrine of composite supplies (see section 7.3.2.1). The supply of health care in a parallel one-on-one situation, as illustrated in figure 7.7, can lead to the following outcomes:

a) the exempt health care supply and the separate element constitute separate supplies for VAT;

b) the health care supply and the separate element are considered one single supply for VAT purposes, whereby the exempt health care constitutes the principal service, while the separate element is regarded as an ancillary service ('absorption'), or the other way around; or

c) the health care supply and the separate element are considered one single supply for VAT purposes, whereby neither the exempt health care supply, nor the separate element can be regarded as a principal service ('sui generis' supply).

a) Separate (elements of) supplies

If the medical care and the separate element that is provided in parallel to that care constitute separate supplies for VAT purposes, they both have to be assessed individually for their VAT consequences. An example is the use of parking services on the hospital premises. The patient visits the hospital for the purpose of receiving medical care. Yet, at the same time the patient is using the hospital parking lot, for which he has to pay an hourly fee. In this example, the supplier of the medical care and the parking services is the hospital.

The assessment of the application of the exemption provision for intramural care is similar to the assessment in basic situations (see section 7.2.2.1). As regards the separate supply, an individual assessment needs to take place. As such, this assessment is again similar to the assessment of the application of the exemption provision in the basic situation. The separate element is, after all, not related in such a way to the exempt supply of health care to form one single supply of VAT.

Article 132(1)(b) contains, unlike the exemption provision for extramural care in Article 132(1)(c) of the EU VAT Directive, an extension to 'closely related activities'. This seems to suggest that, even if it is established that the element does not form a single supply together with an exempt health care service (as a result of absorption), the application of the definition of 'closely related activities' could still bring this separate element within the scope 
of the exemption provision for intramural care. As I explained before, this would, in my view, not be in line with the qualification of supplies as a result of the application of Article 2 of the EU VAT Directive and, hence, the application of the doctrine of composite supplies. ${ }^{543}$ In the Ygeia case, which also concerned, in my view, a parallel one-on-one situation, the CJEU held that:

"...only the supply of services which are logically part of the provision of hospital and medical care-services, and which constitute and indispensable stage in the process of the supply of those services to achieve their therapeutic objectives, is capable of amounting to 'closely related activities' within the meaning of that provisions. Only such services are of a nature to influence the cost of health care which is made accessible to individuals by the exemption in question". 544

Furthermore, the CJEU emphasized that it is not sufficient for the service to be regarded as being of great assistance; it must be essential to achieve the therapeutic objectives.

If the criteria of being 'ancillary' is applied strictly, it leads to the conclusion that elements of supplies that constitute a supply separate from the (principal) health care service on the basis of the criteria applied by the CJEU on composite supplies cannot be regarded as closely related activities (see also section 7.3.2.1) As a result, these separate (elements of) supplies, that are obviously not provided as ancillary to the principal supply, cannot fall under the exemption provision for intramural care in parallel one-on-one situations. This is supported by the definition of Article 134 of the EU VAT Directive. According to this Article, the exemption in Article 132(1)(b) shall not be granted "where the supply is not essential to the transactions exempted". The extension of Article 132(1)(b) of the EU VAT Directive to 'closely related activities' is, therefore, in my view not so broad that it could also cover elements of supplies which are considered to be separate on the basis of the theory of composite supplies. As pointed out in section 7.3.2.1, the 'closely related' test can therefore be considered superfluous in parallel one-on-one situations. The CJEU obviously has a different point of view. When assessing the exemption provision for intramural care - the notion of 'closely related activities' in particular - in parallel one-on-one situations, the CJEU seems to ignore the doctrine of composite supplies. Whereas, in my view, the application of this doctrine and, hence, the qualification of supplies on the basis of Article 2 of the EU VAT Directive takes precedence over the assessment of the notion of 'closely related activities'.

\section{b) Absorption}

In section 7.3.2.1, the example of the provision of telephone services and the hiring out of televisions to in-patients was discussed (based on the subject matter in the Ygeia case). This is an example of a parallel one-on-one situation. In the Madgett and Baldwinn case, the CJEU

\footnotetext{
${ }^{543}$ See section 7.3.2.1.

${ }^{544}$ CJEU 1 December 2005, Joined Cases C-395/04 and C-394/04 Ygeia, ECLI:EU:C:2005:734, para. 25.
} 
held that a service can be considered to be ancillary to a principal service when it constitutes not an end in itself but a means of enhancing the enjoyment or benefit of the principal service supplied by the provider. ${ }^{545}$ The provision of the telephone services and hiring out of televisions to in-patients is in my view ancillary to the principal hospital care that is provided to those patients.

In case of absorption, the ancillary supply is absorbed in the principal health care supply and hence disappears. The separate element is hence not relevant for the assessment of the application of the exemption provision for intramural care. The assessment of the principal health care service is similar to the assessment of the application of the exemption provision for intramural care in the basic situation (see section 7.2.2.1).

\section{c) Sui generis}

The third possibility in the case of composite supplies is that the (elements of) supplies have to be considered a single supply for VAT, without any absorption. This means there is a 'new', indivisible supply of its own nature. In case of a sui generis supply, the separate element like in the case of absorption - disappears and cannot be individually assessed for the application of the exemption for intramural care. The sui generis supply has to be assessed on its own merits, in the same way as the assessment of the application of the exemption provision for intramural care in the basic situation (see section 7.2.2.1). A sui generis supply is not likely to fit easily within the scope of the exemption provision, as the exemption provisions have to be applied in a strict manner. Also, the result of the application of the principle of fiscal neutrality will be limited in this regard, as this principle cannot extend the scope of an exemption provision in the absence of clear wording (see section 7.3.2.1).

\subsubsection{Assessment of the application of the exemption provision for extramural care in parallel one-on-one situations}

In this section I will assess the application of the exemption provision for extramural care in parallel one-on-one situations. The assessment of the application of the exemption provision for extramural care on supplies in a basic situation was discussed in section 7.2.3.1. I showed that the exemption provision of Article 132(1)(c) of the EU VAT Directive contains qualitative requirements as regards the supply, the supplier, and the relationship between the supplier and the supply. In basic situations, the application of the exemption provision for extramural care depends thus in the first place on the professional qualifications of the health care supplier. Only if these qualifications fall within the scope of the medical and paramedical professions as defined by the Member States in their national VAT legislation, the application of the exemption is in principle possible. Secondly, the supplied service needs to constitute medical care to qualify under the exemption provision. Finally, the health care provided needs

\footnotetext{
${ }^{545}$ CJEU 22 October 1998, Joined Cases C-308/96 and C-94/97 Madgett and Baldwin, ECLI:EU:C:1998:496, para. 24.
} 
to be within the field of expertise of the medical profession of the supplier ('regular care'). In section 7.2.3.1, I submitted that the exclusion of 'non-regular' services - of qualifying health care professionals - from the exemption is in my view in line with the aim of the medical exemption provisions. It is, after all, their aim to make health care more accessible to individuals, as opposed to improving the accessibility to all health-related supplies. Although, it may be the mere result of a choice by the legislator - to keep the application of the VAT system feasible - to require qualitative qualifications from a supplier, instead of assessing the application of the exemption solely on the basis of the quality of the supply itself. It was also shown in section 7.2.3.1 that a supplier who does not possess the required professional qualifications - according to the national definition - can still benefit from the exemption provision if his professional qualifications can be regarded as being of equivalent value compared to those of persons exercising qualifying (para) medical professions. This became clear from the Solleveld case, in which the CJEU held that this approach is in line with the aim of the exemption provision and the application of the principle of fiscal neutrality. ${ }^{546}$ In section 7.2.3.1, I explained that the importance which is given to the qualitative qualifications of the supplier is in my view in line with definitions used by international organizations. Moreover, the requirement of sufficient professional knowledge ensures that services of unorthodox doctors or charlatans do not fall within the scope of the exemption provision for extramural care. This is in my view justifiable on the basis of the aim of the medical exemption provisions: making health care more accessible to individuals.

The assessment of the application of the exemption provision for extramural care in parallel one-on-one situations includes an assessment of the extra element that is provided by the same supplier. For example, a health care professional offers complementary courses to the patients in which he teaches the patients how to deal with their medical condition in their daily lives. As pointed out earlier, Article 132(1)(c) of the EU VAT Directive does not contain an extension to closely related activities. The scope of the exemption provision for extramural care therefore seems to cover fewer services than the scope of the exemption provision for intramural care. As was shown in previous sections, however, this does not necessarily influence the VAT treatment of the services at hand, as the 'closely related' test is in fact superfluous in parallel one-on-one situations that concern intramural health care. With the qualification of transactions - as a result of the application of Article 2 of the Directive and the doctrine of composite supplies - it should, after all, already become clear whether the extra element has to be taken into account separately for VAT purposes. Hence, the extra element can only be included under the exemption provision for intramural care if it is 'absorbed' by the exempt (principal) health care supply. See also section 7.3.2.1 in this regard.

${ }^{546}$ CJEU 27 April 2006, Joined Cases C-444/04 and C-443/04 Solleveld, ECLI:EU:C:2006:257, para. 41; CJEU 8 June 2006, Case C-106/05 L.u.P., ECLI:EU:C:2006:380, para. 32; CJEU 14 April 2016, Case C-555/15 Gabarel, ECLI:EU:C:2016:272, para. 38. 


\section{Single or multiple supplies}

Prior to the VAT assessment of the application of the exemption provision for extramural care on supplies in parallel one-on-one situations, it has to be established whether the provided (elements of) supplies have to be considered separate supplies, a sui generis supply or whether there is a single supply where the ancillary supply is absorbed into the principal health care service. In the example mentioned in the previous paragraph, it could be argued - depending on the factual and contractual agreement - that the provision of the complementary courses is a supply separate from the supply of extramural health care. In case these courses would, for example, also be open to other persons who did not receive the extramural health care from the supplier or in the case the courses would be optional for patients, the provision of the courses would have to be taken into account separately for VAT purposes - i.e. apart from the health care services - in my view. Those circumstances indicate that it is not artificial to split the provision of health care from the provision of the courses. There seems to be no reason to assume that the provision of health care and the provision of the courses by the supplier to a typical consumer are so closely linked that they form, objectively, a single, indivisible economic supply, which would be artificial to split (i.e. no 'sui generis' supply). Furthermore, the provision of the courses does not seem to be an ancillary service which has as its aim a better enjoyment of the health care services (i.e. no absorption into a single health care supply). As a result, the provision of the courses has to be treated as a separate supply for VAT purposes. The assessment of the application of the VAT exemption on this separate supply is, in principle, similar to the assessment of the application of the exemption provision for extramural care in basic situations (see section 7.2.3.1) and will probably depend on the question whether the provision of the care, as such, qualifies as medical care and has as its aim diagnosing, treating or, in so far as possible, curing diseases or health disorders. This is not very likely but could perhaps be defended if it could be established that the courses contribute to the revalidation of the patient and is open only for persons suffering or having suffered from the medical condition which the course is about. If the provision of the courses by the qualifying health care professional cannot be qualified as medical care, those services are not exempt under Article 132(1)(c) of the EU VAT Directive.

\section{Therapeutic continuum}

In the previous section, I showed that, for the assessment of the application of the exemption provision for extramural health care in parallel-one-on-one situations, the qualification of the supply (or supplies) is an essential step. The same was concluded in section 7.3.2.1 as regards the application of the exemption provision for intramural care for supplies in such a situation. In this section, I will discuss the 'therapeutic continuum' criterion. This is a criterion, introduced by the CJEU, for the purpose of the application of the exemption provision for extramural care in parallel situations.

In the previous section, I pointed out that the extra element provided in a parallel one-on-one situation may fall within the scope of the exemption provision if it can be 'absorbed' - as an 
ancillary supply - in the exempt principal service, on the basis of the doctrine of composite supplies. If one would disregard this step, like the CJEU appears to do in case of parallel oneon-one situations, it could be assessed if the extra element falls under the notion of 'closely related activities' and hence would fall within the scope of the exemption provision. The extension of the scope of a medical exemption to closely related activities, is, however, only possible in the case of intramural care.

The assessment of the exemption provision for extramural health care in parallel two-to-one situations in section 7.3.2.5 shows that the CJEU appears to apply more criteria to assess whether a supply that is provided in parallel to the principal health care supply can be exempted from VAT. In the Klinikum Dortmund case, ${ }^{547}$ the CJEU applies a 'therapeutic continuum' criterion. Note that the case concerned supplies made in a parallel two-on-one situation. In that case, the extra element - i.e. a supply of goods - was, provided by another supplier than the supplier of the exempt principal health care. For a more detailed discussion of that case, I refer to section 7.3.2.5. I deduce from that case that, in case of a 'therapeutic continuum' (between the supply of health care and parallel services), the parallel supply can qualify under the exemption provision for extramural care if it is considered physically and economically indissociable from the health care service. ${ }^{548}$ At the same time, I deduce from the reasoning of both the AG and CJEU in that case that supplies cannot be considered physically and economically indissociable in case they are provided by independent suppliers. ${ }^{549}$ The latter is the case in parallel two-on-one situations. As a result, the 'therapeutic continuum' criterion that was introduced in a case concerning parallel twoon-one situations does not seem to be of any use in those situations.

Nevertheless, the 'therapeutic continuum' criterion may still be useful in parallel one-on-one situations. At the same time, the application of that criterion does not seem to broaden the scope of the exemption provision for extramural care in parallel one-on-one situations, as the criteria mentioned by the CJEU in the Klinikum Dortmund case - i.e. 'physically and economically indissociable' - appear to be stricter than the criteria used for qualifying a supply as ancillary to a principal supply on the basis of the doctrine of composite supplies ('absorption'). In other words, if the parallel supply is not 'absorbed' under the exemption provision for extramural health care as a result to the qualification of supplies on the basis of the doctrine of composite supplies, it is not likely that that parallel supply is to be considered part of a 'therapeutic continuum' and physically and economically indissociable from the principal health care service. However, since the CJEU appears to disregard the doctrine of composite supplies in case of parallel one-on-one situations, the reasoning may still be relevant in practice.

\footnotetext{
${ }^{547}$ CJEU 13 March 2014, Case C-366/12 Klinikum Dortmund, ECLI:EU:C:2014:143.

548 Idem, para. 36.

549 Ibid.
} 


\subsubsection{Parallel two-on-one situations}

In parallel one-on-one situations, both (elements of) supplies are carried out by the same health care suppliers. In a parallel two-on-one situation, the related supply is carried out by another supplier than the supplier providing the principal service. In figure 7.8 , the following example of supplies in a parallel two-on-one situation was shown:

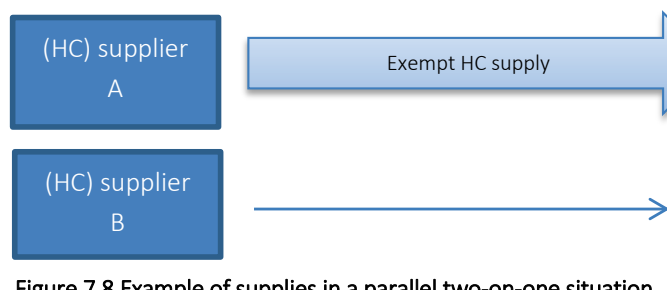

Figure 7.8 Example of supplies in a parallel two-on-one situation

\subsubsection{Assessment of the application of the exemption provision for intramural care in parallel two-on-one situations}

In section 7.3.2.3 I concluded that the 'closely related' test, which is necessary for the assessment of the application of the exemption provision for intramural care, is superfluous in parallel one-on-one situations. The potential absorption of the ancillary service under the exempt principal health care service is already dealt with while qualifying the nature of the supply under Article 2 of the EU VAT Directive. In parallel two-on-one situations, there are two separate taxable persons providing (elements of) supplies to the patient. It should be recalled that, in principle, all transactions are considered distinct and independent. ${ }^{550}$ There is, for example, a single supply for VAT in case of the 'absorption' of the ancillary supply in the principal supply. In cases where two or more elements or acts - supplied by the taxable person to a typical customer - are so closely linked that they form, objectively, a single, indivisible economic supply, this constitutes a 'sui generis' supply (see also section 7.3.2.1).

Due to the assumption that supplier A and supplier B both have a legal relationship with the same recipient as regards their individual supply, it is, in my view, not artificial to split those supplies for the purpose of VAT. Therefore, I believe, in line with the case law referred to in section 7.3.2.1, that the supplies have to be assessed individually for VAT purposes and cannot form (together) an independent transaction for VAT. In Mapfre, the CJEU, however, made some differentiations as regards this point of view, as it indicates that there is a possibility to treat supplies made by two different suppliers as a single supply for VAT. ${ }^{551}$ It held that the fact of assessing supplies made by independent economic operators separately (for VAT), cannot constitute, in itself, an artificial splitting of a single economic transaction,

550 CJEU 29 March 2007, Case C-111/05 Aktiebolaget NN, ECLI:EU:C:2007:195, para. 22; CJEU 27 September 2012, Case C-392/11 Field Fisher Waterhouse, ECLI:EU:C:2012:597, para. 14; CJEU 17 January 2013, Case C224/11 BGŻ Leasing, ECLI:EU:C:2013:15, para. 29.

${ }^{551}$ CJEU 16 July 2015, Case C-584/13 Mapfre asistencia and Mapfre warranty, ECLI:EU:C:2015:488. 
capable of distorting the functioning of the VAT system. ${ }^{552}$ Therefore, the CJEU found it appropriate to examine whether the elements concerned - despite the fact that they were supplied by two independent economic operators - could constitute a single transaction. ${ }^{553}$ To some extent, I can follow the reasoning by the CJEU, especially since it appears that the CJEU has assigned value to the viewpoint of a typical consumer, where it comes to assessing whether a transaction is from an economic point of view a single supply. It could be argued that one should therefore focus on the transaction in the way it is received by the recipient (the 'complete package'), while ignoring the individual legal relationship between the recipient and the independent suppliers. On the other hand, this would reduce the feasibility of the EU VAT system in my view. It would put suppliers in a position where they are dependent on information of other suppliers in order to determine their VAT position, which causes legal uncertainty.

Another reason why it should in my view not be possible to combine supplies made by two different suppliers (being independent taxable persons) into a single supply for VAT purposes is that this disregards the economic reality. The CJEU held in Paul Newey that the contractual position normally reflects the economic and commercial reality of transactions. ${ }^{554}$ At the same time, the consideration of economic and commercial realities is a fundamental criterion for the application of the VAT system. ${ }^{555}$ The CJEU pointed out that the contractual terms, however, should be redefined in cases where it becomes apparent that the contracts do not wholly reflect the economic and commercial reality of the transactions concerned, ${ }^{556}$ especially in case non-artificial arrangements are set up with the sole aim of obtaining a tax advantage. ${ }^{557}$ In case supplies are made in a parallel-two-on-one situation and it does not become apparent that the contractual terms do not reflect economic or commercial reality, I do not see a reason for redefining the contractual arrangements in a way that the individual supplies actually constitute a single transaction together for the purpose of VAT.

In conclusion, based on the above, I am of the opinion that, in parallel two-on-one situations, the qualification of the nature of the supply under Article 2 of the EU VAT Directive, including the assessment of composite supplies, cannot - in itself - lead to the conclusion that (elements of) supplies by independent suppliers qualify as a single transaction for VAT. As shown above, the reasoning of the CJEU in Mapfre, however, opened the door for qualifying supplies of independent economic operators as a single supply for VAT purposes.

This is different for the assessment of qualifying under the notion of 'closely related activities', as referred to in Article 132(1)(b) of the EU VAT Directive. From the CJEU case law,

\footnotetext{
552 Idem, para. 52.

553 Idem, para. 53.

${ }^{554}$ CJEU 20 June 2013, Case C-653/11 Paul Newey, ECLI:EU:C:2013:409, para. 43.

${ }^{555}$ Idem, para. 42.

${ }^{556}$ Idem, para. 44 and para. 50.

${ }^{557}$ Idem, para. 46.
} 
it follows that it is not necessary for a transaction to be closely related to the exempt service to be carried out in the same relationship as the principal service. ${ }^{558}$ A supply can even be closely related if provided in successive situations, meaning that it actually precedes the exempt supply in the supply chain (see section 7.4). The CJEU has not explicitly confirmed that in a parallel two-on-one situation one of the provided transactions can be regarded as closely related to the other - intramural health care - transaction. Since it does accept a close relationship in the sense of Article 132(1)(b) of the EU VAT Directive between an exempt health care supply and a preceding supply (made to the health care supplier), I see no reason for assuming that a close relationship between parallel supplies in two-on-one situations would be impossible. ${ }^{559}$ Furthermore, in cases CopyGene and Future Health Technologies, the CJEU did not reject a possible close relationship between services of stem cell banks (or 'bio banks') to parents and possible medical services in the future on grounds that the services of those stem cell banks are rendered by a different supplier than the future medical services. ${ }^{560}$

In my view, there can thus be a close relationship between services rendered in a parallel two-on-one situation, however, only if the requirements developed by the CJEU for establishing 'closely related activities' are fulfilled. The transactions can only be closely related to intramural care if they are actually supplied ancillary to the hospital or medical care received by the patients in question and constituting the principal service. Furthermore, the supply has to be essential to achieving the therapeutic objectives pursued by the hospital services and medical care in connection with which they have been supplied (see section 7.3.2.1). The criterion of 'essential' seems the most difficult to fulfil. This implies that the medical treatment by Supplier A in figure 7.3 in itself would not be sufficient to achieve the therapeutic objectives. In practice, one would expect supplier A to purchase the services (i.e. hiring in qualified staff or expertise) or goods that are essential to perform the medical treatment for the patient. On grounds of fiscal neutrality, however, the services of supplier B should not be treated differently for VAT purposes if rendered in a successive situation (to supplier A) or in a parallel two-on-one situation (directly to the patient). As long as it can be established that the transaction is supplied ancillary to the hospital service and essential to achieving the therapeutic objectives pursued by the hospital or medical treatment rendered

\footnotetext{
${ }^{558}$ CJEU 14 June 2007, Case C-434/05 Horizon College, ECLI:EU:C:2007:343, para. 31; CJEU 11 July 1985, Case C107/84 Commission vs. Germany, ECLI:EU:C:1985:332, para. 20; CJEU 8 March 2001, Case C-240/99 Skandia, ECLI:EU:C:2001:140, paras. 40 and 41; CJEU 13 December 2001, Case C-235/00 CSC Financial services, ECLI:EU:C:2001:696, paras. 39 and 40; CJEU 3 March 2005, Case C-472/03 Arthur Andersen, ECLI:EU:C:2005:135, para. 39; Compare A-G Opinion 26 September 2013, Case C-366/12 Klinikum Dortmund, ECLI:EU:C:2013:618, paras. 26 and 27; A-G Opinion 8 March 2007, Case C-434/05 Horizon College, ECLI:EU:C:2007:149, para. 47.

559 CJEU 11 January 2001, Case C-76/99 Commission vs. France, ECLI:EU:C:2001:12, para. 30; CJEU 8 June 2006, Case C-106/05 L.u.P., ECLI:EU:C:2006:380, para. 37.

${ }^{560}$ CJEU 10 June 2010, Case C-262/08 CopyGene, ECLI:EU:C:2010:328; CJEU 10 June 2010, Case C-86/09 Future Health Technologies, ECLI:EU:C:2010:334; I am not aware of any possible obligations under national law that future medical treatment has to be performed by that same stem cell or bio bank. This was at least not taken into consideration by the CJEU.
} 
by supplier A. It could, in my view, also be considered contrary to the objectives of the VAT exemptions for health care - i.e. reducing the costs of health care in order to make that health care more accessible to individuals - if a close relationship between two transactions would be rejected due to the fact that the ancillary transaction is rendered by an independent taxable person. ${ }^{561}$

In section 7.3.2.1, the conclusion was drawn that the criteria for a supply to be considered 'closely related' to the principal supply are stricter than the criteria for a supply to be considered 'ancillary'. This is because the 'closely related' test requires the ancillary transaction to also be 'essential'. On the other hand, the scope of application of the 'closely related' test appears broader. Whereas, composite supplies can only be found in parallel situations, closely related supplies can also be found in successive situations (see section 7.4). I explained in this section why I hold the opinion that supplies made by two independent taxable persons should not be regarded as a single transaction for VAT. Therefore, in my view, in parallel two-on-one situations, the extra supply can only come within the scope of the exemption provision for intramural care as a result of the 'closely related' test.

\subsubsection{Assessment of the application of the exemption provision for extramural care in parallel two-on-one situations}

Also, extramural health care can be provided in a parallel two-on-one situation. A supply of extramural health care in a two-on-two situation involves a VAT exempt supply of extramural health care, accompanied by another (element of a) supply carried by another supplier but to the same recipient. Both suppliers individually entered into a legal relationship with the recipient. An example of a provision of extramural care in a parallel two-on-one situation is shown in figure 7.5 .

\section{Introduction}

The assessment of the application of this exemption provision on the supply by supplier $A$ in the basic situation has been discussed in section 7.2.3.1. Like in the parallel one-on-one situation, an extra (element of a) supply is added. In that situation the extra supply was provided by the same supplier (supplier A), whereas in this situation, the extra supply is provided by another supplier (supplier B). The assessment of the exemption provision for extramural care in this parallel-two-on-one situation is discussed by means of an example. In figure 7.6, an example of the supply of extramural health care, accompanied by a separate supply is illustrated. In this example, supplier A is (a foundation that runs) a hospital. It is assumed that supplier A qualifies as a taxable person for VAT purposes. ${ }^{562}$ Supplier A

\footnotetext{
${ }^{561}$ In that regard I agree with A-G Sharpston in A-G Opinion 26 September 2013, Case C-366/12 Klinikum Dortmund, ECLI:EU:C:2013:618, para. 27.

${ }^{562}$ Some EU Member States consider the services of public hospitals as non-economic supplies (out of the scope of VAT), see section 6.1.3.
} 
provides hospital care to in-patients, as well as to out-patients. The latter thus concerns extramural care. For the purpose of this assessment, the example only concerns the extramural health care provided by supplier A. It is assumed that the health care provided to out-patients would be exempt from VAT under Article 132(1)(c) of the EU VAT Directive, if supplied in the basic situation. ${ }^{563}$ Supplier B in this example is a separate legal entity, running a pharmacy on the premises of the hospital run by supplier A. In case the care provided by supplier A to out-patients requires the use of drugs, a prescription is provided by supplier $A$. With that prescription, the patient can collect the drugs from the pharmacy (supplier B). ${ }^{564}$

Example of a supply of extramural health care in a parallel two-on-one situation (figure 7.6)
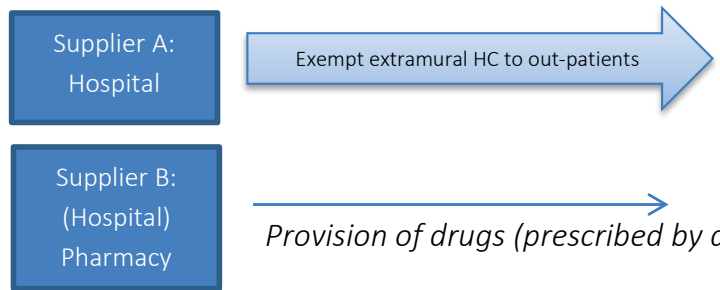

\section{Out-patients}

(Hospital)

Pharmacy

Provision of drugs (prescribed by doctor)

The purpose of the assessment in this section is to establish the scope of application of the exemption provision for extramural health care, in case a separate (element of a) supply is provided by another supplier than the supplier of the exempt health care (the principal service), parallel to that care. In the given example, the question arises whether the provision of drugs (prescribed by the hospital) by the pharmacy to out-patients can be covered within the scope of Article 132(1)(c) of the EU VAT Directive. At this point, I emphasize that the provision of drugs to in-patients, parallel to the supply of intramural health care falls within the scope of Article 132(1)(b) of the EU VAT Directive care as a 'closely related activity', even if that care is provided by a different supplier than that of the principal care. ${ }^{565}$

\footnotetext{
${ }^{563}$ The supply of hospital and medical care to in-patients is covered under the scope of Article 132(1)(b) of the EU VAT Directive.

${ }^{564}$ The example given resembles the dispute in the Klinikum Dortmund case; From para. 2.9 of HM Revenue \& Customs, 2014, VAT liability of health institutions supplies, VAT Notice 701/31 of 22 August 2014, it can be derived that also in the United Kingdom it occurs in the UK that pharmacists operate from an independent pharmacy within hospital premises.

565 This can be derived from the reasoning in A-G Opinion 26 September 2013, Case C-366/12 Klinikum Dortmund, ECLI:EU:C:2013:618, paras. 27 and 39; CJEU 20 June 2002, Case C-287/00 Commission vs. Germany, ECLI:EU:C:2002:388, paras. 48-49.
} 


\section{Single or multiple supplies?}

By itself, the provision of drugs - if provided in the basic situation - does not fall within the scope of Article 132(1)(c) of the EU VAT Directive. The supply may, however, be subject to a reduced rate for pharmaceutical products on basis of Article 98 and Annex III (3) to the EU VAT Directive. As was indicated in section 7.3.3, the application of VAT in parallel two-on-one situations differs in my view from the application of VAT in parallel one-on-one situations with regard to the qualification of composite supplies. In my opinion, the qualification of multiple (elements of) supplies as a single supply for VAT is only possible in parallel one-on-one situations. The fact that the supplies in a parallel two-on-one situation are consumed from two individual suppliers in my view confirms the independence of the two supplies. This may be different in situations where it is obvious that the contracts or transactions between the two individual suppliers and the recipient do not reflect the economic reality. ${ }^{566}$ It is, in my view, not possible in the given example of a parallel two-on-one situation to qualify the extramural health care, provided to the out-patients, together with the supply of drugs by the pharmacy as a single transaction for the application of VAT. At least, not on the basis of the composite supply doctrine, which is based on Article 2 of the EU VAT Directive. As was explained in section 7.3.2.4, the CJEU in Mapfre does not exclude that possibility in a parallel two-on-one situation. As indicated, I disagree with that opinion for several reasons. In my view, such an approach disregards economic neutrality. Furthermore, it could lead to impracticalities, bringing about a less feasible VAT system and increased legal uncertainty for suppliers who depend on the information of other suppliers in order to determine their VAT position. For example, in the situation illustrated in figure 7.6, this would mean that the pharmacy would have to make itself aware whether the patient receiving the drugs also receives medical treatment and whether the supply of drugs can be seen as a means to better enjoy the health care service or whether the supply of the drugs and the health care together constitute an indivisible 'sui generis' supply. I must admit that, in the example shown in figure 7.6, receiving the information needed - in order to determine the qualification of the supply for VAT - is probably not too complicated, as in that example there is a relationship between the health care supplier (hospital) and the hospital pharmacy and the hospital pharmacy perhaps can rely on information provided by the health care supplier as regards the qualification of the supply. I assume, however, that the availability of information on patients and their treatment is limited as a result of privacy legislation.

I indicated above that supplies in a two-on-one situation should in my view not be considered a single transaction for VAT purposes, at least not on the basis of the doctrine of composite supplies. In that regard, I would like to point out some considerations the Advocate General

\footnotetext{
${ }^{566}$ See section 5.3.3.1; CJEU 21 February 2006, Case C-255/02 Halifax and Others, ECLI:EU:C:2006:121, para. 98; CJEU 20 June 2013, Case C-653/11 Paul Newey, ECLI:EU:C:2013:409, para. 43.
} 
made in its conclusion in Klinikum Dortmund. ${ }^{567}$ The dispute in Klinikum Dortmund also concerned the provision of extramural health care and a parallel supply of drugs to the recipient of the extramural health care. The Advocate General basically considered four options in order to determine the VAT qualification of the supply of the drugs:

1. the supply is strictly necessary at the time when the care was provided and not physically and economically dissociable from the provision of the care; ${ }^{568}$

2. the supply of care and the administration of the drugs are to be regarded as so closely linked that they form, objectively, a single, indivisible economic supply, which would be artificial to split; ${ }^{569}$

3. the supply of the drugs is to be regarded as ancillary to the principal service in that it does not constitute an end in itself but a means of enjoying the supplier's principal service better (that might apply to the supply of services which are logically part of the provision of medical care services and, which constitute an indispensable stage in the process of the supply of those services to achieve their therapeutic objectives); ${ }^{570}$ or

4. the supply of drugs to the out-patient has to receive the same VAT treatment as the supply of medicine to in-patients. ${ }^{571}$

The first option is based on the Court's reasoning in Commission vs. United Kingdom. ${ }^{572}$ In that case the CJEU explicitly stated that the supply of medicines is physically and economically dissociable from the provision of the (health care) service. According to the CJEU, only minor provisions of goods which are strictly necessary at the time when the care is provided fall within the scope of Article 132(1)(c) of the EU VAT Directive. The second and third option seem to follow from the composite supplies doctrine. With the second option, the Advocate General seems to consider whether there is a 'sui generis' supply. The reasoning, after all, seems to be based on, inter alia, the CJEU's reasoning in Levob ${ }^{573}$ (see also section 7.3.2.1). The third option - whether the administration of drugs should be regarded as ancillary to the principal service - concerns the question whether there is a single supply as a result of 'absorption'. The fourth option is based on the principle of fiscal neutrality.

It is interesting and new - as opposed to prior case law - that the Advocate General for the first time acknowledges that the provision of the extramural care and the supply of the drugs are part of a 'therapeutic continuum'. Hereafter, I will discuss the importance of the

\footnotetext{
${ }^{567}$ A-G Opinion 26 September 2013, Case C-366/12 Klinikum Dortmund, ECLI:EU:C:2013:618.

568 Idem, para. 41.

${ }^{569}$ Idem, para. 42.

570 lbid.

${ }^{571}$ Idem, para. 43.

${ }^{572}$ CJEU 23 February 1988, Case 353/85 Commission vs. United Kingdom, ECLI:EU:C:1988:82, para. 35.

${ }^{573}$ CJEU 27 October 2005, Case C-41/04 Levob Verzekeringen and OV Bank, ECLI:EU:C:2005:649.
} 
'therapeutic continuum' and its role in the assessment of the application of the exemption provision for extramural care in two-on-one situations in more detail.

The term 'therapeutic continuum' was not used before by the CJEU in VAT cases prior to Klinikum Dortmund. ${ }^{574}$ I presume the Advocate General, in its opinion, wished to express the coherence between the supply of extramural care and the supply of drugs in the light of the therapeutic treatment at issue. ${ }^{575}$ The Advocate General even held that the supply of drugs, at issue in the main proceedings, was in fact 'essential' at the time of providing the care during the outpatient treatment, given that, otherwise, such a provision of care would have no purpose. ${ }^{576}$ At the same time, the Advocate General admits that it is difficult to consider that the supply of the drugs and the health care are a single supply for VAT on grounds that the supplies would be physically and economically indissociable or that they are so closely linked that it would be artificial to split them. ${ }^{577}$ The Advocate General continues with the finding that the patient in fact receives more than one supply: medical care from the doctor and health care staff (employed by the hospital) and a supply of drugs by the hospital pharmacy (which was managed by the hospital). ${ }^{578}$ Thereafter, the Advocate General continues as follows:

"[w]here separate supplies are made by separate persons, it seems inevitable that those supplies cannot 'form, objectively, a single, indivisible economic supply, which it would be artificial to split' or be 'physically and economically dissociable [...]". 579

Thereafter it explicitly holds:

"...the separation between the person supplying the drugs and the person providing the medical care must in my view preclude the two from being regarded together as a single supply, regardless of the fact that neither supply can serve any useful purpose without the other - in contrast to, for example, the situation examined in Deutsche Bank, ... where two comparably interlinked supplies were made by the same taxable person."

\footnotetext{
574 CJEU 13 March 2014, Case C-366/12 Klinikum Dortmund, ECLI:EU:C:2014:143.

575 According the Oxford Dictionary a 'continuum' is "A continuous sequence in which adjacent elements are not perceptibly different from each other, but the extremes are quite distinct".

${ }^{576}$ A-G Opinion 26 September 2013, Case C-366/12 Klinikum Dortmund, ECLI:EU:C:2013:618, paras. 46-47, as confirmed by the CJEU (CJEU 13 March 2014, Case C-366/12 Klinikum Dortmund, ECLI:EU:C:2014:143, para. 35).

${ }^{577}$ A-G Opinion 26 September 2013, Case C-366/12 Klinikum Dortmund, ECLI:EU:C:2013:618, para. 47.

578 Idem, paras. 48-49; CJEU 13 March 2014, Case C-366/12 Klinikum Dortmund, ECLI:EU:C:2014:143, para. 36. The Dutch language version of para. 49 of the A-G Opinion indicates the supplies are made by two different taxable persons.

${ }^{579}$ A-G Opinion 26 September 2013, Case C-366/12 Klinikum Dortmund, ECLI:EU:C:2013:618, para. 49.

580 Ibid.
} 
The Advocate General thus seems to rule out the possibility to regard the supply of the care and the supply of the drugs as a single supply for VAT (not as a sui generis supply, nor a single supply as a result of absorption) on the basis of the finding that the supplies were in fact made by two different persons. ${ }^{581}$ The Advocate General did indicate that the supply of the drugs to the patient and the supply of medical care may be 'closely related' and that such a close relationship will qualify a supply of drugs to be exempted in case it relates to medical care that is exempted under the exemption provision for intramural care, but not in case the related health care is exempt under the exemption provision for extramural care. ${ }^{582}$ With this remark, the Advocate General has the opinion that the criterion of 'therapeutic continuum' broadens the scope of the exemption provision for extramural care to related activities, where the criterion of 'closely related serves' to broaden the exemption provision for intramural care to related activities. While referring to the possibility of a qualification as a 'closely related' supply, the Advocate General seems to acknowledge that closely related supplies can be found to exist in parallel two-to-one situations, whereas in these situations a therapeutic continuum cannot be found to exist. This supports my earlier remarks that supplies in a two-on-one situation should not be considered as one transaction for the purpose of VAT, on the basis of the doctrine of composite supplies. As was already indicated in section 7.3.2.4, the CJEU in Mapfre, however, opened the door for qualifying supplies of independent economic operators as a single supply for VAT purposes. It is, therefore, remarkable that both the Advocate General and the CJEU in the Klinikum Dortmund case have disregarded the remarks made by the CJEU in Mapfre - which was clearly of an earlier date - on the possibility of regarding supplies from two independent economic operators as a single transaction for VAT. ${ }^{583}$ The disregard of the consideration made in Mapfre supports my view even more in that in a two-to-one situations one cannot treat both transactions together as one health care supply for VAT, especially since the Klinikum Dortmund case explicitly concerns health care supplies.

In its judgment in Klinikum Dortmund, the CJEU took the same approach. It acknowledged the presence of a 'therapeutic continuum' between the supply of the health care and the supply of the drugs. It also held that that the latter supply is essential at the time of providing the care. ${ }^{584}$ Thereafter, the CJEU explicitly refers to the remarks that were made by the Advocate General on the fact that, despite the 'therapeutic continuum', the patient appears to receive more than one supply - i.e. first, the medical care from the doctor and health care staff and, second, drugs from the hospital pharmacy - and that this may prevent them from being

\footnotetext{
581 It even referred to Deutsche Bank (CJEU 19 July 2012, Case C-44/11 Deutsche Bank, ECLI:EU:C:2012:484) where, by contrast, the supplies where made by the same taxable person.

582 Idem, para. 49.

${ }^{583}$ CJEU 16 July 2015, C-584/13 Mapfre asistencia and Mapfre warranty, ECLI:EU:C:2015:488, paras. 52-53; See also section 7.3.2.4.

${ }^{584}$ CJEU 13 March 2014, Case C-366/12 Klinikum Dortmund, ECLI:EU:C:2014:143, para. 35.
} 
considered indissociable, physically and economically. ${ }^{585}$ It seems, thus, that the CJEU - in the same way as the Advocate General - attaches great importance to the fact that the supplies were received from independent suppliers. I deduce from the CJEU's reference to the reasoning of the Advocate General that if the supplies are indeed supplied by different persons, they cannot form, objectively, a single indivisible economic supply which would be artificial to split or be physically and economically indissociable. This would, after all, be in line with the wording of the Advocate General in this regard. ${ }^{586}$ Unfortunately, the CJEU has not elaborated on this any further. It stated in its following consideration that - on basis of the information provided to it - it is not convinced whether the dispensing of the drugs should be considered physically and economically indissociable from the provision of the care or not. ${ }^{587}$

\section{Therapeutic continuum in parallel two-on-one situations}

In section 7.3.2.3, I indicated that the CJEU introduced the criterion 'therapeutic continuum' in Klinikum Dortmund in its case law. Although, the term 'therapeutic continuum' was not explicitly defined in that case, it can be deduced that, in case the medical treatment comprises of interrelated activities and are part of a therapeutic schedule, those interrelated activities may qualify as a single supply for VAT purposes if they are physically and economically indissociable from each other. From this reasoning, I conclude that a therapeutic continuum also encompasses supplies that are provided in succession (in time), as long as they are part of a therapeutic schedule. ${ }^{588}$

The presence of a 'therapeutic continuum' appeared to be meaningful to the AG and later the CJEU and seemed to open the door to the qualification as a single supply in parallel situations. However, the fact that the supplies in that case were made by two different persons turned out to be of more importance and outweighed the arguments made on the existence of a 'therapeutic continuum'. For the purpose of the assessment of the application of the exemption for extramural health care in parallel-two-on-one situations, the establishment of the presence of a 'therapeutic continuum' is hence superfluous in my view. After all, I deduced from Klinikum Dortmund that the presence of a 'therapeutic continuum' is ruled out as a possibility in case supplies are received from independent suppliers. As indicated in section 7.3.2.3, the 'therapeutic continuum' criterion may still be useful in

\footnotetext{
${ }^{585}$ Idem, para. 36.

${ }^{586}$ A-G Opinion 26 September 2013, Case C-366/12 Klinikum Dortmund, ECLI:EU:C:2013:618, para. 49; see also section 7.3.2.3.

${ }^{587}$ Idem, para. 37.

${ }^{588}$ That would, in my view, be in keeping with what the CJEU held in CopyGene in relation to the exemption for intramural care. In that case the CJEU held that neither the purpose of the exemption, nor the general scheme of the Directive require the presence of a 'temporal requirement' (CJEU 10 June 2010, Case C-262/08 CopyGene, ECLI:EU:C:2010:328, para. 45).
} 
parallel one-on-one situations. At the same time, I am of the opinion that its effect on the scope of the exemption provision for extramural care will be limited. I pointed out in that regard that, if the parallel supply is not 'absorbed' under the exemption provision for extramural health care as a result of the application of the doctrine of composite supplies, it is not likely that that parallel supply is to be considered part of a 'therapeutic continuum'.

It may be that the CJEU introduced the 'therapeutic continuum' criterion with the intention to use it as another means to guarantee the access to health care by making sure the costs of health care are not increased by the imposition of VAT on supplies that are part of the same therapeutic schedule as the actual medical service. In that case, unfortunately, it has to be concluded that its effect seems to be minor, as indicated above.

\section{Assessment of the application exemption for extramural health care in parallel two-on-one situations}

In the previous sections, I showed that, in my view, the CJEU in Klinikum Dortmund confirmed that, in case of the provision of extramural health care in parallel two-to-one situations, the two (elements of) supplies can in principle not be regarded a single supply for VAT purposes on the basis of the composite supply doctrine. With its decision, it disregarded the reasoning of the CJEU in Mapfre, which was decided on an earlier date. In Mapfre, the CJEU opened the door for qualifying supplies of independent economic operators as a single supply for VAT purposes. I also showed why, in my opinion, supplies of independent suppliers should not be taken together as a single supply (nor a 'sui generis' supply) for the purpose of VAT. If that would be done, the economic reality would be disregarded without an appropriate reason. Furthermore, as was explained, this could lead to legal uncertainty for suppliers and would make the VAT system less feasible.

Example of a supply of extramural health care in a parallel two-on-one situation (figure 7.6):

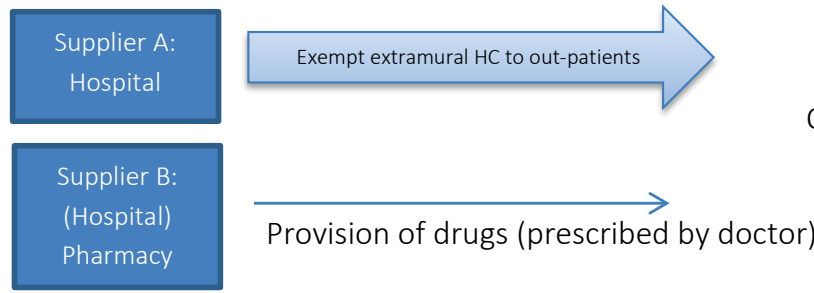

Returning to the example given in figure 7.6, I conclude - on basis of the foregoing - that the two supplies qualify as a single supply for VAT purposes. The reason being that in this parallel two-on-one situation, supplies are made by two separate suppliers (the hospital and 
the hospital pharmacy). The assessment of the application of the exemption provision for extramural care in the two-on-one situation showed that the scope of the exemption provision does not apply to parallel provided supplies by other suppliers. In my opinion, this is, however, not the direct consequence of the application of the exemption provision. It is the result of the qualification of the supply as a result of the application of Article 2 of the EU VAT Directive and, hence, the application of the doctrine of composite supplies. The application of the doctrine already excludes, in my view, the possibility to include the parallel supply in a single transaction together with the principal health care supply. The reasoning of the CJEU in Mapfre in my opinion, does not alter this conclusion, for the reasons mentioned above.

Qualifying the supply of drugs as a separate supply for the purpose of VAT entails that it has to be assessed individually to determine the VAT consequences. The supply of drugs may be subject to a reduced rate on the basis of Article 98 and Annex III (3) of the EU VAT Directive. At this point, it is interesting to note once more that, according to the CJEU, the application of reduced rates has as its purpose to render less onerous and thus more accessible to final consumers - who ultimately bear the VAT - certain goods regarded as being particularly necessary. ${ }^{589}$ The scope of the exemption provision for extramural care in parallel-two-onone supply, in the given example, does not reach so far that it also includes the parallel supply of drugs. Yet, as a result of a reduced rate on that supply, accessibility to health care is still ensured to a certain extent.

It is interesting to consider at this point what would have happened if the exact same supplies as in the example illustrated in figure 7.6 would have been made by the same taxable person (i.e. in a parallel one-on-one situation). See the illustration below:
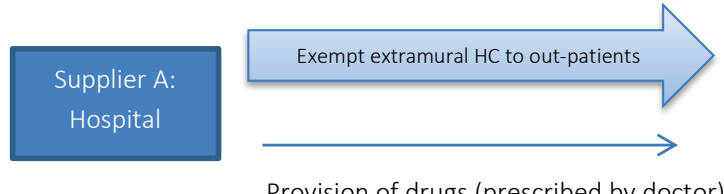

Out-patients

Provision of drugs (prescribed by doctor)

Figure 7.9 Example of a supply of extramural health care and the provision of drugs to out-patients

I deduce from the Klinikum Dortmund case that, in such situations, it has to be assessed whether the supplies together form a 'therapeutic continuum'. If a 'therapeutic continuum' is found to exist and the supplies are considered to be physically and economically indissociable, this could lead to the conclusion that the supplies together qualify as a single supply for VAT purposes. The supply is then, as a whole, exempt.

\footnotetext{
${ }^{589}$ CJEU 17 January 2013, Case C-360/11 Commission vs. Kingdom of Spain, ECLI:EU:C:2013:17, para. 48; CJEU 9 March 2017, Case C-573/15 Oxycure Belgium, ECLI:EU:C:2017:189, para. 22.
} 
Note that the reasoning of the CJEU in Commission vs. United Kingdom, ${ }^{590}$ on the supplies of medicine in relation to the provision of health care is not applicable in relation to this example, as that case concerned the application of the exemption for intramural care, which explicitly includes 'closely related activities'.

I already noted in this regard that, in my view, the qualification of supplies as a result of the application of Article 2 of the EU VAT Directive, precedes the application of exemption provisions on basis of Article 132(1)(b) and (c) of the EU VAT Directive. This means that an exemption of the supply of drugs in a parallel one-on-one situation would only be possible in the first place in case that supply would be absorbed in the exempt health care service on the basis of the application of the doctrine of composite supplies. This occurs if the health care service can be regarded as constituting the principal service, while the supply of drugs is to be regarded as ancillary to the principal service. The supply of drugs can be considered to be ancillary to a principal service where it constitutes not an end in itself but a means of enhancing the enjoyment or benefit of the principal service supplied by the provider. The CJEU held in Klinikum Dortmund that - in the case at issue - the supply of drugs is 'essential' at the time of providing the care, given that otherwise the provision of care would have no purpose. In section 7.3.2.1, I noted that the criterion of 'essential' is in my view more strict than the criteria for absorption in relation to the application of the composite supplies doctrine (i.e. a means of enhancing the enjoyment of benefit of the principal service). If a supply of drugs cannot thus, on basis of the factual circumstances, be considered 'essential' to a principal health care service, it should, in my view, be absorbed in that principal health care service on the basis of the application of the doctrine of composite supplies (i.e. the application of Article 2 of the EU VAT Directive). As a result, the parallel supply becomes part of the health care supply, and that supply is as a whole exempt under the exemption provision for extramural care. In such a situation, it is not necessary to establish the presence of a 'therapeutic continuum', since the application of the doctrine of composite supplies already provided an answer to the question whether the parallel supply of drugs in this oneon-one situation falls under the exemption provision.

The assessment of the application of the exemption provision for extramural care in this example of a supply in a parallel one-on-one situation, supports my view that the effect of the 'therapeutic continuum' criterion on the scope of the exemption provision for extramural care is limited. If the parallel supply is not 'absorbed' under the exemption provision for extramural health care as a result of the application of the doctrine of composite supplies, it is not likely that that parallel supply is to be considered part of a 'therapeutic continuum'.

The examples above - of supplies of drugs in relation to extramural health care - show that the VAT consequences of the parallel supply differ in parallel one-on-one and parallel two-on-

${ }^{590}$ CJEU 23 February 1988, Case 353/85 Commission vs. United Kingdom, ECLI:EU:C:1988:82. 
one situations. In practice, this may lead to interesting questions. For example, it may occur that the hospital mentioned in the examples above is a member of a VAT group together with the hospital pharmacy. ${ }^{591}$ As a result, they are regarded as a single taxable person for VAT purposes. This would automatically put them in a parallel one-on-one situation, whereas if they would not form a VAT group they are considered two independent taxable persons for VAT and provide their services a parallel two-on-one situation.

\subsubsection{Consequences of the application of the exemption provisions in parallel situations}

In the previous sections, the application of the exemption provisions for medical care have been assessed in parallel situations. As was explained in 7.3.2, a parallel situation is in fact an extension of the basic situation. In parallel situations an extra supply is made in parallel to the health care supply. This can either be another supply by the same supplier (parallel one-onone situation) or another supply by a different supplier (parallel two-on-one situation) to the same health care recipient. The basic situation only contained one (single element) supply from the supplier to the health care recipient.

For the purpose of assessment, it was assumed that the health care supply would qualify under one of the exemption provisions for medical care. This made it possible to show in how far it would be possible that the extra element would also qualify under the exemption provision. The assessment of the application of the medical exemption provisions in parallel situations showed that the qualification of supplies - as a result of the application of Article 2 of the EU VAT Directive - and, hence, the doctrine of composites supplies plays an important role. I showed in this section that the extension of the exemption provision for intramural care to closely related activities appears to be superfluous in these situations.

In a parallel one-on-one situation, a parallel supply may come within the scope of the exemption provision of intramural care on the basis of the application of the doctrine of composite supplies. As a result, the supply - as a whole - is exempt from VAT. The direct consequences of the application of an exemption provision on this supply resembles the consequences of the application of an exemption provision in the basic situation (see section 7.2.2.2). In parallel one-on-one situations, where parallel supplies are made next to extramural care, the parallel supply may also come within the scope of the exemption provision on the basis of the application of the doctrine of composite supplies. In relation to parallel situations of extramural care, the CJEU has introduced the 'therapeutic continuum' criterion. The assessment of the application of the exemption provision for extramural care showed that this criterion, however, does not seem to broaden the scope of the exemption provision compared to the application of the doctrine of composite supplies.

In my view, in a parallel one-on-one situation, the exemption of the parallel supply thus depends on the outcome of the application of the doctrine of composite supplies (i.e. the application of Article 2 of the EU VAT Directive). This is the case for intramural health care, as well as for extramural health

${ }^{591}$ As a result of the application of Article 11 of the EU VAT Directive. 
care. The VAT qualification of the parallel supply is thus not dependent on the type of health care. This is in line with the aim of the exemption provisions for health care of making health care more accessible to individuals. In case a parallel supply constitutes a supply ancillary to the principal health care supply, the type of health care (extramural or intramural) should in my view be irrelevant for determining whether the parallel supply comes within the scope of the exemption provision.

I demonstrated in the previous sections why - in parallel two-on-one situations - the parallel supply cannot come within the scope of a medical exemption on the basis of the application of the doctrine of supplies, despite the reasoning of the CJEU in Mapfre. In a parallel two-on-one situation concerning intramural care, the (distinct) parallel supply can, however, still come within the scope of the exemption provision of extramural care if that supply is 'closely related' to the principal health care service. In parallel two-on-one situations concerning extramural care, this is not possible as the exemption provision for extramural care does not include closely related activities. Also, the presence of a therapeutic continuum, in such a situation, cannot bring the parallel supply within the scope of the exemption provision in my view.

Unlike in parallel one-on-one situations, the VAT consequences of the parallel supply in parallel two-on-one situations depend on the type of health care that is provided. The fact that the supplies are made by two different suppliers precludes the parallel supply from falling within the scope of a medical exemption provision. In cases of intramural care, the exemption provision, however, also includes closely related activities. It was shown in section 7.3.3. that, as a result, parallel supplies in a two-on-one situation may also fall under the exemption provision for intramural care. The assessment of the application of the exemption provision for extramural care in parallel two-on-one situations shows that it is not possible to include the parallel supply under the exemption provision for extramural care.

Considering, once more, the aim of the medical exemption provisions of making health care more accessible to individuals, it is remarkable that the type of health care provided in a parallel-two-on-one situation is decisive for the VAT treatment of the parallel supply. In my view - considering that overarching aim of the medical exemption provisions - positive EU VAT law should not make a distinction between intramural or extramural health care in relation to the purpose of making health care more accessible to individuals.

The deviating VAT consequences, as a result of the type of parallel situation, bring along side effects. For example, in case a patient consumes a parallel supply alongside an exempt extramural health care supply, it appears to make a difference whether the supplies are made in a parallel two-on-one or a parallel one-on-one situation (see the example in section 7.3.2.5). If the care is received in a one-on-one situation, both supplies may be exempt, whereas if the care is received in a two-on-one situation, the parallel service may be taxed. Assuming that the imposition of VAT would lead to an increased price of the health care for the consumer, that health care is less accessible in a parallel two-on-one situation compared to a parallel one-on-one situation. This may, thus, influence choices of health care recipients. 
In the following section, I will assess the application of the exemption provisions for medical care in successive situations. Like in parallel situations, the supplies in successive situation are an extension of the supplies in the basic situation.

\subsection{The hindering effect of VAT exemptions in the health care sector in successive situations}

In this section, the application of the medical exemption in successive situations will be assessed. The purpose of this assessment is to be able to show the effect of the application of positive EU VAT law on health care supplied in this specific situation and in order to compare this outcome to the effects of that application in other common types of situations.

In a regular supply chain, the supplies follow each other in time and are carried out successively. The ultimate supply in the supply chain is made to a 'final consumer', as no further supplies will be made. The effect of the application of VAT exemptions for medical care in relation to the ultimate supply (a supply in a basic situation) was already discussed in section 7.2. In this section, the example of the supply used in the basic situation is extended in order to also cover the penultimate supply in the supply chain. This situation is referred to as a successive situation. In the figure below, it is shown where in the model health care system supplies in a successive situation take place.

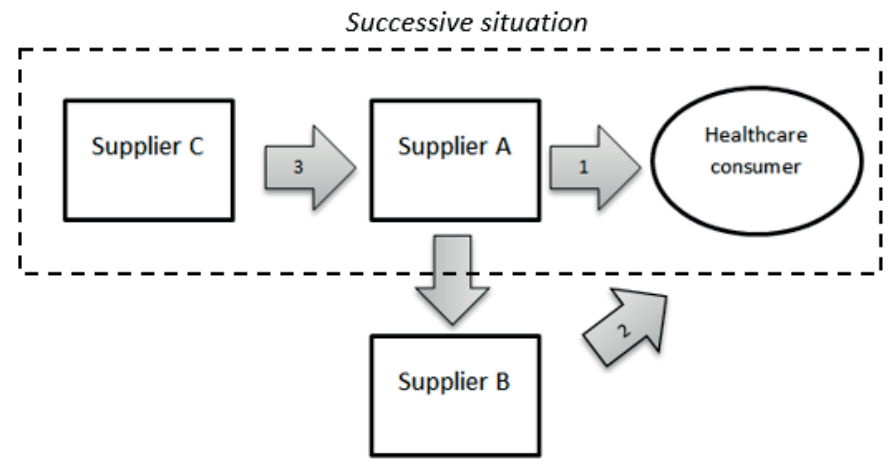

Figure 7.10 A successive situation in the model health care system.

\subsubsection{Introduction}

In this section, it will be examined how the application of positive EU VAT law impedes the principle of access to health care in the penultimate supply in the chain on the access to health care. The ultimate supply to the recipient is assumed to qualify under one of the exemption provisions for medical care. It is also assumed that the penultimate supply on itself (i.e. individually, without the presence of a related supply) does not qualify within the scope of one of those exemption provisions. 


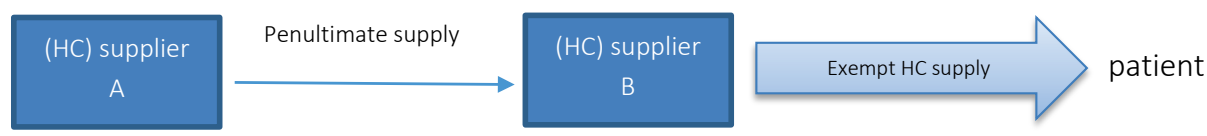

Figure 7.11 Example of supplies in a successive situation

In figure 7.7 two separate supplies by two different suppliers are shown. For the purpose of this example, it is assumed that there is no direct legal relationship between Supplier A and the patient, concerning the transactions carried out. It assumed that the penultimate supply in the supply chain is purchased by Supplier B in connection with the supply of medical care to the patient. The question that arises is what the consequences for the levy of VAT on the supply to the final consumer are, in case the supply that is purchased by the health care supplier relates to his onward supply to the final consumer. This is relevant for establishing the effects of consuming health care in a successive situation as opposed to, for example, in a basic situation.

\subsubsection{The application of VAT Exemptions in the health care sector in successive situations}

The imposition of VAT on a penultimate supply, as shown in figure 7.7, is expected to have a direct influence on the costs of the health care provided to the patient. Supplier B can, on the basis of Article 168 of the EU VAT Directive, only deduct VAT on purchased supplies in so far they are used for taxed transactions. Since the ultimate supply, made by Supplier B, is exempt in the given example, it is not able to deduct the possible input VAT on the supply received from Supplier A. Imposition of VAT on the penultimate supply would therefore directly increase the cost price for Supplier B and hence the costs of health care for the patient.

\subsubsection{Composite supplies in successive situations}

For the purpose of this assessment, it is assumed that the penultimate supply in the previous example, by itself (if provided individually, without the presence of a related supply), does not qualify within the scope of one of the medical exemption provisions. Therefore, it will have to be established whether the application of the VAT exemption for medical care on the ultimate supply (also) has an effect on the VAT treatment of the penultimate supply. Since the two supplies are part of the same supply chain, it is assumed that the penultimate supply has a relationship with the ultimate supply.

In section 7.3.2.1, I showed that it is possible that two separate (elements of) supplies in a parallel situation can be treated as a single supply for VAT purposes on the basis of the doctrine of composite supplies. The assessment that was made showed that this is only possible in case the supplies are made by the same taxable person. In a successive situation, as illustrated in figure 7.7, supplier A is by definition another taxable person than supplier B. Hence, even though the penultimate and the ultimate supply relate to each other - i.e. Supplier B must have purchased the goods or services with a view to making the ultimate supply to the patient - the supplies cannot be regarded as a single supply on basis of the 
doctrine of composite supplies and can, therefore, not come within the scope of one of the exemptions as a result of the qualification of supplies on the basis of Article 2 of the Directive.

Perhaps the penultimate supply can still be 'absorbed' by the exemption provision that applies on the ultimate supply if that supply falls under the notion of 'closely related activities'. Obviously, this seems only possible if supplier B provides intramural health care. In the following subsections an assessment of the application of the exemption provisions for extramural and intramural health care in successive situations will be made.

\subsubsection{Assessment of the application of the VAT exemption for intramural care in successive situations}

As indicated in the previous section, supplies that are made in a parallel situation cannot be considered as a single transaction for the purpose of VAT on the basis of the doctrine of composite supplies. The reason for this is that the supplies are made by two different suppliers. In section 7.3.2.1, I indicated that a supply that is made in parallel to an exempt health care supply can be considered 'closely related' to that health care supply, despite the fact that those supplies are made by different suppliers. As a result, the parallel supply may come within the scope of the exemption provision that applies in relation to the (principal). This is only the case if that health care concerns intramural care, as the exemption provision for intramural care also includes 'closely related activities'. The exemption provision for extramural care does not contain such an extension. As a result, in cases concerning successive supplies of intramural health care, the penultimate supply can only come within the scope of the exemption provision if the penultimate supply constitutes a 'closely related activity'. The application of positive EU VAT law on the provision of health care in successive situations has been the subject of a number of CJEU cases, as will become clear in this section. In line with my previous remark, it will be shown that these cases usually involve the question whether the penultimate supply constitutes a 'closely related activity'.

\section{Closely related activities in successive situations}

Although it may not be directly obvious, one could distinguish a successive situation in the Commission vs. France case. That case evolved around the question whether fees (fixed allowances) that were paid by laboratories for the transmission of a sample were subject to VAT. These transmission fees are fees for transferring samples that have been taken by one laboratory (the sample-taking laboratory) to another laboratory for analysis (analysing laboratory). It was common ground between the parties in the Commission vs. France case that both the sample-taking and the analysis of the samples fall within the scope of the exemption provision for intramural health care. The dispute only concerned the subjection of the transmission fee to VAT. Under French law, the sample-taking laboratory and the analysing laboratory could either cooperate under a collaboration contract or a fixed-fee contract, depending on the required specialty. From the facts in the judgment it can be understood that the difference between those two contracts is that, under the collaboration 
contract the sample-taking laboratory is legally responsible in relation to the patient for both the sample-taking and the analysis and is the one that invoices the patient for these services, whereas, under fixed fee contracts, the sample-taking and the analysis are two legally distinct acts for which the patient is invoiced separately. By way of illustration, the transactions under the fixed fee contract are shown below (figure 7.8).

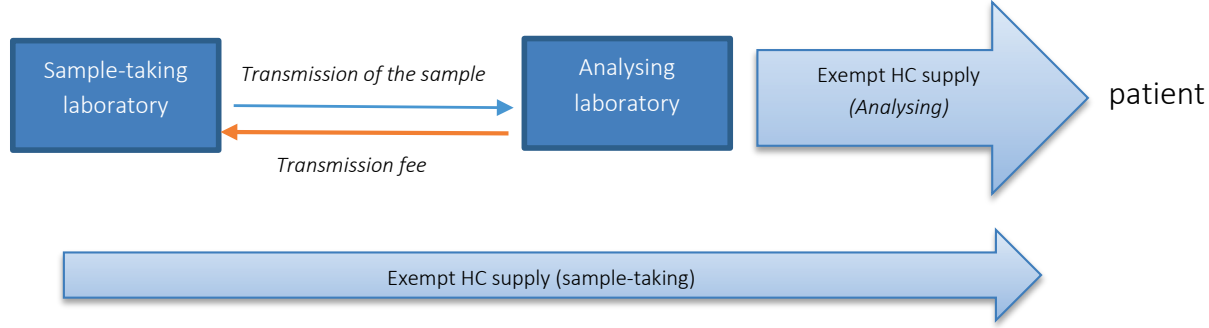

\section{Figure 7.12 Example of supplies in a successive situation (sample-taking)}

III ligure 1.0 u is musudieu ulat num me sample-takirly idnurdury and the analysing laboratory carry out a transaction falling within the scope of the VAT exemption for extramural health care. What was not covered under the exemption provision, according to the French Republic, was the transmission of the sample from the sample-taking laboratory to the analysing laboratory. The transmission fee, the level of which was fixed by ministerial order, was thus subject to VAT. In my view a successive situation can be distinguished here. If we compare figure 7.8 to figure 7.7 , the transmission of the sample can be seen as a penultimate supply, whereas the VAT exempt analysis of the sample constitutes the ultimate supply. The CJEU examined in Commission vs. France whether the transmission of the sample could fall under the definition of 'closely related activities'. It pointed out that it is appropriate to take into account the purpose for which the samples are taken. If a patient has to undergo an analysis in order for an authorized health care supplier to make his diagnosis and with a therapeutic aim, the transmission of the sample must be regarded as closely related to the analysis and is therefore exempt from VAT according to the CJEU. It pointed out that the transmission of the sample logically takes place between the taking of the sample and the analysis itself. ${ }^{592}$ Although the CJEU did bring up the objective of the exemption provision - i.e. to reduce health care costs in order to keep health care accessible for individuals - in this case, it seems that both the purpose of the transmission of the sample and the fact that it was a logical step in the process were decisive for the CJEU to consider the transmitting of the sample as 'closely related' to the analysis. ${ }^{593}$ In this successive situation, the CJEU accepted quite 'easily' the application of the exemption provision on the penultimate supply. The purpose of the penultimate supply was to enable the diagnosis which had a therapeutic aim and was carried out by the health care supplier, making it a supply closely related to the ultimate supply.

\footnotetext{
${ }^{592}$ CJEU 11 January 2001, Case C-76/99 Commission vs. France, ECLI:EU:C:2001:12, para. 24.

${ }^{593}$ Idem, paras. 23-24.
} 
Five years after Commission vs. France, the CJEU delivered its judgement in the L.u.P. case, ${ }^{594}$ another case concerning the application of the VAT exemption for intramural health care in relation to laboratory services. It also concerned medical services in a successive situation. L.u.P. GmbH was a private limited company (laboratory) that carried out medical tests on prescription from a General Practitioner. There was no direct contractual relationship between the laboratory and the patient receiving the care from the General Practitioner. The CJEU made clear in its judgment by referring to Commission vs. France that not only medical tests carried out by laboratories on behalf of patients in the context of a direct contractual relationship with those patients come within the scope of the VAT exemption for intramural care. The Commission's argument that activities carried out upstream from the services that are provided by the ultimate service provider are not exempt was thus rejected by the CJEU. ${ }^{595}$ The CJEU did not elaborate on a possible qualification of the laboratory service as a 'closely related activity', as the matter focussed on the question whether it was allowed that the Member State in question made the exemption of the medical tests subject to conditions to which the care provided by the general practitioners who prescribed the tests is not subject. ${ }^{596}$ It appears that Member States do enjoy this discretion, although the Member State may not require, for the application of the exemption, that the penultimate supply is carried out under the sole responsibility of members of paramedical professions. ${ }^{597}$

From the cases Commission vs. France and L.U.P., it became clear that a penultimate supply may fall within the scope of the exemption provision of intramural care in case that penultimate supply has a therapeutic purpose and forms a logical step in the treatment of the patient. ${ }^{598}$ Another case on intramural health care concerning a successive situation - in which the CJEU seems to apply stricter criteria compared to the CJEU in Commission vs. France - is De Fruytier II. ${ }^{599}$ In this case, the penultimate supply constituted the transport of human organs and samples of human origin. These transport services were carried out for hospitals and laboratories, under the authority and responsibility of a medical doctor. ${ }^{600}$ After establishing that the transport of the human organs and samples did as such not qualify as medical care under one of the exemption provisions, the CJEU examined whether the service could qualify as a service closely related to intramural care. In my view, the CJEU seems to apply in De Fruytier // criteria that are stricter, in comparison to the CJEU in Commission vs. France. This is probably the result of the judgment in the Ygeia case (on supplies in parallel one-on-one situations), which was ruled upon in the meantime. In Ygeia, as was explained in section 7.3.2.1, the CJEU held that a supply should not only facilitate the exempt service in

\footnotetext{
${ }^{594}$ CJEU 8 June 2006, Case C-106/05 L.u.P., ECLI:EU:C:2006:380.

${ }^{595}$ CJEU 8 June 2006, Case C-106/05 L.u.P., ECLI:EU:C:2006:380, paras. 37-38.

${ }^{596}$ Idem, para. 44.

${ }^{597}$ Idem, para. 51.

${ }^{598}$ CJEU 11 January 2001, Case C-76/99 Commission vs. France, ECLI:EU:C:2001:12; CJEU 8 June 2006, Case C106/05 L.u.P., ECLI:EU:C:2006:380.

${ }^{599}$ CJEU 2 July 2015, Case C-334/14 De Fruytier II, ECLI:EU:C:2015:437.

${ }^{600}$ Idem, para. 7.
} 
order to be 'closely related', it has to be logically part of the provision of hospital and medical care services and constitute an indispensable stage in the process of the supply of those services to achieve their therapeutic objectives. Only such services are, according to the CJEU, capable of influencing the cost of health care which is made accessible to individuals by the exemption in question. ${ }^{601}$ The CJEU in De Fruytier // repeated that consideration and held that it is for the referring court to determine whether or not the transport of human organs and samples is indispensable. ${ }^{602}$ In Ygeia, the CJEU used the word essential - in line with case law on the education exemption - and held that, for a service to qualify as a 'closely related activity', it has to be essential to achieving the therapeutic objectives. ${ }^{603}$

It can be deduced from the foregoing CJEU cases that the penultimate supply in a successive situation can come within the scope of the exemption provision, in case the penultimate supply can be considered a supply 'closely related' to the exempt ultimate health care supply. It appears that, over time, the criteria used by the CJEU in order to establish the presence of a 'closely related' activity in a parallel situation became stricter. In Commission vs. France (2001), the CJEU assessed the purpose of the penultimate supply, and whether that supply was a logical step in the treatment process, in order to determine whether the penultimate supply was 'closely related' to the ultimate supply. In the more recent case De Fuytier II (2015), the CJEU held that the penultimate supply also has to constitute an indispensable stage in achieving the therapeutic objectives ${ }^{604}$.

\subsubsection{Assessment of the application of the VAT exemption for extramural care in successive situations}

In section 7.4.2.1 I showed that it is only possible for a penultimate supply to be covered within the scope of the exemption provision for medical care that applies to the ultimate supply if that supply concerns intramural care. This is because only that medical exemption provision (Article 132(1)(b) of the EU VAT Directive) contains an extension to 'closely related' activities. Furthermore, in my view, the penultimate supply cannot form a single service together with the ultimate supply, as the doctrine of composite supplies cannot be applied if the supplies are made by two different suppliers, see section 7.3.2.4.

This would lead to the conclusion that if the penultimate supply in a supply chain is, as such, not covered under the application of the exemption provision for extramural care, the supply is in principle taxed with VAT. The CJEU decision in the Verigen case, ${ }^{605}$ however, proves

\footnotetext{
${ }^{601}$ CJEU 1 December 2005, Joined Cases C-395/04 and C-394/04 Ygeia, ECLI:EU:C:2005:734, para. 25.

${ }^{602}$ CJEU 2 July 2015, Case C-334/14 De Fruytier II, ECLI:EU:C:2015:437, para. 30.

${ }^{603}$ Idem, para. 29. The CJEU based its reasoning on the Commission vs. Germany case in which it was at issue whether university research could qualify as a service closely related to university education (CJEU 20 June 2002, Case C-287/00 Commission vs. Germany, ECLI:EU:C:2002:388, paras. 48-49).

${ }^{604}$ CJEU 2 July 2015, Case C-334/14 De Fruytier II, ECLI:EU:C:2015:437.

${ }^{605}$ CJEU 18 November 2010, Case C-156/09 Verigen, ECLI:EU:C:2010:695.
} 
otherwise. This case dealt with the application of the exemption provision for extramural care in successive situations. The main proceedings in that case concerned the application of the exemption for intramural care on services made by a biotechnology company ('VSTI'). VSTI operated in the field of tissue engineering. Its activities consisted of researching, developing, producing, and marketing technologies to diagnose and treat human tissue diseases. The customers of VSTI - doctors or clinics - sends tissue that is taken from patients to VSTI. VSTI subsequently treats the tissue. The cells that result from the tissue are possibly used to produce a cartilage plaster. In either event - i.e. regardless of whether the cells are used - the cells are sent to the customer of VSTI in order to be implanted in the patient again. ${ }^{606}$

The second preliminary question in the Verigen case reads as follows:

"If any of the above questions is answered in the negative, is Article 13(A)(1)(c) of the Sixth Directive to be interpreted as meaning that the removal of the joint cartilage cells from the cartilage material taken from a human being and the subsequent cell multiplication constitute the "provision of medical care" where the cells obtained from the cell multiplication are reimplanted in the donor?" 607

The CJEU explained that, according to case law, the concept of 'provision of medical care' is intended to cover services which have as their purpose diagnosing, treating and, in so far as possible, curing diseases or health disorders. Nevertheless, the therapeutic purpose of a service must not necessarily be confined within a particularly narrow range. ${ }^{608}$ In Verigen, it was not disputed that the process consisting of the removal of cartilage material to extract cells, which is then multiplied for reimplantation in a patient has, overall, a therapeutic purpose. ${ }^{609}$ According to the CJEU, the services provided by VSTI are an essential, inherent and inseparable part of that process. It pointed out that none of the stages can usefully be performed in isolation from the others. ${ }^{610}$ Directly after that finding, the CJEU concluded that the extraction of joint cartilage cells from cartilage material taken from a human and the subsequent multiplication of the cells for reimplantation for a therapeutic purpose are covered under the concept of 'provision of medical care', referred to in Article 132(1)(c) of the EU VAT Directive. Moreover, the CJEU stipulates that such an interpretation is in line with the objective of reducing the cost of health care. ${ }^{611}$ The objective of the exemption for extramural care seems to justify the inclusion of a penultimate supply within its scope. According to the CJEU, this is not altered by the fact that the services are not carried out by

\footnotetext{
${ }^{606}$ Idem, paras. 9-11.

${ }^{607}$ Idem, para. 19.

${ }^{608}$ Idem, para. 24.

${ }^{609}$ Idem, para. 25.

${ }^{610}$ Idem, para. 26.

${ }^{611}$ Idem, para. 27.
} 
qualified medical practitioners. With reference to the previous case law, the CJEU held that it is not necessary for every aspect of therapeutic care to be provided by medical staff. ${ }^{612}$ It should be noted that Verigen only concerned the scope of the concept 'provision of medical care' in relation to the exemption provision for extramural care. It did not assess the other criteria that are mentioned in that provision, and therefore it seems that the qualification of the ultimate service under the exemption provision for extramural care was not disputed.

I deduce from the considerations made by the CJEU in Verigen that - in a successive situation - the penultimate supply may fall within the scope of the exemption provision for extramural care, provided that the ultimate supply is covered under the exemption provision for extramural care. This is the case if it can be established that the overall process has a therapeutic purpose and the penultimate supply is an essential, inherent and inseparable part of that process.

In successive situations, as illustrated in figure 7.10, the ultimate supply and the penultimate supply are carried out by different taxable persons. In the previous section, I showed that, despite the fact that the penultimate supply is made by another supplier, it may still come within the scope of the exemption provision that applies to the ultimate supply, in case of intramural care. The reason for this is that the exemption provision for intramural care explicitly includes 'closely related' transactions. The exemption provision for extramural care does not contain such an extension. Nevertheless, as can be deduced from the reasoning of the CJEU in Verigen, a penultimate supply can be covered under the exemption provision for extramural care.

This is remarkable when one compares this to the case law of the CJEU on the application of the exemption provision for extramural care in parallel two-on-one situations. From Klinikum Dortmund, which concerns such a situation, I deduce that the parallel supply - despite the presence of a therapeutic continuum - cannot come within the scope of the exemption provision for extramural care in case the parallel supply is carried out by another supplier than the supplier of the health care (see section 7.3.2.3). If the CJEU, in Klinikum Dortmund, would have applied the reasoning it applied in Verigen, the former case could have led to a different outcome. In Klinikum Dortmund, the CJEU explicitly confirmed that the supply of drugs (the parallel supply in that case) was essential in relation to the health care provided. In section 7.3.2.3, I indicated that, in my opinion, the reason for the CJEU to reject the application for the exemption provision for extramural care would be the fact that the parallel supply was carried out by another supplier than the supplier that provided the health care.

In the beginning of this section I noted that, in my view, a penultimate supply cannot form a single service together with the ultimate supply, as the doctrine of composite supplies cannot

${ }^{612}$ Idem, para. 28. 
be applied if the supplies are carried out by two different suppliers. The assessment of the exemption provision for intramural care showed that the (distinct) penultimate supply can still come under the exemption provision if it is 'closely related' to the (ultimate) supply of intramural care. The exemption provision for extramural care does not contain an extension to 'closely related' activities. The Verigen case shows that in situations concerning extramural care, however, the penultimate supply may still also be exempt.

\subsubsection{Example of the application of the exemption provision for health care in the successive situation: hiring out of medical staff}

In the previous sections, the application of the medical exemption provisions has been assessed in relation to successive supplies. Before discussing the consequences of the application of the exemption provisions in a successive situation, I will discuss a practicerelated example of supplies made in a parallel situation. The example concerns the hiring out of staff. Health care suppliers who perform exempt health care services do not enjoy the right to deduct input taxation as a result of the application of Article 168 of the EU VAT Directive. The hiring out of staff is a service which is, in principle, taxed with VAT. Therefore, it is capable of causing a substantial VAT burden. For this reason, it is often at issue whether the hiring out of staff can be qualified as an exempt service, especially since labour may be relatively expensive. In most of the cases, the staff is hired out to carry out or support the exempt health care services provided by the supplier who hires the staff. The imposition of VAT on the hiring out of staff is thus capable of increasing costs of health care and can, therefore, hinder access to health care.

Within a health care supply chain, the hiring out of staff usually occurs as a supply that precedes the health care supply to the final consumer. ${ }^{613}$ The supply of staff then falls under the category of successive supplies. It is a service purchased by the health care supplier in order to carry out its activities. To clarify the effects of the application of positive EU VAT law in relation to the hiring out of medical staff to health care suppliers, the following example of a successive supply will be used in this section.

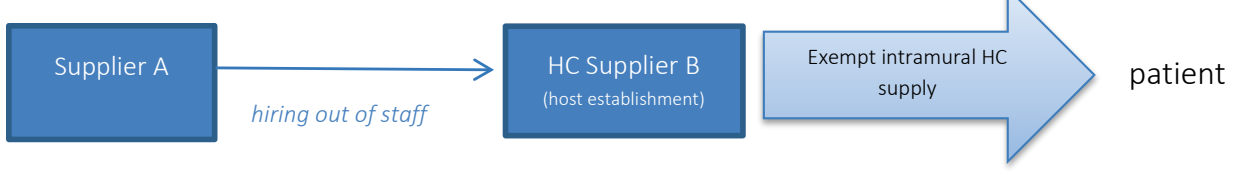

Figure 7.13 Example of supplies in a successive situation: hiring out of medical staff.

For the purpose of this assessment, it is assumed that the health care suppliers in the example above are considered to be taxable persons on basis of Article 9 of the EU VAT Directive and that they are not excluded for their activities as a result of the application of Article 13 of the EU VAT Directive. Furthermore, it is assumed that the hiring out of staff (service) constitutes a taxable event on basis of Article 2 of the EU VAT Directive. It is also

${ }^{613}$ By analogy CJEU 14 June 2007, Case C-434/05 Horizon College, ECLI:EU:C:2007:343. 
assumed that the health care supply carried out by Supplier B falls within the scope of the exemption provision for intramural care.

\subsubsection{Hiring out of medical staff as a closely related service}

Hiring out of staff is a service consisting of an employer making staff available to another person. If staff is hired out, it is, in practice, common that the establishment that engages the staff formally remains the employer, whereas the host establishments fulfil the role as the material employer. In contracts regarding the supply of staff it is, therefore, usually stipulated that a certain member of staff will work for the host establishment for a certain number of hours. Instead of hiring out a certain staff member to the host establishment for a certain number of hours, the host establishment could also have chosen to a buy a certain product. For example, a health care supplier that needs a new IT system may a hire an IT consultant in order to develop the new system. The health care supplier may, alternatively, approach an IT company to develop a new IT-system. In the latter case, the health care supplier buys a product ('the new IT-system'). In that case it is not relevant which staff members of the ITcompany actually developed the IT-system.

In practice, it occurs that parties (the taxable person and the tax authorities) often disagree on the nature of the supply in the case of hiring out medical staff. In line with the example of the IT-system above, it has to be established in such cases whether a host establishment is actually hiring in medical staff or receiving the supply of health care. It is often in the interest of a host establishment (performing exempt supplies) to receive the supply of health care, provided that this supply would fall within the scope of an exemption provision. In that way, the host establishment is not confronted with non-deductible input taxation.

A service, consisting of the hiring out of staff, is not mentioned explicitly in any of the exemption provisions listed in the EU VAT Directive. Therefore, the service is, in principle, taxed with VAT. Since the hiring out of staff in the example given in figure 7.13 concerns a penultimate supply in a successive situation of health care supplies, it has to be examined whether the hiring out of staff can come within the scope of an exemption provision for medical care.

\subsubsection{The horizon criteria}

There has not yet been a CJEU case on the application of VAT on penultimate supplies concerning the hiring out of medical staff, where the ultimate supplies constitute a supply of extramural health care. Therefore, I will refer to the case of Horizon College. ${ }^{614}$ The CJEU made clear in that case that it is possible for a penultimate supply to be regarded as 'closely related' to the exempt ultimate supply, i.e. education provided to students. The penultimate supply in that case concerned the hiring out of staff. The exemption provision for education,

${ }^{614}$ CJEU 14 June 2007, Case C-434/05 Horizon College, ECLI:EU:C:2007:343. 
in Article 132(1)(i) of the EU VAT Directive, also contains an extension to 'closely related' activities, similar to the extension in Article 132(1)(b) of the EU VAT Directive.

In Horizon College, the CJEU held that that the supply of staff (teachers) from one educational establishment to another may qualify as a service closely related to education. The CJEU pointed out in that case that the national court must verify that the establishment making the teacher available and the host establishment both qualify as educational establishments mentioned in Article 132(1)(i) of the EU VAT Directive. Furthermore, the placement had to be of a nature and quality such that, without recourse to such a service, there could be no assurance that the education provided by the host establishment and, consequently, the education from which students benefit, would have an equivalent value. Finally, the basic purpose of the placement may not be to obtain additional income by carrying out a transaction which is in direct competition with commercial enterprises liable for VAT.

These horizon criteria are useful in relation to the supply of staff within the education sector. The question is whether these criteria can also be used for the supply of staff in relation to health care transactions. The CJEU has not yet confirmed explicitly that these criteria can be used for the interpretation of closely related activities in the light of the application of the exemption provision for intramural health care. However, the fact that the CJEU applies a uniform interpretation of the wording 'closely related' both in relation to education as well as to health care indicates, in my view, that the supply of staff within the medical sector may also qualify as a service which is closely related to the principal health care service.

If applied analogously, the criteria for an exempt supply of staff in the medical sector would be the following:

a. the establishment making the staff available and the host establishment both qualify as a person mentioned in Article 132(1)(b) of the EU VAT Directive;

b. the service has to be vital for ensuring a certain level of quality of the hospital and medical care provided to the patients; and

c. the basic purpose of the service is not to obtain additional income by carrying out a transaction which is in direct competition with commercial enterprises liable for VAT.

Hereafter, the criteria are discussed in relation to the example that was presented previously:

Ad a To fulfil the first criterion, both the establishment of employment and the host establishment have to be bodies according to public law or a hospital, a centre for medical treatment or diagnosis or another other duly recognized establishment of a similar nature. The CJEU in Horizon College concluded that both bodies have to be a bodies mentioned under the exemption provision on the basis of a textual interpretation of that provision. ${ }^{615}$

${ }^{615}$ CJEU 14 June 2007, Case C-434/05 Horizon College, ECLI:EU:C:2007:343, paras. 34-36. 
The text of Article 132(1)(b) of the EU VAT Directive also leads to that conclusion, as it only exempts hospital and medical care and closely related activities if carried out by the bodies mentioned in that article. The fact that the supply of staff takes place as a successive supply requires that both the suppliers that are active in the same supply chain, with the ultimate aim to provide health care to a recipient, have to qualify under Article 132(1)(b) of the EU VAT Directive in order to avoid an additional VAT burden. At the same time, this also seems to lead to the conclusion that a supply of staff from Supplier A will always be taxed with VAT in case it is not a qualifying body. In Go Fair Zeitarbeid, a case concerning a supply of staff by a temporary-work agency to a body devoted to social wellbeing, the CJEU took a similar approach. ${ }^{616}$ That case centred around the exemption of Article 132(1)(g) of the EU VAT Directive on the supply of services and of goods closely linked to welfare and social security work. The CJEU concluded that a temporary-work agency, which supplies workers to establishments recognized as being devoted to social wellbeing, do not come within the notion of 'bodies recognised as being devoted to social wellbeing' contained in Article 132(1)(g) of the EU VAT Directive. This underlines my assumption that the criteria, originating in the Horizon College case, should be applied in relation to other exemption provisions, in addition to the exemption for education, in case the exemption contains the wording 'closely related' or 'closely linked'.

In Horizon College, the CJEU even explicitly confirmed that, in order for the service to be regarded as ancillary to the principal service and thus a means to better enjoying the principal service, it is not necessary that for those services to be supplied directly to the recipients of the principal service. ${ }^{617}$

The condition that the host establishment needs to qualify as a body mentioned in the exemption provision is straightforward. In case of consecutive supplies, the fact is that it is the host establishment, Supplier B in the example, who is carrying out the principal service.

Criteria a. is perhaps also clear if read in conjunction with criterion b. The fact that staff is provided by a qualifying body contributes to the quality of the principal service carried out by the host establishment. In Solleveld, concerning extramural care, the CJEU noted that not all medical care is exempted, the latter concerning only that of sufficient quality with regard to the professional training of the providers. ${ }^{618}$ It considered that one of the objectives of the exemption for extramural care is to ensure that the exemption applies only to medical care provided by practitioners with the required professional qualifications. This was used as a contra argument against the stretching of the exemption provision on grounds of fiscal neutrality. If extended to the exemption for intramural care, it has to be concluded that the quality requirement in Article 132(1)(b) of the EU VAT Directive ensures that only medical

\footnotetext{
${ }^{616}$ CJEU 12 March 2015, Case C-594/13 Go Fair Zeitarbeit OHG, ECLI:EU:C:2015:164.

${ }^{617}$ CJEU 14 June 2007, Case C-434/05 Horizon College, ECLI:EU:C:2007:343, para. 32.

${ }^{618}$ CJEU 27 April 2006, Joined Cases C-444/04 and C-443/04 Solleveld, ECLI:EU:C:2006:257, para. 37.
} 
care of a sufficient quality is exempted under that provision. This objective would then take precedence over arguments based on fiscal neutrality. However, the Solleveld case concerned services directly rendered by a health care supplier to a patient. Hence, it concerned the qualification of the principal service and not the qualification of a service potentially related to the principal service.

On the contrary, it can be reasoned that the quality requirement, in combination with the principle of fiscal neutrality, justifies in a successive situation that the services purchased by Supplier B are exempt. If the hiring in of staff is essential and necessary to guarantee a certain level of quality of the principal health care service that is rendered by Supplier $B$, why would it not be sufficient to exempt the supply of staff by Supplier A without also requiring that Supplier $A$ is an establishment qualifying under the exemption provision. One could perhaps compare this to the situation in which Supplier B would purchase laboratory services.

$A d b$ The CJEU in Horizon College held that, in order to qualify as a service closely related to the exempt principal service, the placement of staff has to be of a nature and quality such that, without recourse to such a service, there could be no assurance that the principal service (in that case education from which the students benefit) would have an equivalent value. From the ruling in the case, I deduce that 'equivalent value' refers to the quality of the exempt principal service that is usually provided by the host establishment. This second condition is the explanation of the word 'essential' within the framework of closely related activities. I come to this conclusion from the reference made by the CJEU to the Kinderopvang Enschede case and the references in that case to the Ygeia case, in which the CJEU held that supplies of goods or services can only be closely linked if they are essential to the transactions exempted. ${ }^{619}$ It is remarkable that in the two latter cases the potential closely linked service was provided to the recipient in a parallel two-on-one situation and not in a successive situation. Furthermore, the Kinderopvang Enschede case concerned the interpretation of the wording 'closely related' in the light of the exemptions in Article 132(1)(g) and 132(1)(h) of the EU VAT Directive. This is yet again an extra indication that the CJEU seeks to apply a uniform interpretation of the wording 'closely related' as the exemption provision at hand and that the horizon criteria are also applicable for the supply of staff in sectors other than the education sector.

In Kinderopvang Enschede, the CJEU ruled that it was for the national court to determine whether the principal exempt service (childcare), provided by supplier $A$, that is used by the recipient on the basis of an (parallel supplied) intermediary service supplied by supplier $\mathrm{B}^{620}$ is of such a nature or quality that it would be impossible to obtain a service of the same value without the assistance of the intermediary service offered by that supplier. ${ }^{621}$ Although the

\footnotetext{
${ }^{619}$ CJEU 9 February 2006, Case C-415/04 Kinderopvang Enschede, ECLI:EU:C:2006:95, para. 30.

${ }^{620}$ In Kinderopvang Enschede, 'supplier B', next to intermediary services, also provided exempt childcare services, however, those were not provided to the recipient of the intermediary services in that case.

${ }^{621}$ CJEU 9 February 2006, Case C-415/04 Kinderopvang Enschede, ECLI:EU:C:2006:95, para. 28.
} 
supply of staff in Horizon College was provided in a successive situation, while the services in Kinderopvang Enschede were supplied in a parallel situation, the CJEU applied the criterion formulated in the latter case by analogy. The CJEU apparently did not make a distinction on the basis of the situation or legal relationship in which the related service was performed.

If applied to the example of the supply of staff in the medical sector shown in figure 7.13 it has to be established that the supply of staff by Supplier $A$ is of such a nature and quality that, without recourse to that staff, Supplier B could not ensure that the health care provided to the patients would be of an equivalent value. It is interesting that the CJEU in Horizon more or less concluded that, with the hiring in of staff from a commercial placement agency, the equivalent value cannot be assured. ${ }^{622}$ The CJEU mentions in that regard the importance of the qualifications of the staff in question and the flexibility of the terms of the supply of staff. In my view, this is not in line with the principle of fiscal neutrality. A successful application of the exemption for the supply of staff by a commercial employment agency, however, is not possible as a result of not complying with the first criterion.

In conclusion, this second condition is fulfilled if it can be demonstrated that the supply of staff by Supplier A is vital to ensure that the medical care supplied by Supplier B to its patients is of an equivalent value. This can be done by referring to the qualifications of the staff that is hired and the flexibility of the terms of the supply.

Ad c The third criterion also stems from Article 134 of the EU VAT Directive. According to the second subparagraph of this article, the exemption shall not be granted "where the basic purpose of the supply is to obtain additional income for the body in question through transactions which are in direct competition with those of commercial enterprises subject to VAT". The CJEU in Horizon College referred to this exclusion as a specific expression of the fiscal neutrality principle. ${ }^{623}$

In the given example, the supply consists of the hiring out of staff. This service, by its nature, competes with services provided by commercial enterprises. Therefore, to fulfil this third criterion, it has to be established that obtaining additional income was not the basic purpose for Supplier A of supplying staff to Supplier B. The CJEU did not further specify what 'additional income' is. It did note that the fact that an establishment engaged in outplacement activities receives payment equal to the salary which it pays to the teachers thus supplied is not, in itself, sufficient to establish that the transaction is not intended to obtain additional income. ${ }^{624}$ The advocate general rightfully noted in that regard that the supply of staff in any event provides additional income if the establishment supplying the staff would have to pay the salary of that staff none the less. ${ }^{625}$ The assessment of this third

\footnotetext{
${ }^{622}$ CJEU 14 June 2007, Case C-434/05 Horizon College, ECLI:EU:C:2007:343, para. 40.

${ }^{623}$ Idem, para. 43.

${ }^{624}$ CJEU 14 June 2007, Case C-434/05 Horizon College, ECLI:EU:C:2007:343, para. 44.

${ }^{625}$ A-G Opinion 8 March 2007, Case C-434/05 Horizon College, ECLI:EU:C:2007:149, para. 83.
} 
criterion therefore requires an investigation of the facts and circumstances underlying the supply of staff in order to determine whether the additional income is an ancillary consequence of the supply or the basic purpose of the supplying establishment.

In the Horizon case, both the Dutch and the Greek governments held that the supply of teachers could not be a closely related service, as the supply is not made to the recipients of the education or vocational training but to the supplier of the principal service. They were of the opinion that a service can only be closely related if the related service is provided in parallel to the principal service. The CJEU in the Horizon case rejected these arguments and held that, also in successive situations, the penultimate supply can fall under the notion of 'closely related'. To qualify as a closely related service, it is not necessary that the service or supply is provided to the same recipient as the principal (exempt) educational transaction. This conclusion could already be drawn from the first case on the interpretation of 'closely related' in Article 132(1)(i) of the EU VAT Directive in the Commission vs. Germany case.

\subsubsection{The hindering effect of the application of the application of VAT in relation to the supply of staff}

Services consisting of the supply of staff to other establishments in the health care sector can, under certain conditions, be covered under Article 132(1)(b) of the EU VAT Directive. The nature of such a service precludes it from being qualified as medical or hospital care under Article 132(1)(b) or Article 132(1)(c) of the EU VAT Directive as it does not constitute a service with the aim of diagnosing, treating or curing diseases or health disorders. It consists of making a staff member available to a host establishment for a certain period of time.

The CJEU held that the supply of staff can qualify as a service closely related to the principal exempt service, at least in relation to an exempt education service and in relation to Article 132(1)(g) of the EU VAT Directive. I concluded from the CJEU's reasoning that it aims at a uniform interpretation of the wording 'closely related' that is included in several exemption provisions in the EU VAT Directive. For that reason, the criteria that are formulated by the CJEU in relation to the exemption of the supply of staff as a service closely related to education in case Horizon College can be applied analogously as regards a supply of staff in the health care sector. Furthermore, in my view, it implicitly confirmed the Commission's viewpoint that the Horizon criteria are mutatis mutandis applicable to the supply of staff in the social-cultural and health care sector. ${ }^{626}$ The exemption provision for intramural health care contains an extension of the scope of the exemption to 'closely related activities', whereas the exemption provision for extramural medical care does not. As a result, a supply of staff in the medical sector can only be exempt if it qualifies as a service closely related to hospital and medical care as described in Article 132(1)(b) of the EU VAT Directive.

\footnotetext{
${ }^{626}$ CJEU 25 March 2010, Case C-79/09 Commission vs. Netherlands, ECLI:EU:C:2010:171, paras. 54 and 62.
} 
Two out of the three Horizon criteria in fact originate from Article 134 of the EU VAT Directive. This article contains two mandatory exclusions from a number of exemption provisions included in Article 132 of the EU VAT Directive. The first criterion that both the establishment making the staff available and the host establishment have to be qualifying bodies does not stem from Article 134 of the EU VAT Directive, but it was formulated by the CJEU on basis of a textual interpretation of Article 132(1)(b) of the EU VAT Directive. The application of this criteria has as a result, inter alia, that the supply of medical staff by employment agencies is per definition excluded from the scope of the exemption provision. ${ }^{627}$ The latter is, as such, justifiable on grounds of fiscal neutrality. The nature of the service supplied is not medical care; it concerns a supply of staff, comparable to the core task of VAT liable (commercial) employment agencies. The application of the Horizon criteria to the example of a supply of health care that was shown in figure 7.13 led to the conclusion that the supply of staff can be exempt as a supply closely related to the principal exempt health care service provided by Supplier B if:

- $\quad$ both the establishment of employment and the host establishment have to be bodies by public law or a hospital, a centre for medical treatment or diagnosis or another other duly recognized establishment of a similar nature;

- if it can be demonstrated that the supply of staff by Supplier A is vital to ensure that the medical care supplied by Supplier B to its patients is of an equivalent value; and

- it has to be established that obtaining additional income was not the basic purpose for Supplier A to supply staff to Supplier B.

It does not appear that the CJEU in Horizon College had the intention to limit the application of the Horizon criteria to situations in which staff is supplied on a temporary basis. Furthermore, in Commission vs. the Netherlands, it stated that the temporary or structural supply of staff is not decisive for the question whether it qualifies as a closely related service. ${ }^{628}$ In my view, the criteria are applicable in situations of a temporary supply of staff as well as a structural supply of staff.

It is striking that none of the criteria nor the other considerations in Horizon College consider a reference to the accessibility to health care. It follows from the facts in that case that it was used by the tax payer as an argument in the favour of applying the exemption. ${ }^{629}$ The CJEU apparently did not have any need to expand upon this argument. The AG did and noted that it seems inevitable that the cost of access to practically any exempt service will include at least some non-deductible input VAT. Furthermore, it held that the 'apparent intention to

\footnotetext{
${ }^{627}$ The third criterion is also problematic as the supply of staff by employment agencies will in almost all cases have as a purpose to obtain (additional) income for those agencies, for the supply of staff is their core activity. ${ }^{628}$ CJEU 25 March 2010, Case C-79/09 Commission vs. Netherlands, ECLI:EU:C:2010:171, paras. 53-54.

${ }^{629}$ A-G Opinion 8 March 2007, Case C-434/05 Horizon College, ECLI:EU:C:2007:149, para. 10.
} 
alleviate the fiscal burden on individual consumers of various socially beneficial services' cannot be decisive regarding the definition of exemptions. ${ }^{630}$ In my view, the CJEU should have taken the accessibility of the health care into account in its assessment.

\subsection{Conclusion}

The purpose of this chapter is to show the application of positive EU VAT law on health care transactions in specific situations in order to be able to answer the first research question, i.e. in which situations the imposition of VAT impedes access to health care. The conceptual analysis of the application of exemption provisions for medical care in chapter 6 already showed that exemptions are, by definition, distortive and hinder access to health care.

In order to demonstrate in which situations and how the application of the medical exemption provisions hinders access to health care, I analysed the application of those exemption provisions in relation to supplies made in types of situations that occur in the model health care system (chapter 2). The model health care system contains situations of supplies that typically occur in EU health care systems. The assessment of the application of exemption provisions in relation to these typical situations allowed me to make observations and draw conclusions that can be useful for the application of EU VAT in relation to all EU health care systems. The model health care system contains supplies in basic situations, parallel situations and successive situations. The figure below shows where these situations occur in the model health care system:

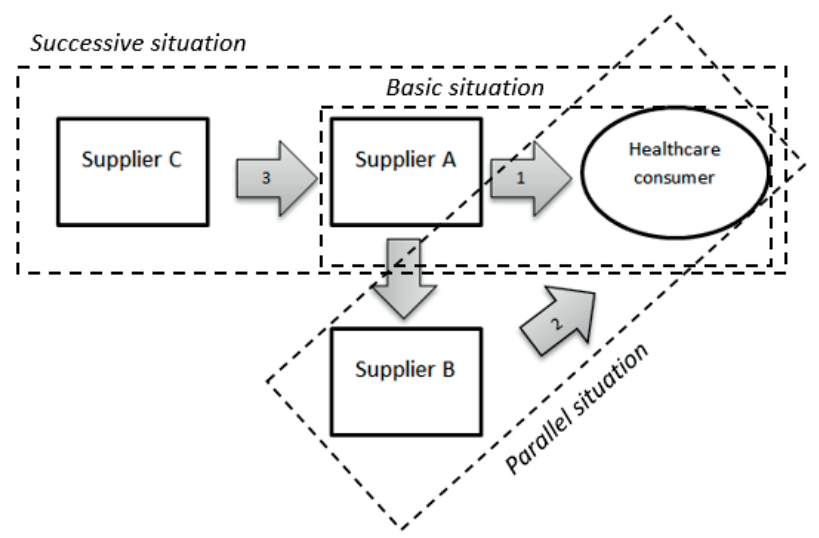

Figure 7.14 Basic, parallel and successive situations in the model health care system.

The assessment showed that the scope of application of the medical exemption provisions in basic situations is different from the scope of application of health care exemptions in parallel situations. Furthermore, the scope of application in these two situates also differs from the scope of application in situations in which health care is supplied as a successive

$\overline{630}$ A-G Opinion 8 March 2007, Case C-434/05 Horizon College, ECLI:EU:C:2007:149, para. 33. 
supply (successive situations). Therefore, I made a distinction between 'basic health care supplies', 'parallel health care supplies' and 'successive health care supplies'. In all three situations, I analysed both the application of the exemption provision for intramural care (Article 132(1)(b) of the EU VAT Directive), as well as the application of the exemption provision for extramural care (Article 132(1)(c) of the EU VAT Directive). An analysis of both exemptions was carried out in each of the situations mentioned above. It appeared that, despite the fact that these health care exemptions have the same aim of making health care more accessible to individuals, their scope differs as regards the extra supplies that are made in successive and parallel situations alongside the supply in the basic situation.

The following sections contain conclusions on the analysis of the application of the exemption provisions for intramural and extramural health care in the situations mentioned. Since the assessment of the health care exemptions differs per type of situation and type of care, the application of positive EU VAT law to health care transactions is often complicated and complex. Section 7.5.9, therefore, contains a schematic overview of the relevant criteria for assessing the VAT exemptions as regards the extra supply carried out in parallel and successive situations.

\subsubsection{Conclusions on the application of the exemption provision for intramural care in the basic situation}

The answer to the central research question in this chapter - i.e. how the application of health care exemptions hinders access to health care in specific situations - can be answered as follows for supplies in basic situations.

The exemption provision in Article 132 (1)(b) of the EU VAT Directive concerns medical care that is supplied in a hospital environment. The exemption is applicable in the basic situation if the (single element supply of) health care provided qualifies as hospital or medical care and the supplier qualifies, according to national standards, as one of the bodies referred to in the exemption provision. Also, minor provisions of goods are covered under the exemption provision if they are physically and economically indissociable from the care provided. The direct effect of the application of the exemption provision in the given example of a basic situation is that no VAT is charged on the health care supply. At the same time, the health care supplier cannot deduct any input VAT that was charged to the supplier on costs made in relation to the health care supplied to the patient. The non-deductible VAT will either be passed on to the recipient of the health care as 'hidden VAT' or lower the profit margin of the health care supplier. The latter is contrary to the legal character of the VAT System, being a tax on (private) consumption. Despite the application of the exemption, the supply provided to the health care recipient is, hence, still not free of VAT. As was explained before, taxation of a health care supply hinders access to health care, as the imposition of VAT on a health care service increases the price of health care. The application of the exemption for extramural care in the basic situation, which has the aim to reduce health care costs and make health care more accessible for individuals, perhaps reduces such an increase, but it does not completely 
relieve the transaction of VAT. The application of positive EU VAT law on health care transactions in the basic situation therefore still impedes the principle of access to health care.

Furthermore, as a result of non-deductible input VAT, suppliers may feel forced to make inefficient economical decisions. The assessment also showed that other side effects of the application of the exemption provision occur. Due to the lack of the harmonization of national recognition procedures for health care suppliers, fiscal neutrality is only ensured within the Member States and not among them. This causes legal uncertainty for suppliers. This can, perhaps, be justified by the fact that these services by nature usually take place in the Member State of 'destination'.

Certain Member States exclude public health care from the application of VAT. In that case, the supplier of the public health care is not considered a taxable person in relation to those services. This results in a situation similar to the application of a VAT exemption on those services.

\subsubsection{Conclusions on the application of the exemption provision for extramural care in the basic situation}

The answer to the central research question in this chapter - i.e. how the application of health care exemptions hinders access to health care in specific situations - can be answered as follows for supplies in the basic situation.

If a health care supply qualifies as medical care, the application of the exemption provision in Article 132(1)(c) of the EU VAT Directive depends on the professional qualifications of the supplier. These need to come within the scope of the medical and paramedical professions as defined by the Member States in their national VAT legislation. Furthermore, the health care provided must fall under the regular exercise of the medical or paramedical professions. Without the required professional qualifications, suppliers can still benefit from the exemption if they provide care similar to that of persons that have the required professional qualifications and demonstrate that their professional qualifications are of an equivalent value to that of a qualifying health care professional.

The consequences of the application of the exemption provision for extramural care resemble those of the application of the exemption provision for intramural care. I demonstrated that the application of Article 132(1)(c) of the EU VAT Directive causes more legal uncertainty for the health care supplier, as a result of the definition of the exemption provision in the EU VAT Directive. This is caused by the fact that, for a correct application of the exemption for extramural care, the supplier has to be aware of the situations in which he is providing regular care and non-regular care. The non-regular care is, after all, only covered under the exemption provision if it falls under the area of expertise of the medical profession.

\subsubsection{Conclusions on the application of the exemption provision for intramural care in parallel one-on-one situations}

In comparison to the basic situation, the parallel one-on-one situation contains an extra element of a supply that is provided to the recipient of the care by the same health care 
supplier as in the basic situation, parallel to the provision of medical care. On basis of the doctrine of composite supplies, the elements have to be qualified for VAT purposes as:

1. separate supplies;

2. a principle and an ancillary supply ('absorption'); or

3. a 'sui generis' supply.

If the elements distinguished in the parallel one-on-one situation form a 'sui generis' supply, the assessment of application of the exemption provision for intramural care is similar to the assessment of the application of the exemption provision for intramural care in basic situations. The extra element that is provided by the health care supplier in this parallel oneon-one situation can also come within the scope of the VAT exemption for intramural care if it is 'absorbed' by the principal exempt service.

I concluded that the application of this composite supply doctrine - which in fact is a means of qualifying supplies, as required for a correct application of Article 2 of the EU VAT Directive - makes the notion of 'closely relates activities' in Article 132(1)(b) of the EU VAT Directive superfluous in parallel one-on-one situations. If the extra element is absorbed by the principal health care supply, a subsequent assessment of that element is no longer necessary. Even if the extra element is not absorbed by the exempt principal service, a subsequent assessment is useless in my view. The criteria to establish whether an activity is 'closely related' to the principal exempt supply are stricter than the criteria for qualifying separate elements as a single supply ('absorption'). The reason for this is that the former criteria require that the provision of the ancillary service is essential in relation to the principal exempt service. If the extra element is not 'absorbed' by the principal exempt service on the basis of the doctrine of composite supplies, it is not likely that it will fall under the notion of 'closely related activities'. The CJEU appears to maintain a different point of view on the relationship between the doctrine of composite supplies and the notion of 'closely related activities'. In the case of multiple element supplies in parallel situations, the CJEU ignores the doctrine of composite supplies on the basis of Article 2 and applies the stricter criteria of the 'closely related' test.

\subsubsection{Conclusions on the application of the exemption provision for extramural care in parallel one-on-one situations}

Prior to the assessment of the application of the exemption provision for extramural care in parallel one-on-one situations, a qualification of the (elements of the) supply has to be made on basis of Article 2 of the EU VAT Directive, by means of applying the doctrine of composite supplies. On the basis of that doctrine, the extra element that is provided by the health care supplier in this parallel one-on-one situation can fall within the scope of the VAT exemption for extramural care if it is 'absorbed' by the principal exempt service. If there is a sui generis supply in a parallel one-on-one situation, the assessment of the application of the exemption 
provision for extramural care is similar to the assessment of the application of the exemption provision for extramural care in basic situations.

Article 132(1)(c) of the EU VAT Directive does not contain an extension to closely related activities. The scope of the exemption provision for extramural care therefore seems to cover fewer services than the scope of the exemption provision for intramural care. This should, however, not necessarily influence the VAT treatment of the services at hand, as, in my view, the 'closely related' test is superfluous in parallel one-on-one situations.

Another criterion that may be relevant in practice is the establishment of a therapeutic continuum'. Despite the fact that the CJEU referred to this possibility in a case concerning the assessment of the exemption provision for extramural health care in parallel two-to-one situations, it can be argued that it also applies in parallel one-on-one situations. According to the CJEU, in the case of a 'therapeutic continuum', the parallel supply can qualify under the exemption provision for extramural care if it is physically and economically indissociable from the principal supply of medical care. The application of this 'therapeutic continuum' criterion does not seem to broaden the scope of the exemption provision for extramural care in parallel one-on-one situations, as it appears to be more strict than the criteria used for qualifying a supply as ancillary to a principal supply on the basis of the doctrine of composite supplies ('absorption'). However, since the CJEU appears to disregard the doctrine of composite supplies in the case of parallel one-on-one situations, the reasoning may still be of relevance.

\subsubsection{Conclusions on the application of the exemption provision for intramural care in parallel two-on-one situations}

In a parallel two-on-one situation, the supplies are carried out by different suppliers. As a result, the qualification of the nature of the (elements of the) supply under Article 2 of the EU VAT Directive, including the assessment of composite supplies, cannot lead to the conclusion that (elements of) supplies made by independent suppliers qualify as a single supply for VAT purposes.

I demonstrated that it follows from the CJEU case law that it is not necessary for an activity to be closely related to the exempt service to be carried out in the same relationship as the principal service. The supply that is performed in parallel to the exempt health care service can, hence, fall within the scope of the exemption provision for intramural care in parallel two-on-one situations if it is considered to be an activity 'closely related' to the exempt health care supply. This requires that the parallel supply is in fact supplied ancillary to the hospital or medical care received by the patients in question and constituting the principal service. Furthermore, the parallel supply has to be essential to achieve the therapeutic objectives pursued by the hospital services and medical care in connection with which they have been supplied. 


\subsubsection{Conclusions on the application of the exemption provision for extramural care in parallel two-on-one situations}

The possibilities of qualifying a supply, performed parallel to an exempt health care supply in a parallel two-on-one situation, under the exemption provision for extramural health care are few. One of the reasons is that, according to the doctrine of composite supplies, the parallel supply cannot form a single supply for VAT together with the exempt health care supply, as the supplies are provided by two independent suppliers. Another reason is that the exemption provision for extramural care does not contain an extension of the scope for 'closely related activities'.

Nevertheless, in a CJEU case on the assessment of the exemption provision for extramural health care in parallel two-to-one situations, the CJEU seemed to open the door for qualifying the parallel supply together with the exempt health care supply as a single supply for VAT purposes. The latter is possible, according to the CJEU, in the case of a 'therapeutic continuum', where the supplies are physically and economically indissociable. The CJEU, however, pointed out that the fact that the supplies were made by two different persons would presumably prevent such a conclusion. The 'therapeutic continuum', although introduced by the CJEU in a case on parallel two-on-one situations, is useless in my view in parallel two-on-one situations.

\subsubsection{Conclusions on the application of the exemption provision for intramural care in successive situations}

Successive situations are situations that cover both the ultimate health care supplies made to the (final) consumer and also the penultimate supply in the supply chain. For the purpose of the assessment, it was assumed that the ultimate supply is covered within the scope of the exemption provision for medical care. The assessment of the exemption provision for intramural care concerned the penultimate supply.

Since the penultimate supply is not supplied by the same health care supplier as the ultimate supply, the penultimate supply cannot be considered to form a single supply for VAT purposes together with the ultimate supply. The penultimate supply can, therefore, not be 'absorbed' under the exemption provision by the ultimate supply on the basis of the doctrine of composite supplies. The penultimate supply can, however, come within the scope of the exemption provision for intramural care if it falls under the notion of 'closely related activities'. From the CJEU cases on the application of the exemption provision for intramural care in successive situations, it can be deduced that a service is considered 'closely related' if it is logically part of the provision of hospital and medical care services and constitutes an indispensable stage in the process of the supply of those services to achieve their therapeutic objectives. Only such services are, according to the CJEU, capable of influencing the cost of health care which is made accessible to individuals by the exemption in question. 


\subsubsection{Conclusions on the application of the exemption provision for extramural care in successive situations}

The penultimate supply in successive situations cannot be covered under the exemption provision for extramural care for being a 'closely related activity', since the exemption provision for extramural care does not contain an extension to such activities. Furthermore, in my view, the penultimate supply cannot form one single service with the ultimate supply, as the doctrine of composite supplies cannot be applied in the case of two different suppliers. However, from the considerations made by the CJEU in a case on the application of the exemption provision for extramural care in successive situations (Verigen case) it can be deduced that it created an opening for including penultimate supplies within the scope of the exemption provision for extramural care in cases where the ultimate supply is covered under that exemption provision. In that case, the overall process has to have a therapeutic purpose and the penultimate supply has to be an essential, inherent and inseparable part of that process.

\subsubsection{Schematic overview of the assessment criteria per situatuion}

\begin{tabular}{|c|c|c|c|c|}
\hline Situation type & Sub type & $\begin{array}{l}\text { Type of } \\
\text { health care }\end{array}$ & See section & $\begin{array}{l}\text { Relevant criteria to assess the VAT exemptions } \\
\text { as regards the supply parallel or penultimate } \\
\text { to the exempt supply }\end{array}$ \\
\hline \multicolumn{5}{|l|}{ Basic situation } \\
\hline & & intramural & 7.2.2.1 & \\
\hline & & extramural & 7.2.3.1 & \\
\hline \multicolumn{5}{|c|}{ Parallel situation } \\
\hline & Parallel one-on-one & intramural & 7.3.2.2 & $\begin{array}{l}\text { - Doctrine of composite supplies } \\
\text { - Notion of 'closely related } \\
\text { activities' }^{631}\end{array}$ \\
\hline & Parallel one-on-one & extramural & 7.3 .2 .3 & $\begin{array}{l}\text { - Doctrine of composite supplies } \\
\text { - } \quad \text { 'Therapeutic continuum' }\end{array}$ \\
\hline & Parallel two-on-one & intramural & 7.3.3.1 & - Notion of 'closely related activities' \\
\hline & Parallel two-on-one & extramural & 7.3 .3 .2 & - 'Therapeutic continuum' ${ }^{633}$ \\
\hline \multicolumn{5}{|c|}{ Successive situation } \\
\hline & & intramural & 7.4 .2 .2 & - Notion of 'closely related activities' \\
\hline & & extramural & 7.4 .2 .3 & - 'Verigen criteria' \\
\hline
\end{tabular}

${ }^{631}$ In section 7.3.2.1 I showed that, in my view, this application of this criterion is superfluous in parallel one-onone situations.

${ }^{632}$ In section 7.5.4 I showed that this criterion might be relevant for practice, however it is from a theoretical point of view superfluous in parallel one-on-one situations.

${ }^{633}$ In section 7.3.3.2 I demonstrated that the CJEU introduced this criterion in a case concerning the application of the exemption provision for extramural care in parallel two-to-one situations, while at the same time the CJEU seems to rule out the possibility for exempting the parallel supply as this supply was performed by another supplier than the supplier performing the exempt principal supply. 
Part IV How to Mitigate the Hindering Effect of EU VAT on Access to Health

Care 


\section{Alternative ways to mitigate the VAT burden on health care transactions while respecting the principle of access to health care}

At the end of this research on the application of positive EU VAT law on health care transactions, I will explore alternative ways to mitigate the VAT burden on health care transactions under an EU VAT system and make recommendations in that regard. To that end, it must first be established what the preconditions of an alternative method have to be. Ideally, an alternative method ensures health care transactions are not affected by VAT - as a result of the imposition of VAT or the forwarding of 'hidden VAT' - since the imposition of VAT on health care transactions hinders access to health care. Furthermore, it appeared from the conceptual assessment in chapter 6 and the assessment of the application of exemption provisions in chapter 7 that the application of positive EU law on health care transactions is rather complex and results in many side effects (e.g. bias to self-supply and other inefficient choices that result in making health care more expensive). It results in a differential treatment of public and private health care suppliers, due to the application of the exemption provision in Article 13 of the VAT Directive. I also showed that the scope of application of the exemptions for health care under positive EU law differs depending on the type of health care (intramural or extramural health care) and the situation in which the health care transactions are provided (i.e. basic situation, parallel situation or successive situation). These forms of differential treatment cannot be justified by the purpose of the exemption provision for health care of making health care more accessible to individuals, nor on the principle of access to health care embedded in the human right to health. In the following sections I will discuss alternative measures. Thereafter, I will propose a 'general exemption for health care' as an alternative for the current exemption provisions for health care under positive EU VAT law.

\subsection{Framework for alternative measures}

Before exploring alternatives and recommending alternatives in relation to the application of EU VAT on health care transactions, the framework on which these alternatives have to be based will be discussed. Proposed alternative measures within the EU VAT system have to take into account the general characteristics of the system, its aims and the fundamental principles underlying it. Next to the legal framework, there are other standards that have to be taken into account. In chapter 5, I demonstrated in that regard that the (the principle of) access to health care has to be taken into account while applying and drafting EU legislation. 


\subsubsection{Purpose of alternative measures}

It is an assumption in this research that the imposition of VAT on health care transactions leads to increased health care costs. ${ }^{634}$ Increased health care costs hinder access to health care. The exemption provisions for health care under positive law aim at reducing health care costs and making that care more accessible to individuals. ${ }^{635}$ According to the CJEU, access to health can be facilitated by means of avoiding the increased costs that result from the imposition of VAT:

"30. ... as regards the purpose of the provisions of Article 132 of Directive 2006/112, it must be recalled that that article aims to exempt from VAT certain activities in the public interest with a view to facilitating access to certain services and the supply of certain goods by avoiding the increased costs that would result if they were subject to VAT...". ${ }^{636}$

From the foregoing, I deduce that the CJEU acknowledged that the hindering effect of the application of positive law is a result of increased costs and that these increased costs are the direct effect of the subjection of those transactions to VAT. From that perspective, it would be ideal if an alternative measure could remove these increased costs fully, i.e. make sure that health care transactions are not affected at all by the imposition of VAT. This also includes a removal of all side effects and other distortions - like differential VAT treatment of health care suppliers - that could result in increased costs.

\subsubsection{Access to health care as a standard}

In chapter 4, I explored the human right to health and more in particular the element of accessibility to health care. I concluded that the application of the human right underpins the purpose of the exemptions for health care. I also demonstrated that the element of accessibility to health care - which is embedded in the human right to health - is based on the ability to pay principle (section 4.2.2). It entails that health care has to be accessible to everyone without discrimination. In chapter 5, I demonstrated in that regard that the (the principle of) access to health care has to be taken into account while applying and drafting EU legislation.

\footnotetext{
${ }^{634}$ Case law on the right of deduction seems to suggest that incurred VAT on acquired goods and supplies is part of the cost components of the taxable transactions for which the acquisitions were made (See, for example, CJEU 22 February 2001, Case C-408/98 Abbey National, ECLI:EU:C:2001:110, para. 28).

${ }^{635}$ See inter alia CJEU 8 June 2006, Case C-106/05 L.u.P., ECLI:EU:C:2006:380, para. 25; CJEU 6 November 2003, Case C-45/01 Dornier, ECLI:EU:C:2003:595, paras. 43 and 48; CJEU 10 September 2002, Case C-141/00 Kügler, ECLI:EU:C:2002:473, para. 24; CJEU 20 November 2003, Case C-212/01 Margarete Unterpertinger, ECLI:EU:C:2003:625, para. 41; CJEU 1 December 2005, Joined Cases C-395/04 and C-394/04 Ygeia, ECLI:EU:C:2005:734, para. 24; A-G Opinion 10 September 2009, Case C-262/08 CopyGene, ECLI:EU:C:2009:541, para. 33

${ }^{636}$ CJEU 5 October 2016, Case C-412/15 TMD, ECLI:EU:C:2016:738, para. 30.
} 


\subsubsection{Legal framework}

For a more detailed discussion of the legal framework in relation to the application of positive EU law on health care transactions, as well as fundamental principles underlying the EU VAT system, I refer to chapter 3. In this section, I will highlight relevant aspects in relation to the second research question, i.e. whether there are alternative ways to tax health care transactions under an EU VAT system that mitigate the hindering effect on the access to health care, without the side effects of the present measures under positive EU Law.

\subsubsection{General consumption tax}

I indicated in section 3.2.1 that - in line with the legal character of VAT, i.e. the aim to tax final consumption at the level of the final consumer - health care consumption is potentially covered within the scope of the VAT system. This is also reflected in the consumption driven model health care system. Furthermore, the broad scope of the definitions for taxable persons (section 3.5) and taxable transactions (section 3.6) have as a result that a large number of health care transactions are covered within the scope of the VAT Directive (see also section 1.1, figure 1.1). The foregoing implies that, without any further measures, health care is subjected to VAT. For that reason, under positive EU law, it was inevitable that the legislator had to include measures with the aim of mitigating the VAT burden in order to promote access to health care. At the same time, this implies that, measures with the aim of mitigating the VAT burden are necessary, unless the increased costs as a result of the imposition of VAT are counterbalanced by means of introducing measures with that purpose outside an EU VAT system. ${ }^{637}$

\subsubsection{All stages tax}

VAT is levied at all stages of the production and distribution process. The application of VAT law in relation to health care, as a result, affects all stages of a health care supply chain up to and including the ultimate supply to a health care consumer. This implies that measures with the aim of mitigating the VAT burden on health care supplies have to take into account the effect at the different stages in a health care supply chain. An example of increased costs as a result of the application of VAT on supplies in preceding stages in a supply chain is the charging forward of non-deductible VAT as a result of the application of exemption provisions.

\subsubsection{System neutrality}

System neutrality is one of the aspects of the neutrality principle, as explained in section 3.3. System neutrality entails that VAT is proportional to the price of the goods and services, despite the number of transactions in the supply chain. This is ensured by the exercise of the right to deduct input VAT. This research showed how the application of the exemption

\footnotetext{
${ }^{637}$ The evaluation of measures outside the VAT system are not part of this research. With the purpose of answering the second research question, the discussion on alternatives is limited to alternatives in a VAT system.
} 
provisions for health care distort system neutrality, mainly as a result of the lack of the possibility to deduct input VAT.

\subsubsection{Legal neutrality and the principle of equality}

Another aspect of neutrality that cannot be disregarded while exploring alternative measures for the application of positive EU VAT law on health care transactions is legal neutrality. I demonstrated in section 3.3 that the principle of neutrality also contains a legal aspect, which demands that the system of VAT has to result in neutrality of competition. Within the field of VAT, the principle of legal neutrality (fiscal neutrality) is actually a reflection of the general principle of equality. ${ }^{638}$ I explained in section 3.3 that the application of fiscal neutrality ensures neutrality as regards competition and therefore only applies in situations concerning competing taxable persons supplying similar goods or services and are, as a result, in competition with each other. Whereas, the general principle of equal treatment also covers other forms of equalities and is not restricted to situations in which persons are in competition with each other. ${ }^{639}$ In relation to health care transactions, the CJEU held that a different treatment of an apparent similar service is only justified if the (professional) qualifications of the providers cannot ensure an equivalent level of quality of the service. ${ }^{640}$

\subsubsection{Ability to pay}

Another principle that I would like to address in this regard is the ability to pay principle. In section 3.4, I demonstrated that the VAT system in itself is not based on the ability to pay principle, as it does not take into account the personal circumstances of health care consumers. I noticed, however, that, in my view, it can be derived from the (proclaimed) purpose of the exemption provisions for health care and the purpose of the application of reduced VAT rates, that the EU VAT system seems to value the ability to pay principle to a certain extent. In chapter 4, I demonstrated that the element of accessibility to health care which is embedded in the human right to health - is based on the ability to pay principle (section 4.2.2). It entails that health care has to be accessible to everyone without discrimination. I also demonstrated that, within an EU context, ability to pay is recognized as one of the overarching values that have to be taken into account when drafting specific proposals concerning health services (section 4.3.1).

It appears that it is a common understanding that health care should be accessible to individuals, regardless of their ability to pay. At the same time, ability to pay is not a principle on which the EU VAT system is based. It is therefore not a requirement that results from the VAT system. However, in the light of the principle of access to care it is desirable.

\footnotetext{
${ }^{638}$ See for example CJEU 27 April 2006, Joined Cases C-444/04 and C-443/04 Solleveld, ECLI:EU:C:2006:257, para. 36; CJEU 6 November 2003, Case C-45/01 Dornier, ECLI:EU:C:2003:595, paras. 42 and 69; CJEU 26 May 2005, Case C-498/03 Kingscrest Associates and Montecello, ECLI:EU:C:2005:322, paras. 29 and 52.

639 Bomer, A.H., 2012, De doorwerking van de algemene rechtsbeginselen in de BTW (diss.), Maastricht University, p. 125; Van Doesum, A.J., 2009, Contractuele samenwerkingsverbanden in de BTW (diss.), p. 32.

${ }^{640}$ CJEU 27 April 2006, Joined Cases C-444/04 and C-443/04 Solleveld, ECLI:EU:C:2006:257, para. 40.
} 


\subsection{Alternatives measures}

In the previous section, I established that it would be ideal if an alternative measure for mitigating the VAT burden on health care supplies ensures that health care transactions are not affected at all by the imposition of VAT. This also includes a removal of all side effects and other distortions - like differential VAT treatment of health care suppliers - that could result in increased costs. In order to be able to discuss alternatives under positive EU VAT law, I discussed some aspects of the legal framework of EU VAT. In the following sections, I will discuss alternative measures.

\subsubsection{Abolition of exemption provisions for health care}

Considering the distortive effect of exemption provisions for health care, a straightforward option to consider is the abolition of those exemption provisions. This would, however, be problematic in relation to the principle of access to health care. As indicated in section 8.1.3.1, it is a result of the general application of VAT that, without any further measures, all supplies of goods and services covered within the scope of EU VAT are taxed against the general rate. In section 8.1.1, I demonstrated that, in order to facilitate access to health care, the increased costs resulting from the imposition of VAT on the supply of goods and services have to be removed. After all, it is these increased costs that are considered to hinder access to health care.

If the exemption provisions for health care would be abolished, this has a direct consequence that health care supplies are subject to full taxation. This hinders access to health care. It can be assumed that the imposition of VAT, in line with its legal character to tax consumption, results in an increased price of health care for health care consumers. ${ }^{641}$ An abolition of health care exemptions, without taking other measures, is therefore not a good alternative in the light of the principle of access to health care.

From a neutrality point view, on the other hand, the abolition of the exemption provisions for health care would be a welcome option. Full taxation entails that the suppliers in the health care supply chain are entitled to deduct input VAT. As a result, they would not have to face complex matters such as proportional deductions. Furthermore, effects like the forwarding of non-deductible input VAT and cascading of VAT would not occur. Another consequence of the abolition of the exemption provisions for health care would be that health care suppliers would no longer have to assess whether and in how far these transactions come within the scope of the exemption provisions. Also, the distortions of fiscal neutrality as a result of the deviation from scope of application of the exemption provisions for intramural and extramural care would not occur. Distortive effects as a result of the application of exemption provisions for health care may result in increased costs for health care suppliers and, as a result, hinder access to health care. With full taxation, these increased costs would not occur.

\footnotetext{
${ }^{641}$ Copenhagen Economics, 2013, VAT in the public sector and exemptions in the public interest, Final report for TAXUD/2011/DE/334, p. 14-15.
} 
Quantitative research in relation to full taxation of public sector bodies (including health care) showed that prices of health care increased as a result of full taxation. ${ }^{642}$ The increase may be less if full taxation would occur against a reduced rate. ${ }^{643}$ In section 8.2.2 the option of the application of reduced rates will be discussed.

\subsubsection{Reduced rates for health care transactions}

Another alternative to applying VAT exemptions on health care transactions would be the application of reduced rates. The application of reduced rates presupposes the abolition of the existing exemption provisions. For that reason, the effects of the application of reduced rates for health care transactions are, to a certain extent, similar to the effects described under section 8.2.1.

Full taxation against the standard rate (section 8.2.1) would imply that the application of VAT on all health care supplies would occur in the same manner. The imposition of VAT would take place irrespective of the type of care (intramural or extramural) and the quality of the health care providers. Definitions for health care and health care suppliers would become irrelevant for the application of VAT. This is an important difference between the application of full taxation against the standard rate and full taxation against the reduced rate.

If a reduced rate would apply to health care transactions, they would - like the current exemption provisions - constitute exceptions to the general principle that all goods and services are taxed. As a result, the same difficulties in relation to assessing the criteria for the application of exemption provisions for health care would occur. Therefore, it is expected that the scope of application of reduced rates on health care transactions can also lead to differential VAT treatment as a result of the type of care (intramural or extramural) and the situation in which the care is provided (basic, parallel or successive).

The application of reduced rates, as opposed to the application of exemption provisions for health care, has, to a certain extent, the same advantages as the alternative of full taxation, described in section 8.2.1. An important disadvantage in comparison to that option is that the application of reduced rates requires an assessment of criteria for their application. This is expected to lead to the same levels as differential treatment, compared to the application of exemption provisions under positive EU VAT law.

Compared to the option of full taxation, the application of reduced rates comes closer to the purpose of removing the increased costs as a result of the imposition of VAT in order to facilitate access to health care, because the supplies are taxed to a lower VAT rate, as a result

\footnotetext{
${ }^{642}$ Idem, p. 202.

${ }^{643}$ Under positive EU VAT law, the reduced VAT rate may not be less than $5 \%$.
} 
of which the increased costs are less. The lower the reduced rate, the less access is hindered. Under positive law, a reduced rate may not be less than $5 \% .{ }^{644}$

On basis of the foregoing, I conclude that the application of reduced rates causes fewer side effects, compared to the application of the exemption provisions for health care. Whether this alternative mitigates the hindering effect on the access to health care depends, in my view, on the applied rate. The application of exemption provisions results in increased costs as a result of charging forward hidden VAT and the other side effects it brings along. Therefore, if a reduced rate could be set to a percentage that results in a VAT burden for the health care consumer equal to or lower than the increased costs that are incurred as a result of the application of exemption provisions, the application of a reduced rate is preferred. Such a calculation would also have to take into account increased costs as a result of the application of reduced rates.

\subsubsection{Full taxation up until the penultimate supply}

Another alternative could be combining the advantages of full taxation against the standard VAT rate with the application of a measure to mitigate the VAT burden in the ultimate supply. This could be a considerable alternative in case the ultimate supply is taxed against the reduced rate. The application of an exemption in the ultimate supply would undo the greatest advantages of full taxation in the preceding stages, i.e. the right to deduct input taxation. The combination of full taxation with a reduced rate is illustrated in figure 8.1 below.

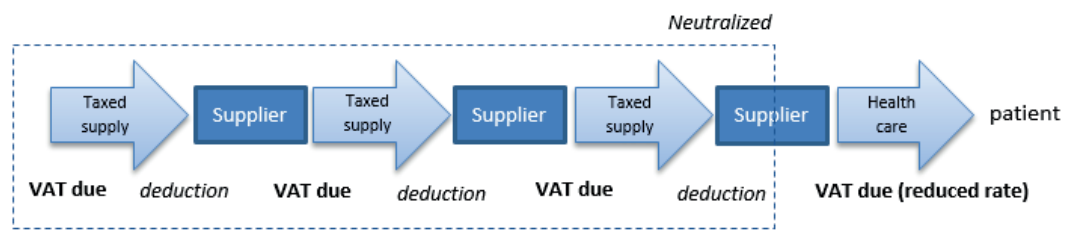

Figure 8.1 Example of the application of full taxation up until the penultimate supply.

The application of full taxation of health care transactions against the standard rate up until the penultimate supply in a (health care) supply chain has the advantage that the imposition of VAT is 'neutralized' at the level of supplier, supplying health care to the health care consumer. As a result of the application of the reduced rate in the penultimate supply, the supplier performing the ultimate supply has the right to deduct input VAT on the basis of the application of Article 168 of the EU VAT Directive. This ensures that there is no previously charged VAT or hidden VAT present in the cost components of the outgoing health care supplies. The ultimate health care supply would be subject to the subject to a reduced rate, as a result of which the health care costs for the health care recipient are only increased to a limited extent, which could be explained as a valuation of ability to pay.

${ }^{644}$ Article 99(1) of the EU VAT Directive. 
I am aware that the foregoing effects resemble the effects of full taxation to a reduced rate (in all stages). In my view, there is, however, a significant difference. A uniform treatment of all health care supplies up until the penultimate supply ensures that all those supplies are, per definition, taxed against the standard rate. Suppliers in B2B relationships therefore do not have to assess the criteria of application for reduced rates or exemptions. This would cause a significant simplification of the application of EU VAT in relation to health care transactions. As a result, this may decrease the costs of health care. The hindering effect of the application of VAT may be mitigated to a large extent.

Such a system will only work if it is not restricted to health care supplies. Otherwise, suppliers within the supply chain that also perform activities other than health care (e.g. educational services) would have to make themselves aware of the fact whether they are supplying within a health care supply chain or not. That would also result in all kinds of undesired qualification problems.

Applying a reduced rate only in the ultimate stage of the supply chain requires proper criteria for application. In relation to health care supplies, such a criterion could be that the reduced rate is only applicable in $\mathrm{B} 2 \mathrm{C}$ health care situations, supplies from taxable persons to natural (non-taxable) persons. Due to the nature of health care supplies, this should be relatively easy to assess for health care suppliers. If this alternative VAT treatment would apply for sectors other than health care, a B2C criterion for the application of a reduced VAT rate in the ultimate supply may not be feasible.

In my opinion, this alternative way of taxing health care transactions is capable of mitigating the hindering effect of the imposition of VAT on health care transactions to a large extent. Therefore, I recommend further research on this concept. At the same time, I am aware that as a result of the fundamental changes in the VAT system that a shift to such a system is not foreseeable in the near future.

\subsubsection{Adjustment of current exemption provisions for health care transactions}

The alternatives that have been discussed in the previous sections require fundamental changes in the EU VAT system. In my opinion, a mitigation of the hindering effect of the imposition of VAT on health care transactions may also occur as a result of a 'smaller' alteration: the introduction of a 'general exemption for health care supplies'.

The conceptual assessment of the application of exemption for health care transactions in this research showed that the scope of application of the exemptions for health care under positive EU law differs depending on the type of health care (intramural or extramural health care) and the situation in which the health care transactions are provided (i.e. basic situation, parallel situation or successive situation). These forms of differential treatment cannot be justified by the purpose of the exemption provision for health care of making health care 
more accessible to individuals nor based on the principle of access to health care embedded in the human right to health.

The different scope of application as a result of the type of care provided and the situations in which the supply takes place is the result of maintaining two different provisions for the exemption of a health care transaction. As indicated above, there appears to be no justification for such a distinction. It could be that the legislator - with an aim of maintaining a feasible VAT system - preferred to exempt all health care activities that take place in a health care facility, instead of making the exemption dependent on the professional qualities of employees of those facilities performing the health care concerned. This is understandable but should not lead to a different scope of application.

\section{Proposal for a 'general exemption for health care supplies'}

Considering the above, I suggest maintaining only one exemption provision for health care services. The exemption provisions for intramural and extramural health care under positive EU law share the same purpose of making health care more accessible to individuals by avoiding the increased costs as a result of the imposition of VAT. ${ }^{645}$ Such a 'general exemption for health care supplies' could contain an extension to 'closely related' activities for situations in which distinct elements of health care supplies cannot be absorbed under the principal health care supply as a result of the application of the doctrine of composite supplies (i.e. two-on-one parallel situations and successive situations). Under positive EU VAT law, only the exemption for intramural health care contained such an extension, which lead to a deviating scope of application and confusing reasoning of the CJEU. The qualification of health care establishments and health care suppliers, whose transactions can be covered within the scope of the general exemption for health care supplies, remains a national issue. I do not consider this as problematic. Health care systems are arranged at a national level. The aim of the exemption provision is to make health care more accessible. I demonstrated in chapter 2, that professional knowledge of health care suppliers is a common criterion to distinguish health care from other health related supplies. It could, as a result of the national discretions, occur that health care transactions are taxed differently in one Member State compared to another. This may be problematic from a neutrality point of view. It may, however, be expected that hospital services are by nature mainly consumed locally. Furthermore, the numbers in cross-border patient mobility show that the actual number of patients currently seeking treatment across the border is still relatively small. ${ }^{646}$

In my view, the introduction of a general exemption for health care supplies - that disregards the type of care provided - would lead to a significant simplification of the

\footnotetext{
${ }^{645}$ CJEU 5 October 2016, Case C-412/15 TMD, ECLI:EU:C:2016:738, para. 30.

${ }^{646}$ Footman, K., Knai, C., Baeten, R. et al., 2014, Cross border health care in Europe, Policy Summary 14, WHO, 2014; Legido-Quigley, H., Passarani, I., Knai, C. et al., 2011, Cross-border healthcare in Europe: clarifying patients' rights, BMJ, 342(7793):364-7.
} 
application of the exemption provisions for health care. As a result, the imposition of VAT on these supplies would result in less increased costs and the accessibility to health would be hindered to a lesser extent.

\subsection{Conclusion}

In this chapter, I explored alternative ways to mitigate the hindering effect on the access to health care, for the purpose of answering the second research question.

'Are there alternative ways to tax health care transactions under an EU VAT system that mitigate the hindering effect on the access to health care and which do not have the side effects of the present measures under positive EU Law ${ }^{\prime 647}$

The alternatives that are considered depart from the assumption that the imposition of VAT on health care transactions leads to increased health care costs and that these increased health care costs hinder access to health care. At the same time, as a result of the general character of VAT, a large number of health care transactions are covered within the scope of the EU VAT Directive. This implies that, without any further measures, health care is subjected to VAT. For that reason, under positive EU law, it was inevitable that the legislator had to include measures with the aim of mitigating the VAT burden in order to promote access to health care. At the same time, this implies that measures with the aim of mitigating the VAT burden on health care transactions are necessary, unless the increased costs as a result of the imposition of VAT are counterbalanced by means of introducing measures with that purpose outside an EU VAT system.

Returning to the second research question, I concluded that, in the first place, the abolition of health care exemptions, without taking other measures, is not a good alternative to the application of positive EU VAT law in the light of the principle of access to health care.

I also concluded that the application of reduced rates results in less side effects, compared to the application of the exemption provisions for health care. Depending on the percentage that will be applied as a reduced rate, it may even mitigate the hindering effect on access to health care. This only occurs, in my view, if a reduced rate could be set to a percentage that results in a VAT burden for the health care consumer equal to or lower than the increased costs that are incurred as a result of the application of exemption provisions.

Another alternative measure that may mitigate the hindering effect on the access to health care is full taxation up until the penultimate supply against the standard rate and the application of a reduced rate on the ultimate supply to the health care consumer. This alternative results in less side effects compared to the application of reduced rates.

${ }^{647}$ See section 1.3 . 
I also concluded that a relatively small alteration of the exemption provisions for health care may mitigate the hindering effect on access to health care, without requiring fundamental changes in the EU system. In that regard, I proposed to introduce a 'general exemption for health care supplies' with unambiguous criteria for its application regardless of the type of care provided (intramural or extramural care). 
Part V Summary and Conclusions 


\section{Summary and conclusions}

\subsection{Introduction}

This research started with the observation that, in relation to the taxation of health care services, in fact two 'forces' play a role. The first force is the application of the EU VAT, being a general tax on consumption and hence aiming to cover a large number of transactions within its scope. The other force is the right to health and, more in particular, access to health care. This force aims to keep health care accessible by trying to remove all kinds of burdens that could possibly hinder that access. The questions that play a role in this research relate to the interaction of these two forces with conflicting aims. As a starting point, I assumed that, under current positive EU VAT law, the application of those two forces has as a result that imposition of EU VAT on health care transactions hinders access to health care. I find support for his hypotheses in the case law on EU health care and in prior studies on the application of VAT exemptions and exclusions, in particular in relation to public sector activities. The hypothesis used in this research therefore is: the imposition of EU VAT on health care transactions hinders access to health care.

In my view, no extensive studies have been conducted so far on the interaction between the application of EU VAT on health care transactions and the application of the standard of access to health care. I believe that, at this point in time, a research on this interaction is useful and even perhaps indispensable for the improvement of EU VAT law and a more efficient levying of VAT that adheres to the current state of health care systems in the EU. Furthermore, the outcomes of such a research, in my view, would not only be relevant in relation to EU VAT but also for studies on the fiscal sustainability of health care systems in the EU.

The assessment of the hypothesis required, on the one hand, an understanding of the application of EU VAT law in relation to health care transactions and, on the other hand, the exploration of the principle of access to health care. In order to be able to weigh the two forces against each other and draw conclusions on the effects of my findings in relation to positive EU VAT law and to make recommendations for improvements to the current system, a research framework was required. By means of the two central research questions, formulated in section 1.3, I aimed to structure this research in a way that the hypothesis is tested and insights are provided on possible improvements to the EU VAT system as regards health care transactions.

\subsection{Summary and conclusions}

\subsubsection{Conclusions as regards the principle of access to health as a standard}

I established that the principle of access to health care is, in the context of human rights law, recognized as one of the interrelated essential elements that have been distinguished in the scope of the human right to health. A further breakdown of the human right to health even 
revealed that accessibility also entails financial access to health care, which could explain the possible references to this human right by the CJEU in case law on the application of EU VAT on health care transactions. The human right to health is recognized in international human rights treaties and other legislative documents. It is included in the International Covenant on Economic, Social and Cultural Rights ('ICESCR'), which is considered the central instrument of protection for the right to health. The ICESCR is legally binding on the State Parties to the Covenant and they have the obligation to progressive realization and some other obligations with immediate effect. The EU, as such, was not a party although all of its Member States are. I concluded that the right to health - and hence, also the element concerning the accessibility of health care - has to be safeguarded while revising or drafting EU (VAT) legislation. I feel confirmed in this view, as the access to health care was explicitly recognized in 2006 as one of the overarching values of EU health care systems that has to be taken into account while drafting proposals concerning health services by the 25 Health Ministers of the EU. So far, I concluded that the access to health care, as part of the human right to health, serves as a valid standard for the application of EU VAT law.

\subsubsection{Conclusions as regards EU health care systems in relation to this research}

In chapter 2 definitions of health care have been explored. These proved to be very broad. Furthermore, as the EU health care systems are organized at the national level, no common definition of EU health care is available. Therefore, I explored definitions that are used by international organizations that conduct qualitative and quantitative research in the field of health care. I assumed that they would apply commonly accepted definitions as their research goals require them to make - often quantitative - comparisons of the functioning and funding of health care systems between EU Member States. The analysis of definitions provided insights into the common denominators of health care systems in the EU. The common denominators distinguished - i.e. common understandings of health care supplies and health care suppliers - have been used to come to a model EU health care system for the purpose of this research. To make sure that the EU model health care system would be reliable and able to provide information on the effect of the imposition of VAT on health care transactions and ultimately the effect on access to health care, certain requirements have been set. Next to the requirements that followed from the analysis of definitions, requirements derived from the VAT system were formulated. The requirements led to a multi-level and demand-driven model health care system, containing basic, parallel and successive transactions. An analysis of the Dutch health care system was carried out to ensure that the model has practical value and no essential elements have been overlooked. This analysis did not call for any alterations in respect of the model health care system.

\subsubsection{Conclusions on the EU VAT perspective on health care transactions}

So far, I explored the normative content of the right to health and concluded that it is a valid standard in relation to the application of EU VAT on health care transactions. In chapter 5, 
explored the relationship between the principle of access to health care and EU VAT. I concluded, like the considerations of the CJEU suggest, that the principle of access to health care indeed has to be taken into account for the application of EU VAT on health care transactions.

Subsequently, with the establishment of the model health care system in chapter 2, it was established which kind of health care transactions potentially take place within the EU. The next step was the assessment of the VAT burden on health care transactions, which was undertaken in chapter 6 . In that chapter, I concluded that the levying of EU VAT on health care transactions, by its nature, increases the cost price of health care transactions. Even if health care transactions are not taxed, as a result of the application of VAT exemptions or exclusions, the health care supplier incurs a substantial amount of input VAT, which he cannot deduct. As a result, the costs of the health care transaction to the health care consumer and hence access to health care is affected. The broad scope of both the subject (taxable person) and the object (taxable transactions) of the tax include a large part of transactions made in the health care sector within the scope of application of EU VAT. Furthermore, I have concluded that current mechanisms that are used for VAT relief of those transactions are not adequate. The application of VAT exemptions and exceptions form an infringement to the general character of the tax. Their application is distortive in many ways. This is already a direct consequence of their definition. The harmonized EU VAT system tends to subject health care transactions to VAT in a uniform manner, although health care systems in the EU are not harmonized. This leads to difficulties as regards the scope of application at the national level. Furthermore, this can lead to an unequal treatment of similar health care transactions in different Member States. This is a concern, as both the mobility of health care consumers and health care suppliers has increased during the last years. Difficulties as regards the scope of application also occur on a large scale in national situations. This leads to legal uncertainty and increased compliance costs. What makes it even more complicated is that the exemption for medical care in the EU VAT Directive is regulated by means of two different exemption provisions, i.e. one for intramural and one for extramural care. In order to improve legal certainty and reduce compliance costs, I would prefer an exemption for health care in a single exemption provision. As such, the legal uncertainty and increased compliance costs are factors that hinder the effective levying of the tax. They are a complicating factor in relation to the imposition of VAT on health care supplies. I concluded that this hindering effect in relation to access to health care cannot be justified by the aims, nor by the principles, of EU VAT law. I also concluded that the application of VAT exemptions and exclusions may force health care suppliers to make choices that are, from an economic point of view, perhaps less efficient. From a cost perspective, for health care suppliers it is in general not efficient to outsource services that are subject to VAT. This phenomenon is referred to as the bias towards insourcing. A similar effect occurs in cases of cooperation between health care suppliers. This also proves to lead to a substantial VAT burden in many cases. 
Even though the CJEU seems to imply that VAT exemptions for health care transactions intend to facilitate access to health care, I demonstrated in chapter 6 that, from a conceptual point of view, exemptions are by definition distortive and are capable of hindering access to health care, in the worst case even with the accumulation of VAT. In conclusion, the levying of EU VAT on health care transactions would increase the costs price of health care transactions. As a result of the application of VAT exemptions and exclusions, a large number of health care transactions are not taxed with VAT. Nevertheless, these transactions are burdened to some extent with increased costs, either as a result of non-deductible input VAT or as a result if substantial compliance costs. The distortive effects of those mechanisms are often not justifiable on grounds of the aims or principles of EU VAT law.

\subsubsection{Conclusions as regards the application of EU VAT in specific types of situations}

In order to be able to answer the first research question completely, I aimed to demonstrate in which types of situations the application of exemption provisions hinders access to health care. In chapter 2, I already identified common types of transactions which typically occur in the health care sector.

It appeared in chapter 7 that the scope of application of health care exemptions differs depending on the situation and relationship in which the health care is provided. The scope of application in basic situations is different from the scope of application of health care exemptions in parallel situations. Furthermore, the scope of application in these two situations also differs from the scope of application in situations in which health care is supplied as a successive supply (successive situations). Therefore, I made a distinction between 'basic health care supplies', 'parallel health care supplies' and 'successive health care supplies'. In all three situations, I analysed both the application of the exemption provision for intramural care (Article 132(1)(b) of the EU VAT Directive), as well as the application of the exemption provision for extramural care (Article 132(1)(c) of the EU VAT Directive). The assessment of the basic health care supplies confirmed the findings in chapter 6. In my view, the application of Article 132(1)(c) of the EU VAT Directive results in more legal uncertainty for the health care suppliers supplying services in basic situations compared to the application of Article 132(1)(b) of the EU VAT Directive. This follows from the way the exemption provision is defined. The exemption provision for extramural care in Article 132 (1)(c) sets requirements as regards the professional qualifications of the providers and demands that the health care provided is within the area of expertise of the medical profession.

The hindering effect of VAT exemptions on access to health care in parallel health care supplies was analysed by distinguishing parallel one-on-one and parallel two-on-one situations. As regards the application of the exemption provision for extramural care, I concluded that the 'closely related test' that is necessary for the assessment of the application of the exemption provision for intramural care is superfluous in parallel one-on- 
one situations. This is because the 'closely related test' requires the ancillary transaction to also be essential. On the other hand, the scope of application of the 'closely related test' appears broader. Where composite supplies can only be found in parallel one-on-one situations, closely related supplies can be found in parallel two-on-one situations and successive situations as well. 


\section{Bibliography}

\section{Literature}

Ahmed, T., De Jesús Butler, I., 2006, The European Union and Human Rights: An International Law Perspective, In: European Journal of International Law, Vol. 17 No.4.

Aujean, M., Jenkins, P. and Poddar, S., 1999, A new approach to public sector bodies, International VAT Monitor vol. 10, no. 1, July/ August 1999, IBFD

Bertinato, L., Busse, R., Fahy, N. et al., 2005, Cross-Border Health Care in Europe, Brussels.

Bomer, A.H., 2012, De doorwerking van de algemene rechtsbeginselen in de BTW (diss.), Maastricht University

Coomans, A.P.M., 2007, Application of the International Convenant on Economic, Social and Cultural Rights in the Framework of International Organisaztions. In: Von Bogdandy, A., Wolfrum, R. (Eds.), Max Planck Yearbook of United Nations Law (11)

Copenhagen Economics, 2011, VAT in the public sector and exemptions in the public interest, Final report for TAXUD/2009/DE/316

Copenhagen Economics, 2013, VAT in the public sector and exemptions in the public interest, Final report for TAXUD/2011/DE/334

De la Feria, R., 2006, The EU VAT System and the Internal Market, IBFD

De la Feria, R., 2009, EU VAT Treatment of Public Sector Bodies: Slowly Moving in the Wrong Direction, Intertax, 37

Denie, A.H.R.M., 1987, De overheid in de omzetbelasting, Kluwer

Donnelly, J., 2013, Universal Human Rights in Theory and Practice, Cornell University Press

Econex, 2011, National Health Systems: Public Service vs. Insurance-Based Models, Health Reform Note 15, p. 1-4, retrievable via: http://www.econex.co.za.

Egholm Elgaard, K., 2016, The Impact of the Charter of Fundamental Rights of the European Union on VAT Law, World Journal of VAT/ GST Law, vol. 5, issue 2. 
Eicker, K., 2005, Do the basic freedoms of the EC Treaty also require an amendment to the national tax laws on charities and non-profit organisations?, EC Tax Review, Volume 14, Issue 3

Footman, K., Knai, C., Baeten, R. et al., 2014, Cross border health care in Europe, Policy Summary $14, \mathrm{WHO}$

Gabriël, M.M. and Van Kesteren, H.W.M., 2011, Calculation of the (Pre-) Pro Rata under EU VAT Law, International VAT Monitor, Volume 22, No 5

Gendron, P.P., 2005, Value Added Tax Treatment of Public Sector Bodies and Non-profit Organizations: A Developing Country Perspective, Bulletin for International Taxation, Volume 59, No. 12, IBFD

Glinos, I.A., Baeten, R., Helble, M. et al., 2010, A typology of cross-border patient mobility. Health \& Place

Harrington, J. and Stuttaford, M. (Eds.), 2010, Global Health and Human Rights: legal and philosophical perspectives, Routledge

Helios, M., 2007, Taxation of non-profit organizations and EC law, EC Tax Review, Volume 16, Issue 2

Henkow, O., 2013, The VAT/GST Treatment of Public Bodies, Series on International Taxation vol. 41, Kluwer Law International

Hermans, H.E.G.M., 2000, Cross-border health care in the European Union: recent legal implications of 'Decker and Kohll', Journal of Evaluation in Clinical Practice, vol.6, issue 4, Blackwell Science

Hessler, K., Buchanan, A., 2002, Specifying the Content of the Human Right to Health Care, In: Medicine and Social Justice: Essays on the Distribution of Health Care, Oxford University Press.

Hunt, P., 2006, The Human Right to the Highest Attainable Standard of Health: New Opportunities and Challenges, Transactions of the Royal Society of Tropical Medicine and Hygiene, 100: 603-607, retrievable via: http://www.essex.ac.uk/hrc/research/projects/rth/docs/Paul_hunt_leading_article.pdf.

Kooijmans, P.H., 2002, Internationaal publiekrecht in vogelvlucht, Kluwer, Deventer, 9th edition.

Kroneman, M., Boerma, W. et al., 2016, The Netherlands: health system review, Health Systems in Transition, vol. 18(2) 
Lameire, N., Joffe, P. and Wiedemann, M., 1999, Healthcare systems - an international review: an overview, Nephrol Dial Transplant 14 [Suppl 6]

Last, J.M. (Ed.), 2007, A Dictionary of Public Health, Oxford University Press, retrievable via: http://www.oxfordreference.com

Legido-Quigley, H., Glinos, I.A., Baeten, R. et al., 2012, Analysing arrangements for crossborder mobility of patients in the European Union: A proposal for a framework. Health Policy

Legido-Quigley, H., Passarani, I., Knai, C. et al., 2011, Cross-border healthcare in Europe: clarifying patients' rights, BMJ

Mackenbach, J.P., Van der Maas, J. (Eds.), 2008, Volksgezondheid en gezondheidszorg, Elsevier gezondheidszorg

Mann, J. M. et al., 1994, Health and Human Rights, Health and Human Rights, Vol. 1, No. 1 Autumn

Post, N., Gijsen, R. et al., 2013, Wat is gezondheidszorg?, In: Volksgezondheid Toekomst Verkenning, Nationaal Kompas Volksgezondheid, Bilthoven: RIVM, retrievable via: http://www.nationaalkompas.nl

Post, N., Gijsen, R. et al., 2018, Wat is gezondheidszorg?, National Institute for Public Health and the Environment (RIVM), retrievable via: http://www.volksgezondheidenzorg.info

Post, N., Gijsen, R. et al., 2018, Zorg: verschillende indelingen, National Institute for Public Health and the Environment (RIVM), retrievable via: http://www.volksgezondheidenzorg.info

Roberts, J. L. and World Health Organization, 1998, Terminology: a glossary of technical terms on the economics and finance of health services, Doc. Nr. EUR/ICP/CARE 94 01/CN01, retrievable via: http://www.euro.who.int.

Rutten, F.F.H. ,2012, The Impact of economic evaluation on healthcare decision-making, Valedictory Lecture of 4 October 2012 at Erasmus University Rotterdam, retrievable via: http://hdl.handle.net/1765/39519

Simons, A.L.C, 1996, EC Court of Justice recognizes the legal character of VAT, EC Tax Review, Volume 5, Issue 2

Terra, B. and Kajus, J., 2014, A Guide to the Recast VAT Directive, Chapter 3, p. 20, IBFD, retrievable via: http://online.ibfd.org

Tobin, J., 2012, The Right to Health in International Law, Oxford University Press 
Toebes, B.C.A, Hartlev, M., Hendriks, A., Herrmann, J.R., 2012, Health and Human Rights in Europe, Intersentia

Toebes, B.C.A., 1999, The Right to Health as a Human Right in International Law, Intersentia/Hart

Van den Berg, M.J., de Boer, D. et al., 2014, Zorgbalans 2014: De prestaties van de Nederlandse gezondheidszorg, RIVM rapport 2014-0038, Rijksinsituut voor Volksgezondheid en Milieu (RIVM), retrievable via: http://www.gezondheidszorgbalans.nl/rapporten

Van den Berg, M.J., De Boer, D., Gijsen, R. et al. (Eds.), 2015, Dutch Health Care Performance Report 2014, National Institute for Public Health and the Environment (RIVM), p. 16, retrievable via: http://www.healthcareperformance.nl

Van der Burgt, M., Van Mechelen-Gevers, E., Te Lintel Hekkert, M., 2012, Introductie in de Gezondheidszorg, Bohn Stafleu van Loghum

Van Doesum, A.J., 2009, Contractuele samenwerkingsverbanden in de BTW (diss.)

Van Doesum, A.J., Van Kesteren, H.W.M., Van Norden, G.J., 2016, Fundamentals of EU VAT Law, Kluwer Law International

Van Hilten, M.E., 2010, Over de neutraliteit van de omzetbelasting en het hellend vlak van de uitzonderingen, Kluwer

Van Norden, G.-J., 2010, Het concern in de btw (diss.), Kluwer

Van Veen, E., Hamilton, G., 2005, De Zorgverzekeringswet in Europees(rechtelijk) perspectief, Tijdschrift voor Gezondheidsrecht

Vyncke, K., Cordewener, A. and De Broe, L., 2011, Towards a Simpler, More Robust and Efficient VAT System by levying VAT at EU Level, International VAT Monitor July/August 2011, IBFD

Wiegers, T., Hopman, P., Kringos, D., De Bakker, D., 2011, NIVEL Overzichtstudies: de eerste lijn, NIVEL 


\section{EU Documents}

Directive 2004/23/EC of the European Parliament and of the Council on setting standards of quality and safety for the donation, procurement, testing, processing, preservation, storage and distribution of human tissues and cells, OJ L 102/48, 31 March 2004

Charter of Fundamental Rights of the European Union of 30 March 2010, 2010/C 83/02

First Council Directive 67/227/EEC of 11 April 1967 on the harmonisation of legislation of Member States concerning turnover taxes, OJ 71, 14 April 1967

Second Council Directive 67/228/EEC of 11 April 1967 on the harmonisation of legislation of Member States concerning turnover taxes, OJ 71, 14 April 1967

Communication from the Commission to the Council and the European Parliament of 7 May 2000 , A strategy to improve the operation of the VAT system within the context of the internal market, $\operatorname{COM}(2000) 348$ final

Green Paper on the future of VAT: Towards a simpler, more robust and efficient VAT system, $\operatorname{COM}(2010) 695$ final

Communication from the Commission to the European Parliament, the Council and the European Economic and Social Committee of 6 December 2011, On the future of VAT:

Towards a simpler, more robust and efficient VAT system tailored to the single market, $\operatorname{COM}(2011) 851$ final

Communication from the Commission on effective, accessible and resilient health systems, $\operatorname{COM}(2014) 215$ final, 4 April 2014.

Proposal for a Sixth Council Directive on the harmonisation of legislation of Member States concerning turnover taxes, Common system of value added tax: uniform basis of assessment, $\operatorname{COM}(73)$ 950, 20 June 1973

Sixth Council Directive 77/388/EEC of 17 May 1977 on the harmonization of the laws of the Member States relating to turnover taxes - Common system of value added tax: uniform basis of assessment, OJ L 145, 13 April 1977

First Report from the Commission to the Council on the application of the common system of value added tax of 14 September 1983, COM(83) 426 final 
Proposal for a 19th Council Directive on the harmonization of the laws of the Member States relating to turnover taxes, amending Directive 77/388/EEC - common system of value added tax, $\operatorname{COM}(84) 648$ final, 5 December 1984

Second Report from the Commission to the Council from 20 December 1988, COM(88) 799 final

Council Conclusions on Common values and principles in European Union Health Systems, OJ C 146, 22 June 2006

Economic and Social Committee Opinion on the proposal for a 19th Council Directive on the harmonization of the laws of the Member States relating to turnover taxes, amending Directive 77/388/EEC, OJ 85/C 218/07, 29 August 1985

Charter of Fundamental Rights of the European Union, OJ C 303, 14 December 2007

Treaty of Lisbon amending the Treaty on European Union and the Treaty establishing the European Community, signed at Lisbon, 13 December 2017, 2007/C 306/01

Regulation (EC) No 883/2004 of the European Parliament and of the Council of 29 April 2004 on the coordination of social security schemes, OJ L 166, 30 April 2004

Council Directive 2006/112/EC of 28 November 2006 on the common system of value added tax, OJ L 347, 11 December 2006

Directive 2011/24/EU of the European Parliament and of the Council of 9 March 2011 on the application of patients' rights in cross-border healthcare, OJ L 88, 2011

Commission Staff Working Document, Accompanying document to the Green Paper on the future of VAT, SEC (2010) 1455 final

European Commission, European Semester Thematic Factsheet: Health Systems, 14 November 2016, retrievable via: https://ec.europa.eu 


\section{CJEU Case Law}

CJEU 5 February 1981, Case C-154/80 Staatssecretaris van Financiën v Coöperatieve Aardappelenbewaarplaats, ECLI:EU:C:1981:38

CJEU 19 January 1982, Case 8/81 Becker, ECLI:EU:C:1982:7

CJEU 1 April 1982, Case C-89/81 Hong-Kong Trade, ECLI:EU:C:1982:121

CJEU 11 July 1985, Case C-107/84 Commission vs. Germany, ECLI:EU:C:1985:332

CJEU 26 March 1987, Case 235/85 Commission vs. Netherlands, ECLI:EU:C:1987:161

CJEU 23 February 1988, Case 353/85 Commission vs. United Kingdom, ECLI:EU:C:1988:82

CJEU 8 March 1988, Case C-102/86 Apple and Pear Development Council, ECLI:EU:C:1988:120

CJEU 15 June 1989, Case C-348/87 Stichting Uitvoering Financiële Acties, ECLI:EU:C:1989:246

CJEU 17 October 1989, Joined Cases C-231/87 and C-129/88 Ufficio distrettuale delle imposte dirette di Fiorenzuola d'Arda e.a $v$ Comune di Carpaneto Piacentino and Others, ECLI:EU:C:1989:381

CJEU 20 June 1991, Case C-60/90 Polysar Investments Netherlands V Inspecteur der Invoerrechten en Accijnzen, ECLI:EU:C:1991:268

CJEU 11 July 1991, Case C-97/90 Lennartz v Finanzamt München III, ECLI:EU:C:1991:315

CJEU 25 July 1991, Case C-202/90 Ayuntamiento de Sevilla v Recaudadores de Tributos de las Zonas primera y segunda, ECLI:EU:C:1991:332

CJEU 3 March 1994, Case C-16/93 Tolsma $v$ Inspecteur der Omzetbelasting, ECLI:EU:C:1994:80

CJEU 6 April 1995, Case C-4/94 BLP Group, ECLI:EU:C:1997:107

CJEU 6 July 1995, Case C-62/93 BP Soupergaz v Greek State, ECLI:EU:C:1995:223

CJEU 11 August 1995, Case C-453/93 Bulthuis-Griffioen v Inspecteur der Omzetbelasting, ECLI:EU:C:1995:265

CJEU 27 June 1996, Case C-107/94 Asscher v Staatssecretaris van Financiën, ECLI:EU:C:1996:251 
CJEU 26 September 1996, Case C-230/94 Renate Enkler v Finanzamt Homburg, ECLI:EU:C:1996:352

CJEU 5 June 1997, Case C-2/95 Sparekassernes Datacenter (SDC), ECLI:EU:C:1997:278

CJEU 28 April 1998, Case C-158/96 Kohll v Union des caisses de maladie, ECLI:EU:C:1998:171

CJEU 22 October 1998, Joined Cases C-308/96 and C-94/97 Madgett and Baldwin, ECLI:EU:C:1998:496

CJEU 25 February 1999, Case C-349/96 Card Protection Plan Ltd (CPP) v Commissioners of Customs \& Excise, ECLI:EU:C:1999:93

CJEU 7 September 1999, Case C-216/97 Jennifer Gregg and Mervyn Gregg v Commissioners of Customs and Excise, ECLI:EU:C:1999:390

CJEU 27 January 2000, Case C-23/98 Heerma, ECLI:EU:C:2000:46

CJEU 21 March 2000, Joined Cases C-110/98 to C-147/98 Gabalfrisa and Others, ECLI:EU:C:2000:145

CJEU 8 June 2000, Case C-98/98 Midland Bank, ECLI:EU:C:2000:300

CJEU 14 September 2000, Case C-384/98 D., ECLI:EU:C:2000:444

CJEU 14 December 2000, Case C-446/98 Fazenda Pública v Câmara Municipal do Porto, ECLI:EU:C:2000:691

CJEU 11 January 2001, Case C-76/99 Commission vs. France, ECLI:EU:C:2001:12

CJEU 22 February 2001, Case C-408/98 Abbey National, ECLI:EU:C:2001:110

CJEU 8 March 2001, Case C-240/99 Skandia, ECLI:EU:C:2001:140

CJEU 12 July 2001, Case C-157/99 Smits and Peerbooms, ECLI:EU:C:2001:404

CJEU 13 December 2001, Case C-235/00 CSC Financial services, ECLI:EU:C:2001:696

CJEU 20 June 2002, Case C-287/00 Commission vs. Germany, ECLI:EU:C:2002:388

CJEU 10 September 2002, Case C-141/00 Kügler, ECLI:EU:C:2002:473

CJEU 6 November 2003, Case C-45/01 Dornier, ECLI:EU:C:2003:595

CJEU 20 November 2003, Case C-212/01 Margarete Unterpertinger, ECLI:EU:C:2003:625 
CJEU 20 November 2003, Case C-307/01 d'Ambrumenil and Dispute Resolution Services, ECLI:EU:C:2003:627

CJEU 20 November 2003, Case C-8/01 Taksatorringen, ECLI:EU:C:2003:621

CJEU 17 February 2005, Joined Cases C-453/02 and C-462/02 Linneweber and Akritidis, ECLI:EU:C:2005:92

CJEU 3 March 2005, Case C-472/03 Arthur Andersen, ECLI:EU:C:2005:135

CJEU 26 May 2005, Case C-498/03 Kingscrest Associates and Montecello, ECLI:EU:C:2005:322

CJEU 27 October 2005, Case C-41/04 Levob Verzekeringen and OV Bank, ECLI:EU:C:2005:649

CJEU 1 December 2005, Joined Cases C-395/04 and C-394/04 Ygeia, ECLI:EU:C:2005:734

CJEU 9 February 2006, Case C-415/04 Kinderopvang Enschede, ECLI:EU:C:2006:95

CJEU 21 February 2006, Case C-255/02 Halifax and Others, ECLI:EU:C:2006:121

CJEU 23 March 2006, Case 210/04 FCE Bank, ECLI:EU:C:2006:196

CJEU 27 April 2006, Joined Cases C-444/04 and C-443/04 Solleveld, ECLI:EU:C:2006:257

CJEU 16 May 2006, Case C-372/04 Watts, ECLI:EU:C:2006:325

CJEU 8 June 2006, Case C-106/05 L.u.P., ECLI:EU:C:2006:380

CJEU 29 March 2007, Case C-111/05 Aktiebolaget NN, ECLI:EU:C:2007:195

CJEU 14 June 2007, Case C-434/05 Horizon College, ECLI:EU:C:2007:343

CJEU 26 June 2007, Case C-284/04 T-Mobile Austria and Others, ECLI:EU:C:2007:381

CJEU 26 June 2007, Case C-369/04 Hutchison 3G and Others, ECLI:EU:C:2007:382

CJEU 18 October 2007, Case C-355/06 J. A. van der Steen v Inspecteur van de Belastingdienst Utrecht-Gooi/kantoor Utrecht, ECLI:EU:C:2007:615

CJEU 13 March 2008, Case C-437/06 Securenta, ECLI:EU:C:2008:166

CJEU 16 September 2008, Case C-288/07 Isle of Wight Council, ECLI:EU:C:2008:505

CJEU 16 October 2008, Case C-253/07 Canterbury Hockey Club and Canterbury Ladies Hockey Club v The Commissioners for Her Majesty's Revenue and Customs, ECLI:EU:C:2008:571 
CJEU 12 February 2009, Case C-515/07 Vereniging Noordelijke Land- en Tuinbouw Organisatie, ECLI:EU:C:2009:88

CJEU 4 June 2009, Case C-102/08 SALIX Grundstücks-Vermietungsgesellschaft, ECLI:EU:C:2009:345

CJEU 2 October 2009, Case C-242/08 Swiss Re Germany Holding, ECLI:EU:C:2009:647

CJEU 29 October 2009, Case C-174/08 NCC Construction Danmark, ECLI:EU:C:2009:669

CJEU 28 January 2010, Case C-473/08 Eulitz, ECLI:EU:C:2010:47

CJEU 18 March 2010, Case C-3/09 Erotic Center, ECLI:EU:C:2010:149

CJEU 25 March 2010, Case C-79/09 Commission vs. Netherlands, ECLI:EU:C:2010:171

CJEU 10 June 2010, Case C-262/08 CopyGene, ECLI:EU:C:2010:328

CJEU 10 June 2010, Case C-86/09 Future Health Technologies, ECLI:EU:C:2010:334

CJEU 17 June 2010, Case C-492/08 Commission vs. France, ECLI:EU:C:2010:348

CJEU 18 November 2010, Case C156/09 Verigen, ECLI:EU:C:2010:695

CJEU 18 December 2010, Case C-175/09 AXA UK, ECLI:EU:C:2010:646

CJEU 22 December 2010, Case C-277/09 RBS Deutschland Holding, ECLI:EU:C:2010:810

CJEU 10 November 2011, Joined Cases C-259/10 and C-260/10 The Rank Group, ECLI:EU:C:2011:719

CJEU 19 July 2012, Case C-44/11 Deutsche Bank, ECLI:EU:C:2012:484

CJEU 27 September 2012, Case C-392/11 Field Fisher Waterhouse, ECLI:EU:C:2012:597

CJEU 15 November 2012, Case C-174/11 Zimmermann, ECLI:EU:C:2012:716

CJEU 17 January 2013, Case C-224/11 BGŻ Leasing, ECLI:EU:C:2013:15

CJEU 17 January 2013, Case C-360/11 Commission vs. Kingdom of Spain, ECLI:EU:C:2013:17

CJEU 13 June 2013, Case C-62/12 Kostov, ECLI:EU:C:2013:391

CJEU 20 June 2013, Case C-219/12 Finanzamt Freistadt Rohrbach Urfahr, ECLI:EU:C:2013:413

CJEU 20 June 2013, Case C-653/11 Paul Newey, ECLI:EU:C:2013:409 
CJEU 13 March 2014, Case C-366/12 Klinikum Dortmund, ECLI:EU:C:2014:143

CJEU 27 March 2014, Case C-151/13 Le Rayon d'Or, ECLI:EU:C:2014:185

CJEU 17 September 2014, Case C-7/13 Skandia America (USA), ECLI:EU:C:2014:2225

CJEU 26 February 2015, Joined cases C-144/13, C-154/13 and C-160/13 VDP Dental Laboratory and Others, ECLI:EU:C:2015:116

CJEU 12 March 2015, Case C-594/13 Go Fair Zeitarbeit OHG, ECLI:EU:C:2015:164

CJEU 2 July 2015, Case C-334/14 De Fruytier II, ECLI:EU:C:2015:437

CJEU 16 July 2015, Case C-584/13 Mapfre asistencia and Mapfre warranty, ECLI:EU:C:2015:488

CJEU 29 October 2015, Case C-174/14 Saudaçor, ECLI:EU:C:2015:733

CJEU 14 April 2016, Case C-555/15 Gabarel, ECLI:EU:C:2016:272

CJEU 28 July 2016, Case C-543/14 Ordre des barreaux francophones et germanophone, ECLI:EU:C:2016:605

CJEU 5 October 2016, Case C-412/15 TMD, ECLI:EU:C:2016:738

CJEU 19 January 2017, Case C-344/15 National Roads Authority, ECLI:EU:C:2017:28

CJEU 9 March 2017, Case C-573/15 Oxycure Belgium, ECLI:EU:C:2017:189

CJEU 20 December 2017, Case C-462/16 Boehringer Ingelheim Pharma, ECLI:EU:C:2017:1006 


\section{A-G Opinions, CJEU}

A-G Opinion 28 March 1996, Case C-230/94 Renate Enkler V Finanzamt Homburg, ECLI:EU:C:1996:145

A-G Opinion 27 January 2000, Case C-384/98 D., ECLI:EU:C:2000:55

A-G Opinion 8 March 2007, Case C-434/05 Horizon College, ECLI:EU:C:2007:149

A-G Opinion 14 June 2007, Case C-355/06 J. A. van der Steen v Inspecteur van de Belastingdienst Utrecht-Gooi/kantoor Utrecht, ECLI:EU:C:2007:352

A-G Opinion 10 September 2009, Case C-262/08 CopyGene, ECLI:EU:C:2009:541

A-G Opinion 11 February 2010, Case C-492/08 Commission vs. France, ECLI:EU:C:2010:72

A-G Opinion 26 September 2013, Case C-366/12 Klinikum Dortmund, ECLI:EU:C:2013:618

A-G Opinion 10 March 2016, Case C-543/14 Ordre des barreaux francophones et germanophone, ECLI:EU:C:2016:157 


\section{Other resources}

Court of Appeal Den Bosch, 11 September 2015, nr. 14/00971, ECLI:NL:GHSHE:2015:3527

Decree of the State Secretary of Finance of 14 May 2013, nr. BLKB2013/810M, Stcrt.nr. 2013/13136 (repealed on 2 April 2016 by Decree of the State Secretary of Finance of 29 March 2016, BLKB2016/433MStcrt. 2016, 17339)

HM Revenue \& Customs, 2014, Health professionals and pharmaceutical products, VAT Notice $701 / 57$ of 28 July 2014

HM Revenue \& Customs, 2014, VAT liability of health institutions supplies, VAT Notice $701 / 31$ of 22 August 2014

OECD, 2013, Health at a Glance 2013: OECD Indicators, OECD Publishing, retrievable via: http://dx.doi.org/10.1787/health_glance-2013-en

OECD, 2014, Definitions, Sources and Methods - Total health and social employment, OECD Health Statistics 2014

OECD, 2015, Fiscal Sustainability of Health Systems Policy Brief, OECD Publishing, retrievable via: http://www.oecd.org/health/health-systems/Fiscal-Sustainability-Health-Systems-PolicyBrief.pdf

OECD, 2015, Fiscal Sustainability of Health Systems: Bridging Health and Finance Perspectives, OECD Publishing

OECD, Eurostat and World Health Organization, 2017, A System of Health Accounts 2011: Revised edition, OECD Publishing

OECD, Health Statistics 2014, retrievable via: http://www.oecd.org/health/healthdata

OECD, World Health Organization and Eurostat, 2011, A System of Health Accounts: 2011 Edition, OECD Publishing

OECD, World Health Organization and Eurostat, 2011, A System of Health Accounts: 2011 Edition, OECD Publishing

PwC, 2011, How the EU VAT Exemptions impact the Banking Sector, retrievable via: http://www.pwc.nl/nl/assets/documents/pwc-db-vat-study-final-report-fo3.pdf

UN Committee on Economic, Social and Cultural Rights (CESCR), General Comment No. 14: The Right to the Highest Attainable Standard of Health (Art. 12 of the Covenant), 11 August 2000 
UN Committee on Economic, Social and Cultural Rights (CESCR), General Comment No. 3: The Nature of States Parties' Obligations (Art. 2, para. 1 of the Covenant), 14 December 1990 UN Economic and Social Council (ECOSOC) resolution 1985/17 of 28 May 1985

UN General Assembly, International Covenant on Economic, Social and Cultural Rights, 16 December 1966, United Nations, Treaty Series, vol. 993

UN General Assembly, Universal Declaration of Human Rights, 10 December 1948, 217 A (III), retrievable via: http://www.un.org/en/documents/udhr

UN Human Rights Council, Report of the Special Rapporteur on the Right of Everyone to the Enjoyment of the Highest Attainable Standard of Physical and Mental Health, Anand Grover: addendum, 21 March 2011, A/HRC/17/25/Add.3

UN International Standard Industrial Classification of all economic activities (ISIC), Statistical Paper Series M, No. 4, Rev. 4, 2008, retrievable via: http://www.unstats.un.org

UN Office of the High Commissioner for Human Rights (OHCHR), Fact Sheet No. 2 (Rev.1), The International Bill of Human Rights, June 1996, No. 2 (Rev.1), retrievable via: http://www.ohchr.org

UN Office of the High Commissioner for Human Rights (OHCHR), Fact Sheet No. 31, The Right to Health, June 2008, retrievable via: http://www.ohchr.org

UN OHCHR Regional Office for Europe, The European Union and International Human Rights Law, retrievable via: http://www.europe.ohchr.org/Documents/Publications/EU_and_Inter national_Law.pdf

World Health Organisation (WHO), 2013, Fact Sheet no. 323: The Right to Health, WHO/OHCHR/323, retrievable via: http://www.who.int/mediacentre/factsheets/fs323/en

World Health Organisation (WHO), 2010, Template on classifying health workers, retrievable via: http://www.who.int/hrh/statistics/workforce_statistics/en

World Health Organisation (WHO), 2000, General Guidelines for Methodologies on Research and Evaluation of Traditional Medicine, WHO/EDM/TRM/2000.1, retrievable via: http://apps.who.int/iris/bitstream/10665/66783/1/WHO_EDM_TRM_2000.1.pdf

World Health Organisation (WHO), 2013, WHO Traditional Medicine Strategy 2014-2023, retrievable via: http://www.who.int/medicines/publications/traditional/trm_strategy14_23/en

World Health Organisation (WHO), 2014, Health System Financing Profile by country, retrievable via: http://apps.who.int/nha/database/Country_Profile/Index/en 
World Health Organization (WHO), 2006, The World Health Report 2006: working together for health

World Health Organization (WHO), 2007, Everybody's business: Strengthening health systems to improve health outcomes: WHO's framework for action 


\section{Valorization addendum}

\section{Societal and economic relevance}

In this research I addressed the question how the application of positive EU VAT law on health care transactions impedes the principle of access to health care. So far, no extensive research has been conducted on the interaction between the application of positive EU VAT law and the access to health care. In my view, the growing importance and recognition of the principle of access to health care on an EU level as a value for designing and improving health care systems on the one hand and CJEU case law on the application of positive EU VAT law on health care transactions on the other hand, demand for such research.

The societal relevance of the research output on EU level is also demonstrated by the fact that the EU health ministers recognized access to health as one of the overarching values of EU health care systems. Unlike the EU VAT system, health care systems are a national matter. Consequently, their design and funding structure differ per Member State. The EU health care systems, however, increasingly interact with each other, inter alia as a result of increased patient mobility and mobility of health care professionals.

The research output is also of economical relevance. It is relevant in the light of discussions on the increased health care spending in the EU. Over the last 20 years, the average annual growth of health spending exceeded the GDP growth in all OECD countries. It is therefore in the common interest of countries to improve the fiscal sustainability of health care. The OECD has indicated that 'distortionary costs' of taxes have to be taken into account in economic policy discussions on the financing of public services. ${ }^{648} \mathrm{I}$ demonstrated in my research the hindering effect of the application of EU VAT and how and to what extent this hindering effect occurs in specific situations. These findings provide for insights on the occurrence of distortionary costs as a result of the application of positive EU VAT law. These insights are not only useful as regards economic policy discussions on the financing of the health care sector, but also as regards the financing of other (public) sectors, i.e. the education sector as this sector is confronted with similar EU VAT rules and is by its nature also predominantly financed with public funds.

\section{To whom are the research results of interest and why?}

As indicated under 1, the research outcome is not only of interest for persons or groups involved in tax law, but also for those involved in health care. In the first place the research output is relevant to EU and national policymakers in the field of tax law, for this research demonstrated that the principle of access to health care serves as a valid standard for the application of positive EU VAT law. Furthermore, it became obvious that a possible

${ }^{648}$ See section 2.2.1.1. 
impediment of the accessibility to health care cannot be ignored while drafting and proposing now regulations in the field of EU VAT. Therefore, the research outcome is also relevant for legislative bodies in the field of taxation on an EU and national level. I explored alternative ways to apply EU VAT on health care transactions, while mitigating the hindering effect on the access to health care.

Also, for policymakers and legislative bodies in the field of health care, the research output is relevant. As indicated under 1., the accessibility of health care is explicitly recognized by the health ministers of the EU as one of the overarching values of EU health care systems, that have to be taken into account while drafting proposals concerning health systems. Furthermore, as was demonstrated in this research, the application of EU VAT on health care transactions brings along side effects, possibly causing distortionary costs. Knowledge on the occurrence of these distortionary cost is interesting for research and discussions in the field of fiscal sustainability of health systems, which has gained more importance in the EU as a result of the exceeded spending on health (see also under 1.).

Besides policymakers and legislative bodies, the research outcome is relevant to a number of other groups. It is useful to students and researchers involved in EU VAT law, as this thesis provides for insights on the scope and application of positive EU VAT law in relation to health care transactions in various specific situations. These situations have been divided in three main categories in which health care may be provided: basic situations, parallel situations and successive situations. The thesis contains a schematic overview containing the criteria for assessment of VAT exemptions for health care per situation. ${ }^{649}$ The insights mentioned above may also be useful to health care practitioners and their advisors. It may for example help them to possibly structure health care transactions in such a way that distortionary costs as a result of the application of positive EU VAT law are reduced or avoided.

Finally, the research output certainly forms a basis for further research for researchers in the field of EU VAT as well as economics. Despite the fact that this research mainly focusses on the legal and practical results of the application of legislation and only takes into account budgetary effects to a very limited extent, it will be of interest to those involved in quantitative research. In this thesis, concrete suggestions are made for alternative provisions in the EU VAT system that require further (quantitative) research.

\section{Into which concrete activities, products, services and processes or commercial activities will the research results be}

\section{translated and shaped?}

The research output may contribute or lead to new proposals in relation to the VAT treatment of health care transactions, or more general, the VAT treatment of public sector bodies. In its 2010 'Green Paper', the European Commission already acknowledged the differential treatment of public sector bodies (i.e. health care providers) as one of the

${ }^{649}$ See section 7.5.9. 
shortcomings of the current EU VAT system. ${ }^{650}$ The conclusions of the public consultation, initiated by the Green Paper, have led to a careful consideration of a gradual phasing out of existing VAT exemptions. Still, up until this point no concrete changes to the EU VAT treatment of public sector bodies have been presented.

As was set out above, the thesis contains a schematic overview containing criteria for the assessment of VAT exemptions for health care in various specific situations. The distinction of specific types of situations in which health care transactions may be provided for the purpose of the application of positive EU VAT law is innovative. It may serve as a tool to come to a consistent application of the provisions of the EU VAT Directive, as well as doctrines that have been developed in CJEU case law, i.e. the doctrine of composite supplies. By this means it may lead to new CJEU case law on the interpretation of EU VAT in relation to health care transactions. For the same reasons, the research output may also serve as a basis for litigation strategies.

Furthermore, after my public defence, I aim to have the thesis published by an internationally operating publisher. This allows to distribute the research output amongst the target groups that have been discussed above.

\section{To what degree can the research results be called innovative in respect to the existing range of products,} services, processes, activities and commercial activities?

As indicated under 1., up until now no extensive research has been conducted on the interaction between the application of positive EU VAT law and the access to health care. It is the first research in the field of VAT in which parallels are drawn between the interpretation of VAT exemption provisions for health care and the human right to health. I demonstrated that the principle of access to health care cannot be denied in relation to the interpretation and application of positive EU VAT law. Furthermore, this research has led to new insights on how the application of positive EU VAT law impedes the access to health care, as well as the specific situations in which this impediment occurs. These situations have as such not been distinguished and compared before. One of the important findings of the research in this regard is that the application of positive EU VAT law on health care transactions may lead to a deviating VAT treatment of health care transactions, depending on the kind of situation in which they are provided, i.e. 'basic situations', 'parallel situations' and 'successive situations'. What is particularly innovative in this research is that specific attention has been paid to the concurrence between the application of the doctrine of composite supplies and the interpretation of the notion of 'closely related activities' in relation to health care transactions.

${ }^{650}$ See section 6.1.2. 


\section{How will this/these plan(s) for valorization be shaped?}

With the output of this research as basis, I am able to conduct further research on the EU VAT treatment of public sector bodies in general and elaborate on specific aspects of that treatment. The output of further research may result in scientific publications. Moreover, as indicated above, I aim to have the thesis published by an internationally operating publisher. This allows to distribute the research output amongst the target groups and contributes to a wide spread and acceptation of the research output. My continued active involvement in research, education and practice contributes to a wide spread and acceptation of the research output as well and enables the research output to be further developed. 


\section{Curriculum vitae}

Mandy Maria Gabriël was born on October 26, 1985 in Brunssum. In 2003, Mandy finished her pre-university education. She obtained her Bachelor degree in Tax Law in 2006 and her Master degree in Tax Law (International Tax Law) in 2007, both at Maastricht University. During her Master study (2006) she started working for EY as an intern and continued working there as a tax advisor after her graduation. In 2008, she started working at Maastricht University, as a junior researcher. First on a part time basis - alongside her position at EY - and as of 2009 on a full-time basis. During the first years she was mainly involved in teaching. Furthermore, she has been a staff representative in the Faculty Council. In 2012 she obtained an Ernst Mach Grant and went to the Vienna University of Economics and Business as a visiting researcher. Throughout her employment for Maastricht University she has been part of the teaching staff of the course European Value Added Tax.

Beside her work at Maastricht University, Mandy joined PwC in Eindhoven in 2011 as a tax adviser. From 2013 Mandy has been working as a tax inspector for the Dutch Tax Authorities in Maastricht. 
